\title{
APPLICATIONS OF ITEM RESPONSE THEORY TO PHYSICAL FUNCTION ASSESSMENT IN RHEUMATOID ARTHRTIS
}


Thesis, University of Twente, 2013

(C) Martijn Oude Voshaar

Printed by Gildeprint Drukkerijen, Enschede, the Netherlands

With financial support of Medisch Spectrum Enschede and Dutch Arthritis Foundation

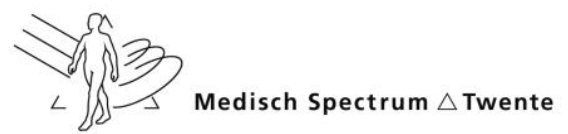

\section{Reumafonds}

The studies presented in this thesis were financially supported by the Stichting Reumaonderzoek Twente and Dutch Arthritis Foundation

ISBN: 978-90-365-3692-9

DOI: $10.3990 / 1.9788036536929$ 


\title{
APPLICATION OF ITEM RESPONSE THEORY TO PHYSICAL FUNCTION ASSESSMENT IN RHEUMATOID ARTHRTIS
}

\author{
PROEFSCHRIFT \\ ter verkrijging van \\ de graad van doctor aan de Universiteit Twente, \\ op gezag van de rector magnificus, \\ Prof. dr. H. Brinksma \\ volgens besluit van het College voor Promoties \\ in het openbaar te verdedigen \\ op woensdag 25 juni 2014, 16:45 \\ door \\ Antonius Hendrikus Oude Voshaar \\ geboren op 31 mei 1982 \\ te Oldenzaal
}


Dit proefschrift is goedgekeurd door de promotoren prof. dr. Mart A.F.J. van de Laar, prof. Dr. Cees A.W. Glas en de assistent-promotor dr. Peter M. ten Klooster 


\section{Samenstelling promotiecommissie}

Promotoren:

Assistent-promotor:

Voorzitter:

Leden:
Prof dr. M.A.F.J. van de Laar

Prof dr. C.A.W. Glas

Dr. P.M. Ten Klooster

Prof. E.R. Seydel

Prof. E. Krishnan

Prof. dr. P.C.M. van Riel

Prof. dr S. van der Linden

Prof. dr. R. Sanderman

Dr H. Vonkeman

Dr. E. Taal
Universiteit Twente

Universiteit Twente

Universiteit Twente

Universiteit Twente

Stanford University

Radboud Universiteit Nijmegen

Universitair Medisch Centrum Maastricht

Rijksuniversiteit Groningen

Universiteit Twente

Universiteit Twente 



\section{Contents}

Chapter $1 \quad$ General introduction

Chapter 2 Systematic review of Dutch and international literature on measurement 15 properties of physical function questionnaires in rheumatoid arthritis

2.1 Measurement properties of physical function questionnaires validated for use in patients with rheumatoid arthritis: A systematic review of the literature

2.2 Meeteigenschappen van vragenlijsten voor fysiek functioneren bijpatiënten met reumatoïde artritis

Chapter 3 Evaluating and modeling measurement invariance in physical function 51 questionnaires in rheumatoid arthritis

3.1 Measurement bias in different versions of the Dutch Health Assessment Questionnaire Disability Index

3.2 Crosscultural measurement equivalence of the Health Assessment Questionnaire II

Chapter 4 Linking scores of physical function questionnaires in rheumatoid arthritis

4.1 Development and evaluation of an item response theory-based crosswalk between the SF36 physical functioning scale and Health Assessment Questionnaire disability index in rheumatoid arthritis

4.2 Linking physical function outcomes in rheumatology: Performance of a crosswalk for converting $H A Q$ scores to SF36 PF-10 score

Chapter 5 Dutch translation and cross-cultural adaptation of the PROMIS(R) physical function item bank and cognitive pre-test in Dutch arthritis patients

Chapter 6 Calibration and evaluation of cross-cultural measurement equivalence of 109 the PROMIS physical function item bank in Dutch patients with rheumatoid arthritis

Chapter 7 Measurement properties of the PROMIS physical function item bank in rheumatoid arthritis; Comparison with HAQ-DI and SF-36 physical functioning scale

Chapter 8 Relative performance of commonly used physical function questionnaires in rheumatoid artyhritis and a PROMIS computerized adaptive test: A simulation study.

Chapter 9

General discussion

Appendix

List of Journal publications 



\section{Chapter 1}

General introduction 


\section{General introduction}

Rheumatoid arthritis (RA) is a chronic, systemic, inflammatory disease of currently unknown cause. The prevalence of RA in western populations has been estimated to be around $1 \%$, with the disorder being observed about twice as often in women as in men (1). The clinical course of RA is characterized by progressive, often chronic, inflammation throughout the connective tissues of the body but especially the synovial joints. Inflammation and thickening of the synovial membranes cause irreversible damage to the joint capsule and the articular cartilage (2).

This characteristic joint damage evolves slowly over the course of the disease, with an incremental effect on the ability of the patient to perform routine daily activities (3). Additional reversible physical disability in RA may result from inflammatory pain and swelling (4). The preservation of physical function is therefore one of the main therapeutic goals in the treatment of RA and physical function has been one of the core outcome domains in RA since the introduction of the first core set of outcome measures in this field (5-7).

Early recommendations for the assessment of physical function in clinical settings included performance assessments on standardized tests of, for example, grip strength, walking time, or buttoning (8). However these have been all but abandoned in modern settings where patient reported outcome measures are favored, as they involve less professional time, have greater content and predictive validity than physical measures, and recognize the patients' own perspective on their disease as a primary treatment outcome (9-12).

Practically all contemporary clinical trials assess patient reported physical function as a study endpoint and numerous patient reported outcome measures have become available for this purpose in RA (13-15). The vast majority of these measures were developed according to the principles of classical test theory which involves administering a fixed set of items to each patient and a scoring rule based on summing of the individual item scores (13). An important limitation to this approach is that physical function scores do not only depend on a patient's level of physical function, but also on characteristics of the specific items used. As a result, physical function scores are only truly comparable in case patients fill out the same items. This is a limitation that has several problematic practical implications. The first is that since physical impairments in RA range from minimal disability to complete incapacity to perform basic activities of daily living, physical function questionnaires need to be either long, which is infeasible, or the range of physical function levels that can be expressed is limited. Many current questionnaires are relatively short and consequently associated with substantial floor and ceiling effects $(9,13,16,17)$. Floor or ceiling effects reflect limitations in the ability of a questionnaire to capture all occurring levels of function and, 
consequently, impose limitations to detect changes in clinical status for patients at, or near, the worst or best score levels respectively. Secondly, study results that utilize different physical function questionnaires are difficult to compare since they usually have different items, response options, and scoring procedures.

Item response theory (IRT) is a statistical framework that allows a more flexible approach to assigning physical function scores (18). In IRT, the probability that a patient will give a certain response to a questionnaire item is modeled as a monotonically increasing function of a patient's overall level of physical function called the item characteristic function. This will be further explained in the appendix. The invariance of item and person statistics is a key distinguishing feature of IRT, compared with classical test theory. It means that the parameters that characterize the item do not depend on the ability distribution of the sample that was used to estimate them and conversely that the parameter(s) that characterize(s) a patient do(es) not depend on the specific set of items that were used to estimate them. Once the item parameters of a set of items are estimated with a reasonable level of precision, fully comparable physical function estimates may be obtained from any subset of items that were jointly calibrated. Moreover, in IRT measurement precision is locally defined and from the item parameters so called information functions describe the contribution of individual items to physical function estimation along the physical function continuum (18). The major advantages of IRT over classical test theory approaches are that it allows different sets of items to be presented to different patients, while still yielding comparable scores and that information regarding their measurement precision in relation to the latent scale can be taken into account when selecting items to be administered. This allows items to be tailored to the physical function levels of specific patient groups. This may be achieved by manually selecting the most relevant items for a given setting based on item characteristics and prior beliefs regarding the level of physical function of a specific research population. However, a more sophisticated option is computerized adaptive testing, where every individual patient is administered a unique set of items selected from a calibrated item bank using a sequential statistical optimization algorithm $(19,20)$. The IRT models that were used in the studies of the current thesis will be introduced briefly in appendix A.

\section{Outline of thesis}

The aim of the current thesis was to explore and further develop the field of patient reported physical function measurement in RA by addressing some practical measurement problems using IRT-based approaches. Chapter 2 presents the results of two systematic reviews of the existing literature that provide an overview of the current generation of physical function questionnaires 
that have been validated for use in RA and an evaluation of the available evidence regarding their measurement properties. Both reviews identify some of the shortcomings associated with the use of the included questionnaires in the field of RA. The following two chapters illustrate how IRT analyses on existing physical function measures can address some of these. In chapter 3, two studies are presented in which the measurement equivalence of different versions of physical function questionnaires are evaluated using IRT analysis. The first study evaluates the cross-cultural measurement equivalence of the HAQ-II and the second study evaluates the equivalence of two different versions of the Dutch HAQ-DI. Chapter 4 describes a series of studies in which two commonly used physical function questionnaires, the HAQ-DI and SF-36 PF-10 were linked using IRT based concurrent calibration in order to develop a 'crosswalk' that can be used to convert scores of either measure to the metric of the other. The crosswalk was developed using data from Dutch patients with RA participating in the Dutch rheumatology monitoring (DREAM) registry. In the second study of chapter 4 , the performance of the crosswalk was evaluated in US patients with RA, systemic lupus erythematosus and fibromyalgia.

The remainder of the thesis focuses on the calibration and evaluation of the patient reported outcomes measurement information system (PROMIS) physical function item bank in Dutch patients with RA(21, 22). First, in chapter 5 the cross-cultural adaptation of the PROMIS physical function item bank for use in Dutch patients with RA is described. Chapter 6 describes the sampling design and IRT calibration of the PROMIS physical function item bank in Dutch patients with RA and the cross-cultural measurement equivalence of the item bank. Chapter 7 describes the measurement properties of the PROMIS physical function item bank in Dutch RA patients. Chapter $\mathbf{8}$ describes the performance of a CAT algorithm based on the calibrated item bank, compared with existing routinely used physical function questionnaires. Finally, in chapter 9 the findings of this thesis are discussed and some directions for future studies are considered.

\section{References}

1. Lawrence RC, Helmick CG, Arnett FC et al. Estimates of the prevalence of arthritis and selected musculoskeletal disorders in the United States. Arthritis Rheum 1998; 41: 778-799.

2. Budd RC, Gabriel SE, O'Dell JR, McInnes IB. Kelley's textbook of rheumatology. Elsevier Health Sciences 2012 .

3. Scott DL, Pugner K, Kaarela K et al. The links between joint damage and disability in rheumatoid arthritis. Rheumatology (Oxford) 2000; 39: 122-132.

4. Aletaha D, Smolen J, Ward MM. Measuring function in rheumatoid arthritis: Identifying reversible and irreversible components. Arthritis Rheum 2006; 54: 2784-2792. 
5. Felson DT, Anderson JJ, Boers M et al. The American College of Rheumatology preliminary core set of disease activity measures for rheumatoid arthritis clinical trials. The Committee on Outcome Measures in Rheumatoid Arthritis Clinical Trials. Arthritis Rheum 1993; 36: 729-740.

6. Wolfe F, Lassere M, van der Heijde D et al. Preliminary core set of domains and reporting requirements for longitudinal observational studies in rheumatology. J Rheumatol 1999; 26: 484-489.

7. Majithia V, Geraci SA. Rheumatoid arthritis: diagnosis and management. Am J Med 2007; 120: 936-939.

8. Pincus T, Sokka T, Kautiainen H. Further development of a physical function scale on a MDHAQ (corrected) for standard care of patients with rheumatic diseases. J Rheumatol 2005; 32: 1432-1439.

9. Pincus T, Sokka T, Kautiainen H. Further development of a physical function scale on a MDHAQ (corrected) for standard care of patients with rheumatic diseases. J Rheumatol 2005; 32: 1432-1439.

10. Wolfe F, Pincus T. Listening to the patient: a practical guide to self-report questionnaires in clinical care. Arthritis Rheum 1999; 42: 1797-1808.

11. Kirwan JR, Hewlett SE, Heiberg T et al. Incorporating the patient perspective into outcome assessment in rheumatoid arthritis--progress at OMERACT 7. J Rheumatol 2005; 32: 2250-2256.

12. Ahlmen M, Nordenskiold U, Archenholtz B et al. Rheumatology outcomes: the patient's perspective. A multicentre focus group interview study of Swedish rheumatoid arthritis patients. Rheumatology (Oxford) 2005; 44: 105-110.

13. Oude Voshaar MA, Ten Klooster PM, Taal E, van de Laar MA. Measurement properties of physical function scales validated for use in patients with rheumatoid arthritis: A systematic review of the literature. Health Qual Life Outcomes 2011; 9: 99.

14. Oude Voshaar AH, Ten Klooster PM, Taal E, Van de Laar MAFJ. Meeteigenschappen van vragenlijsten voor fysiek functioneren bij patiënten met reumatoïde artritis. Nederlands tijdschrift voor reumatologie 2012; 3: 6 - 11 .

15. Kalyoncu U, Dougados M, Daures JP, Gossec L. Reporting of patient-reported outcomes in recent trials in rheumatoid arthritis: a systematic literature review. Ann Rheum Dis 2009; 68: 183-190.

16. Wolfe F, Michaud K, Pincus T. Development and validation of the health assessment questionnaire II: a revised version of the health assessment questionnaire. Arthritis Rheum 2004; 50: 3296-3305.

17. Stucki G, Stucki S, Bruhlmann P, Michel BA. Ceiling effects of the Health Assessment Rheum Dis 1995; 54: 461-465.

18. Hambleton RK, Swaminathan H, Rogers HJ. Fundamentals of item response theory. Sage Publications, Inc 1991.

19. Wainer H, Dorans NJ, Green BF et al. Computerized adaptive testing: A primer. Lawrence Erlbaum Associates, Inc 1990.

20. van der Linden WJ, Glas CA. Computerized adaptive testing: Theory and practice. Springer 2000. 
14 Chapter 1 


\section{Chapter 2}

Systematic review of Dutch and international literature on measurement properties of physical function questionnaires in rheumatoid arthritis

Oude Voshaar MA, Ten Klooster PM, Taal E, van de Laar MA. Measurement properties of physical function scales validated for use in patients with rheumatoid arthritis: A systematic review of the literature. Health Qual Life Outcomes. 2011;9:99.

Oude Voshaar AH, Ten Klooster PM, Taal E, Van de Laar MAFJ. Meeteigenschappen van vragenlijsten voor fysiek functioneren bij patiënten met reumatoïde artritis. Nederlands tijdschrift voor reumatologie 2012; 3: 6 - 11. 


\section{Abstract}

Background: The aim of this study was to systematically review the content validity and measurement properties of all physical function (PF) scales which are currently validated for use with patients with rheumatoid arthritis (RA)

Methods: Systematic literature searches were performed in the Scopus and PubMed databases to identify articles on the development or psychometric evaluation of PF scales for patients with RA. The content validity of included scales was evaluated by linking their items to the International Classification of Functioning Disability and Health (ICF). Furthermore, available evidence of the reliability, validity, responsiveness, and interpretability of the included scales was rated according to published quality criteria.

Results: The search identified 26 questionnaires with PF scales. Ten questionnaires were rated to have adequate content validity. Construct validity, internal consistency, test-retest reliability and responsiveness was rated favourably for respectively 15, 11, 5, and 6 of the investigated scales. Information about the absolute measurement error and minimal important change scores were rarely reported.

Conclusion: Based on this literature review, the disease-specific HAQ and the generic SF-36 can currently be most confidently recommended to measure PF in RA for most research purposes. The HAQ, however, was frequently associated with considerable ceiling effects while the SF-36 has limited content coverage. Alternative scales that might be better suited for specific research purposes are identified along with future directions for research. 


\section{Background}

Patients' assessment of physical function (PF) is a core outcome domain of disease status in rheumatoid arthritis (RA)(1,2). Physical function scales are used in the majority of clinical trials to assess the effectiveness of treatment and have become established instruments for assessing health outcomes in clinical practice and observational studies as well (3-5).

A number of efforts have currently been undertaken to compare the variety of diseasespecific and generic PF scales that have been validated for use in patients with RA over the years (6-11) . However, previous efforts have been limited to descriptive reviews of well-known instruments or non-systematic selections of the available literature on their measurement properties. To date, there are no comprehensive studies available that systematically evaluate the evidence for the quality of the measurement properties of all PF scales that are validated for patients with RA. Furthermore, until recently there was no comprehensive conceptual framework available to define physical function in RA and with which to judge the relevance and comprehensiveness of the items of PF scales. Therefore, content validity could only be evaluated indirectly in previous efforts, for example by evaluating whether patients were included in the item selection process. Currently, the International Classification of Functioning, disability and Health (ICF) provides a comprehensive frame of reference, which allows the relevance and comprehensiveness of the items of PF scales to be examined directly by linking them to their respective ICF codes. Within the ICF classification, the 'activity' dimension constitutes the individual's perspective on functioning and is defined as 'difficulties an individual may have in executing activities (12). This dimension consists of the chapters domestic life, self-care and mobility, which respectively coincide with instrumental) activities of daily living (IADL \& ADL) and mobility which are traditionally used terms in the literature on physical functioning (13)

The most relevant ICF categories for a particular condition are summarized in a core set. The ICF Core Set for RA is a list of the ICF categories, which represent the typical functional problems experienced by patients with RA (14). The outcome measures in rheumatology (OMERACT) group accepts the ICF core set for RA as the best currently available external standard of functioning and recognizes its utility for assessing the content validity of existing measurement instruments (15).

The aim of this study was to systematically review the content validity and measurement properties of all PF scales that have been validated for use in patients with RA, by linking their content to the ICF and to appraise the currently available evidence of the quality of their measurement properties in order to offer recommendations for the use of PF scales for various purposes and settings. 


\section{Methods}

Study selection

An extensive literature search was conducted to retrieve all relevant articles related to the psychometric evaluation of PF scales in RA. A validated and sensitive search strategy for finding studies on measurement properties of patient-reported outcomes (PROs) was followed to design the search strings (16) and applied to the Scopus (1972-2010) and PubMed databases (1975-2010) in January 2011. This search strategy consists of four sets of independent searches that are later merged. The first search contains various synonyms of the construct of interest (i.e., physical function). The second search contains search terms for the population of interest (i.e., RA patients). The third search contains the validated and sensitive filter for the identification of studies investigating measurement properties of health-related PROs and the fourth search contains an exclusion filter. For more details about the content of the filters we refer to Terwee et al (16). The full search strings used in PubMed are available from the corresponding author.

Two reviewers (MOV and PTK) independently screened the titles and abstracts of the search results to identify potentially relevant studies. Studies were eligible if they were published in English, the main focus of the article was the development or psychometric evaluation of a questionnaire, at least part of the study population consisted of patients with RA, and the questionnaire was intended for use in adults. Final decisions on inclusion of studies in the review were made by consensus after both reviewers read all full-text articles that were deemed potentially relevant by either reviewer individually.

Questionnaires were retained for further review if they contained at least one scale addressing an aspect of overall PF (i.e., the ability to carry out basic or instrumental activities of daily living or mobility tasks), and were not limited to assessing the functioning of specific joints or limbs. Given the difficulty of assessing the quality of the applied translation procedures and the equivalence of translated versions of the questionnaires, only studies examining the measurement properties of the original language version were included. In case the original language of a questionnaire is spoken as the majority language in other countries, studies from those countries were considered to have used the original version, unless stated otherwise in the article. Finally, because the quality criteria used in this study require at least 50 patients per analysis to be eligible for rating, studies were included if analyses were reported for at least 50 patients with RA (17). Furthermore, in case patient groups with various diseases were studied that were not analysed per patient group, studies were included if the study population contained at least $50 \%$ patients with $\mathrm{RA}$, as has been done in similar, previous systematic reviews (18). 
To ensure that all relevant studies were retrieved, a second series of searches was performed with the names of the retained questionnaires as search terms in addition to the words "rheumatoid arthritis" and references of included studies and studies citing the original article were manually searched using Scopus citation tracker. Lastly, search results were verified against previous nonsystematic review articles of PF scales (6-11).

The full name of each retained questionnaire, the year of its development, and the language it was developed in were extracted, as well as the names of all scales relevant to the assessment of $\mathrm{PF}$ and their respective number of items. The consensus based standards for the selection of health status measurement instruments (COSMIN) checklist (19) was used to identify and extract information on measurement properties that are considered relevant for PROs. The COSMIN checklist was developed in a Delphi study among 43 experts in the field of health outcome measurement and contains standards for which measurement properties are most relevant to HRPROs and standards for how these measurement properties should be evaluated in terms of study design and statistical analysis. Two reviewers (MOV \& PTK) independently scored the checklist according to instructions in the manual for all included studies. Consensus about the ratings was reached by discussion. The quality of the measurement properties was rated according to quality criteria that were proposed for the COSMIN checklist (17).

\section{Validity}

Validity refers to the degree to which a scale measures what it sets out to measure (20). Since no gold standard exists for patient reported physical function, scales should demonstrate content and construct validity (21). Content validity should be assessed by making judgments about the relevance and the comprehensiveness of the items for assessing physical functioning of patients with RA (19). The relevance of a scale was rated positively if all items of a scale could be linked to ICF codes that are included in the ICF core set for RA and belong to one of the three chapters of the activity domain: self-care, domestic life or mobility. A scale was considered to measure PF comprehensively in case its content covers all three chapters of the activity dimension of the ICF. For this analysis all items of the included scales were linked to the ICF according to peer-reviewd linking rules (22). Construct validity refers to the extent to which scores on a questionnaire relate to other measures in a manner that is consistent with theoretically derived hypotheses concerning the constructs that are measured (23). However, in the included studies, hypotheses were rarely specified a priori when the construct validity of a scale was examined. This lack of hypotheses about the magnitude of expected relationships with clinical or other PROs limits interpretation of the results. Based on text book recommendations, included studies that did specify hypotheses and previous experience with validating PF scales, the following set of hypotheses was specified (24- 
33): A PF scale with adequate construct validity should correlate most strongly with other PF instruments, it should correlate second most strongly with other patient-reported measures of physical aspects of health (e.g., pain or the physical component score of the SF-36). PRO measures of non-physical aspects of health and clinical outcome measures (e.g., tender and swollen joint counts) should be less strongly related to the PF scale than the previous measures. Finally, we would expect the least strong correlations with (biological) process measures of disease activity. With respect to the absolute magnitude of correlations, a valid measure of PF was expected to correlate strongly $(r>0.60)$ with other measures of PF and measures of other aspects of physical health and moderately $(0.30<r<0.60)$ with clinical outcome measures and patient reported nonphysical aspects of health. Following the quality criteria of Terwee et al for a positive rating for construct validity (17), at least $75 \%$ of hypotheses should be confirmed and, in case a scale was validated against other established (multi-item) self-reported measures of PF, we considered it to be vital that the correlation was strong $(r>0.60)$.

\section{Internal consistency}

Scales that are internally consistent are made up of items that all measure the same concept and consequently produce correlated scores. When correlations among items are too high, however, redundant content is indicated (17). Questionnaires received a positive rating for internal consistency if factor analysis indicated the homogeneity of each relevant scale in a sufficiently large sample ( $\geq 5$ patients for every item in the analysis) and Cronbach's $\alpha$ was $\geq 0.70$, but $\leq 0.95$ for each relevant scale or the person separation index (or person reliability) was $\geq 0.70$ if Rasch analysis was applied (17)

\section{Reproducibility}

This concerns the degree to which repeated measurements in stable patients provide similar results. We assessed agreement and test-retest reliability. Studying agreement is important to detect systematic differences between measurements and to establish how much scores of individual patients can be expected to vary from one occasion to the next when there is no real change in functional status $(34,35)$. The standard error of measurement (SEM) or limits of agreement (LOA) (34) were considered to be adequate parameters of agreement. Agreement was considered acceptable if the minimal important change (MIC, see under interpretability) was greater than the smallest detectable change, which can be calculated from the SEM, or if the MIC was outside the LOA. Because the MIC was not commonly reported, we also gave a positive rating in case the authors provided convincing arguments that agreement was acceptable.

Scales that are reliable, reproducibly distinguish between patients with unchanged levels of $\mathrm{PF}$, despite measurement error. A positive rating for test-retest reliability was given if the intraclass 
correlation coefficient (ICC) for continuous measures or weighted kappa for categorical measures was $\geq 0.70$ in a sample of at least 50 stable patients over a period of one to six weeks (17).

\section{Responsiveness}

The ability of a questionnaire to detect clinically meaningful changes over time, even if those changes are small, is called responsiveness (36). Measuring change over the course of a therapeutic intervention with known effectiveness was considered to be the most appropriate technique for assessing responsiveness of PF scales $(37,38)$. A positive rating was given when adequate statistics, such as the standardized effect size or the standardized response mean, indicated a treatment effect of at least 0.30 , which constitutes a moderate magnitude according to Cohen (39). Because observed treatment effects depend critically on contextual elements such as the treatment used, the disease severity of the study sample, and the employed time frame, an adequate description of these elements was required for a positive rating as well.

\section{Interpretability}

Finally, it is important that clinicians and policy makers are able to assign qualitative meaning to questionnaire scores. Three aspects of interpretability were given individual ratings. First, minimally important change (MIC) scores should be documented. The MIC is the smallest change in score perceived to be important. Given that PRO measurement is inherently about the patients' perspective and that there is no objective gold standard for adequate changes in functional status, anchor-based techniques where patients rated the amount of change they experienced on a transition question, were considered to be appropriate. A positive rating was given if an adequate external indicator was used to categorize patients according to change status, the indicators were adequately described, and the relationship of the indicator with the questionnaire was sufficiently documented (37).

Secondly, substantial floor and ceiling effects should be absent. A large percentage of patients at the floor or ceiling of a measure limits the interpretability of change scores because further deterioration or improvement in functional status may occur but cannot be detected by the scale. A positive rating was given when $\leq 15 \%$ of patients either scored the lowest or highest possible score (17).

Finally, presenting scale scores for relevant subgroups of patients or before and after treatment and relating questionnaire scores to other outcome measures facilitates interpretability. A positive rating was given if at least two of the following types of information were presented: means and standard deviations before and after treatment with proven effectiveness, differences in scores between relevant groups, relating scores to patient's global ratings of change in disability or presenting information on the relationship of scores to other well-known measures of disability. 


\section{Results}

\section{Selection of studies}

The main search yielded a total of 3257 hits, of which 306 studies met the inclusion criteria and were retrieved for review. Of the 110 questionnaires that were psychometrically evaluated in the studies, 65 did not contain a (separate) PF scale and 18 questionnaires were limited to assessing the functioning of specific limbs or joints. The 51 studies identified by the main search that examined the measurement properties of the original language version of one of the 26 retained questionnaires were kept for review. Manual searching and reference checking resulted in the identification of 3 additional studies that were reviewed as well.

\section{Description of the questionnaires}

Table 1 summarizes the characteristics of the included questionnaires. In case a questionnaire was originally developed for use in patient groups other than RA, the original article about the development of the questionnaire was consulted. For descriptive purposes, questionnaires were grouped as generic (7 questionnaires) in case they were developed for use in diverse or general populations or disease-specific (19 questionnaires) when the questionnaire was developed for use in arthritic populations, according to the original articles. 
Table 1: Descriptive information of included questionnaires

\begin{tabular}{|c|c|c|c|c|}
\hline Questionnaire & Year & $\begin{array}{l}\text { Original } \\
\text { language }\end{array}$ & $\begin{array}{l}\text { Target } \\
\text { population }\end{array}$ & Relevant scales (\# of items) \\
\hline \multicolumn{5}{|c|}{ Generic questionnaires } \\
\hline $\mathrm{BI}$ & 1955 & $\begin{array}{l}\text { English } \\
\text { (US) }\end{array}$ & Chronic illnesses & Barthel Index (10) \\
\hline GARS & 1993 & Dutch & Older patients & $\begin{array}{l}\text { Activities of daily living (8), Instrumental activities of daily } \\
\text { living (11) }\end{array}$ \\
\hline MHIQ & 1976 & $\begin{array}{l}\text { English } \\
\text { (US) }\end{array}$ & $\begin{array}{l}\text { General } \\
\text { population }\end{array}$ & Physical function index (24) \\
\hline NHP & 1980 & $\begin{array}{l}\text { English } \\
(\mathrm{UK})\end{array}$ & $\begin{array}{l}\text { General } \\
\text { population }\end{array}$ & Physical Mobility (8) \\
\hline SF-36 & 1992 & $\begin{array}{l}\text { English } \\
\text { (US) }\end{array}$ & $\begin{array}{l}\text { General } \\
\text { population }\end{array}$ & Physical functioning (10) \\
\hline SIP & 1975 & $\begin{array}{l}\text { English } \\
\text { (US) }\end{array}$ & Sick populations & Ambulation (12), Body care and movement (23), Mobility (10) \\
\hline WHODAS-II & 1999 & Multilingual & $\begin{array}{l}\text { General } \\
\text { population }\end{array}$ & Getting Around (5), Self-care (4), Life activities (8) \\
\hline \multicolumn{5}{|c|}{ Diseases specific Questionnaires } \\
\hline FSI & 1980 & $\begin{array}{l}\text { English } \\
\text { (US) }\end{array}$ & Osteoarthritis & $\begin{array}{l}\text { Mobility (3), Personal care (4), Home chores (4), Hand } \\
\text { activities (3) }\end{array}$ \\
\hline AIMS & 1979 & $\begin{array}{l}\text { English } \\
\text { (US) }\end{array}$ & $\begin{array}{l}\text { Arthritic } \\
\text { conditions }\end{array}$ & $\begin{array}{l}\text { Mobility (4), Physical activity (5), Activities of daily living (4), } \\
\text { Dexterity (5) }\end{array}$ \\
\hline Short AIMS & 1991 & $\begin{array}{l}\text { English } \\
\text { (US) }\end{array}$ & $\begin{array}{l}\text { Arthritic } \\
\text { conditions }\end{array}$ & $\begin{array}{l}\text { Mobility (2), Physical activity (3), Activities of daily living (2), } \\
\text { Dexterity (3), Household activities (4) }\end{array}$ \\
\hline $\begin{array}{l}\text { Shortened } \\
\text { AIMS }\end{array}$ & 1989 & $\begin{array}{l}\text { English } \\
\text { (US) }\end{array}$ & $\begin{array}{l}\text { Arthritic } \\
\text { conditions }\end{array}$ & $\begin{array}{l}\text { Mobility (2), Physical activity (2), Activities of daily Living (2), } \\
\text { Dexterity (2), Household activities (2) }\end{array}$ \\
\hline AIMS2 & 1991 & $\begin{array}{l}\text { English } \\
\text { (US) }\end{array}$ & $\begin{array}{l}\text { Arthritic } \\
\text { conditions }\end{array}$ & $\begin{array}{l}\text { Mobility (5), Walking and bending (5), Hand and finger } \\
\text { function (5), Arm function (5), Self-care (4), Household (4) }\end{array}$ \\
\hline AIMS2-SF & 1993 & French & $\begin{array}{l}\text { Arthritic } \\
\text { conditions }\end{array}$ & Physical component (12) \\
\hline CSHQ-RA & 2006 & $\begin{array}{l}\text { English } \\
\text { (US) }\end{array}$ & $\begin{array}{l}\text { Rheumatoid } \\
\text { arthritis }\end{array}$ & Dexterity (7), Mobility (8) \\
\hline $\begin{array}{l}\text { CSHQ-RA, } \\
\text { revised }\end{array}$ & 2006 & $\begin{array}{l}\text { English } \\
\text { (US) }\end{array}$ & $\begin{array}{l}\text { Rheumatoid } \\
\text { arthritis }\end{array}$ & Dexterity (6), Mobility (6) \\
\hline CSSRD-FAS & 1995 & $\begin{array}{l}\text { English } \\
\text { (US) }\end{array}$ & $\begin{array}{l}\text { Rheumatoid } \\
\text { arthritis }\end{array}$ & Personal care (14). Mobility (1), Transfer (1) Work/play (18) \\
\hline $\mathrm{FFbH}$ & 1990 & German & Polyarthritis & Funktions fragenbogen (18) \\
\hline HAQ & 1980 & $\begin{array}{l}\text { English } \\
\text { (US) }\end{array}$ & $\begin{array}{l}\text { Arthritic } \\
\text { conditions }\end{array}$ & Disability index (20) \\
\hline HAQ-II & 2004 & $\begin{array}{l}\text { English } \\
\text { (US) }\end{array}$ & $\begin{array}{l}\text { Arthritic } \\
\text { conditions }\end{array}$ & Disability index (10) \\
\hline $\begin{array}{l}\text { MDHAQ } \\
\text { ADL })\end{array}$ & 1983 & $\begin{array}{l}\text { English } \\
\text { (US) }\end{array}$ & $\begin{array}{l}\text { Arthritic } \\
\text { conditions }\end{array}$ & Disability index (10) \\
\hline $\begin{array}{l}\text { MDHAQ } \\
\text { ADL })\end{array}$ & 2005 & $\begin{array}{l}\text { English } \\
\text { (US) }\end{array}$ & $\begin{array}{l}\text { Arthritic } \\
\text { conditions }\end{array}$ & Disability index (14) \\
\hline MHÁQ & 1983 & $\begin{array}{l}\text { English } \\
\text { (US) }\end{array}$ & $\begin{array}{l}\text { Arthritic } \\
\text { conditions }\end{array}$ & Disability index (8) \\
\hline ROAD & 2005 & Italian & Early arthritis & $\begin{array}{l}\text { Upper extremity function (5), Lower extremity function (4), } \\
\text { Activities of daily living/work (3) }\end{array}$ \\
\hline IRGL & 1990 & Dutch & Arthritis & Mobility (7), Self-care (8) \\
\hline TFCQ & 1982 & $\begin{array}{l}\text { English } \\
\text { (US) }\end{array}$ & arthritis & $\begin{array}{l}\text { Mobility (4), Personal care (4), Arm/hand functions (7), } \\
\text { Work/play (4) }\end{array}$ \\
\hline SIP-RA & 1993 & Swedish & arthritis & Body care and movement (14), Mobility (5) \\
\hline
\end{tabular}

BI = Barthel Index, GARS = Groningen Activity Restriction Scale, MHIQ = McMaster Health Index Questionnaire, NHP = Nottingham Health Profile, SF-36 = MOS 36 item short form Health survey, WHODAS-II = World Health Organization Disability Schedule-II, FSI = Functional Status Index, AIMS = Arthritis Impact Measurement Scales, Short AIMS = Short Arthritis Impact Measurement Scales, Shortened AIMS = Shortened Arthritis Impact Measurement Scales, AIMS2 = Arthritis Impact Measurement Scales 2, CSHQ-RA = Cedars-Sinai Health Related Quality of Life for Rheumatoid Arthritis instrument, CSHQ-RA Revised = Cedars-Sinai Health Related Quality of Life for Rheumatoid Arthritis instrument Revised, CSSRD-FAS-FAS $=$ Cooperative Systematic Studies for Rheumatic Diseases group Functional Assessment Survey, FFbH = Funktionsfragenbogen, Hannover, MDHAq $=$ Multidimensional Health Assessment Questionnaire, M-HAQ = Modified Health Assessment Questionnaire, HAQ = Health Assessment Questionnaire, HAQ-II = Health Assessment Questionnaire II, ROAD = Recent Onset Arthritis Disability Questionnaire, SIP-RA = Sickness Impact Profile for Rheumatoid Arthritis, TFCQ = Toronto Functional Capacity Questionnaire IRGL = Impact van Reuma op Gezondheid en Leven. 


\section{Measurement properties}

Ratings of the measurement properties are presented in table 2. Each measurement property is qualified as adequate with good methodological quality $(+)$, indeterminate because of doubtful methodological quality (0), or inadequate with good methodological quality (-), Question marks indicate insufficient information about an aspect.

\section{Content validity}

In total, only 30 out of 591 (5\%) concepts that were identified in the items could not be linked to the ICF. The vast majority of concepts were linked to the chapters Mobility (47\%), Self-care (23\%) or Domestic life $(10 \%)$. Questionnaires were rated for relevance and comprehensiveness Of the generic questionnaires, the GARS, MHIQ, NHP and SF-36 were rated positively for relevance because all their PF items could be linked to one of the ICF chapters mobility, self-care or domestic life (see table 2). Three generic questionnaires were rated negatively for relevance. The BI and SIP contain items related to faecal and urinary incontinence (ICF codes B5253 and B6202), and an item about transferring oneself (D420), which is not part of the ICF core set for RA. The SIP also contains an item that was linked vestibular function of balance (B2351), which belongs to the domain body functions. The WHODAS-II contains an item that was linked to the general tasks and demands category (D2302) from chapter 2, general tasks and demands and an item linked to remunerative employment (D850). Thirteen disease-specific questionnaires were rated positively for relevance because all their respective PF items could be linked to mobility, self-care or domestic life categories featuring in the core set. Five disease-specific questionnaires were rated negatively for relevance. SIP-RA contains an item that was linked to vestibular function of balance (B2351), which belongs to the domain body functions and an item linked to the category mobility of a single joint (B7101) from the body functions chapter. The CSHQ-RA contains an item linked to mobility of a single joint(B7101) as well and multiple items linked to sensory of pain (B280) in its dexterity and mobility scale and one item linked to sleep function (B134). The CSSRD-FAS contains an item linked to remunerative employment (D850). The AIMS contains an item related to carrying out daily routine (D2308) and the ROAD contains an item that was linked to basic interpersonal interactions (D710). In the analysis of comprehensiveness, nine questionnaires, four of which generic, were rated negatively (see table 2). All negatively rated questionnaires lack items assessing the domestic life chapter of the ICF (i.e., IADL). Overall, only ten questionnaires received favorable ratings for both aspects of content validity, indicating that all their items are relevant to the assessment of PF of patients with RA and all three relevant ICF chapters are measured by the items making up the scale. 


\section{Construct validity}

Of the included generic scales, the construct validity of the WHODAS-II could not be rated because only the construct validity of the total score was investigated, which also includes scales measuring non-physical aspects of quality of life. The MHIQ was rated favourably because it demonstrated adequate known-groups validity. The GARS, NHP and SF-36 were tested for convergent and/or divergent validity and given positive ratings because the results were in accordance with $>75 \%$ of hypotheses. The BI was rated negatively because it did not correlate strongly with the HAQ $(r=0.42)$ and the SIP was correlated only moderately to patient reported PF $(r=0.41)$. For the disease specific scales, no information was available to rate the construct validity of the FSI, TFCQ and both versions of the MDHAQ. An indeterminate ratings was given to the SIP-RA because sub-scale scores were only being correlated to the total score. Eleven disease specific scales received a positive rating for construct validity. The AIMS2 and AIMS2-SF were rated favourably because respectively known-group comparisons and multitrait methods indicated adequate construct validity. The remaining nine scales received positive ratings because the pattern of correlations was in sufficient agreement with our hypotheses. Only the ROAD, IRGL and shortened AIMS were given negative ratings for construct validity. all of the subscales of the ROAD were found to be inadequately related to the HAQ $(r=0.17-0.32)$, and the SF-36 PF scale $(r=0.18-0.32)$. Furthermore, because the scales were generally weakly related to other measures relevant to our hypotheses (see supplementary material) eventually only 4 out of 25 (16\%) hypotheses were confirmed. For the IRGL and the shortened AIMS, 65\% and 51\% of hypotheses were confirmed, respectively.

\section{Internal consistency}

For 11 out of 22 questionnaires for which information on internal consistency was found, factor analysis was applied before calculating Cronbach's $\alpha$. The AIMS was the only questionnaire to receive a negative rating, because $\alpha<0.70$ was reported for the physical activities and activities of daily living subscales. The HAQ-II and SF-36 were rated indeterminate because internal consistency was tested with Rasch analysis and although the person separation index was deemed acceptable $(\geq 0.70)$ in both cases, there was no assessment of the dimensionality of the scales beyond the reporting of item level fit statistics. The AIMS2-SF and both versions of the MDHAQ were rated indeterminate because a single scale was created for PF, while factor analysis had indicated the presence of multiple dimensions. Inappropriate statistical methods were used for the TFCQ, the sample size was $<50$ patients for the MHIQ, and for the SIP-RA internal consistency analysis was performed on the total questionnaire scores only, rather than on individual scales, 
leading to indeterminate ratings for these questionnaires as well. For the remaining questionnaires that were rated indeterminate, factor analysis had not been applied.

\section{Reproducibility}

The HAQ, CSHQ-RA, revised CSHQ-RA, ROAD, and AIMS2-SF were rated positive for reliability. The NHP, AIMS, IRGL, and both of the AIMS short forms were rated indeterminate for reliability because the Pearson product moment correlation was used instead of the ICC. The SIP, MHIQ, WHODAS-II, SF-36, AIMS2, and MHAQ were rated indeterminate because the sample size was $<50$. ICCs for individual items only were reported for the FSI. Only the CSSRDFAS received a negative rating, because ICCs $<0.70$ were observed for the transfer and mobility scales in stable patients. The LOA or SEM was presented for only four questionnaires. For the ROAD, the limits of agreement were not related to the MIC, nor were arguments provided with respect to the acceptability of the level of agreement between scores on different times. For the HAQ, MHAQ, and SF-36, the SEM or LOA were estimated in a sample $<50$ patients. Therefore, agreement was rated indeterminate for all scales.

\section{Responsiveness}

Information on responsiveness was found for 17 questionnaires. Six questionnaires were rated positive for responsiveness, because either the standardized effect size or the standardized response mean statistic showed moderate improvements in scores after effective treatment, with adequate descriptions of contextual factors. Studies on the GARS, WHODAS-II, and HAQ-II also utilized appropriate statistics, but their results couldn't be interpreted because insufficient information was presented about the study design or results. Methods that merely rely on the significance of the difference between scores at two time points were used for the CSHQ-RA, revised CSHQ-RA, TFCQ, and short AIMS. These statistical techniques were considered inadequate because p-values are inversely related to sample size. For the SIP and SIP-RA unconventional methods were used to examine its responsiveness. The remaining scales that were rated indeterminate had sample sizes $<50$ patients.

\section{Interpretability}

MICs were reported for four questionnaires. Marked floor effects were reported for the SF-36, where $22 \%$ of a sample stratified to equally represent patients from all four Steinbrocker functional classes scored the worst possible score. However, this was caused almost exclusively by patients in Steinbrocker functional classes III and IV. Ceiling effects of up to $31 \%$ of patients were reported for the MHAQ, $16 \%$ for the HAQ, and $>15 \%$ for the WHODAS-II. For the remaining questionnaires that were rated, floor and ceiling effects were all well below the cut-off point of 
$15 \%$. For seven questionnaires, two or more types of score distributions were presented that can facilitate the interpretation of questionnaire scores. 


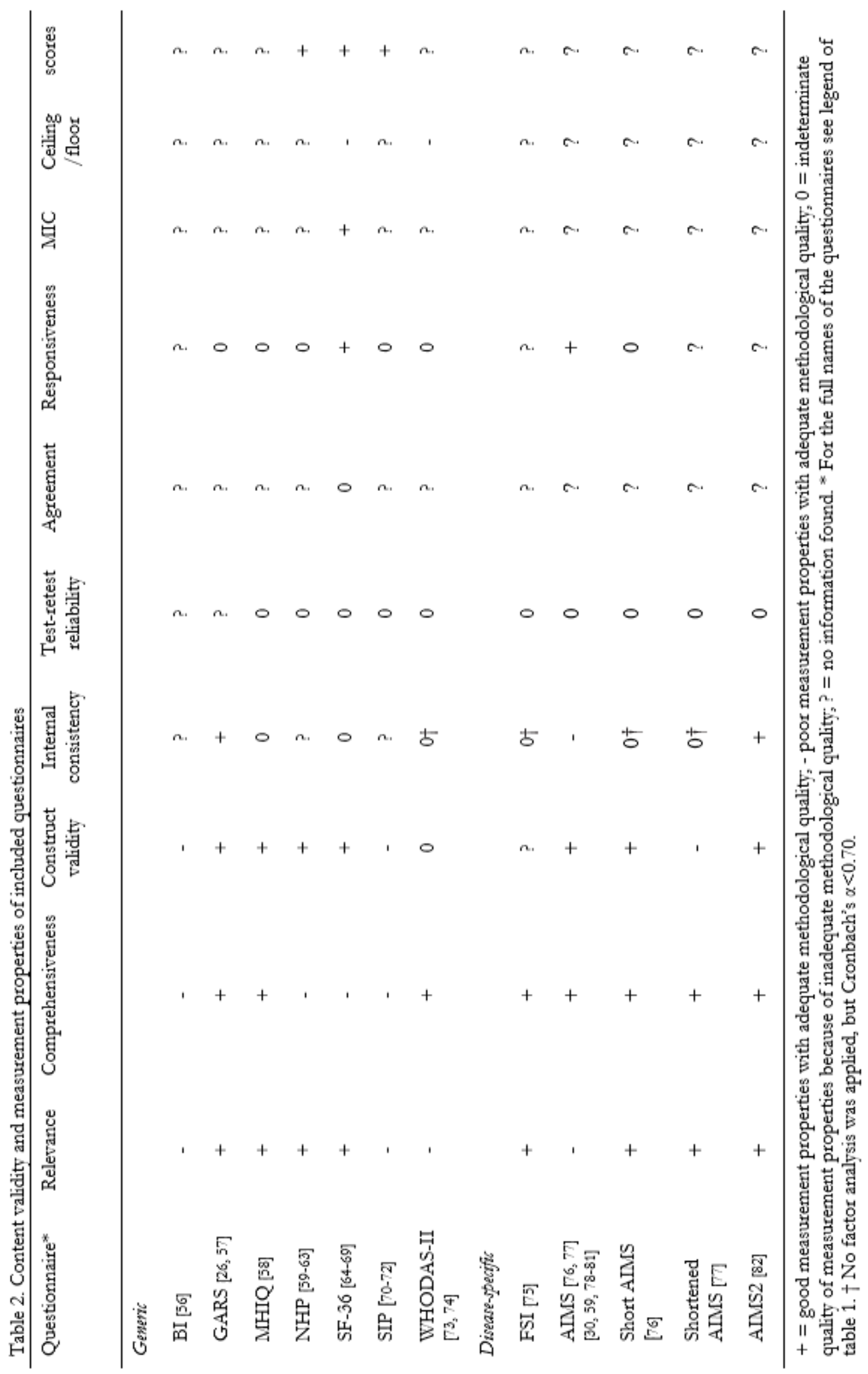




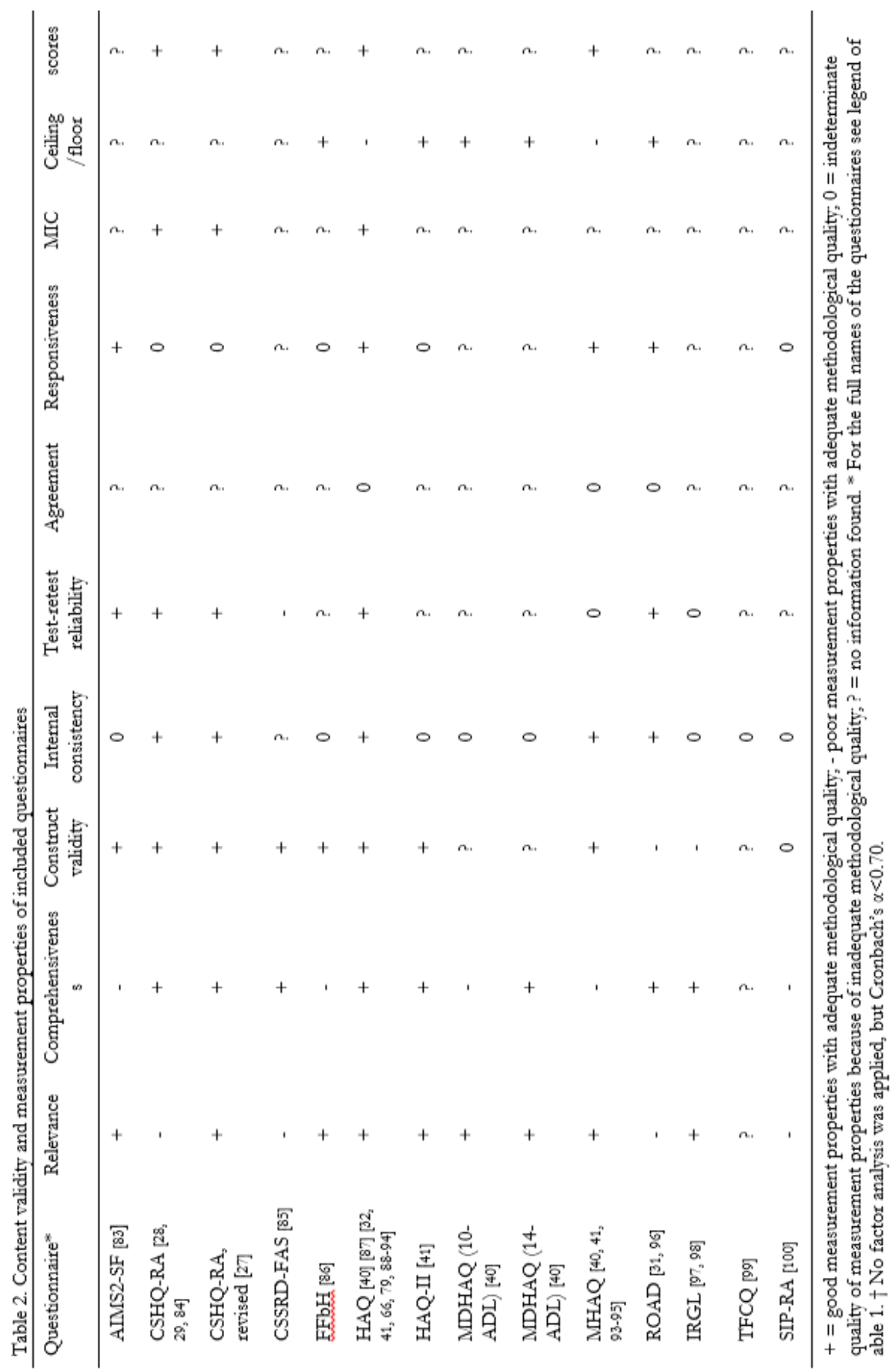




\section{Discussion}

This study systematically reviewed the literature on measurement properties of PF scales that are validated for use in patients with RA. The results of this review provide a comprehensive assessment of the available evidence for the utility of available scales for patients with RA and may inform the appropriate selection of self-reported PF scales for various purposes in clinical practice and research.

PROs are commonly classified as disease-specific or generic. In this systematic review, a pragmatic classification was employed based on the intended target population of the included questionnaires. However, it should be noted that although developed for use in arthritic populations, PF scales that were classified as disease-specific do not necessarily have content that is exclusively relevant in these populations. In fact, some scales such as the HAQ which is often referred to as a disease-specific measure, assesses physical disability in general and does not focus on specific disease-associated impairments. As a result, the scale has been used across a wide range of general and clinical populations(3).

Of the disease-specific scales that were rated positively for both aspects of validity, the HAQ received the most favourable overall evaluation. Owing to its longstanding and extensive use in RA, the measurement properties of the HAQ have been exhaustively studied. This review showed that it has predominantly favourable measurement properties that have been studied with adequate methodological rigor. The HAQ met the standards we set for responsiveness and its testretest reliability was found to be very high in a sample of stable patients, indicating that the scale is appropriate for evaluative purposes (i.e., to track physical functioning over time), both at the group level and at the individual level. However, one important limitation of the HAQ is that multiple studies noted a considerable group of patients scoring the best possible score. Therefore, it may not be the most appropriate scale for use in patient populations with relatively good functional capacity, since it cannot measure improvement in a substantial proportion of patients. Both the MDHAQ (14 ADL) and the HAQ-II were rated favorably for all aspects of validity as well and were specifically developed to address the ceiling effects of the original HAQ (40, 41).Both scales indeed demonstrated substantially smaller ceiling effects in direct comparison with the original HAQ, indicating that these scales might be more appropriate than the original HAQ for use in relatively well functioning groups. Another advantage of these scales is that they contain only 14 and 10 items, making them more feasible for use in clinical practice or when administering multiple PROs simultaneously. However, the measurement properties of HAQ-II and MDHAQ (14-ADL) have been less extensively studied. In particular, before recommending their use in evaluative studies, the responsiveness of these scales should be compared to that of the HAQ and their 
reproducibility in stable patients should be established. The revised CSHQ-RA and AIMS2 were also rated favorably for validity, but no information is available known about their distributional properties and the evidence testifying to the responsiveness of the revised CSHQ-RA is limited to methods that rely on statistical significance. Further research is required before a comprehensive evaluation of the quality of the revised CSHQ-RA is possible. The AIMS2 might be the most comprehensive disease-specific questionnaire. Its items were linked to 31 relevant ICF categories and issues such as fine hand use and arm use and domestic life are addressed in more detail than in the HAQ, which was also noted by Stucki et al (14). However, with its 28 items it is also the most lengthy questionnaire and much of the work on its measurement properties is outdated. Further psychometric testing is therefore desirable. Finally, the short AIMS was also rated favorably for all aspect of validity, but it contains scales that lack internal consistency, perhaps because some subscales consist of only 2 items or because the response format is often yes/no. Therefore we would not recommend it for use or for further testing.

The CSHQ-RA and ROAD are among the most recently developed disease-specific scales and the methodology of the work on their measurement properties conforms to the rigorous methodological standards of COSMIN, enhancing the interpretability of their psychometric quality in this review. Regrettably however, these scales suffer from irrelevant content. Therefore their use cannot be recommended for the assessment of PF, despite generally favorable evaluations for their other measurement properties.

Although it is well known that measurement properties are context-specific attributes that can differ across populations, previous studies have paid no attention to verifying the content validity of the included generic scales for use in RA patient groups. Therefore, by linking their content to the comprehensive ICF core set for RA, this review provides the first assessment of the content validity of included generic scales for assessing physical functioning of patients with RA.

The SF-36 PF scale is probably the most frequently used generic scale in patients with RA. However, although all of its items are relevant, it measures predominantly mobility and has no content relevant to the assessment of domestic life, which was already recognized as an important shortcoming by its developers (42). Another limitation of the scale is that it has been associated with substantial floor effects (i.e., patients scoring the worst possible score). Most of its measurement properties have been studied in patients with RA, but studies of more rigorous methodological quality are desirable. For instance, no studies were found reporting on the dimensionality of the original version and its reproducibility has been studied in small patient groups $(\mathrm{n}<25)$ only. On the other hand, the SF-36 PF-10 is the only generic PF scale that was rated positively for responsiveness. 
Except for the MHIQ, the other health profiles, (SIP and NHP) demonstrated limited content coverage as well. Because health profiles intend to cover all major areas of health, it might be expected that content coverage within their components is less comprehensive. The GARS on the other hand is a dedicated PF instrument which is reflected in the finding that its content more comprehensively reflects the overall PF domain. Therefore, the GARS may be well suited when the primary outcome of interest is physical function rather than overall health. However, as with most generic scales in this review, its measurement properties are currently poorly understood. More research is required to establish its performance in longitudinal settings before its use can be recommended.

With the inclusion of items of the participation chapters of the ICF, the WHODAS-II covers a wider spectrum of disability than just physical function. The same applies to the BI and SIP. These measures include multiple items belonging to ICF categories E120 (Products and technology for personal use in daily living), E30 (support and relationships) and B5253 and B6202 (fecal/urinary incontinence). Therefore, they might be better thought of as measures of dependence rather than physical function per se. This interpretation is further strengthened by the observation that the SIP and BI were evaluated negatively for construct validity. In particular, both scales correlated only moderately with other PF instruments.

With respect to rating the measurement properties of the included scales, it was notable that in one-third of the studies that assessed reliability, samples of less than 25 patients were used. Although observed ICCs were generally well above the commonly accepted cut-off point of 0.70 , it is important that reliability is studied in sufficiently large samples. Simulation studies have shown that even when a value as high as 0.80 is observed, a sample size of 60 patients is required to reliably conclude that ICC $>0.70$ in the population the sample was drawn from $(43,44)$. Furthermore, for most scales, information on reproducibility of scores was limited to reports on test-retest reliability. For evaluative purposes, especially when monitoring functional status of individual patients, it is informative to report on the absolute agreement of test-retest scores for patients with unchanged functional status as well. Representative values of the LOA or SEM can serve as benchmarks for distinguishing real change in functional status from changes due to random measurement error (17). Finally, minimally important change scores have not been widely reported and should be addressed in future research, as they greatly enhance the interpretability of change scores. Instruments should be administered longitudinally before and after treatment known to improve $\mathrm{PF}$, and health transition questions should be included as external criteria of change (26). A point worth mentioning is that this systematic review is limited to traditional static questionnaires. 
Recently, item response theory (IRT) based item banking is receiving increasing attention in PRO assessment. Of special relevance to PF assessment in RA populations is the patient reported outcome measurement information system (PROMIS) initiative. PROMIS is an NIH initiative aimed at revising instruments in many domains including PF, using IRT calibrations and computerized adaptive testing (CAT) (45). The PROMIS PF item bank contains 124 calibrated items and CAT algorithms allow for the adaptive selection of the most relevant item for a particular patient in terms of relative difficulty based on previous answers given by that patient (46). The main advantage of using these modern psychometric approaches is that the use of extensive item banks potentially eliminates floor and ceiling effects, while the CAT algorithm ensures that patients only need to answer a minimum number of questions $(47,48)$. Short forms can also be developed from the PROMIS item banks. For example, the PROMIS HAQ has been developed from the PROMIS PF item bank(46). Unfortunately, none of the PROMIS studies met the inclusion criteria for this review of at least 50\% RA patients, however the PROMIS PF item bank is likely to become a prominent measurement system in RA and it would be highly interesting for future research to study the psychometric properties of the PROMIS PF item bank specifically for RA populations.

There are some limitations to our study that deserve attention. First, we used the ICF as an external standard to evaluate the content validity of the included scales, as have a number of previous similar systematic reviews $(49,50)$. The ICF aims to provide a common language for functional status assessment in clinical practice and research. However, most included scales were developed before the ICF was available. Moreover, concerns have been voiced regarding the exhaustiveness of the ICF as a comprehensive classification of disability (51) and several validation studies of the ICF core set for RA have found some omissions from the perspective of patients and physicians that future research should address $(52,53)$. Therefore some caution must be taken when interpreting the results of the analysis of content validity. Still, the ICF is frequently recommended for assessing the content validity of health status instruments (15) and 95\% of all PF items included in this systematic review could be linked to at least one ICF code. Moreover, the items that were linked to ICF categories other than mobility, self-care or domestic life were all clearly irrelevant to the assessment of PF. Our results therefore seem to indicate that the ICF is a useful taxonomic tool for assessing the relevance of disability items, such as those included in this systematic review. Second, for most scales, the work on their measurement properties was predominantly or exclusively performed with the original language versions. However, the majority of the studies on the measurement properties of the AIMS2 and AIMS2-SF concerned translated versions. Users of translated versions are therefore advised to examine if a validation study is available for their language version, rather than solely depending on the results of this review. For 
several translations, individual items were omitted, changed, or added in order to adapt a questionnaire for use in a different culture. Since in some instances up to $10 \%$ of items were changed, it is unclear to what degree measurement properties are generalizable across versions and cultures $(54,55)$.

\section{Conclusions}

None of the scales met all the rigorous quality requirements we set. However the disease-specific HAQ can confidently be recommended for most applications in patients with RA. Longitudinal or experimental studies in patient groups with relatively good functional capacity may require scales with broader measurement range such as the MDHAQ (14 ADL) or HAQ-II. However, since their longitudinal performance is currently poorly documented, their test-retest reliability and responsiveness should be addressed by future research first. The SF-36 is the most thoroughly evaluated generic scale that is currently most suited for studies that want to compare RA patients with other populations. In particular, it is the only generic scale with adequate proven responsiveness. However it has limited coverage of the PF domain and therefore it would be desirable to compare its performance in longitudinal settings with that of the GARS and MHIQ, which more comprehensively measure PF.

\section{References}

1. Boers M, Tugwell P, Felson DT, van Riel PL, Kirwan JR, Edmonds JP, Smolen JS, Khaltaev N, Muirden KD: World Health Organization and International League of Associations for Rheumatology core endpoints for symptom modifying antirheumatic drugs in rheumatoid arthritis clinical trials. J Rheumatol Suppl 1994, 41:86-89.

2. Felson DT, Anderson JJ, Boers M, Bombardier C, Chernoff M, Fried B, Furst D, Goldsmith C, Kieszak S, Lightfoot R et al: The American College of Rheumatology preliminary core set of disease activity measures for rheumatoid arthritis clinical trials. The Committee on Outcome Measures in Rheumatoid Arthritis Clinical Trials. Arthritis Rheum 1993, 36(6):729-740.

3. Bruce B, Fries JF: The Health Assessment Questionnaire (HAQ). Clin Exp Rheumatol 2005, 23(5 Suppl 39):S14-18.

4. Kalyoncu U, Dougados M, Daures JP, Gossec L: Reporting of patient-reported outcomes in recent trials in rheumatoid arthritis: a systematic literature review. Ann Rheum Dis 2009, 68(2):183-190.

5. Wolfe F, Lassere M, van der Heijde D, Stucki G, Suarez-Almazor M, Pincus T, Eberhardt K, Kvien TK, Symmons D, Silman A et al: Preliminary core set of domains and reporting requirements for longitudinal observational studies in rheumatology. J Rheumatol 1999, 26(2):484-489.

6. Carr A: Adult Measures of Quality of Life: The Arthritis Impact Measurement Scales (AIMS/AIMS2), Disease Repercussion Profile (DRP), EuroQoL, Nottingham Health Profile (NHP), Patient Generated Index (PGI), Quality of Well Being Scale (QWB), RAQoL, Short Form 36 (SF 36), Sickness Impact Profile (SIP), 
SIP RA, and World Health Organization's Quality of Life Instruments (WHOQoL, WHOQoL 100, WHOQoL Bref). Arthritis Care \& Research 2003, 49(S5):S113-S133.

7. Katz PP: Measures of adult general functional status: The barthel index, katz index of activities of daily living, health assessment questionnaire (HAQ), MACTAR patient preference disability questionnaire, and modified health assessment questionnaire (MHAQ). Arthrit care res 2003, 49(5):S15-S27.

8. Lubeck DP: Health-related quality of life measurements and studies in rheumatoid arthritis. Am J Manag Care 2002, 8(9):811-820.

9. Stenstrom CH, Nisell R: Assessment of disease consequences in rheumatoid arthritis: a survey of methods classified according to the International Classification of Impairments, Disabilities, and Handicaps. Arthritis Care Res 1997, 10(2):135-150.

10. Wolfe F, Pincus T: Listening to the patient: a practical guide to self-report questionnaires in clinical care. Arthritis Rheum 1999, 42(9):1797-1808.

11. Lillegraven S, Kvien TK: Measuring disability and quality of life in established rheumatoid arthritis. Best Pract Res Clin Rheumatol 2007, 21(5):827-840.

12. Organization WH: International classification of functioning, disability and health: ICF: World Health Organization; 2001.

13. Räty S, Aromaa A, Koponen P: Measurement of physical functioning in comprehensive national health surveys - ICF as a framework. In.: National Public Health Institute, KTL. ; 2003.

14. Stucki G, Cieza A: The International Classification of Functioning, Disability and Health (ICF) Core Sets for rheumatoid arthritis: a way to specify functioning. Annals of the rheumatic diseases 2004, 63(suppl 2):ii40.

15. Boonen A, Stucki G, Maksymowych W, Rat AC, Escorpizo R, Boers M: The OMERACT-ICF Reference Group: integrating the ICF into the OMERACT process: opportunities and challenges. J Rheumatol 2009, 36(9):2057-2060.

16. Terwee CB, Jansma EP, Riphagen, II, de Vet HC: Development of a methodological PubMed search filter for finding studies on measurement properties of measurement instruments. Qual Life Res 2009, 18(8):11151123.

17. Terwee CB, Bot SD, de Boer MR, van der Windt DA, Knol DL, Dekker J, Bouter LM, de Vet HC: Quality criteria were proposed for measurement properties of health status questionnaires. J Clin Epidemiol 2007, 60(1):34-42.

18. van der Leeden M, Steultjens MP, Terwee CB, Rosenbaum D, Turner D, Woodburn J, Dekker J: A systematic review of instruments measuring foot function, foot pain, and foot-related disability in patients with rheumatoid arthritis. Arthritis Rheum 2008, 59(9):1257-1269.

19. Mokkink LB, Terwee CB, Patrick DL, Alonso J, Stratford PW, Knol DL, Bouter LM, de Vet HC: The COSMIN checklist for assessing the methodological quality of studies on measurement properties of health status measurement instruments: an international Delphi study. Qual Life Res 2010, 19(4):539-549.

20. Lohr KN, Aaronson NK, Alonso J, Burnam MA, Patrick DL, Perrin EB, Roberts JS: Evaluating quality-oflife and health status instruments: development of scientific review criteria. Clin Ther 1996, 18(5):979-992.

21. Guyatt GH, Feeny DH, Patrick DL: Measuring health-related quality of life. Ann Intern Med 1993, 118(8):622-629.

22. Cieza A, Geyh S, Chatterji S, Kostanjsek N, Ustun B, Stucki G: ICF linking rules: an update based on lessons learned. J Rehabil Med 2005, 37(4):212-218. 
23. Kirshner B, Guyatt G: A methodological framework for assessing health indices. J Chronic Dis 1985 , 38(1):27-36.

24. Ten Klooster PM, Oude Voshaar MA, Taal E, van de Laar MA: Comparison of measures of functional disability in patients with gout. Rheumatology (Oxford) 2011, 50(4):709-713.

25. ten Klooster PM, Taal E, van de Laar MA: Rasch analysis of the Dutch Health Assessment Questionnaire disability index and the Health Assessment Questionnaire II in patients with rheumatoid arthritis. Arthritis Rheum 2008, 59(12):1721-1728.

26. Suurmeijer TP, Doeglas DM, Moum T, Briancon S, Krol B, Sanderman R, Guillemin F, Bjelle A, van den Heuvel WJ: The Groningen Activity Restriction Scale for measuring disability: its utility in international comparisons. Am J Public Health 1994, 84(8):1270-1273.

27. Chiou CF, Sherbourne CD, Cornelio I, Lubeck DP, Paulus HE, Dylan M, Chang CH, Weisman MH: Development and validation of the revised Cedars-Sinai health-related quality of life for rheumatoid arthritis instrument. Arthritis Rheum 2006, 55(6):856-863.

28. Chiou CF, Sherbourne CD, Cornelio I, Lubeck DP, Paulus HE, Dylan M, Weisman M: Revalidation of the original Cedars-Sinai health-related quality of life in rheumatoid arthritis questionnaire. J Rheumatol 2006, 33(2):256-262.

29. Russak SM, Sherbourne CD, Lubeck DP, Paulus HD, Chiou CF, Sengupta N, Borenstein J, Ofman J, Moadel A, Weisman MH: Validation of a rheumatoid arthritis health-related quality of life instrument, the CSHQRA. Arthritis Rheum 2003, 49(6):798-803.

30. Potts MK, Brandt KD: Evidence of the validity of the Arthritis Impact Measurement Scales. Arthritis Rheum 1987, 30(1):93-96.

31. Salaffi F, Stancati A, Neri R, Grassi W, Bombardieri S: Measuring functional disability in early rheumatoid arthritis: the validity, reliability and responsiveness of the Recent-Onset Arthritis Disability (ROAD) index. Clin Exp Rheumatol 2005, 23(5 Suppl 39):S31-42.

32. Peck JR, Smith TW, Ward JR, Milano R: Disability and depression in rheumatoid arthritis. A multi-trait, multi-method investigation. Arthritis Rheum 1989, 32(9):1100-1106.

33. Swinscow TDV, Campbell MJ, ebrary I: Statistics at square one: Bmj London; 2002.

34. Bland JM, Altman DG: Statistical methods for assessing agreement between two methods of clinical measurement. Lancet 1986, 1(8476):307-310.

35. Bland JM, Altman DG: Measurement error and correlation coefficients. BMJ 1996, 313(7048):41-42.

36. Guyatt GH, Deyo RA, Charlson M, Levine MN, Mitchell A: Responsiveness and validity in health status measurement: a clarification. J Clin Epidemiol 1989, 42(5):403-408.

37. Revicki DA, Cella D, Hays RD, Sloan JA, Lenderking WR, Aaronson NK: Responsiveness and minimal important differences for patient reported outcomes. Health Qual Life Outcomes 2006, 4:70.

38. Verhoeven AC, Boers M, van Der Linden S: Responsiveness of the core set, response criteria, and utilities in early rheumatoid arthritis. Ann Rheum Dis 2000, 59(12):966-974.

39. Cohen J: Statistical power analysis for the behavioral sciences: Lawrence Erlbaum; 1988.

40. Pincus T, Sokka T, Kautiainen H: Further development of a physical function scale on a MDHAQ (corrected) for standard care of patients with rheumatic diseases. J Rheumatol 2005, 32(8):1432-1439.

41. Wolfe F, Michaud K, Pincus T: Development and validation of the health assessment questionnaire II: a revised version of the health assessment questionnaire. Arthritis Rheum 2004, 50(10):3296-3305. 
42. Ware JE, Jr., Sherbourne CD: The MOS 36-item short-form health survey (SF-36). I. Conceptual framework and item selection. Med Care 1992, 30(6):473-483.

43. Donner A, Eliasziw M: Sample size requirements for reliability studies. Stat Med 1987, 6(4):441-448.

44. Giraudeau B, Mary JY: Planning a reproducibility study: how many subjects and how many replicates per subject for an expected width of the 95 per cent confidence interval of the intraclass correlation coefficient. Stat Med 2001, 20(21):3205-3214.

45. Patient Reported Outcomes Measurement Information System (http://www.nihpromis.org/)

46. Fries JF, Cella D, Rose M, Krishnan E, Bruce B: Progress in assessing physical function in arthritis: PROMIS short forms and computerized adaptive testing. J Rheumatol 2009, 36(9):2061-2066.

47. Fries JF, Krishnan E, Rose M, Lingala B, Bruce B: Improved responsiveness and reduced sample size requirements of PROMIS physical function scales with item response theory. Arthritis Res Ther 2011, 13(5):R147.

48. Rose M, Bjorner JB, Becker J, Fries JF, Ware JE: Evaluation of a preliminary physical function item bank supported the expected advantages of the Patient-Reported Outcomes Measurement Information System (PROMIS). J Clin Epidemiol 2008, 61(1):17-33.

49. Lindner HY, Natterlund BS, Hermansson LM: Upper limb prosthetic outcome measures: review and content comparison based on International Classification of Functioning, Disability and Health. Prosthet Orthot Int 2010, 34(2):109-128.

50. Stamm T, Geyh S, Cieza A, Machold K, Kollerits B, Kloppenburg M, Smolen J, Stucki G: Measuring functioning in patients with hand osteoarthritis--content comparison of questionnaires based on the International Classification of Functioning, Disability and Health (ICF). Rheumatology (Oxford) 2006, 45(12):1534-1541.

51. Tesio L: From codes to language: is the ICF a classification system or a dictionary? BMC Public Health 2011, 11 Suppl 4:S2.

52. Gebhardt C, Kirchberger I, Stucki G, Cieza A: Validation of the comprehensive ICF Core Set for rheumatoid arthritis: the perspective of physicians. J Rehabil Med 2010, 42(8):780-788.

53. Coenen M, Cieza A, Stamm TA, Amann E, Kollerits B, Stucki G: Validation of the International Classification of Functioning, Disability and Health (ICF) Core Set for rheumatoid arthritis from the patient perspective using focus groups. Arthritis Res Ther 2006, 8(4):R84.

54. Chu EM, Chiu KY, Wong RW, Tang WM, Lau CS: Translation and validation of Arthritis Impact Measurement Scales 2 into Chinese: CAIMS2. Arthritis Rheum 2004, 51(1):20-27.

55. Rosemann T, Szecsenyi J: Cultural adaptation and validation of a German version of the Arthritis Impact Measurement Scales (AIMS2). Osteoarthritis Cartilage 2007, 15(10):1128-1133.

56. Bakheit A, Harries SR, Hull RG: Validity of a self-administered version of the Barthel Index in patients with rheumatoid arthritis. Clin Rehabil 1995, 9(3):234-237.

57. Doeglas D, Krol B, Guillemin F, Suurmeijer T, Sanderman R, Smedstad LM, Briancon S, van den Heuvel W: The assessment of functional status in rheumatoid arthritis: a cross cultural, longitudinal comparison of the Health Assessment Questionnaire and the Groningen Activity Restriction Scale. J Rheumatol 1995, 22(10):1834-1843. 
58. Chambers LW, Macdonald LA, Tugwell P, Buchanan WW, Kraag G: The McMaster Health Index Questionnaire as a measure of quality of life for patients with rheumatoid disease. J Rheumatol 1982, 9(5):780784.

59. Fitzpatrick R, Ziebland S, Jenkinson C, Mowat A: Importance of sensitivity to change as a criterion for selecting health status measures. Qual Health Care 1992, 1(2):89-93.

60. Fitzpatrick R, Ziebland S, Jenkinson C, Mowat A: A generic health status instrument in the assessment of rheumatoid arthritis. Br J Rheumatol 1992, 31(2):87-90.

61. Jenkinson C, Fitzpatrick R, Argyle M: The Nottingham Health Profile: an analysis of its sensitivity in differentiating illness groups. Soc Sci Med 1988, 27(12):1411-1414.

62. Jenkinson C, Fitzpatrick R: Measurement of health status in patients with chronic illness: comparison of the Nottingham health profile and the general health questionnaire. Fam Pract 1990, 7(2):121-124.

63. Houssien DA, Jonsson T, Davies E, Scott DL: Rheumatoid factor isotypes, disease activity and the outcome of rheumatoid arthritis: comparative effects of different antigens. Scand J Rheumatol 1998, 27(1):46-53.

64. Birrell FN, Hassell AB, Jones PW, Dawes PT: How does the short form 36 health questionnaire (SF-36) in rheumatoid arthritis (RA) relate to RA outcome measures and SF-36 population values? A cross-sectional study. Clin Rheumatol 2000, 19(3):195-199.

65. Russell AS, Conner-Spady B, Mintz A, Maksymowych WP: The responsiveness of generic health status measures as assessed in patients with rheumatoid arthritis receiving infliximab. J Rheumatol 2003, 30(5):941947.

66. Taylor WJ, McPherson KM: Using Rasch analysis to compare the psychometric properties of the Short Form 36 physical function score and the Health Assessment Questionnaire disability index in patients with psoriatic arthritis and rheumatoid arthritis. Arthritis Rheum 2007, 57(5):723-729.

67. Tugwell P, Wells G, Strand V, Maetzel A, Bombardier C, Crawford B, Dorrier C, Thompson A: Clinical improvement as reflected in measures of function and health-related quality of life following treatment with leflunomide compared with methotrexate in patients with rheumatoid arthritis: sensitivity and relative efficiency to detect a treatment effect in a twelve-month, placebo-controlled trial. Leflunomide Rheumatoid Arthritis Investigators Group. Arthritis Rheum 2000, 43(3):506-514.

68. Kosinski M, Zhao SZ, Dedhiya S, Osterhaus JT, Ware JE, Jr.: Determining minimally important changes in generic and disease-specific health-related quality of life questionnaires in clinical trials of rheumatoid arthritis. Arthritis Rheum 2000, 43(7):1478-1487.

69. Tuttleman M, Pillemer SR, Tilley BC, Fowler SE, Buckley LM, Alarcon GS, Trentham DE, Neuner R, Clegg DO, Leisen JC et al: A cross sectional assessment of health status instruments in patients with rheumatoid arthritis participating in a clinical trial. Minocycline in Rheumatoid Arthritis Trial Group. J Rheumatol 1997, 24(10):1910-1915.

70. Deyo RA, Inui TS: Toward clinical applications of health status measures: sensitivity of scales to clinically important changes. Health Serv Res 1984, 19(3):275-289.

71. Deyo RA, Inui TS, Leininger J, Overman S: Physical and psychosocial function in rheumatoid arthritis. Clinical use of a self-administered health status instrument. Arch Intern Med 1982, 142(5):879-882.

72. Deyo RA, Inui TS, Leininger JD, Overman SS: Measuring functional outcomes in chronic disease: a comparison of traditional scales and a self-administered health status questionnaire in patients with rheumatoid arthritis. Med Care 1983, 21(2):180-192. 
73. Baron M, Schieir O, Hudson M, Steele R, Kolahi S, Berkson L, Couture F, Fitzcharles MA, Gagne M, Garfield $\mathrm{B}$ et al: The clinimetric properties of the World Health Organization Disability Assessment Schedule II in early inflammatory arthritis. Arthritis Rheum 2008, 59(3):382-390.

74. Meesters JJ, Verhoef J, Liem IS, Putter H, Vliet Vlieland TP: Validity and responsiveness of the World Health Organization Disability Assessment Schedule II to assess disability in rheumatoid arthritis patients. Rheumatology (Oxford) 2010, 49(2):326-333.

75. Jette AM: Functional Status Index: reliability of a chronic disease evaluation instrument. Arch Phys Med Rehabil 1980, 61(9):395-401.

76. Lorish CD, Abraham N, Austin JS, Bradley LA, Alarcon GS: A comparison of the full and short versions of the Arthritis Impact Measurement Scales. Arthritis Care Res 1991, 4(4):168-173.

77. Wallston KA, Brown GK, Stein MJ, Dobbins CJ: Comparing the short and long versions of the Arthritis Impact Measurement Scales. J Rheumatol 1989, 16(8):1105-1109.

78. Anderson JJ, Firschein HE, Meenan RF: Sensitivity of a health status measure to short-term clinical changes in arthritis. Arthritis Rheum 1989, 32(7):844-850.

79. Buchbinder R, Bombardier C, Yeung M, Tugwell P: Which outcome measures should be used in rheumatoid arthritis clinical trials? Clinical and quality-of-life measures' responsiveness to treatment in a randomized controlled trial. Arthritis Rheum 1995, 38(11):1568-1580.

80. Meenan RF, Anderson JJ, Kazis LE, Egger MJ, Altz-Smith M, Samuelson CO, Jr., Willkens RF, Solsky MA, Hayes SP, Blocka KL et al: Outcome assessment in clinical trials. Evidence for the sensitivity of a health status measure. Arthritis Rheum 1984, 27(12):1344-1352.

81. Meenan RF, Gertman PM, Mason JH: Measuring health status in arthritis. The arthritis impact measurement scales. Arthritis Rheum 1980, 23(2):146-152.

82. Meenan RF, Mason JH, Anderson JJ, Guccione AA, Kazis LE: AIMS2. The content and properties of a revised and expanded Arthritis Impact Measurement Scales Health Status Questionnaire. Arthritis Rheum 1992, 35(1):1-10.

83. Guillemin F, Coste J, Pouchot J, Ghezail M, Bregeon C, Sany J: The AIMS2-SF: a short form of the Arthritis Impact Measurement Scales 2. French Quality of Life in Rheumatology Group. Arthritis Rheum 1997, 40(7):1267-1274.

84. Weisman MH, Paulus HE, Russak SM, Lubeck DP, Chiou CF, Sengupta N, Ofman JJ, Borenstein J, Moadel $\mathrm{AB}$, Sherbourne CD: Development of a new instrument for rheumatoid arthritis: the Cedars-Sinai HealthRelated Quality of Life instrument (CSHQ-RA). Arthritis Rheum 2003, 49(1):78-84.

85. Egger MJ, Ward JR, Karg MB, Williams HJ, Reading JC: Reliability and validity of the CSSRD functional assessment survey in rheumatoid arthritis. Cooperative Systematic Studies of Rheumatic Diseases. Arthritis Care Res 1995, 8(1):21-27.

86. Zochling J, Stucki G, Grill E, Braun J: A comparative study of patient-reported functional outcomes in acute rheumatoid arthritis. J Rheumatol 2007, 34(1):64-69.

87. Bombardier C, Raboud J: A comparison of health-related quality-of-life measures for rheumatoid arthritis research. The Auranofin Cooperating Group. Control Clin Trials 1991, 12(4 Suppl):243S-256S.

88. Fitzpatrick R, Newman S, Lamb R, Shipley M: A comparison of measures of health status in rheumatoid arthritis. Br J Rheumatol 1989, 28(3):201-206. 
89. Fries JF, Spitz P, Kraines RG, Holman HR: Measurement of patient outcome in arthritis. Arthritis Rheum 1980, 23(2):137-145.

90. Greenwood MC, Doyle DV, Ensor M: Does the Stanford Health Assessment Questionnaire have potential as a monitoring tool for subjects with rheumatoid arthritis? Ann Rheum Dis 2001, 60(4):344-348.

91. Pope JE, Khanna D, Norrie D, Ouimet JM: The minimally important difference for the health assessment questionnaire in rheumatoid arthritis clinical practice is smaller than in randomized controlled trials. J Rheumatol 2009, 36(2):254-259.

92. Rohekar G, Pope J: Test-retest reliability of patient global assessment and physician global assessment in rheumatoid arthritis. J Rheumatol 2009, 36(10):2178-2182.

93. Wolfe F: Which HAQ is best? A comparison of the HAQ, MHAQ and RA-HAQ, a difficult 8 item HAQ (DHAQ), and a rescored 20 item HAQ (HAQ20): analyses in 2,491 rheumatoid arthritis patients following leflunomide initiation. J Rheumatol 2001, 28(5):982-989.

94. Ziebland S, Fitzpatrick R, Jenkinson C, Mowat A: Comparison of two approaches to measuring change in health status in rheumatoid arthritis: the Health Assessment Questionnaire (HAQ) and modified HAQ. Ann Rheum Dis 1992, 51(11):1202-1205.

95. Pincus T, Callahan LF, Brooks RH, Fuchs HA, Olsen NJ, Kaye JJ: Self-report questionnaire scores in rheumatoid arthritis compared with traditional physical, radiographic, and laboratory measures. Ann Intern Med 1989, 110(4):259-266.

96. Salaffi F, Bazzichi L, Stancati A, Neri R, Cazzato M, Consensi A, Grassi W, Bombardieri S: Development of a functional disability measurement tool to assess early arthritis: the Recent-Onset Arthritis Disability (ROAD) questionnaire. Clin Exp Rheumatol 2005, 23(5):628-636.

97. Evers AW, Taal E, Kraaimaat FW, Jacobs JW, Abdel-Nasser A, Rasker JJ, Bijlsma JW: A comparison of two recently developed health status instruments for patients with arthritis: Dutch-AIMS2 and IRGL. Arthritis Impact Measurement Scales. Impact of Rheumatic diseases on General health and Lifestyle. Br J Rheumatol 1998, 37(2):157-164.

98. Huskes C, Kraaimaat F, Bijlsma JW: Development of a self-report questionnaire to assess the impact of rheumatic diseases on health and lifestyle. J Rehabil Sci 1990, 3(3):65-70.

99. Helewa A, Goldsmith CH, Smythe HA: Independent measurement of functional capacity in rheumatoid arthritis. J Rheumatol 1982, 9(5):794-797.

100. Sullivan M, Ahlmen M, Bjelle A, Karlsson J: Health status assessment in rheumatoid arthritis. II. Evaluation of a modified Shorter Sickness Impact Profile. J Rheumatol 1993, 20(9):1500-1507. 


\section{Abstract}

Objective: To compare the measurement properties of Dutch Questionnaires for measuring Physical function in patients with rheumatoid arthritis (RA). Het vergelijken van de meeteigenschappen van Nederlandstalige vragenlijsten voor het meten van fysiek functioneren bij patiënten met reumatoïde artritis (RA).

Design: Systematic review

Method: Systematic literature searches were performed in the PubMed, Scopus \& Picarta databases to identify publications describing the development or evaluation of physical function scales in Dutch patients with rheumatoid arthritis RA. Content validity was evaluated by linking items to the International Classification of Functioning, Disability and Health. Construct validity, reliability, responsiveness and interpretability was evaluated using published quality criteria.

Results: 18 publications were identified, evaluating the measurement properties of 10 questionnaires with physical function scales. 5 questionnaires were rated to have adequate content validity. Construct validity, internal consistency, test-retest reliability and responsiveness were evaluated favorably for respectively, 6,5,2 and 4 questionnaires. For none of the included questionnaires, information was available to evaluate agreement or minimally clinically important differences.

Conclusion: The disease specific Health Assessment Questionnaire and Arthritis Impact Measurement Scales are currently the most thoroughly validated questionnaires for measuring physical function in patients with RA. Measurement properties of generic questionnaires have been insufficiently studies in patients with RA. 
Over the last decade, the use of self-report questionnaires has increased in clinical studies and clinical practice. So called patient reported outcomes (PROs) provide unique information about the perspective of the patient on the impact of their disease and the efficacy of treatment. The use of valid and reliable PRO's is therefore increasingly considered important, also for labeling claims (1).

However, for evaluating different aspects of health a large number questionnaires are often available, each with different levels of available evidence regarding the quality of their measurement properties. Moreover, usually disease specific, considered to have optimal content validity and responsiveness, and generic questionnaires, which can be used to compared between patient groups, are available (2). Systematic reviews that critically compare the content and measurement properties of different questionnaires that are available may provide guidelines for the selection of adequate measures for a given purpose (3).

Physical function is one of the most important outcomes in clinical studies in patients with rheumatoid arthritis (RA)(4). Recently we performed a systematic review of physical function questionnaires in RA (5). The results revealed that 26 physical function questionnaires have been validated for patients with RA. The study only considered studies that evaluated the measurement properties of the original version. However, not all questionnaires have been translated to the Dutch language or validated for use in patients with RA. Moreover the content and measurement properties of translated version are not necessarily equivalent to the original version. The objective of the current study was to systematically evaluate the measurement properties of the available Dutch questionnaires for measuring physical function in patients with RA.

\section{Method}

The general methodology and results of our previous review were adopted for the current study as well (5). For that study an elaborate systematic literature search was performed in the PubMed and Scopus data bases, according to a validated search strategy (6) More detail regarding the search strategy were described elsewhere (5). For the current study we excluded all studies with non-Dutch patients and additionally searched for publications in de PiCarta database of Dutch libraries and on the websites of relevant journals.

\section{Methodological quality}

Each study was evaluated independently by 2 authors for methodological quality using the consensus-based standards for the selection of health status measurement instruments (COSMIN) checklist. (7) The meteorological quality of the assessment of each measurement property was evaluated for each study separately. In case the methodological quality of the assessment of a 
measurement property of a questionnaire was rated good or excellent, the study was used to rate the measurement property of the questionnaire. Therefore no quality ratings were given to in case measurement properties had only been evaluated with inadequate methodological rigor.

\section{Data extraction and evaluation of measurement properties}

Only physical function scales of included questionnaires were rated. If possible, each scale was evaluated for content validity (relevance and comprehensiveness), cross-cultural validity (translation process) construct validity (hypothesis testing), internal consistency, test-retest reliability and responsiveness. Moreover information about interpretability, floor and ceiling effects was also extracted. Measurement properties were rated by 2 independent authors according to the quality criteria proposed by Terwee et al (8). However with respect to content validity, construct validity and responsiveness different or additional procedures were used.

Content validity refers to the comprehensiveness and relevance of an instrument. Content validity was evaluated by linking a scale's items to the ICF core set for RA (9), according to proposed linking rules. (10). Relevance was evaluated favorably in case all a scale's items could be linked to ICF codes correspondent to one of the three activity chapters of the ICF (mobility, selfcare and domestic life).Comprehensiveness was evaluated favorably in case each chapter was represented by at least one item.

Cross-cultural validity was rated favorably in case at least two forward and backward translations were made, the results of the translation process was evaluated by a committee of experts and the resulting version pre-tested in the target population.

Construct validity refers to the degree to which scores are related to scores on other measurement instruments in theoretically plausible ways. A physical function questionnaire with adequate construct validity should correlate most strongly with other PROs of physical function, followed by PROs of other physical aspects of health (e.g. pain), PROs of other, non-physical aspects of health (e.g. anxiety) and clinical outcomes (e.g. Disease Activity Score-28). With respect to the absolute magnitude of correlations we expected strong correlation $(r>0.60)$ with other instruments for physical function and physical aspects of health and moderate correlations $(0.30<$ $\mathrm{r}<0.60$ ) with non-physical aspects of health and clinical outcomes. For an instrument to be rated favorably for construct validity at least $75 \%$ of hypotheses should be confirmed for a questionnaires (8). Only questionnaires that were correlated with 3 or more other constructs were eligible for rating.

Scales with high internal consistency have items that all measure the same construct and therefore all correlate highly with the total score. However if the intercorrelation between items is too high, a scale likely contains redundant items. A positive rating was given in case factor analysis 
had established the homogeneity of each subscale in a sufficiently large sample $(>5$ patients per item) and Cronbach's $\alpha$ (or 'person reliability index' for Rasch analysis) was $>0.70$ but $<0.95$ for each subscale.

Test-retest reliability was rated favorably in case the intra-class correlation coefficient for continuous data or weighted kappa for ordinal data was $>0.70$ in a sample of at least 50 stable patients with a retest period within 6 weeks.

The ability of a questionnaire to detect clinically relevant change over time is called responsiveness. The commonly used approach of calculating standardized change scores before and after treatment with proven efficacy was considered the most appropriate design (11). A positive rating was given in case and adequate parameter such as the standardized effect size (ES) or standardized response mean (SRM) indicated a treatment effect of at least moderate magnitude. Because the observed treatment effect depend on contextual elements such as the specific treatment they had to be appropriately described as well.

Finally, interpretability and ceiling and floor effect were rated. Interpretability was rated favorably in case at least of the following were reported: mean scores and standard deviation before and after effective treatment, score differences between two or more relevant (patient) groups, change scores split out according to change status or presenting information about the relationship between scores on the questionnaire and other measures of physical function. A positive rating for floor and ceiling effects was given in case $\leq 15 \%$ of patients scored the highest or lowest score, respectively.

\section{Results}

The search for internationally published articles yielded 3257 results, of which 306 met the initial inclusion criteria (figure) Of the 110 questionnaires that were evaluated in these studies, 65 did not contain a separate physical function scale and another 18 were limited to evaluating specific limbs or joints. After excluding 255 studies of questionnaires that were not relevant for this review and 35 studies with non-Dutch patients, 18 studies remained that evaluated the measurement properties of 10 of the 26 remaining questionnaires. The additional systematic search for papers published in Dutch yielded 2 extra publications. However both were double publications.

\section{Description of questionnaires}

For the descriptive data on the questionnaires in table 1 the original papers were consulted. The ratings for measurement properties of the questionnaires was summarized in table 2 . The questionnaires were categorized as disease specific and generic questionnaires. Two of the 10 included questionnaires were developed in the Netherlands, while the majority of the remaining 
questionnaires were developed in the United States. WHODAS-II was developed simultaneously in multiple countries. Multiple Dutch versions of the HAQ have been developed in the Netherlands, (12), that differ slightly in the total number of items and exact wordings, but overlap for the most part and are being used interchangeably (13). Considering the small differences between versions these were considered to be one questionnaire in this review.

Table 1. Descriptive information for the included scales

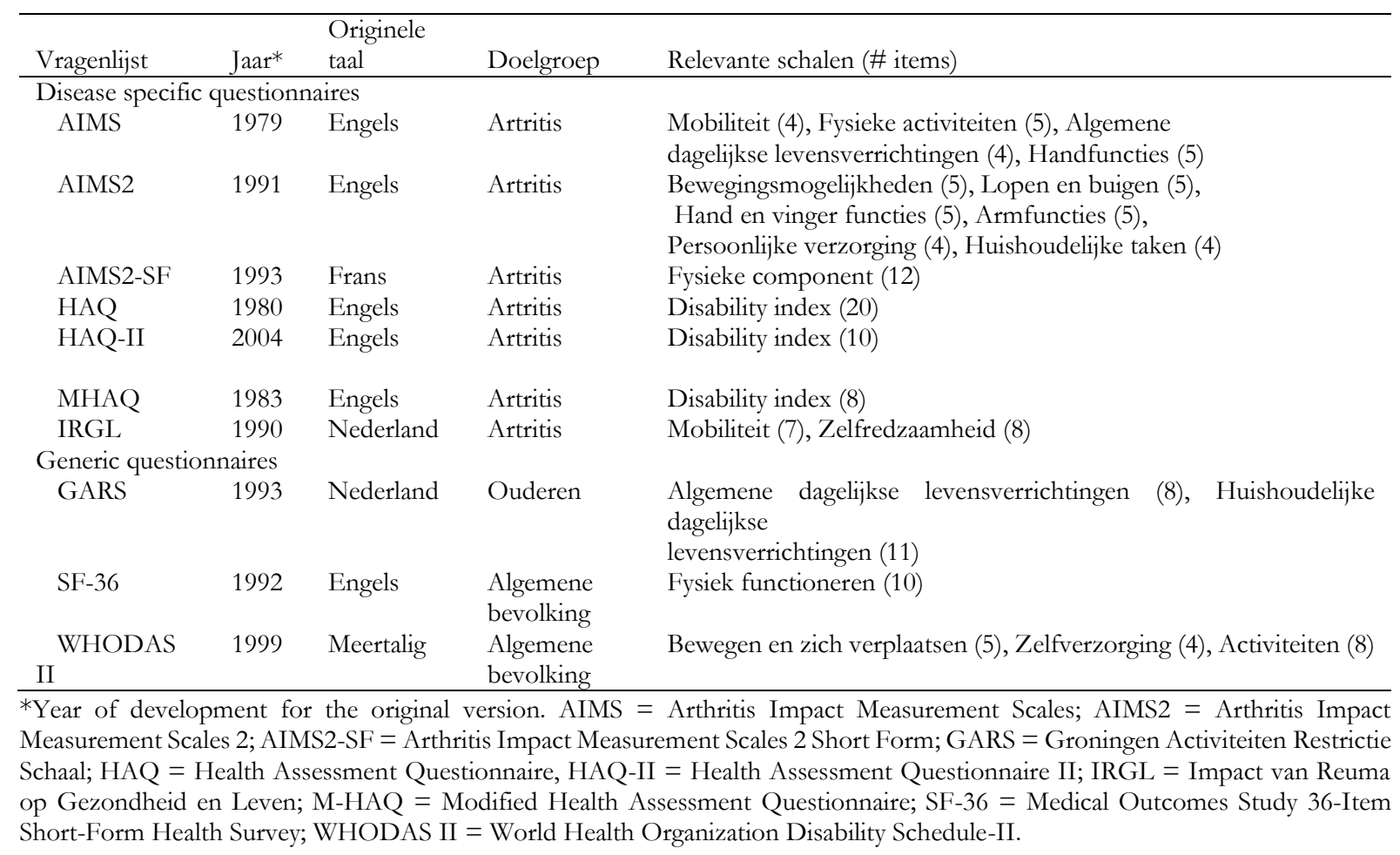

\section{Validity}

Only two questionnaires were rated negatively for relevance. The AIMS contained one item that was linked to an ICF code for 'daily routine'. WHODAS II also contained one item linked to daily routine and on item related to remunerative employment. AIMS2-SF, MHAQ \& SF-36 were rated negatively for comprehensiveness because they contained no items reflecting domestic life.

Six out of 10 questionnaires were rated positively for construct validity. IRGL was rated negatively because only $65 \%$ of hypotheses could be confirmed. The MHAQ could not be rated because it had only been related to AIM2 and the AIMS-SF scales. However the correlations were of the expected magnitude in both cases. Construct validity of the WHODAS-II could not be rated because only correlations with the total score were reported. Finally, no information was available to rate the construct validity of SF-36 in RA.

None of the translated versions of the disease-specific questionnaires could be rated for cross-cultural validity because insufficient information was reported on the translation process. 
Only for the HAQ-II forward and backward translation was reported, however no evaluation of the quality of the translation by an expert committee was performed and no pretest was reported for any of the questionnaires.

The generic SF-36 and WHODAS-II were rated positively because the current guidelines for cross-cultural translation were followed.

\section{Internal consistency}

AIMS2, AIMS2-SF and GARS were rated positively for internal consistency because factor analysis was performed and Cronbach's $\alpha>0.70$ was reported for each subscale. Internal consistency of HAQ and HAQ-II was evaluated using Rasch analysis, after the homogeneity of the scales was confirmed by factor analysis of the residuals. AIMS, IRGL, MHAQ \& WHODAS-II were rated doubtful because Cronbach's $\alpha$ had been reported but no factor analysis had been performed. Internal consistency was below 0.70 for the mobility scale of AIMS and the moving \& getting around scale of WHODAS-II. No information was available about the internal consistency of the SF-36

Reproducibility

Test-retest reliability was rated favorably for AIMS2 and AIMS2-SF because ICC $>0.70$ was reported for a group of stable patients. Test-retest reliability of IRGL was rated doubtful because Pearson's correlation coefficient was used. WHODAS-II could not be rated because the sample of patients was $<50$

\section{Responsiveness}

Responsiveness of AIMS2, HAQ and SF-36 was rated positively because adequate statistical parameters indicated a treatment effect of at least moderate magnitude while the patient group, treatment and time interval between measurements was adequately described. GARS and WHODAS-II were rated doubtful because contextual elements were inadequately described. MHAQ and AIMS2-SF were rated doubtful because SRM were calculated in a sample of patietns who were not receiving effective treatment.

\section{Interpretability}

Interpretability of AIMS2, AIMS2-SF and HAQ were rated positive. For all these questionnaires change scores before and after treatment were presented and scores were related to other measures of physical function by means of Bland-Altman plots. Information about the distribution of scores was available for four questionnaires. HAQ, HAQ-II and AIMS2-SF did not exhibit bottom and ceiling effects, while for WHODAS-II $>15 \%$ of patients in the sample scored the highest possible score for self-care. 
Table 2. Ratings of measurement properties

\begin{tabular}{|c|c|c|c|c|c|c|c|c|c|}
\hline $\begin{array}{l}\text { Questionn } \\
\text { aire }\end{array}$ & Relevance & $\begin{array}{l}\text { Comprehens } \\
\text { iveness }\end{array}$ & $\begin{array}{l}\text { Cross- } \\
\text { cultural } \\
\text { validity }\end{array}$ & $\begin{array}{l}\text { Construct } \\
\text { validity }\end{array}$ & $\begin{array}{l}\text { Internal } \\
\text { consistency }\end{array}$ & $\begin{array}{c}\text { Test- } \\
\text { retest } \\
\text { reliability }\end{array}$ & $\begin{array}{c}\text { Respons } \\
\text { iveness }\end{array}$ & $\begin{array}{c}\text { Interpre } \\
\text { tability }\end{array}$ & $\begin{array}{l}\text { Floor \& } \\
\text { Ceiling } \\
\text { effects }\end{array}$ \\
\hline \multicolumn{10}{|c|}{ Disease specific } \\
\hline AIMS $^{23,24}$ & - & + & $?$ & + & $?$ & 0 & ? & - & ? \\
\hline${ }_{29}$ AIMS225- & + & + & ? & + & + & + & + & + & ? \\
\hline $\begin{array}{l}\text { AIMS2- } \\
\text { SF }^{27,28,30}\end{array}$ & + & - & $?$ & + & + & + & 0 & + & + \\
\hline $\mathrm{HAQ}_{35,29,36,37}{ }^{31-}$ & + & + & ? & + & + & ? & + & + & + \\
\hline $\begin{array}{l}\text { HAQ- } \\
\mathrm{II}^{35}\end{array}$ & + & + & ? & + & + & ? & ? & - & + \\
\hline IRGL $^{38,26}$ & + & + & n.v.t. & - & 0 & 0 & ? & - & ? \\
\hline$\underset{7,28}{\text { MHAQ }^{2}}$ & + & - & $?$ & ? & 0 & ? & 0 & - & ? \\
\hline Generic & & & & & & & & & \\
\hline${ }_{4} \mathrm{GARS}^{39,3}$ & + & + & n.v.t. & + & + & ? & 0 & - & $?$ \\
\hline$S F-36^{40}$ & + & - & + & ? & ? & ? & + & - & ? \\
\hline WHOD & - & + & + & 0 & 0 & 0 & 0 & - & - \\
\hline
\end{tabular}

AS II 36

*Information about content validity from original paper; + = positive rating; - = negative rating; ? = no or insufficient information; 0 insufficient methodological quality $)$. AIMS = Arthritis Impact Measurement Scales; AIMS2 = Arthritis Impact Measurement Scales 2; AIMS2-SF = Arthritis Impact Measurement Scales 2 Short Form; GARS = Groningen Activiteiten Restrictie Schaal; HAQ $=$ Health Assessment Questionnaire, HAQ-II = Health Assessment Questionnaire II; IRGL = Impact van Reuma op Gezondheid en Leven; M-HAQ = Modified Health Assessment Questionnaire; SF-36 = Medical Outcomes Study 36-Item Short-Form Health Survey; WHODAS II = World Health Organization Disability Schedule-II.

\section{Conclusion}

Our review identified 10 questionnaires for physical function that have been evaluated in Dutch patients with RA. Of the disease specific questionnaires HAQ and AIMS2 were the most thoroughly validated. Both questionnaires received nog unfavorable ratings, while most of their measurement properties were evaluated with adequate methodological rigor. For the Dutch HAQ no information was yet available regarding its test-retest reliability, while for AIMS2 no information was available regarding floor or ceiling effects. Considering that HAQ was sufficiently reliable in the previous international review (5), HAQ and AIMS2 appear the most suited questionnaires for assessing physical function in Dutch patients with RA.

Although most generic questionnaires have been evaluated thoroughly validated in general population samples in the Netherlands, it is less clear which generic questionnaires has the most favorable measurement properties in RA population in the Netherlands, since fewer studies have been performed in the field of RA. For discriminative purposes, that is to discriminate between groups of patients the GARS appears to be most appropriate given the currently available evidence, because sufficient empirical evidence is available regarding its construct validity and internal consistency. Since SF-36 was the only questionnaire with sufficient support for its responsiveness, it is the preferred choice for evaluative studies were physical function elves of patients are 
monitored over time. However, the reaming measurement properties of SF-36 have not yet been thoroughly evaluated

Although some measurement properties such as construct validity and internal consistency were evaluated for most questionnaires, other measurement properties have received less attention. For example, no studies have evaluated agreement or clinical relevant change scores. However clinically relevant change scores for original HAQ and SF-36 are available in the international literature $(12,13)$.

However, because measurement properties may vary across versions, it is unsure whether these also apply to the Dutch version. Furthermore, reproducibility received little attention in the included studies. Only one study reported about the test-retest reliability of two questionnaires. Finally none of the disease specific questionnaires could be rated favorably for cross-cultural validity. Both the process of translating the questionnaire as the rational for making changes with respect to the original version were insufficiently reported.

\section{Conclusion}

HAQ and AIMS2 appear to be the most suited questionnaires for assessing physical function in RA. No information is currently available regarding test-retest reliability of HAQ and for both HAQ and AIMS2 cross-cultural validity should be established in future studies. It is currently not possible to confidently recommend a generic questionnaire to assess physical lfunction, in light of the paucity of available studies.

\section{References}

1. FDA. Guidance for industry: Patient-reported outcome measures: Use in medical product development to support labeling claims: US Food and Drug administration; 2009.

2. Guyatt GH, Feeny DH, Patrick DL. Measuring health-related quality of life. Ann Intern Med. 1993;118(8):622-9.

3. Mokkink LB, Terwee CB, Stratford PW, Alonso J, Patrick DL, Riphagen I, et al. Evaluation of the methodological quality of systematic reviews of health status measurement instruments. Qual Life Res. 2009;18(3):313-33.

4. Felson DT, Anderson JJ, Boers M, Bombardier C, Chernoff M, Fried B, et al. The American College of Rheumatology preliminary core set of disease activity measures for rheumatoid arthritis clinical trials. Arthritis Rheum. 1993;36(6):729-40.

5. Oude Voshaar MA, Ten Klooster PM, Taal E, van de Laar MA. Measurement properties of physical function scales validated for use in patients with rheumatoid arthritis: A systematic review of the literature. Health Qual Life Outcomes. 2011;9:99. 
6. Terwee CB, Jansma EP, Riphagen, II, de Vet HC. Development of a methodological PubMed search filter for finding studies on measurement properties of measurement instruments. Qual Life Res. 2009;18(8):111523.

7. Mokkink LB, Terwee CB, Knol DL, Stratford PW, Alonso J, Patrick DL, et al. The COSMIN checklist for evaluating the methodological quality of studies on measurement properties: a clarification of its content. BMC Med Res Methodol. 2010;10:22.

8. Terwee CB, Bot SD, de Boer MR, van der Windt DA, Knol DL, Dekker J, et al. Quality criteria were proposed for measurement properties of health status questionnaires. J Clin Epidemiol. 2007;60(1):34-42.

9. Stucki G, Cieza A. The International Classification of Functioning, Disability and Health (ICF) Core Sets for rheumatoid arthritis: a way to specify functioning. Ann Rheum Dis. 2004;63 Suppl 2:ii40-ii5.

10. Cieza A, Geyh S, Chatterji S, Kostanjsek N, Ustun B, Stucki G. ICF linking rules: an update based on lessons learned. J Rehabil Med. 2005;37(4):212-8.

11. Revicki DA, Cella D, Hays RD, Sloan JA, Lenderking WR, Aaronson NK. Responsiveness and minimal important differences for patient reported outcomes. Health Qual Life Outcomes. 2006;4:70.

12. Kosinski M, Zhao SZ, Dedhiya S, Osterhaus JT, Ware JE, Jr. Determining minimally important changes in generic and disease-specific health-related quality of life questionnaires in clinical trials of rheumatoid arthritis. Arthritis Rheum. 2000;43(7):1478-87.

13. Pope JE, Khanna D, Norrie D, Ouimet JM. The minimally important difference for the health assessment questionnaire in rheumatoid arthritis clinical practice is smaller than in randomized controlled trials. J Rheumatol. 2009;36(2):254-9 
50 | Chapter 2 


\section{Chapter 3}

Evaluating and modeling measurement invariance in physical function questionnaires in rheumatoid arthritis

Oude Voshaar MA, Ten Klooster PM, Vonkeman HE, Kievit W, van Riel PL, van de Laar MA. Measurement bias in different versions of the Dutch Health Assessment Questionnaire Disability Index. Ann Rheum Dis. 2013 Jul 12.

Oude Voshaar MA, Glas CA, ten Klooster PM, Taal E, Wolfe F, van de Laar MA. Crosscultural measurement equivalence of the Health Assessment Questionnaire II. Arthritis Care Res (Hoboken). 2013 Jun;65(6):1000-4. 
The Health Assessment Questionnaire (HAQ) Disability Index is the most frequently used and validated measure of physical function for patients with rheumatoid arthritis (RA)(1). Various translated versions of this questionnaire have been used in clinical research in the Netherlands. In 2007, a standardized translation, the consensus HAQ, was introduced and a letter detailing its development appeared in this journal (2). The Dutch DREAM registry (3), a multicentre observational cohort study that monitors RA patients undergoing different treatment regimens, soon adopted the consensus HAQ.

The consensus HAQ differs in a number of ways from the previously used version that was developed in Nijmegen(4). Differences include the handling and number of aids and the translation of item 13: 'are you able to reach and get down a 5-pound object (such as a bag of sugar) from just above your head?'. In the Nijmegen version, the weight of the object had been changed to 1 kilo, down from 5 pounds in the original HAQ (2.5 kilo in the consensus HAQ).

Particularly this change is potentially problematic, because getting down a heavier object is obviously a more difficult task. Problematic to the extent that this change may lead to systematically higher disability scores on the consensus HAQ as compared to the Nijmegen HAQ . Moreover, studies predating the consensus-HAQ that compare disability scores, such as the QUEST-RA study could be similarly compromised (5).

We investigated the measurement equivalence of the two Dutch HAQ versions, using data from the DREAM biological registry. 886 and 1065 patients filled in either the Nijmegen or consensus-HAQ at baseline. The standard scoring method, which takes help and aids into account, was used to obtain HAQ scores. The HAQ rating scale ranges from 0 (without any difficulty) to 3 (unable to do). Item Response Theory (IRT) analyses were performed, following sophisticated methodology based on the Lagrange Multiplier statistic (L.M.), as detailed in previous publications $(6,7)$ Measurement inequivalence or differential item functioning (DIF) occurs if item performance is dependent on the HAQ version used.

As shown in table 1, only the 'reaching' category showed significant DIF after applying the Bonferroni correction for multiple comparisons. Patients scored 0.15 points lower on the Zandbelt version of this category than expected by the IRT model that assumes no difference between versions. Conversely, on the consensus-HAQ, patients scored 0.13 points higher than expected. Subsequent item level analysis indicated that the DIF was caused by item 13 (L.M. = 126.23) and not item 14 , the other item making up the reaching category (L.M. = 15.87).

At the HAQ-DI total score level, table 1 shows that minor deviations from expected scores across the remaining categories counterbalanced DIF in the reaching category, to the extent that the HAQ-DI expected total scores were nearly identical to the observed total scores, for both 
versions of the HAQ. Moreover, the agreement between disability scores estimated from an IRT model that accounts for the observed differences, by assigning version specific parameters to the reach category, and the original IRT model was very high $(\mathrm{ICC}=0.997)$.

Taken together, these results indicate that both versions produce practically interchangeable total scores.

Table 1: DIF analysis

\begin{tabular}{|c|c|c|c|c|c|c|}
\hline & L.M. & $P$ & Zandbelt HAQ & & Consensus HAQ & \\
\hline & & & Observed score & Expected score & Observed score & Expected score \\
\hline Dressing & 4.15 & 0.04 & 1.07 & 1.05 & 0.77 & 0.79 \\
\hline Rising & 0.86 & 0.35 & 0.90 & 0.89 & 0.66 & 0.67 \\
\hline Eating & 0.37 & 0.54 & 1.34 & 1.35 & 1.06 & 1.06 \\
\hline Walking & 0.47 & 0.49 & 0.93 & 0.94 & 0.72 & 0.71 \\
\hline Hygiene & 28.46 & 0.02 & 1.55 & 1.46 & 1.07 & 1.15 \\
\hline Reaching & 163.83 & $<0.01 *$ & 1.12 & 1.27 & 1.14 & 1.01 \\
\hline Grasping & 4.52 & 0.03 & 1.52 & 1.49 & 1.18 & 1.20 \\
\hline Activities & 0.91 & 0.34 & 1.32 & 1.33 & 1.65 & 1.64 \\
\hline HAQ-DI & $\mathrm{n} / \mathrm{a}$ & $\mathrm{n} / \mathrm{a}$ & 1.21 & 1.22 & 1.03 & 1.03 \\
\hline
\end{tabular}

\section{References}

1. Oude Voshaar MA, ten Klooster PM, Taal E, van de Laar MA. Measurement properties of physical function scales validated for use in patients with rheumatoid arthritis: a systematic review of the literature. Health Qual Life Outcomes 2011;9:99.

2. Boers M, Jacobs JW, van Vliet Vlieland TP, van Riel PL. Consensus Dutch health assessment questionnaire. Ann Rheum Dis 2007;66(1):132-3.

3. Kievit W, Fransen J, Oerlemans AJ, Kuper HH, van der Laar MA, de Rooij DJ, et al. The efficacy of antiTNF in rheumatoid arthritis, a comparison between randomised controlled trials and clinical practice. Ann Rheum Dis 2007;66(11):1473-8.

4. Zandbelt MM, Welsing PM, van Gestel AM, van Riel PL. Health Assessment Questionnaire modifications: is standardisation needed? Ann Rheum Dis 2001;60(9):841-5.

5. Sokka T, Kautiainen H, Toloza S, Makinen H, Verstappen SM, Lund Hetland M, et al. QUEST-RA: quantitative clinical assessment of patients with rheumatoid arthritis seen in standard rheumatology care in 15 countries. Ann Rheum Dis 2007;66(11):1491-6.

6. Oude Voshaar MA, Glas CA, Klooster PM, Taal E, Wolfe F, van de Laar MA. Cross-cultural measurement equivalence of the health assessment Questionnaire-II. Arthritis Care Res (Hoboken) 2012. 
7. Glas CAW. Detection of differential item functioning using Lagrange multiplier tests. Statistica Sinica 1998;8:647-68.

54 | Chapter 3 


\begin{abstract}
Objective: To evaluate the cross-cultural measurement equivalence of the US and Dutch Health Assessment Questionnaire II (HAQ-II) in rheumatoid arthritis (RA).

Methods: Item response theory (IRT) analyses were performed on US ( $\mathrm{n}=18747)$ and Dutch ( $\mathrm{n}=1022)$ HAQ-II data to evaluate the equivalence of cross-cultural item performance. Observed inconsistencies were modeled by assigning country-specific item parameters to biased items. The impact of cross-cultural item bias on the comparability of the Dutch and US total scores was analyzed by evaluating the agreement between physical function levels estimated from an IRT model with country specific-item parameters for biased items and the physical function levels estimated from the original model that does not account for cultural bias.

Results: Two items showed significant cross-cultural bias. However, the agreement in physical function estimates between the respecified and original model was very high with ICC $>0.99$ and the Bland-Altman limits of agreement ranging from -0.08 to 0.07 on a latent scale with a mean of 0 and standard deviation 1 .

Conclusions: This study suggests that the Dutch and US HAQ-II produce total scores that can be interpreted interchangeably across countries in RA studies, despite some minor bias at the item level.
\end{abstract}


Rheumatoid arthritis (RA) is a musculoskeletal disease frequently associated with impaired ability to execute everyday activities. Physical function (PF) therefore is a core outcome domain in this field. Increasingly, benefits of item response theory (IRT) are being recognized in the assessment of patient-reported outcomes, including PF. For example, the Rasch analysis-based Health Assessment Questionnaire II (HAQ-II) was developed to overcome the limited measurement range and cumbersomeness of assessing patients with the original Health Assessment Questionnaire Disability Index (HAQ-DI) ${ }^{1}$.

Although most psychometric properties of the HAQ-II are well established ${ }^{2}$, nothing is currently known about its cross-cultural measurement equivalence. However, PF scores are often pooled or compared across countries. It is important to verify that observed score differences or similarities across cultures reflect true differences or similarities in PF levels, rather than cultural bias.

Traditionally, researchers have tried to achieve equivalence trough elaborate cross-cultural translation procedures. These procedures aim to develop equivalent versions by having qualified translators and content experts reach consensus about difficult to translate items. Although important, these procedures does not necessarily yield equivalent versions from a measurement perspective. Cross-cultural measurement equivalence exists only when the relations between observed scale scores and the latent attribute measured by the scale are identical across cultures ${ }^{3}$. Therefore, cross-cultural measurement equivalence studies are a necessary next step in evaluating cross-cultural validity. The aim of this study was to investigate the crosscultural measurement equivalence of the original US and Dutch HAQ-II using IRT modeling.

\section{Patients and methods}

Data from the Dutch version of the HAQ-II data analyzed from two studies. In the first study, three waves of data collection were carried out at the outpatient rheumatology clinic of Medisch Spectrum Twente in Enschede, the Netherlands ${ }^{4}$. All consecutive patients visiting the clinic answered demographic questions and completed standard self-reported measures of disease activity and health status. The baseline data of 472 patients with a clinical diagnosis of RA were used. In the second study a random selection of 999 outpatients with a clinical diagnosis of RA was asked to participate in a survey study on fatigue. 550 patients agreed to participate in this study 5 .

The US HAQ-II data represented a random sample of 18,747 subjects with RA who were participating in a longitudinal study of RA outcomes in the US National Data Bank for Rheumatic Diseases (NDB) ${ }^{6}$. Participants were volunteers recruited from the practices of US rheumatologists who completed mailed or internet questionnaires about their health at 6-month intervals between 
2002 and 2011. The participants were not compensated for their participation. For each patient, the diagnosis of RA was made by their rheumatologist. The NDB utilizes an open cohort design in which patients are enrolled continuously.

\section{Measures}

The HAQ-II consists of 10 items. ${ }^{1}$ Each item is scored on a 4-point rating, where $0=$ without any difficulty and 3 = unable to do. The HAQ-II is scored by averaging the items when at least 8 items are completed. Pain and general health were assessed using an 11-point numerical rating scale (range 0-10) in the Dutch studies and a 10-cm visual analog scale (VAS) in the US study. Higher values indicate worse pain or general health in both countries.

\section{Statistical analysis}

IRT model.

The generalized partial credit model $(\mathrm{GPCM})^{7}$ was used to obtain item and person parameters using marginal maximum likelihood (MML) estimation for all analyses. The GPCM is an IRT model that pertains to polytomously scored items such as the items of the HAQ-II. The GPCM models the relationship between item responses and the measured trait by person and item parameters. In the case of the HAQ-II, person parameters reflect an individual's estimated standing on a latent PF continuum. Because higher HAQ-II scores indicate worse PF, higher values on the latent continuum also indicate worse PF. Each HAQ-II item is characterized by a discrimination parameter, reflecting its ability to discriminate between levels of PF, and three threshold parameters, each marking the location on the latent PF continuum where two consecutive response options are equally likely to be endorsed. Higher values indicate that respondents favor the higher response option at higher levels of PF (i.e. higher values reflect the 'easiness' of the item at the level of response options). Since item characteristics are statistically separated from respondent characteristics, cross-cultural equivalence can be investigated by evaluating whether the item parameters are identical across cultures.

Differential item functioning (DIF) analysis

Preceding the analysis of crosscultural measurement equivalence, DIF was evaluated for background variables that might confound the results of the main analysis. DIF occurs if item response is dependent on background variables. Subsequently, to investigate crosscultural measurement equivalence, we evaluated the presence of crosscultural DIF. Estimates of the GPCM model parameters were computed, assuming different ability distributions for both countries. Lagrange Multiplier (LM) statistics, which are based on the difference between average observed item scores and average item scores expected by the model, were calculated to establish DIF ${ }^{8}$. Besides a formal statistical test, that tests the null-hypothesis that item parameters are the same 
across countries, the LM tests are accompanied by the effect size statistics (ES) that reflect the average deviation of observed item scores from model expectations (absolute residuals) ${ }^{8}$. The technique is sensitive to uniform (i.e. an item is systematically more difficult for either population) and non-uniform DIF (i.e. an item is less strongly related to the overall PF trait in either population) ${ }^{8}$. Because of the large sample sizes in this study and the high number of statistical tests performed, we expected minor model deviations to reach statistical significance. Therefore, an ES $>0.10$ was considered to indicate significant DIF across countries, irrespective of the statistical significance of the LM tests. This cut-off point has previously been used in research with the original HAQ-DI, which has the same response format as the HAQ-II ${ }^{9}$. Initially, the much larger US sample dominated the concurrent item parameter estimates and spuriously inflated the deviation of Dutch observed scores from model expectations. To obtain comparable parameter estimates we created five random US samples with an equal amount of respondents as the total Dutch sample and reran the analysis five times, once with each of the random US samples. The results were analyzed on a sample by sample basis and the results of the analyses were pooled, by calculating effect size statistics after averaging the observed and expected average item scores for each score group across samples.

Next we created a fitting overall model for the full data set, that accounted for the observed cross-cultural DIF. This was achieved by assigning country-specific item parameters to items exhibiting DIF. LM statistics pertaining to the form of the item response curves were calculated after assigning separate parameters to items with substantial cross-cultural DIF to evaluate fit for the final respecified model. The rationale of this test is to partition the latent PF continuum into a number of segments and to evaluate whether an item's item characteristic curve conforms to the form predicted by the model in each of these segments ${ }^{10}$. These statistics can be used to identify misfitting items and, together, provide a test of overall model fit. Fit was considered acceptable case no items were found with ES $>0.10$.

\section{Impact of DIF}

Finally, we investigated the influence of cross-cultural DIF on total test scores. Because the presence of DIF might impact on the comparability of scores across cultures but the presence of DIF might also cancel itself out across items, the impact of DIF was investigated within a framework that pertains to the total scores ${ }^{11}$. We estimated the latent PF level of the patients based on the item parameters calculated from the original model and subsequently assigned countryspecific parameters to items exhibiting significant DIF and reestimated the latent PF level of patients. The agreement between the resulting latent PF estimates was analyzed by calculating the intraclass correlation coefficient (ICC) and the limits of agreement according to the Bland-Altman 
method $^{12}$. The ICC's were calculated from a 2-way random effects model for single measures. The assumption of the $95 \%$ limits of agreement approach that the mean and SD of the differences are constant throughout the range of measurements and that these differences are from an approximately normal distribution, were visually inspected after limits of agreement and mean differences were calculated.

\section{Results}

The demographic and clinical characteristics of the study sample are listed in Table 1. The US sample was composed of fewer males and the mean age was lower; the samples were otherwise comparable. The Dutch samples did not significantly differ by HAQ-II scores, pain and general health, although patients in the first study were significantly younger (mean difference $=3.87$ years ,$P=<0.01$ ) and had significantly shorter disease duration (mean difference $=4.96$ years, $P=<$ $0.01)$.

Table 1: Sample characteristics.

$\begin{array}{ll}\text { Dutch patients } & \text { US patients } \\ (n=1022) & (n=18747)\end{array}$

\begin{tabular}{lll}
\hline & & \\
Gender, \% female & 69.4 & 78.8 \\
Age (years), mean (SD) & $64.1(13.3)$ & $60.8(13.2)$ \\
Disease duration (years), mean (SD) & $15.3(13.3)$ & $14.8(11.31)$ \\
HAQ-II (0-3), mean (SD) & $1.01(0.65)$ & $0.99(0.67)$ \\
Pain (0-10), mean (SD)* & $4.4(2.5)$ & $3.8(2.8)$ \\
General health (0-10), mean (SD)* & $4.4(2.7)$ & $3.7(2.5)$ \\
\hline
\end{tabular}

* numerical rating scale for Dutch patients, Visual analog scale for us patients; HAQ-II $=$ Health Assessment Questionniare II disability index

\section{DIF analysis}

Because the US and Dutch samples significantly differed in terms of age and sex, we evaluated the presence of DIF for age (after creating 3 equally large age groups) and gender in the combined Dutch and US samples preceding further analysis. The results indicated that no items showed DIF for either variable. ES statistics ranged from $0.00-0.05$ for age and $0.00-0.07$ for sex.

Next, 5 cross-cultural DIF analyses were done using the 5 US samples and the Dutch data. The results of these analyses are summarized in table 2. Most tests reached statistical significance in most of the samples. However, the observed deviations from model expectations were minor and only for items 3 (are you able to stand up from a straight chair) and 7 (are you able walk up two flights of stairs?) exceeded the ES threshold of 0.10 . Moreover, Items 3 and 7 were consistently 
identified as exhibiting uniform DIF in all five samples, whereas none of the remaining items were flagged for DIF in any of the samples (see table 2).

Table 2: Differential item functioning across countries.

\begin{tabular}{lrccc}
\hline Item & \multicolumn{1}{c}{ LM (range) } & DF & $P$ (range) & E.S. (range) \\
\hline Get on and off the toilet? & $24.86(16.07-29.98)$ & 3 & $0.00(0.00-0.00)$ & $0.04(0.03-0.05)$ \\
Open car doors? & $4.47(2.32-3.03)$ & 3 & $0.26(0.09-0.51)$ & $0.02(0.01-0.02)$ \\
Stand up from a straight chair? & $79.01(70.11-88.46)$ & 3 & $0.00(0.00-0.00)$ & $0.11(0.11-0.11)$ \\
Walk outdoors on flat ground? & $6.60(1.81-19.28)$ & 3 & $0.30(0.00-0.61)$ & $0.01(0.00-0.01)$ \\
Wait in a line for 15 minutes? & $33.54(23.87-36.83)$ & 3 & $0.00(0.00-0.00)$ & $0.07(0.06-0.07)$ \\
Reach and get down an object from & $9.39(4.37-12.14)$ & 3 & $0.06(0.01-0.19)$ & $0.02(0.02-0.02)$ \\
just above your head? & & & & \\
Go up 2 or more flights of stairs? & $89.05(73.26-98.45)$ & 3 & $0.00(0.00-0.00)$ & $0.12(0.10-0.12)$ \\
Do outside work (such as yard work)? & $6.09(2.45-10.28)$ & 3 & $0.18(0.02-0.48)$ & $0.01(0.00-0.02)$ \\
Lift heavy objects? & $17.94(11.37-32.29)$ & 3 & $0.00(0.00-0.01)$ & $0.01(0.00-0.01)$ \\
Move heavy objects? & $5.48(4.17-7.57)$ & 3 & $0.15(0.06-0.24)$ & $0.03(0.01-0.05)$ \\
\hline
\end{tabular}

LM (range) =average and range of LM statistic over the 5 random samples; DF = degrees of freedom; $P$ (range) $=$ average and range of P's over the 5 random samples; E.S. = Effect size: average of observed scores - expected scores over three score groups, averaged over 5 random samples.

\section{IRT modeling}

Item 7, which had the largest amount of DIF according to the previous analysis, was assigned country-specific parameters first. The DIF analyses were repeated at this point to evaluate whether the DIF in item 3 was still present, because the presence of DIF in 1 item potentially influences the estimated item parameters of the other items ${ }^{13}$. The DIF in item 3 was still present at this point; therefore item 3 was assigned country-specific parameters as well. The subsequent analysis failed to identify more items with substantial DIF and fit for this respecified model was investigated next.

Overall model fit

The validity of the model with country specific parameters was evaluated in the total data set. LM tests for item characteristic curves were obtained, along with the estimated item parameters. For the present analysis, observed and posterior expected scores were computed using a partitioning of respondents into three equally large score level groups. As anticipated, most LM statistics reached statistical significance because of the sample size, especially in the US sample. However, table 3 shows that the absolute differences between observed mean item scores and mean item scores expected by the model were of negligible magnitude for most items, considering the 0-3 rating scale range of the HAQ-II. At the scale level, the mean difference between model expected HAQ-II scores and observed HAQ-II scores was 0.019 (1.009 vs 0.99) for the US and 0.043 (1.053 vs 1.01) for the Dutch data. Taking into consideration the small discrepancy between observed and expected HAQ-II item and total scores, the overall conclusion was that the model with country specific parameters for items 3 and 7 fit very well. This finding indicates that the same underlying latent scale of PF applies to both countries, except that the US patients experience 
relatively more difficulty standing up from a straight chair (item 3) and going up 2 flights of stairs (item 7) than the Dutch patients, as indicated by lower threshold parameters (see table 3).

\section{Effect of DIF}

The agreement in latent PF estimates between the original model and the model respecified to allow country specific item parameters for items 3 and 7 was very high. The ICC was $>0.999$ and the limits of agreement ranged from -0.08 to -0.01 (see figure 1). Given that the latent scale is set to have a mean of 0 and a standard deviation of 1 for the US patients (mean $=0.137, \mathrm{SD}=1.072$ for Dutch patients), these results suggest that bias at the test level was very minor.

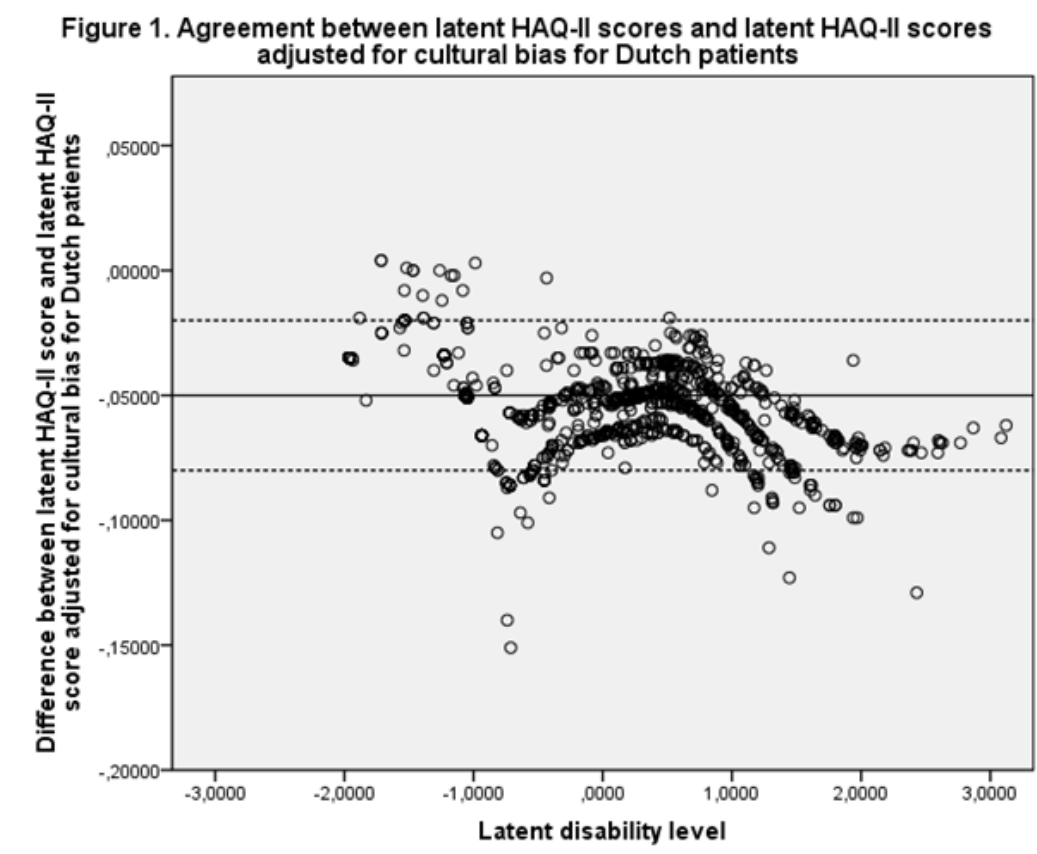

Agreement between latent HAQ-II scores and latent HAQ-II scores with country-specific item parameters for items 3 and 7 , displayed in a Bland-Altman diagram, including lines for mean difference and upper and lower $95 \%$ limits of agreement $\left(\mathrm{R}^{2}=0.10\right)$.

\section{Discussion}

The objective of this study was to evaluate the cross-cultural equivalence of the Dutch HAQ-II using IRT modeling. The results suggest that all HAQ-II items function equivalently across gender and age but that items 3 and 7 were both slightly more difficult for US patients. However, at the test level the impact of DIF on total HAQ-II scores was negligible, supporting the cross-cultural equivalence of Dutch and US HAQ-II scores.

The observed bias in items 3 and 7 is difficult to explain in terms of obvious translation or cultural issues. One of 2 previous studies that evaluated cultural equivalence of US and European versions of PF scales also found that an item about standing up from a straight chair was more easy for Dutch than for Canadian patients ${ }^{14}$. Conversely, items about ascending stairs were not culturally biased in either of the studies ${ }^{14}{ }^{15}$. Given the small absolute magnitude of DIF, the strict 
definition of DIF used in the current study and the inconsistent findings of similar items exhibiting DIF in previous studies, cultural bias of these items should probably not be exaggerated.

In the subsequent analysis of impact of DIF we found that the PF levels of patients estimated from a model that accounted for the observed DIF by assigning country-specific item parameters to significantly biased items and those from a model that did not were highly in agreement with each other. At the test level, the observed DIF appeared to have very little impact on estimated PF level.

In cases where substantial test level bias is observed, the procedure used in this study can be employed to make scores comparable again between countries. The resulting model would then argue that the same construct is measured in both countries, but some of the item locations on the latent scale are different, reflecting the observed bias. This is an interesting feature since in some cases it is impossible to correct for observed cross-cultural bias. For instance, even if it were known beforehand that respondents from two countries respond differently to the item 'are you able to stand up from a straight chair?' it is challenging to correct for this observed difference without changing the conceptual and semantic meaning of the question. This approach can also be extended to situations where different, culturally relevant, items are used for different cultures, provided there are sufficient anchor items that are administered in both countries that are not culturally biased.

Previous studies established the unidimensionality of the HAQ-II while using the same data as the current study. Therefore we did not analyze the dimensionality of the HAQ-II preceding the IRT analysis ${ }^{14}$. Considering that previous work demonstrated its psychometric comparability to the original HAQ-DI, the HAQ-II may be substituted for the HAQ-DI in clinical research in RA. The HAQ-II has the advantage of being shorter and easier to score, which reduces the burden on physicians and patients.

There are several limitations of the present study. First, The HAQ-II items were administered alongside other PF items, which might have influenced response behavior. Generalization of the results to situations where the HAQ-II is administered as an autonomous questionnaire should therefore be done with some reservation. Second, the different study settings in both countries caused the samples to differ in key demographics. Although we did not observe age or gender DIF, non-observed systematic differences between samples might have influenced the results.

Overall, this study suggests that the Dutch and US HAQ-II produce total scores that can be interpreted interchangeably across cultures, despite some minor bias at the item level. 


\section{References}

1 Wolfe F, Michaud K, Pincus T. Development and validation of the health assessment questionnaire II: a revised version of the health assessment questionnaire. Arthritis Rheum 2004;50(10):3296-305.

2. Oude Voshaar MA, Ten Klooster PM, Taal E, van de Laar MA. Measurement properties of physical function scales validated for use in patients with rheumatoid arthritis: A systematic review of the literature. Health Qual Life Outcomes 2011;9:99.

3. Ellis BB. Differential item functioning: Implications for test translations. Journal of Applied Psychology 1989;74(6):912.

4. ten Klooster PM, Taal E, van de Laar MA. Rasch analysis of the Dutch Health Assessment Questionnaire disability index and the Health Assessment Questionnaire II in patients with rheumatoid arthritis. Arthritis Rheum 2008;59(12):1721-8.

5. Nikolaus S, Bode C, Taal E, Oostveen A, Glas C, van de Laar M. Calibration of a multidimensional item bank to measure fatigue in rheumatoid arthritis patients. (submitted) 2012.

6. Wolfe F, Michaud K. The National Data Bank for rheumatic diseases: a multi-registry rheumatic disease data bank. Rheumatology (Oxford) 2011;50(1):16-24.

7. Muraki E. A generalized partial credit model: Application of an EM algorithm. Applied psychological measurement 1992;16(2):159.

8. Glas CAW. Detection of differential item functioning using Lagrange multiplier tests. Statistica Sinica 1998;8:647-68.

9. van Groen MM, ten Klooster PM, Taal E, van de Laar MA, Glas CA. Application of the health assessment questionnaire disability index to various rheumatic diseases. Qual Life Res 2010;19(9):1255-63.

10. Glas CAW. Modification indices for the 2-pl and the nominal response model. Psychometrika 1999;64(3):273-94.

11. Teresi JA. Different approaches to differential item functioning in health applications. Advantages, disadvantages and some neglected topics. Med Care 2006;44(11 Suppl 3):S152-70.

12. Bland JM, Altman DG. Statistical methods for assessing agreement between two methods of clinical measurement. Lancet 1986;1(8476):307-10.

13. Glas C, Verhelst N. Testing the Rasch model. New York: Springer, 1995.

14. Roorda LD, Jones CA, Waltz M, Lankhorst GJ, Bouter LM, van der Eijken JW, et al. Satisfactory cross cultural equivalence of the Dutch WOMAC in patients with hip osteoarthritis waiting for arthroplasty. Ann Rheum Dis 2004;63(1):36-42.

15. Bjorner JB, Kreiner S, Ware JE, Damsgaard MT, Bech P. Differential item functioning in the Danish translation of the SF-36. J Clin Epidemiol 1998;51(11):1189-202. 
64 | Chapter 3 


\section{Chapter 4}

Linking scores of physical function questionnaires in rheumatoid arthritis

Klooster PM ten, Oude Voshaar MAH, Gandek B, Rose M, Bjorner JB, Taal E, et al. Development and evaluation of a crosswalk between the SF-36 physical functioning scale and Health Assessment Questionnaire disability index in rheumatoid arthritis. Health Qual Life Outcomes 2013;11:199.

Oude Voshaar MAH, Klooster PM ten, Taal E, Wolfe F, Vonkeman HE, Glas CAW, et al. Linking physical function outcomes in rheumatology: Performance of a crosswalk for converting HAQ scores to SF36 PF-10 scores. acceptd for publication at Arbritis care \& research 


\section{Abstract}

Background: The SF-36 physical functioning scale (PF-10) and the Health Assessment Questionnaire disability index (HAQ-DI) are the most frequently used instruments for measuring self-reported physical function in rheumatoid arthritis (RA). The objective of this study was to develop a crosswalk between scores on the PF-10 and HAQ-DI in RA.

Methods: Item response theory (IRT) methods were used to co-calibrate both scales using data from 1791 RA patients. The appropriateness of a Rasch-based crosswalk was evaluated by comparing it with crosswalks based on a two-parameter and a multi-dimensional IRT model. The accuracy of the final crosswalk was cross-validated using baseline $(n=532)$ and 6-month follow-up $(n=276)$ data from an independent cohort of early RA patients.

Results: The PF-10 and HAQ-DI adequately fit a unidimensional Rasch model. Both scales measured a wide range of functioning, although the HAQ-DI tended to better target lower levels of functioning. The Rasch-based crosswalk performed similarly to crosswalks based on the twoparameter and multidimensional IRT models. Agreement between predicted and observed scale scores in the cross-validation sample was acceptable for group-level comparisons. The longitudinal validity in discriminating between disease response states was similar between observed and predicted scores.

Conclusion: The crosswalk developed in this study allows for converting scores from one scale to the other and can be used for group-level analyses in patients with RA. 


\section{Background}

The SF-36 physical functioning scale (PF-10) $(1,2)$ and the Health Assessment Questionnaire disability index (HAQ-DI) $(3,4)$ are well-established instruments for measuring self-reported physical functioning. The SF-36 and the HAQ-DI were originally developed as generic measures to allow comparisons across populations $(2,5)$. but both instruments have also been thoroughly examined for use in several specific conditions, including rheumatoid arthritis (RA) (6).

Since the inclusion of patient-reported physical disability into core sets of outcomes for clinical trials and observational studies in RA $(7,8)$, an increasing number of RA studies now assess and report physical functioning. Although variation in the choice of instrument exists, the HAQDI and PF-10 are among the most frequently used $(9,10)$. Both measures, however, differ considerably in their content, number of items, and scoring procedures, making it difficult to directly compare results obtained with the two scales. One way to overcome this problem is to link scores from the HAQ-DI and PF-10 (11). This would allow the development of a concordance table, or crosswalk, to convert scores from one instrument to another and enable comparison of data from studies that used either one of the instruments.

Several methods are available for linking scale scores that vary in design, statistical techniques, and the degree to which exchangeability can be achieved $(11,12)$. Item response theory (IRT) offers a flexible and powerful framework for score linking by its inherent ability to calibrate different items of the same concept on a common underlying metric (13-16). Several examples of how to use IRT modeling to develop crosswalks between different instruments intended to measure the same health domain have been reported (17-20). IRT, however, makes certain assumptions about the nature of the data, in particular with respect to dimensionality. A variety of models are available, which differ in their restrictiveness with respect to the assumptions made and the number of parameters used to describe items (21). Consequently, the type of linking and the accuracy of the resulting crosswalk may depend in part on the specific IRT model used.

The most basic form of IRT-based linking is possible when the responses on the two instruments follow the same Rasch model; that is, if it can be shown that they pertain to the same unidimensional latent trait and that all items are equally discriminating. In the Rasch model, the observed sum score is a sufficient statistic for the latent trait estimate (22). If the Rasch model fits, linking boils down to estimating the trait level associated with an observed score on instrument $\mathrm{A}$ and then finding the observed score on instrument B associated with that trait level. In this approach, the statistical equating error is merely a function of the reliability of the two instruments, that is, the reliability with which trait levels can be estimated using either of the two instruments. 
If the Rasch model does not fit, a more general model can be used such as a two-parameter IRT model that includes a discrimination parameter for differentially weighting the association of items with the latent variable. Although this extension may improve model fit, linking is less straightforward as the observed sum score is no longer a sufficient statistic for the trait level and, conditional on an observed sum score, estimates of trait levels vary to some degree. In this approach, an observed score on instrument $\mathrm{A}$ is associated with an expected trait level and from this expectation an expected observed score on instrument B is estimated. As such, the resulting crosswalk contains a second source of statistical error, attributable to the variation of the trait level given observed sum scores. This error, in turn, is a function of the magnitude of the discrimination indices, that is, the strength of the association of the items with the latent variable.

The linking approach can be further generalized by assuming that the two instruments measure two different, yet correlated latent variables. This situation can be modeled by a twodimensional IRT model, where the responses on one instrument pertain to one latent variable, and the aggregation of the two latent variables has a two-dimensional normal distribution. Again, the observed sum score on instrument B is estimated from the observed score on instrument A via the IRT model. Added to the two sources of statistical error already identified, is an error associated with the magnitude of the correlation between the two latent variables, that is, the strength of the association between the two assumed latent scales.

To date, no studies have attempted to link PF-10 and HAQ-DI scores. Moreover, although many studies have reported high correlations between the instruments, the degree and consequences of the multidimensionality that would result from combining the scales are unclear. Some previous studies have suggested that the PF-10 and HAQ-DI, or a selection of its items used in the modified HAQ, do essentially measure the same concept $(23,24)$. However, studies that examined whether items from both scales could actually be calibrated on a common IRT metric did not unequivocally support either a unidimensional or multidimensional latent structure $(25,26)$. Moreover, these studies did not compare the performance of different IRT models to further examine the impact of multidimensionality.

This study presents the development and evaluation of a crosswalk between the PF-10 and the HAQ-DI in a large and clinically diverse sample of patients with RA who completed both instruments. The appropriateness of different IRT models is taken into account by comparing the calibrations and performance of a crosswalk based on a one-parameter Rasch model with those of its two-parameter and multidimensional extensions. The accuracy of the final crosswalk is crossvalidated in an independent sample of patients with early RA participating in a treatment-to-target study. 


\section{Methods}

Study populations

Two independent datasets were used for this study. The first dataset was used for IRT calibrations and development and comparison of the crosswalks between the PF-10 and the HAQ-DI. Accuracy and validity of the final crosswalk were tested in the second dataset.

Calibration sample

This dataset was derived from the Dutch Rheumatoid Arthritis Monitoring (DREAM) registry (27). The DREAM registry is an observational multicenter cohort study that monitors the course of RA patients undergoing different treatment regimens in the Netherlands. Clinical, laboratory, and patient-reported outcomes are routinely collected and stored. Patient-reported outcomes are generally completed online. Within the different DREAM cohorts, 1791 unique patients simultaneously completed the SF-36 and HAQ-DI at least once between 2003 and 2012. For every patient, the first available simultaneous assessment was selected for analysis.

Cross-validation sample

The second, independent dataset included data from patients participating in the DREAM remission induction cohort (28). The remission induction cohort consists of patients with early RA participating in a treat-to-target strategy aimed at achieving fast remission. The strategy has been shown to be highly effective, with the largest improvement in disease activity observed in the first 6 months of treatment (28). Data from 532 patients who completed the HAQ-DI and SF-36 at baseline were used to cross-validate the accuracy of the Rasch-based crosswalk. To study the longitudinal performance of the crosswalk, available data of 276 patients who also completed the HAQ and PF-10 after six months were used.

\section{Measures}

SF-36 physical functioning scale (PF-10)

The PF-10 is one of the eight scales of the SF-36 Health Survey and consists of 10 items measuring perceived current limitations in a variety of physical activities on a 3-point response scale from 1 (yes, limited a lot) to 3 (no, not limited at all). Where there are no missing data, observed PF-10 scores can have 21 possible values, with higher scores indicating more favorable levels of physical functioning. Using traditional scoring, scores on the PF-10 items are summed and linearly transformed to range between 0 and 100. Additionally, the summed scores can be standardized using norm-based scoring based on a mean score of 50 and a standard deviation of 10 in the 1998 US general population (29). Previous Rasch modeling of the PF-10 indicated that the items form a unidimensional, hierarchical continuum with stable item difficulty estimates across diverse patient groups $(24,30)$. 
Health Assessment Questionnaire disability index (HAQ-DI)

The HAQ-DI contains 20 items measuring physical disabilities over the past week in eight categories of daily living: dressing and grooming, rising, eating, walking, hygiene, reach, grip, and activities. Each item is scored on a 4-point rating scale from 0 (without any difficulty) to 3 (unable to do). Additionally, the HAQ-DI contains four sections on the use of aids and devices or need for help from another person for performing activities in any of the eight categories. Two scoring methods can be used to calculate total HAQ-DI scores (31). The standard disability index (SDI) adjusts category scores upwards for the use of aids or devices or help from others. The alternative disability index (ADI) does not take the use of aids and devices into account. For both scoring methods, the total disability score (HAQ-DI) is calculated by determining the highest score in each of the eight categories and then averaging the category scores. As a result, observed scores on the HAQ-DI can take on 25 possible values between 0 and 3, with higher values indicating more disability. Recent Rasch analyses have shown that the categories of the HAQ-DI constitute a unidimensional scale $(24,32)$.

\section{Statistical analyses}

IRT modeling

The maximum likelihood estimation procedure was utilized to estimate the structural model parameters and the latent disability levels of patients were estimated using the expected a posteriori (EAP) method throughout all IRT analyses. Model fit of all estimated models was assessed using Lagrange multiplier (LM) item fit statistics specifically targeted at polytomously scored items (33,34). Absolute differences (effect sizes; ES) between expected and observed item scores for high, average and low scoring individuals were computed. In accordance with previous research, model fit was considered acceptable if all ES statistics were $<0.10(35,36)$. As the ES is weighted by the number of response categories, this cutoff reflects differences between observed and expected score frequencies of $2.5 \%$ for the HAQ-DI and $3.33 \%$ for the PF-10, respectively. All IRT analyses were performed with the MIRT software package (37).

Development of the crosswalk

Initial IRT analysis and cross-calibration of the PF-10 and HAQ-DI were performed in the calibration sample. To achieve consistent response patterns, PF-10 scores were reversed (so a lower score indicates better function) preceding analysis. Item parameters for the Rasch-based crosswalk were obtained using the polytomous partial credit model (PCM) (38). First, the 10 PF-10 items and the eight HAQ-DI category scores were jointly calibrated in the same model. After the structural model parameters were estimated, questionnaire-specific scoring runs on the HAQ-DI and PF-10 items only were performed to estimate EAP scores associated with all possible total score levels 
and to create scoring tables mapping this relation. In these runs the item parameters of the HAQDI and PF-10 items, respectively, were fixed to the values obtained in the initial co-calibration. Subsequently, each possible total score was linked to the total score on the other instrument for which the absolute distance between EAP scores on the latent scale was the smallest. The total procedure was separately performed for both the HAQ-SDI based category scores and the HAQADI based category scores.

Next, the validity and appropriateness of the Rasch-based crosswalk was evaluated by determining its precision to correctly predict HAQ-DI scores from PF-10 scores and vice versa and comparing the results to the precision of two additional crosswalks that were developed using the two-parameter and multidimensional extensions of the PCM. Using the same general approach as outlined above, we first re-estimated the model parameters using the generalized partial credit model (GPCM). The GPCM model is a two-parameter IRT model for polytomous data which includes a discrimination parameter that accounts for the different reliability of individual items with respect to measuring the underlying latent trait. As such, the PCM is nested within the GPCM. Finally, a between-item, multidimensional GPCM model was estimated. Again, the GPCM model is nested within the multidimensional GPCM model. In this model, all items were specified to load on their own questionnaire-specific dimension, and the relation between the dimensions was modeled by their correlation. Because in this model the two dimension-specific EAP scores are estimated concurrently, no separate scoring runs needed to be performed for the HAQ-DI and PF-10 to obtain questionnaire-specific EAP estimates associated with all possible total scores.

Agreement between patients' observed and predicted scores on the PF-10 and HAQ-DI was assessed by computing intraclass correlation coefficients (ICCs) with 95\% confidence intervals using two-way mixed effects models with absolute agreement for single measurements (type A,1) (39). ICCs were considered adequate for group level comparisons when $\geq 0.70$ (40).

Cross-validation of the results

The final step of the analyses was to apply the crosswalk in the cross-validation sample and to evaluate the agreement between observed and predicted HAQ-DI and PF-10 scores. Agreement between patients' observed and crosswalked scores on the PF-10 and HAQ-DI at baseline $(\mathrm{n}=532)$ was again assessed by computing ICCs (type A,1). Additionally, Bland-Altman plots of the difference against the mean of predicted and observed scores were constructed $(41,42)$. As a final test of the validity of the crosswalk, observed and predicted change scores and total effect sizes (Cohen's d) were calculated for patients who completed both measures at baseline and 6-month follow-up ( $\mathrm{n}=276$ ). The relative efficiency of the change scores to discriminate between responder status was analyzed using one-way analysis of variance (ANOVA) tests $(43,44)$. The 28 -joint 
Disease Activity Score (DAS28), a pooled index that includes a tender joint count, a swollen joint count, the erythrocyte sedimentation rate, and the patient's global assessment of general health, was used as the external criterion for determining response to treatment (45). Patients were classified as good responders at 6 months when the DAS28 score had improved at least 1.2 points and the final score was $\leq 3.2$ (46). For purposes of comparing results, relative validity (RV) coefficients with $95 \%$ bias-corrected and accelerated bootstrap confidence intervals $(44,47)$ for the predicted scores in relation to the actual observed scores were computed.

\section{Results}

\section{Patient characteristics}

The calibration and cross-validation samples were comparable with respect to demographic characteristics (Table 1). However, baseline physical functioning levels were substantially better in the cross-validation sample, as measured with both the HAQ-DI and the PF-10. Patients in the cross-validation sample had moderately active disease on average at baseline according to the DAS28.

Table 1. Patient characteristics

\begin{tabular}{lcc}
\hline Sex, \% female & $\begin{array}{c}\text { Calibration } \\
\text { sample } \\
(\mathrm{n}=1791)\end{array}$ & $\begin{array}{c}\text { Cross-validation } \\
\text { sample } \\
(\mathrm{n}=532)\end{array}$ \\
Age in years, mean (SD) & 69.2 & 63.0 \\
HAQ-SDI (0-3), mean (SD)* & $56.54(13.31)$ & $56.48(14.26)$ \\
PF-10 (0-100), mean (SD) & $1.08(0.71)$ & $0.65(0.65)$ \\
DAS28, mean (SD)* & $53.89(26.35)$ & $67.39(25.71)$ \\
VAS Pain (0-100), mean (SD)* & - & $4.28(1.51)$ \\
VAS General Health (0-100), mean (SD)* & - & $43.38(26.23)$ \\
& - & $44.49(26.48)$
\end{tabular}

HAQ-SDI = Health Assessment Questionnaire standard disability index; PF-10 $=$ SF-36 physical functioning scale; DAS28 = 28-joint Disease Activity Score; VAS Pain = visual analog scale for patient's pain in the past week; VAS General Health $=$ visual analog scale for patient's general health in the past week. $*$ Higher values indicate worse health states.

\section{Development of the Rasch-based crosswalk}

Total scores on the PF-10 and HAQ-DI were strongly correlated ( $r=-0.75$ for both the HAQSDI and HAQ-ADI). Both the Rasch-based co-calibration of the HAQ-SDI and PF-10 items and the co-calibration of HAQ-ADI and PF-10 items resulted in a model that adequately fitted the data according to the LM tests, with all accompanying ESs $<0.10$ (Supplementary Tables 1 and 2).

Figure 1 presents the test information functions which describe the local reliability of the PF-10 and HAQ-SDI. Both scales measured an approximately equally wide range of physical functioning with high precision. Overall, the PF-10 was slightly more precise at better levels of 
physical functioning (i.e., lower theta values), whereas the HAQ-SDI tended to provide more information at worse levels of functioning.

Table 2 presents the resulting Rasch-based crosswalks between the PF-10 and HAQ-DI. Separate cross-walks are presented for the standard and alternative scoring rule of the HAQ-DI. As would be expected, predicted HAQ-ADI scores were generally lower than predicted HAQ-SDI scores, for a given level of the PF-10. This effect was strongest in the range of HAQ-DI scores from 1 to 2, where for the same observed PF-10 total scores, the estimated HAQ-SDI scores were consistently 0.25 points (i.e. two score levels) higher than the HAQ-ADI scores. Observed HAQADI and HAQ-SDI scores $\geq 2.75$ were linked to locations on the EAP theta scale that were below the lowest possible score for the PF-10 scale. Conversely, observed PF-10 scores of 95 and 100 were linked to EAP scores that reflect levels of function that are not represented in the HAQ-DI. They were therefore linked to the value zero in the crosswalks.

\section{Comparative performance of the Rasch-based crosswalk.}

Model fit of the co-calibrations based on the two-parameter GPCM and the multi-dimensional IRT model improved marginally as compared with the Rasch model (Supplementary Tables 3-6). For both the GPCM and the multi-dimensional model, ESs were also $<0.10$ and generally slightly smaller than those observed in the Rasch model. The correlation between the latent dimensions in the multidimensional models was 0.73 . The crosswalks based on the GPCM and multi-dimensional IRT model were almost identical to the Rasch-based crosswalk. Correlations between predicted scores based on the different crosswalks were very high ( $\mathrm{r}$ 's $>0.988$ ). Moreover, the crosswalks based on the two-parameter and multidimensional models did not perform substantially better in terms of agreement between observed and predicted total scores on the PF-10 and HAQ-DI (Table 3). Considering that the Rasch-based calibration fitted the data well according to pre-specified criteria and that the agreement between observed and predicted scale scores did not improve much in the more general models, it was concluded that the Rasch-based crosswalk was adequate for converting total scale scores. 


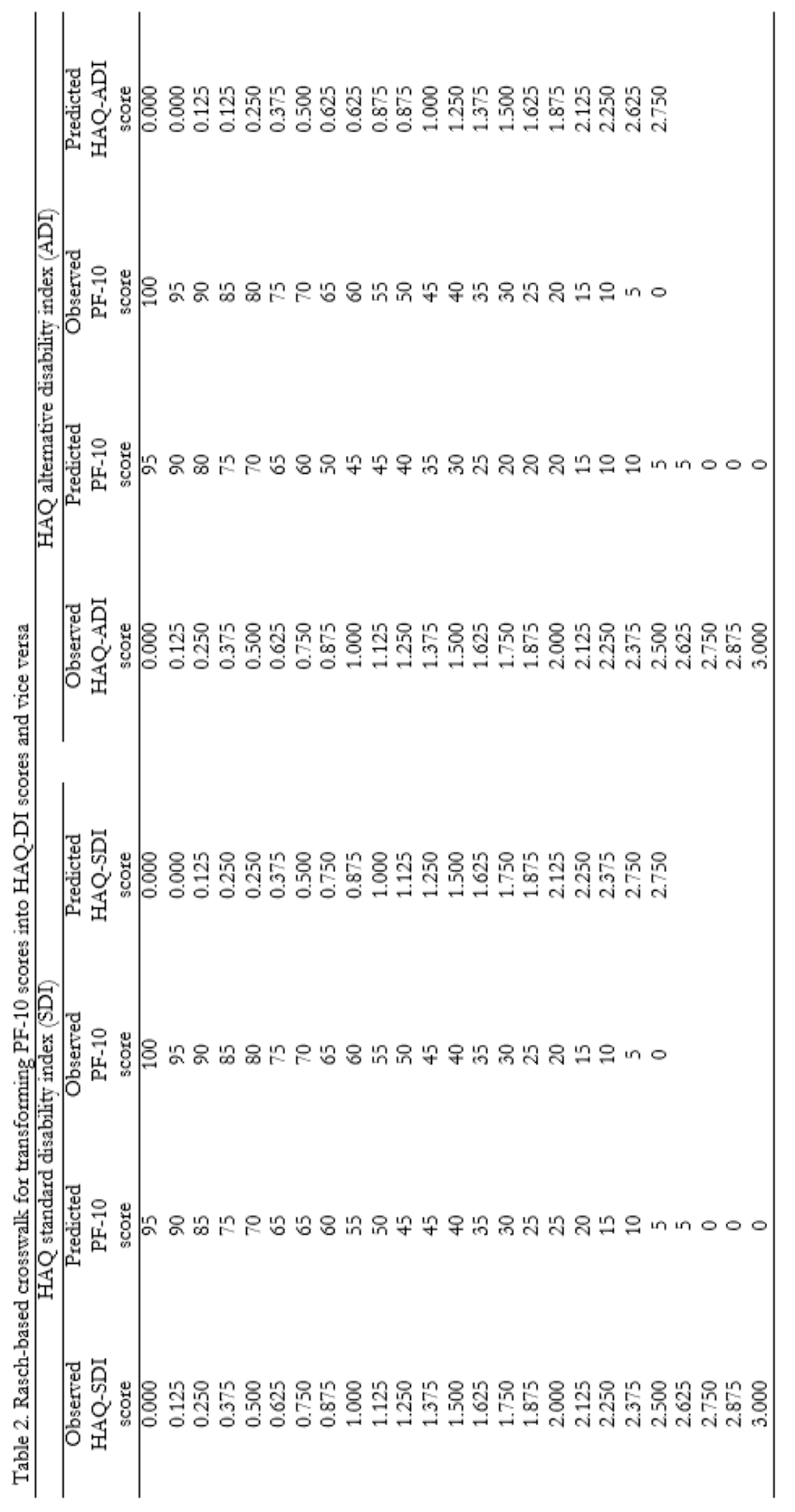

74 | Chapter 4 


\section{Cross-validation of the results}

The agreement between observed scores and scores predicted from the Rasch-based crosswalk was high in the cross-validation sample. The ICCs (95\% CI) between predicted and actual scores were 0.78 (0.74 to 0.81 ) for the HAQ-SDI, 0.77 (0.72 to 0.80 ) for the HAQ-ADI and 0.79 (0.75 to 0.82 ) for the PF-10, indicating adequate agreement for group-level comparisons. Additionally, group mean differences on both scales were small in magnitude (Table 4). Intra-individual differences were similarly distributed above and below the mean and not related to the magnitude of the measurement (Figure 2). However, the limits of agreement were wide for both scales and showed substantial discrepancies in agreement within individual patients.

With respect to the observed 6-month change scores in the total cross-validation sample (Table 5), standardized improvements were largest for the HAQ-DI (ES = 0.55), closely followed by the HAQ-SDI $(\mathrm{ES}=0.49)$ and the PF-10 (ES = 0.40). In terms of differentiating between levels of longitudinal treatment response, the HAQ-ADI was slightly more efficient than the HAQ-SDI and PF-10. Relative validity coefficients of the predicted scores were close to, and not significantly different from, those of the actual observed scores for all three scales.

Table 3. Agreement (ICC, 95\% CI) between observed and predicted total scale scores using crosswalks based on the different IRT models in the calibration sample $(n=1791)$

\begin{tabular}{lccc}
\hline & $\begin{array}{c}\text { Rasch } \\
\text { model }\end{array}$ & $\begin{array}{c}\text { Two-parameter } \\
\text { model }\end{array}$ & $\begin{array}{c}\text { Multi-dimensional } \\
\text { model }\end{array}$ \\
\hline HAQ-SDI & $0.739(0.717$ to 0.760$)$ & $0.741(0.719$ to 0.762$)$ & $0.739(0.717$ to 0.760$)$ \\
HAQ-ADI & $0.737(0.714$ to 0.758$)$ & $0.737(0.715$ to 0.758$)$ & $0.735(0.712$ to 0.756$)$ \\
PF-10 (predicted from HAQ-SDI) & $0.746(0.724$ to 0.767$)$ & $0.745(0.722$ to 0.765$)$ & $0.742(0.720$ to 0.763$)$ \\
PF-10 (predicted from HAQ-ADI) & $0.748(0.726$ to 0.768$)$ & $0.750(0.728$ to 0.770$)$ & $0.749(0.727$ to 0.769$)$ \\
\hline
\end{tabular}

ICC = intraclass correlation coefficient; HAQ-SDI = Health Assessment Questionnaire standard disability index; HAQ-ADI $=$ Health Assessment Questionnaire alternative disability index; PF-10 = SF-36 physical functioning scale.

Table 4. Agreement between observed and predicted scores on the HAQ-DI and PF-10 in the cross-validation sample $(\mathrm{n}=532)$

\begin{tabular}{|c|c|c|c|c|c|}
\hline & ICC $(95 \%$ CI $)$ & $\begin{array}{c}\text { Mean }(\mathrm{SD}) \\
\text { observed } \\
\text { scores }\end{array}$ & $\begin{array}{l}\text { Mean (SD) } \\
\text { predicted } \\
\text { scores } \\
\end{array}$ & $\begin{array}{l}\text { Mean (SD) } \\
\text { difference }\end{array}$ & LOA \\
\hline HAQ-SDI & $\begin{array}{c}0.78(0.74 \text { to } \\
0.81)\end{array}$ & $0.65(0.64)$ & $0.72(0.71)$ & $-0.07(0.44)$ & -0.93 to 0.80 \\
\hline HAQ-ADI & $\begin{array}{c}0.77(0.72 \text { to } \\
0.80)\end{array}$ & $0.53(0.57)$ & $0.63(0.65)$ & $-0.10(0.40)$ & -0.88 to 0.68 \\
\hline PF-10 (predicted from HAQ- & 0.79 (0.75 to & $67.39(25.71)$ & $69.60(23.26)$ & -2.21 & -33.18 to \\
\hline SDI) & $0.82)$ & $67.39(25.71)$ & $69.62(23.01)$ & $(15.80)$ & 28.76 \\
\hline PF-10 (predicted from HAQ- & 0.79 (0.76 to & & & -2.23 & -32.88 to \\
\hline $\mathrm{ADI}$ & $0.82)$ & & & $(15.64)$ & 28.42 \\
\hline
\end{tabular}


Table 5. Baseline to 6-month mean changes in physical functioning scores across levels of DAS28 treatment response in the cross-validation sample $(n=276)$

\begin{tabular}{|c|c|c|c|c|c|c|}
\hline & $\begin{array}{c}\text { Non- } \\
\text { responders } \\
(\mathrm{n}=71)\end{array}$ & $\begin{array}{l}\text { Moderate } \\
\text { responders } \\
(\mathrm{n}=71)\end{array}$ & $\begin{array}{c}\text { Good } \\
\text { responders } \\
(\mathrm{n}=134)\end{array}$ & $F$ & $\mathrm{RV}$ & ES \\
\hline \multicolumn{7}{|l|}{ HAQ-ADI } \\
\hline Observed & 0.00 & -0.41 & -0.62 & 31.26 & 1.00 & 0.55 \\
\hline Predicted & -0.08 & -0.13 & -0.47 & 16.12 & 0.52 & 0.36 \\
\hline \multicolumn{7}{|l|}{ HAQ-SDI } \\
\hline Observed & 0.01 & -0.36 & -0.49 & 30.16 & 1.00 & 0.49 \\
\hline Predicted & -0.09 & -0.16 & -0.54 & 16.92 & 0.56 & 0.38 \\
\hline \multicolumn{7}{|l|}{ PF-10 } \\
\hline Observed & 3.57 & 7.26 & 19.56 & 18.64 & 1.00 & 0.40 \\
\hline Predicted from HAQ-ADI & 0.42 & 16.26 & 24.92 & 32.37 & 1.74 & 0.57 \\
\hline Predicted from HAQ-SDI & -1.05 & 11.76 & 15.07 & 29.62 & 1.59 & 0.45 \\
\hline
\end{tabular}

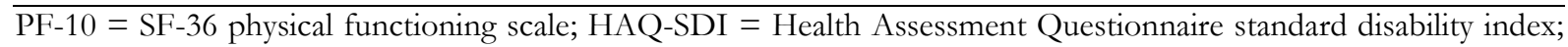
HAQ-ADI = Health Assessment Questionnaire alternative disability index; $F=$ F-statistic from one-way ANOVA; $\mathrm{RV}=$ Relative validity (ratio of F-statistics compared with observed HAQ-ADI); ES = Cohen's $d$ effect size. 


\section{Discussion}

This study used IRT methods to analyze and link two widely used scales for measuring physical functioning, the PF-10 and the HAQ-DI. Results showed that it was possible to develop a straightforward Rasch-based crosswalk between both scales that can be used to estimate scores on one scale from scores on the other in patients with RA. The Rasch-based crosswalk performed similarly to crosswalks based on its two-parameter and multidimensional extensions. The application of the crosswalk in an independent sample of patients with early RA indicated that the crosswalk can be validly used for group-level analyses in RA populations.

Test linking or test equating has long been the focus of research in educational and psychological settings $(12,48)$. More recently, the desire for standardization has also found its way to health outcomes measurement. As in educational testing, linking of existing health outcome instruments could enhance meaningful comparison and interpretation of results across studies and populations. With the rise of IRT in health outcomes assessment, new techniques have become available to achieve this objective. This is reflected in an increasing number of studies that have linked different patient-reported measures using IRT-based methods, including several measures of physical functioning $(15,17,19,49-55)$. These crosswalks allow researchers to compare their results with studies and populations where another instrument was used and may improve the common understanding of the specific underlying construct. Moreover, they may be particularly useful for compilation of findings in meta-analytic studies or longitudinal studies focusing on measuring effects or changes (56). A such, crosswalks are an important step in achieving better interpretation and comparability of patient-reported outcomes measures across different studies (57). A next possible step in the standardization and promotion of a common measurement system of patient-reported outcomes, is the development of large IRT-calibrated item banks such as those developed by the Patient-Reported Outcomes Measurement Information System (PROMIS) initiative (58). These item banks can be used to build flexible short forms and computer adaptive tests for different populations or clinical conditions, while scores on these measures remain directly comparable. Recent studies have already shown the promise of this approach in RA (59).

The current study used an elaborate approach for cross-calibrating the HAQ-DI with the PF-10 and developing and evaluating the crosswalk, especially in its choice for comparing different IRT models. IRT linking studies usually do not explain or justify their use of a specific IRT model, such as the Rasch model or more general models. When using IRT analysis, however, the differences in model assumptions should be taken into account and the final model choice should be motivated by considering aspects such as the unidimensionality and the discrimination equality of the items (60). Moreover, it should be shown to what degree the used model holds. In the case 
of using IRT for linking total scale scores, the specific model used may have consequences for the robustness and accuracy of the resulting crosswalk. This article presents a straightforward and practical IRT-based approach of linking total scale scores that includes comparing the fit and performance of different nested IRT models. This approach can be used for future studies aimed at linking different instruments intended to measure the same construct. An important feature of the approach is that it can be used for calibrating scales with polytomous items, which is the case with most patient-reported outcomes. Contrary to the Rasch model, tests of model fit for more complex models for polytomous items which are based on test statistics with known asymptotic distributions are rare. Therefore, the presented approach uses the LM test throughout all fit analyses (34).

Additionally, most IRT linking studies to date have not tested the performance of the crosswalks in clinically different, independent samples. To our knowledge, this study is the first to cross-validate a crosswalk of physical functioning scales in a clinical setting. One recent study did validate a crosswalk for fatigue using data from a subsequent time point, but acknowledged that using an independent sample would have been preferable (56). With the objective in mind of creating a robust crosswalk in this study, its development was performed in a large and diverse sample of RA patients with a wide range of physical functioning levels. Subsequently, the performance of the crosswalk was examined in a specific sample of patients with early disease.

The results of the IRT calibrations suggested that the PF-10 and the HAQ-DI essentially measure the same unidimensional construct and could be adequately fitted to the same Rasch model. The finding that the simple Rasch model performed similarly to more general models in calibrating both scales may have several theoretical and practical advantages (61-63). An advantage in the case of total score linking is that each observed total instrument score is associated with only one latent trait (theta) score, making the resulting crosswalk more straightforward and robust against statistical error.

The evaluation of the measurement precision of the PF-10 and HAQ-DI under the Rasch model showed that the HAQ-DI and the PF-10 both measured a wide range of physical functioning in patients with RA. However, the HAQ-DI provided its optimal measurement precision at worse levels of physical function, whereas the PF-10 had better precision at somewhat better levels on the physical function continuum. This corresponds with previously reported ceiling effects of the HAQ-DI in less disabled populations (24,64-66) and floor effects of the PF-10 in more disabled populations (67-70). These effects were also apparent in the final crosswalk, where the HAQ-DI was better able to distinguish different scores at the lower end of the physical functioning spectrum and the PF-10 could better distinguish scores at the upper end. This supports 
previous findings that combining items from the HAQ-DI and PF-10 can reduce floor and ceiling effects and results in a scale with increased measurement precision and sensitivity to change across a wider range of physical functioning (25).

In the current study, separate crosswalks were developed for so-called standard (SDI) and alternative disability index (ADI) scoring of the HAQ-DI (5). In the standard scoring method, the score on a category of daily living is corrected upwards when a respondent indicates the use of help from others or a device for performing one of the items in this category. Consequently, SDI scores are generally higher than ADI scores. Although the average difference between both scoring methods has been reported to be very small in general populations or populations with mild disability (71), SDI scores have been shown to be up to 0.15 to 0.26 points higher than ADI scores in samples with increasing disability levels $(65,72-74)$. In the current study, this resulted in higher predicted scores for the SDI than for the ADI, especially for patients with worse levels of functioning. Therefore, care must be taken in using the correct crosswalk when converting PF-10 and HAQ-DI scores. Unfortunately, published studies do not always clearly specify which method was used to compute the HAQ-DI scores $(75,76)$. If necessary and possible, researchers should therefore re-analyze the original data to compute the correct HAQ-DI scores.

Additionally, we presented the cross-walk for both the original and the norm-based scoring method of the PF-10. The original 0-100 scoring has been most frequently used in the literature to date. Since the introduction of version 2 of the SF-36, however, all eight scales can also be linearly transformed to T-scores based on normative data from the US general population (29). This normbased scoring method has become increasingly popular as it allows for easier interpretation of differences across scales and populations.

The two RA samples used to develop and evaluate the crosswalk in this study correspond with the two major populations of interest in current clinical studies in RA. The sample used to cross-calibrate the PF-10 and HAQ-DI represents the general and clinically diverse RA population seen in the everyday clinical practice and the distribution of age, sex, and functional disability scores in this sample corresponds closely with the characteristics reported in other large observational studies (77-79). The cross-validation was performed in a sample of RA patients with a maximum symptom duration of one year. This population is gaining increasing research interest, mainly due to the development of effective biological treatments and the implementation of new treatment guidelines $(80,81)$. The finding that the crosswalk also performed well in this very specific sample, provides further support for its wide applicability in RA research.

It should be noted, however, that RA is characterized by very specific disease mechanisms and physical manifestations, such as a high frequency of dexterity problems. Consequently, the IRT 
item parameters of the HAQ-DI and PF-10 may vary between conditions and populations as was previously shown for the HAQ-DI across different rheumatic diseases (35). Therefore, future studies should cross-validate the crosswalk in both general and other disease-specific populations.

Further, the crosswalk is not suitable for use at the individual patient level. Although ICCs between observed and predicted scores were adequate for group-level analyses, they were not sufficiently high to warrant individual level analyses. This was confirmed by the Bland-Altman analyses, which showed that observed and predicted scores were characterized by high intraindividual variation. Therefore, cross-walked scores are not equivalent at an individual level and cannot be used interchangeably.

\section{Conclusions}

In sum, the crosswalk developed in this study enables the conversion of PF-10 scores into HAQDI scores and vice versa in patients with RA. Using the crosswalk will allow for group-level comparisons of data from studies that used either of the scales and can facilitate more meaningful interpretation and comparison of results. Future studies should examine the robustness of the crosswalk in other populations.

\section{References}

1. Stewart AL, Kamberg CJ: Physical functioning measures. In Measuring functioning and well-being. Edited by Stewart AL, Ware JE, Jr.: Duke University Press; 1992: 86-101

2. Ware JE, Jr., Sherbourne CD: The MOS 36-item short-form health survey (SF-36). I. Conceptual framework and item selection. Med Care 1992, 30:473-483.

3. Fries JF, Spitz P, Kraines RG, Holman HR: Measurement of patient outcome in arthritis. Arthritis Rheum 1980, 23:137-145.

4. Fries JF, Spitz PW, Young DY: The dimensions of health outcomes: the Health Assessment Questionnaire, disability and pain scales. J Rheumatol 1982, 9:789-793.

5. Bruce B, Fries JF: The Health Assessment Questionnaire (HAQ). Clin Exp Rheumatol 2005, 23:S14-18.

6. Oude Voshaar MA, ten Klooster PM, Taal E, van de Laar MA: Measurement properties of physical function scales validated for use in patients with rheumatoid arthritis: A systematic review of the literature. Health Qual Life Outcomes 2011, 9:99.

7. Boers M, Tugwell P, Felson DT, van Riel PL, Kirwan JR, Edmonds JP, Smolen JS, Khaltaev N, Muirden KD: World Health Organization and International League of Associations for Rheumatology core endpoints for symptom modifying antirheumatic drugs in rheumatoid arthritis clinical trials. J Rheumatol 1994, 21:86-89.

8. Wolfe F, Lassere M, van der Heijde D, Stucki G, Suarez-Almazor M, Pincus T, Eberhardt K, Kvien TK, Symmons D, Silman A, et al: Preliminary core set of domains and reporting requirements for longitudinal observational studies in rheumatology. J Rheumatol 1999, 26:484-489. 
9. Kalyoncu U, Dougados M, Daures JP, Gossec L: Reporting of patient-reported outcomes in recent trials in rheumatoid arthritis: a systematic literature review. Ann Rheum Dis 2009, 68:183-190.

10. Kirkham JJ, Boers M, Tugwell P, Clarke M, Williamson PR: Outcome measures in rheumatoid arthritis randomised trials over the last 50 years. Trials 2013, 14:324.

11. Dorans NJ: Linking scores from multiple health outcome instruments. Qual Life Res 2007, 16:85-94.

12. Lim RL: Linking results of distinct assessments. Appl Meas Educ 1993, 6:83-102.

13. Chang $\mathrm{CH}$, Reeve BB: Item response theory and its applications to patient-reported outcomes measurement. Eval Health Prof 2005, 28:264-282.

14. McHorney CA: Generic health measurement: past accomplishments and a measurement paradigm for the $21 \mathrm{st}$ century. Ann Intern Med 1997, 127:743-750.

15. McHorney CA, Cohen AS: Equating health status measures with item response theory: illustrations with functional status items. Med Care 2000, 38:II43-II59.

16. Reise SP, Waller NG: Item response theory and clinical measurement. Annu Rev Clin Psychol 2009, 5:27-48.

17. Fisher WP, Jr., Eubanks RL, Marier RL: Equating the MOS SF36 and the LSU HSI Physical Functioning Scales. J Outcome Meas 1997, 1:329-362.

18. Orlando M, Sherbourne CD, Thissen D: Summed-score linking using item response theory: application to depression measurement. Psychol Assess 2000, 12:354-359.

19. Carmody TJ, Rush AJ, Bernstein I, Warden D, Brannan S, Burnham D, Woo A, Trivedi MH: The Montgomery Asberg and the Hamilton ratings of depression: a comparison of measures. Eur Neuropsychopharmacol 2006, 16:601-611.

20. Fischer HF, Tritt K, Klapp BF, Fliege H: How to compare scores from different depression scales: equating the Patient Health Questionnaire (PHQ) and the ICD-10-Symptom Rating (ISR) using Item Response Theory. Int J Methods Psychiatr Res 2011, 20:203-214.

21. Hambleton RK, Swaminathan H, Rogers HJ: Fundamentals of item response theory. Newbury Park, CA: Sage; 1991.

22. Andersen EB: Sufficient statistics and latent trait models. Psychometrika 1977, 42:69-81.

23. Escalante A, del RI, Cornell JE: Latent variable approach to the measurement of physical disability in rheumatoid arthritis. Arthritis Rheum 2004, 51:399-407.

24. Taylor WJ, McPherson KM: Using Rasch analysis to compare the psychometric properties of the Short Form 36 physical function score and the Health Assessment Questionnaire disability index in patients with psoriatic arthritis and rheumatoid arthritis. Arthritis Rheum 2007, 57:723-729.

25. Martin M, Kosinski M, Bjorner JB, Ware JE, Jr., Maclean R, Li T: Item response theory methods can improve the measurement of physical function by combining the modified health assessment questionnaire and the SF36 physical function scale. Qual Life Res 2007, 16:647-660.

26. Rose M, Bjorner JB, Becker J, Fries JF, Ware JE: Evaluation of a preliminary physical function item bank supported the expected advantages of the Patient-Reported Outcomes Measurement Information System (PROMIS). J Clin Epidemiol 2008, 61:17-33.

27. Kievit W, Fransen J, Oerlemans AJ, Kuper HH, van de Laar MA, de Rooij DR, De Gendt CM, Ronday KH, Jansen TL, van Oijen PC, et al: The efficacy of anti-TNF in rheumatoid arthritis, a comparison between randomized controlled trials and clinical practice. Ann Rheum Dis 2007, 66:1473-1478. 
28. Vermeer M, Kuper HH, Hoekstra M, Haagsma CJ, Posthumus MD, Brus HL, van Riel PL, van de Laar MA: Implementation of a treat-to-target strategy in very early rheumatoid arthritis: results of the Dutch Rheumatoid Arthritis Monitoring remission induction cohort study. Arthritis Rheum 2011, 63:2865-2872.

29. Ware JE, Kosinski M, Dewey JE: How to score version 2 of the SF-36 health survey (standard \& acute forms). Lincoln, RI: QualityMetric Inc; 2000.

30. Haley SM, McHorney CA, Ware JE, Jr.: Evaluation of the MOS SF-36 physical functioning scale (PF-10): I. Unidimensionality and reproducibility of the Rasch item scale. J Clin Epidemiol 1994, 47:671-684.

31. Fries JF: The Health Assessment Questionnaire (HAQ) and the Improved HAQ. Stanford: Stanford University School of Medicine, Division of Immunology \& Rheumatology; 2009. Available at: http://aramis.stanford.edu/haq.html.

32. ten Klooster PM, Taal E, van de Laar MA: Rasch analysis of the Dutch Health Assessment Questionnaire disability index and the Health Assessment Questionnaire II in patients with rheumatoid arthritis. Arthritis Rheum 2008, 59:1721-1728.

33. Glas CAW: Modification indices for the 2-PL and the nominal response model. Psychometrika 1999, 64:273294.

34. Glas CAW: Testing fit to IRT models for polytomously scored items. In Handbook of polytomous item response theory models. Edited by Nering ML, Ostini R. New York, NY: Routledge; 2010: 185-210

35. van Groen MM, ten Klooster PM, Taal E, van de Laar MA, Glas CA: Application of the health assessment questionnaire disability index to various rheumatic diseases. Qual Life Res 2010, 19:1255-1263.

36. Oude Voshaar MA, Glas CA, ten Klooster PM, Taal E, Wolfe F, van de Laar MA: Cross-cultural measurement equivalence of the Health Assessment Questionnaire-II. Arthritis Care Res (Hoboken) 2012.

37. Glas CA: Preliminary manual of the software program Multidimensional Item Response Theory (MIRT). University of Twente, Enschede, The Netherlands 2010. Available at: http://www.utwente.nl/gw/omd/en/employees/employees/glas.doc/.

38. Masters GN, Wright BD, van der Linden W, Hambleton R: The partial credit model. Handbook of modern item response theory 1997:101-122.

39. McGraw KO, Wong SP: Forming inferences about some intraclass correlation coefficients. Psychological Methods 1996, 1:30-46.

40. Lohr KN: Assessing health status and quality-of-life instruments: Attributes and review criteria. Quality of Life Research 2002, 11:193-205.

41. Bland JM, Altman DG: Statistical methods for assessing agreement between two methods of clinical measurement. Lancet 1986, i:307-310.

42. Bland JM, Altman DG: Comparing methods of measurement: why plotting difference against standard method is misleading. Lancet 1995, 346:1085-1087.

43. McHorney CA, Ware JE, Jr., Raczek AE: The MOS 36-Item Short-Form Health Survey (SF-36): II. Psychometric and clinical tests of validity in measuring physical and mental health constructs. Med Care 1993, 31:247-263.

44. Liang MH, Larson MG, Cullen KE, Schwartz JA: Comparative measurement efficiency and sensitivity of five health status instruments for arthritis research. Arthritis Rheum 1985, 28:542-547. 
45. Prevoo ML, van 't Hof MA, Kuper HH, van Leeuwen MA, van de Putte LB, van Riel PL: Modified Disease Activity Scores that include twenty-eight-joint counts: development and validation in a prospective longitudinal study of patients with rheumatoid arthritis. Arthritis Rheum 1995, 38:44-48.

46. Fransen J, van Riel PL: The Disease Activity Score and the EULAR response criteria. Clin Exp Rheumatol 2005, 23:S93-99.

47. Deng N, Ware J: Using bootstrap confidence intervals to compare relative validity coefficients: an example with PRO measures of chronic kidney disease (CKD) impact. Value Health 2012, 15:A159.

48. Dorans NJ: Equating, Concordance, and Expectation. Applied Psychological Measurement 2004, 28:227-246.

49. McHorney CA: Use of item response theory to link 3 modules of functional status items from the Asset and Health Dynamics Among the Oldest Old study. Arch Phys Med Rehabil 2002, 83:383-394.

50. Bjorner JB, Kosinski M, Ware JE, Jr.: Using item response theory to calibrate the Headache Impact Test (HIT) to the metric of traditional headache scales. Qual Life Res 2003, 12:981-1002.

51. Holzner B, Bode RK, Hahn EA, Cella D, Kopp M, Sperner-Unterweger B, Kemmler G: Equating EORTC QLQ-C30 and FACT-G scores and its use in oncological research. Eur J Cancer 2006, 42:3169-3177.

52. Velozo CA, Byers KL, Wang YC, Joseph BR: Translating measures across the continuum of care: using Rasch analysis to create a crosswalk between the Functional Independence Measure and the Minimum Data Set. J Rehabil Res Dev 2007, 44:467-478.

53. Haley SM, Ni P, Lai JS, Tian F, Coster WJ, Jette AM, Straub D, Cella D: Linking the activity measure for post acute care and the quality of life outcomes in neurological disorders. Arch Phys Med Rehabil 2011, 92:S37-43.

54. Fischer HF, Wahl I, Fliege H, Klapp BF, Rose M: Impact of cross-calibration methods on the interpretation of a treatment comparison study using 2 depression scales. Med Care 2012, 50:320-326.

55. Askew RL, Kim J, Chung H, Cook KF, Johnson KL, Amtmann D: Development of a crosswalk for pain interference measured by the BPI and PROMIS pain interference short form. Quality of Life Research 2013.

56. Noonan VK, Cook KF, Bamer AM, Choi SW, Kim J, Amtmann D: Measuring fatigue in persons with multiple sclerosis: creating a crosswalk between the Modified Fatigue Impact Scale and the PROMIS Fatigue Short Form. Quality of Life Research 2012, 21:1123-1133.

57. Fries JF, Krishnan E, Bruce B: Items, Instruments, Crosswalks, and PROMIS. J Rheumatol 2009, 36:10931095.

58. Cella D, Yount S, Rothrock N, Gershon R, Cook K, Reeve B, Ader D, Fries JF, Bruce B, Rose M: The PatientReported Outcomes Measurement Information System (PROMIS): progress of an NIH Roadmap cooperative group during its first two years. Med Care 2007, 45:S3-S11.

59. Fries JF, Cella D, Rose M, Krishnan E, Bruce B: Progress in assessing physical function in arthritis: PROMIS short forms and computerized adaptive testing. J Rheumatol 2009, 36:2061-2066.

60. Siemons L, Ten Klooster PM, Taal E, Glas CA, Van de Laar MA: Modern psychometrics applied in rheumatology--A systematic review. BMC Musculoskelet Disord 2012, 13:216.

61. Tennant A, McKenna SP, Hagell P: Application of Rasch analysis in the development and application of quality of life instruments. Value Health 2004, 7 Suppl 1:S22-26.

62. Andrich D: Controversy and the Rasch model: a characteristic of incompatible paradigms? Med Care 2004, 42:I7-16

63. Bond TG, Fox CM: Applying the Rasch model: Fundamental measurement in the human sciences. Mahwah, NJ: Lawrence Erlbaum; 2007. 
64. Stucki G, Stucki S, Bruhlmann P, Michel BA: Ceiling effects of the Health Assessment Questionnaire and its modified version in some ambulatory rheumatoid arthritis patients. Ann Rheum Dis 1995, 54:461-465.

65. Uhlig T, Haavardsholm EA, Kvien TK: Comparison of the Health Assessment Questionnaire (HAQ) and the modified HAQ (MHAQ) in patients with rheumatoid arthritis. Rheumatology (Oxford) 2006, 45:454-458.

66. Wolfe F, Michaud K, Pincus T: Development and validation of the Health Assessment Questionnaire II: a revised version of the Health Assessment Questionnaire. Arthritis Rheum 2004, 50:3296-3305.

67. Andresen EM, Fouts BS, Romeis JC, Brownson CA: Performance of health-related quality-of-life instruments in a spinal cord injured population. Arch Phys Med Rehabil 1999, 80:877-884.

68. Freeman JA, Hobart JC, Langdon DW, Thompson AJ: Clinical appropriateness: a key factor in outcome measure selection: the 36 item short form health survey in multiple sclerosis. J Neurol Neurosurg Psychiatry 2000, 68:150-156.

69. Kersten P, Mullee MA, Smith JA, McLellan L, George S: Generic health status measures are unsuitable for measuring health status in severely disabled people. Clin Rehabil 1999, 13:219-228.

70. Lai SM, Perera S, Duncan PW, Bode R: Physical and social functioning after stroke: comparison of the Stroke Impact Scale and Short Form-36. Stroke 2003, 34:488-493.

71. Walsh M, Macgregor D, Stuckless S, Barrett B, Kawaja M, Scully MF: Health-related quality of life in a cohort of adult patients with mild hemophilia A. J Thromb Haemost 2008, 6:755-761.

72. Katz P, Morris A, Yelin E: Subclinical disability in valued life activities among individuals with rheumatoid arthritis. Arthritis Rheum 2008, 59:1416-1423.

73. Langston AL, Campbell MK, Fraser WD, Maclennan G, Selby P, Ralston SH: Clinical determinants of quality of life in Paget's disease of bone. Calcif Tissue Int 2007, 80:1-9.

74. Lovas K, Kalo Z, McKenna SP, Whalley D, Pentek M, Genti G: Establishing a standard for patient-completed instrument adaptations in Eastern Europe: experience with the Nottingham Health Profile in Hungary. Health Policy 2003, 63:49-61.

75. Johnson SR, Lee P: The HAQ disability index in scleroderma trials. Rheumatology (Oxford) 2004, 43:12001201.

76. Zandbelt MM, Welsing PM, van Gestel AM, van Riel PL: Health Assessment Questionnaire modifications: is standardisation needed? Ann Rheum Dis 2001, 60:841-845.

77. Wolfe F: A reappraisal of HAQ disability in rheumatoid arthritis. Arthritis Rheum 2000, 43:2751-2761.

78. Krishnan E, Sokka T, Hakkinen A, Hubert H, Hannonen P: Normative values for the Health Assessment Questionnaire disability index: benchmarking disability in the general population. Arthritis Rheum 2004, 50:953-960.

79. Louie GH, Reveille JD, Ward MM: Challenges comparing functional limitations in rheumatoid arthritis and ankylosing spondylitis. Clin Exp Rheumatol 2009, 27:S83-91.

80. Combe B, Landewe R, Lukas C, Bolosiu HD, Breedveld F, Dougados M, Emery P, Ferraccioli G, Hazes JM, Klareskog L, et al: EULAR recommendations for the management of early arthritis: report of a task force of the European Standing Committee for International Clinical Studies Including Therapeutics (ESCISIT). Ann Rheum Dis 2007, 66:34-45.

81. Smolen JS, Aletaha D, Bijlsma JW, Breedveld FC, Boumpas D, Burmester G, Combe B, Cutolo M, de Wit M, Dougados M, et al: Treating rheumatoid arthritis to target: recommendations of an international task force. Ann Rheum Dis 2010, 69:631-637. 


\section{Abstract}

\section{Objective}

To evaluate the reliability of a crosswalk that was developed in the Netherlands, between the Health Assessment Questionnaire Disability Index (HAQ-DI) and the SF-36 Physical Functioning scale (PF-10) in a sample of patients with various rheumatic diseases in the United States (US).

\section{Methods}

Baseline data from patients with rheumatoid arthritis (RA,N=29020), fibromyalgia ( $F M, N=3776)$, and systemic lupus erythematosus (SLE, N=1609) participating in the National data bank for rheumatic diseases were analyzed. Reliability of the crosswalk was evaluated by calculating intraclass correlation coefficients (ICC's) and agreement between observed and predicted scores was evaluated using the Bland-Altman approach.

\section{Results}

The crosswalk produced reliable conversions for both the HAQ-DI (range ICC $=0.70$ to 0.77 ) and PF-10 (range ICC $=0.73$ to 0.78 ) in all three diseases groups. The mean difference between observed and expected scores was close to zero in US patients with RA. For all three disease groups, the limits of agreement were fairly wide and conversion at the level of individual patients is not recommended.

\section{Conclusion}

The crosswalk produced reliable conversions at the group level in a cross-cultural setting and can be used to convert HAQ-DI to PF-10 scores and vice versa in US patients with RA, FM or SLE. 
Physical function (PF) has long been recognized as a core outcome domain in clinical and observational studies in rheumatology $(1,2)$. PF is assessed using patient reported outcome measures and over the years a variety of physical function questionnaires have become available in this field. A drawback of the availability of different measures for the same construct is that measures have different items and scoring procedures. This is a significant barrier to the interpretation of studies that utilize different instruments. To achieve comparability of scores from different measures, a number of statistical linking or equating techniques can be utilized to convert the system of units of one measure to that of another (3). The resulting conversion tables or crosswalks aid the interpretability of research results from studies that apply the cross-walked instruments and allow study results using different questionnaires to be pooled for descriptive or inferential purposes.

The SF-36 physical functioning scale (PF-10) (4) and the Health Assessment Questionnaire disability index (HAQ-DI) (5) are among the most commonly used instruments for measuring selfreported physical functioning in patients with different rheumatic diseases. Recently we developed an item response theory based crosswalk that can be used to convert PF-10 scores to HAQ-DI scores and vice versa in a sample of Dutch patients with rheumatoid arthritis (RA). In a subsequent analysis in an independent data set we showed that the developed crosswalk could be used to accurately estimate HAQ-DI scores from PF-10 scores and vice versa in Dutch patients with early RA(6). However, the relationship between physical function scores and the latent physical function construct may differ between patients with different cultural backgrounds or between patients with different diseases. For example, previous research has shown that HAQ-DI items function differently between patients with gout, osteoarthritis and RA(7). Therefore the generalizability of a crosswalk needs to tested before it can be used in a new setting.

In the current study we evaluated the cross-cultural generalizability of the crosswalk in a sample of patients with RA, fibromyalgia (FM) and systemic lupus erythematosus (SLE) participating in a large-scale open cohort study in the United States (US).

\section{Methods}

\section{Ethics}

All participants were informed about the study procedures and signed an informed consent form. The National data bank for rheumatic diseases was approved by the Via Christi Institutional Review Board of Wichita, Kansas.

Patients 
Baseline data of people with RA, FM or SLE who participated in a longitudinal study of outcomes in the US National Data Bank for Rheumatic Diseases (NDB) were selected for analysis. (8). Participants were volunteers, recruited from the practices of US rheumatologists. At study entry, basic demographic information was collected as well as patient-reported outcomes, including the HAQ-DI and SF-36. Patients were not compensated for their participation. The diagnosis was made by the patients' rheumatologist. The NDB utilizes an open cohort design in which patients are enrolled continuously. Data at study entry was selected for analysis.

Measures

Medical Outcomes Study 36-Item Short Form Health Survey

The Medical Outcomes Study 36-Item Short Form Health Survey (SF-36) is a 36 item multidimensional questionnaire assessing different aspects of health represented in eight scales. Physical (PCS) and mental (MCS) health component and MCS scores were calculated by the scoring algorithm described in the SF-36 Physical and Mental Health Summary Scales User's Manual. The physical functioning scale ( PF-10) is one of the eight scales of the SF-36 and consists of 10 items measuring perceived current limitations in a variety of physical activities on a 3-point response scale from 1 (yes, limited a lot) to 3 (no, not limited at all). Scores on the PF-10 items are summed and linearly transformed to range between 0 and 100. Observed PF-10 scores can have 21 possible values, with higher scores indicating more favorable levels of physical functioning.

Health Assessment Questionnaire disability index (HAQ-DI)

The HAQ-DI contains 20 items measuring physical disabilities over the past week in eight categories of daily living: dressing and grooming, rising, eating, walking, hygiene, reach, grip, and activities. Each item is scored on a 4-point rating scale from 0 (without any difficulty) to 3 (unable to do). Additionally, the HAQ-DI contains four sections on the use of aids and devices or need for help from another person for performing activities in any of the eight categories. Two scoring methods can be used to calculate total HAQ-DI scores. The standard disability index (SDI) adjusts category scores upwards for the use of aids or devices or help from others. The alternative disability index (ADI) does not take the use of aids and devices into account. For both scoring methods, the total disability score is calculated by summing and averaging the highest item score of each category. As a result, observed scores on the HAQ-DI can take on 25 possible values between 0 and 3, with higher values indicating more disability.

\section{Statistical analysis}

Reliability of the crosswalk was evaluated by computing intraclass correlation coefficients (ICCs) with $95 \%$ confidence intervals using two-way mixed effects models with absolute agreement for single measurements (type A,1) (9). ICCs are generally considered adequate for group level 
comparisons when $\geq 0.70(10)$. Additionally, Bland-Altman plots of the difference against the mean of predicted and observed scores were constructed (11). All analyses were performed using SPSS version 21

\section{Results}

\section{Patient characteristics}

Baseline data on a total of 34.405 patients were selected for analysis. The majority of the sample were patients with RA and on average patients reported mild to moderate levels of disability (table 1). The crosswalk that can be used to convert HAQ-ADI and HAQ-SDI scores to the SF-36 metric and vice versa is presented in table 2 . It can be seen in the table that observed HAQ-ADI and HAQ-SDI scores $\geq 2.75$ correspond to a score of 0 on the PF-10. Conversely, observed PF-10 scores of 95 and 100 were linked to a score of 0 on the HAQ-ADI and HAQ-SDI. This suggests that the HAQ-DI can measure levels of extremely poor function that are not represented in the PF-10 and, conversely that some levels of extremely good physical function can be measured with PF-10, but not with HAQ-DI. However most of the HAQ-ADI or HAQ-SDI and PF-10 score levels could be linked to a corresponding score level on the other instrument, which suggests that both questionnaires measure similar levels of function in the RA population.

Table 1 Patient characteristics

\begin{tabular}{llll}
\hline & FM $(\mathrm{n}=3776)$ & SLE $(\mathrm{n}=1609)$ & RA $(\mathrm{n}=29020)$ \\
\hline Age (SD) & $53.44(12.25)$ & $47.55(13.23)$ & $58.15(13.65)$ \\
Disease duration, years (SD) & $13.20(10.38)$ & $13.45(10.33)$ & $12.28(10.91)$ \\
Sex, \% female & $94.2 \%$ & $88 \%$ & $77 \%$ \\
PCS (SD) & $31.69(8.96)$ & $37.20(11.35)$ & $36.06(10.79)$ \\
MCS (SD) & $41.29(12.31)$ & $44.31(11.66)$ & $48.15(11.65)$ \\
HAQ-ADI (SD) & $0.95(0.62)$ & $0.58(0.59)$ & $0.84(0.69)$ \\
HAQ-SDI (SD) & $1.08(0.64)$ & $0.71(0.67)$ & $0.94(0.72)$ \\
PF-10 (SD) & $50.56(26.86)$ & $65.259(29.28)$ & $59.20(28.81)$ \\
\hline
\end{tabular}

PCS = SF-36 Physical component score; MCS = SF-36 Mental component score; HAQ-ADI Health Assessment Questionnaire Alternative Disability index; HAD-SDI = Health Assessment Questionnaire Standard Disability index; PF-10 $=$ SF-36 physical functioning scale 
Table 2 Conversion table between HAQ-DI and PF-10 scores

\begin{tabular}{|c|c|c|c|c|c|c|c|}
\hline \multicolumn{4}{|c|}{ HAQ standard disability index (SDI) } & \multicolumn{4}{|c|}{ HAQ alternative disability index (ADI) } \\
\hline $\begin{array}{c}\text { Observed } \\
\text { HAQ-SDI } \\
\text { score }\end{array}$ & $\begin{array}{c}\text { Predicted } \\
\text { PF-10 } \\
\text { score }\end{array}$ & $\begin{array}{l}\text { Observed } \\
\text { PF-10 } \\
\text { score }\end{array}$ & $\begin{array}{c}\text { Predicted } \\
\text { HAQ-SDI } \\
\text { score }\end{array}$ & $\begin{array}{c}\text { Observed } \\
\text { HAQ-ADI } \\
\text { score }\end{array}$ & $\begin{array}{l}\text { Predicted } \\
\text { PF-10 } \\
\text { score }\end{array}$ & $\begin{array}{l}\text { Observed } \\
\text { PF-10 } \\
\text { score }\end{array}$ & $\begin{array}{c}\text { Predicted } \\
\text { HAQ-ADI } \\
\text { score }\end{array}$ \\
\hline 0.000 & 95 & 100 & 0.000 & 0.000 & 95 & 100 & 0.000 \\
\hline 0.125 & 90 & 95 & 0.000 & 0.125 & 90 & 95 & 0.000 \\
\hline 0.250 & 85 & 90 & 0.125 & 0.250 & 80 & 90 & 0.125 \\
\hline 0.375 & 75 & 85 & 0.250 & 0.375 & 75 & 85 & 0.125 \\
\hline 0.500 & 70 & 80 & 0.250 & 0.500 & 70 & 80 & 0.250 \\
\hline 0.625 & 65 & 75 & 0.375 & 0.625 & 65 & 75 & 0.375 \\
\hline 0.750 & 65 & 70 & 0.500 & 0.750 & 60 & 70 & 0.500 \\
\hline 0.875 & 60 & 65 & 0.750 & 0.875 & 50 & 65 & 0.625 \\
\hline 1.000 & 55 & 60 & 0.875 & 1.000 & 45 & 60 & 0.625 \\
\hline 1.125 & 50 & 55 & 1.000 & 1.125 & 45 & 55 & 0.875 \\
\hline 1.250 & 45 & 50 & 1.125 & 1.250 & 40 & 50 & 0.875 \\
\hline 1.375 & 45 & 45 & 1.250 & 1.375 & 35 & 45 & 1.000 \\
\hline 1.500 & 40 & 40 & 1.500 & 1.500 & 30 & 40 & 1.250 \\
\hline 1.625 & 35 & 35 & 1.625 & 1.625 & 25 & 35 & 1.375 \\
\hline 1.750 & 30 & 30 & 1.750 & 1.750 & 20 & 30 & 1.500 \\
\hline 1.875 & 25 & 25 & 1.875 & 1.875 & 20 & 25 & 1.625 \\
\hline 2.000 & 25 & 20 & 2.125 & 2.000 & 20 & 20 & 1.875 \\
\hline 2.125 & 20 & 15 & 2.250 & 2.125 & 15 & 15 & 2.125 \\
\hline 2.250 & 15 & 10 & 2.375 & 2.250 & 10 & 10 & 2.250 \\
\hline 2.375 & 10 & 5 & 2.750 & 2.375 & 10 & 5 & 2.625 \\
\hline 2.500 & 5 & 0 & 2.750 & 2.500 & 5 & 0 & 2.750 \\
\hline 2.625 & 5 & & & 2.625 & 5 & & \\
\hline 2.750 & 0 & & & 2.750 & 0 & & \\
\hline 2.875 & 0 & & & 2.875 & 0 & & \\
\hline 3.000 & 0 & & & 3.000 & 0 & & \\
\hline
\end{tabular}

The reliability of the crosswalk was high across diagnostic subgroups for both the HAQDI and PF-10 in the NDB data (Table 3). ICC's between predicted and actual scores ranged from 0.72 to 0.78 indicating that the crosswalk is sufficiently reliable for group level use across diagnostic sub-groups in the US data. Visual inspection of the Bland-Altman plots revealed that individual errors appeared to be unsystematically distributed across the observed physical function levels. Mean differences between observed and predicted scores were small in magnitude across diagnostic groups on both scales (Table 3). However bias was marginally higher in FM and SLE patients than it was in RA patients. The limits of agreement were fairly wide for both scales and showed substantial discrepancies in agreement within individual patients across conditions. 
Table 3: Agreement between observed and predicted scores on the HAQ-DI and PF-10

\begin{tabular}{|c|c|c|c|c|c|}
\hline & ICC $(95 \% \mathrm{CI})$ & $\begin{array}{l}\text { Mean Observed } \\
\text { score (SD) }\end{array}$ & $\begin{array}{l}\text { Mean predicted } \\
\text { score (SD) }\end{array}$ & $\begin{array}{l}\text { Mean difference } \\
\text { (SD) }\end{array}$ & LOA \\
\hline \multicolumn{6}{|l|}{$\mathbf{R A}$} \\
\hline$H A Q-A D I$ & 0.77 (0.76 to 0.77$)$ & $0.84(0.69)$ & $0.83(0.77)$ & $0.01(0.49)$ & -0.95 to 0.97 \\
\hline$H A Q-S D I$ & $0.77(0.76$ to 0.77$)$ & $0.94(0.72)$ & $1.00(0.83)$ & $-0.03(0.54)$ & -1.08 to 1.02 \\
\hline$P F-10$ & 0.78 (0.77 to 0.78$)$ & $59.20(28.81)$ & $58.26(27.02)$ & $1.03(18.54)$ & -35.30 to 37.37 \\
\hline \multicolumn{6}{|l|}{ FM } \\
\hline HAQ-ADI & $0.72(0.69$ to 0.74$)$ & $0.95(0.62)$ & $1.04(0.75)$ & $-0.09(0.51)$ & -1.00 to 0.91 \\
\hline HAQ-SDI & $0.70(0.65$ to 0.74$)$ & $1.08(0.64)$ & $1.23(0.79)$ & $-0.15(0.54)$ & -1.22 to 0.92 \\
\hline PF-10 & $0.73(0.71$ to 0.75$)$ & $50.56(26.86)$ & $53.17(24.11)$ & $-2.53(18.64)$ & -39.06 to 34.00 \\
\hline \multicolumn{6}{|l|}{ SLE } \\
\hline$H A Q-A D I$ & $0.76(0.73$ to 0.79$)$ & $0.58(0.60)$ & $0.69(0.74)$ & $-0.11(0.46)$ & -1.01 to 0.79 \\
\hline$H A Q-S D I$ & $0.77(0.72$ to 0.80$)$ & $0.71(0.67)$ & $0.84(0.82)$ & $-0.13(0.50)$ & -1.11 to 0.85 \\
\hline PF-10* & $0.78(0.75$ to 0.80$)$ & $65.25(29.28)$ & $68.62(24.94)$ & $-3.28(17.92)$ & -38.40 to 31.84 \\
\hline
\end{tabular}

HAQ-ADI Health Assessment Questionnaire Alternative Disability index; HAD-SDI = Health Assessment Questionnaire Standard Disability index; PF-10 = SF-36 physical functioning scale; LOA= Limits of agreement

\section{Discussion}

The current study evaluated the reliability of a recently developed crosswalk for converting HAQDI to PF-10 physical function scores in RA. The results of the current study represent a crossvalidation of the developed conversion tables in an independent data set of patients from a different cultural background and of patients with different rheumatic diseases.

The mean differences between observed and predicted HAQ-DI or PF-10 scores were very close to zero in US RA patients. This demonstrates that accurate group level conversions can be obtained using the crosswalk in the setting of US RA patients. The magnitude of the limits of agreement in the current study corresponded closely to those observed in a study of test-retest reliability of the HAQ-DI (12). This suggests that the observed reliability of the crosswalk reflects the reliability of the questionnaires, which corroborates the assumption that the measurement error of the crosswalk is a function of the reliability of the crosswalked instruments (6). Since the limits of agreement were fairly wide for both SF-36 and HAQ-DI, conversion for individual patients is not recommended.

The crosswalk was slightly less reliable in SLE and FM compared to US RA patients. However, the magnitude of the mean difference between observed and predicted scores was still smaller than one total score level for both the HAQ (i.e. 0.125 units) and the PF-10 (i.e. 5 units) in SLE and FM, and therefore probably not clinically relevant. Nevertheless, the crosswalk slightly underestimated mean physical function levels for converted HAQ-DI scores and slightly overestimated mean physical function levels for converted PF-10 scores in SLE and FM. 
The HAQ-DI and PF-10 are the most commonly used physical function questionnaires in clinical research as well as clinical practice in rheumatology, and have become core outcomes in the field of RA. The results of the current study suggest that the crosswalk can be used for descriptive purposes in for example systematic reviews. Moreover, physical function outcomes of studies using different questionnaires may also be pooled for group-level inferential purposes, for example to calculate standardized treatment effects on physical function in meta-analyses or to evaluate trends in longitudinal studies where different measures were used at different time points. However, it should be kept in mind that any estimate of a sample's mean using the crosswalk will be affected by measurement error associated with converting scores, Although Ten Klooster et al (6) showed that estimated effect size statistics in a sample of $276 \mathrm{RA}$ patients were quite close to the actually observed effect sizes, use of the crosswalk for inferential purposes is not recommend in small sample sizes (13). Finally, reliability was consistently slightly higher for conversion of HAQ-DI scores to the PF-10 metric, which likely reflects the marginally higher internal reliability of the HAQ-DI compared with the PF-10. Consequently, for both descriptive and inferential purposes, score conversions to the PF-10 metric should be the preferred application of the crosswalk if possible.

Cross-walking commonly used instruments offers a useful tool that addresses some of the problems associated with the proliferation of multiple measures of a single construct. However the accuracy of converted scores is limited by the reliability of the individual instruments. Additional sources of measurement error may be introduced and have to be accounted for in a crosswalk for instruments that measure more dissimilar constructs. Moreover, a multitude of instruments usually exist that can potentially be used for any given purpose.. For example, in RA numerous iterations of the HAQ are used in various settings. It is probably not feasible to develop separate crosswalks for all pairs of instruments. A more comprehensive approach to achieving comparability of physical function outcomes would be to create a single metric for physical function using a large, calibrated item bank such as for example the PROMIS initiative (14). Such a metric has the important advantage that physical function estimates on a common scale can be obtained from any and all combinations of the calibrated items.

Previous studies that compared US and Dutch PF scales in patients with rheumatic diseases generally found cross cultural item bias to be present in one or a few items $(15,16)$. However, the current results suggest the relationship between HAQ-ADI and PF-10 scores was not affected in important ways by cross-culturally biased items in the HAQ-DI or PF-10. . The average score bias of expected scores predicted by the crosswalk was of similar magnitude in US RA patients as in the original Dutch sample for both the HAQ-DI and PF-10 (6). The same conclusion regarding 
equivalence of Dutch and US PF total scores was reached in a previous study of cultural bias of the HAQ-II (16). The current results therefore add to the body of evidence of cross-cultural validity and interchangeability of Dutch and US physical function scores in RA .

The results of the current study suggest that the crosswalk provides accurate group level conversions of scores between HAQ-DI and PF-10 in US patients with RA, FM and SLE.

\section{References}

1. Felson DT, Anderson JJ, Boers M et al. The American College of Rheumatology preliminary core set of disease activity measures for rheumatoid arthritis clinical trials. The Committee on Outcome Measures in Rheumatoid Arthritis Clinical Trials. Arthritis Rheum 1993; 36: 729-740.

2. Wolfe F, Lassere M, van der Heijde D et al. Preliminary core set of domains and reporting requirements for longitudinal observational studies in rheumatology. J Rheumatol 1999; 26: 484-489.

3. Dorans NJ. Linking scores from multiple health outcome instruments. Qual Life Res 2007; 16 Suppl 1: 85-94.

4. Ware JE, Jr., Sherbourne CD. The MOS 36-item short-form health survey (SF-36). I. Conceptual framework and item selection. Med Care 1992; 30: 473-483.

5. Fries JF, Spitz P, Kraines RG, Holman HR. Measurement of patient outcome in arthritis. Arthritis Rheum 1980; 23: 137-145.

6. Ten Klooster PM, Oude Voshaar MA, Gandek B et al. Development and evaluation of a crosswalk between the SF-36 physical functioning scale and Health Assessment Questionnaire disability index in rheumatoid arthritis. Health Qual Life Outcomes 2013; 11: 199.

7. van Groen MM, ten Klooster PM, Taal E et al. Application of the health assessment questionnaire disability index to various rheumatic diseases. Qual Life Res 2010; 19: 1255-1263.

8. Wolfe F, Michaud K. The National Data Bank for rheumatic diseases: a multi-registry rheumatic disease data bank. Rheumatology (Oxford) 2011; 50: 16-24.

9. McGraw KO, Wong SP. Forming inferences about some intraclass correlation coefficients. Psychological Methods 1996; 1: 30-46.

10. Terwee CB, Bot SD, de Boer MR et al. Quality criteria were proposed for measurement properties of health status questionnaires. J Clin Epidemiol 2007; 60: 34-42.

11. Bland JM, Altman DG. Statistical methods for assessing agreement between two methods of clinical measurement. Lancet 1986; 1: 307-310.

12. Wolfe F, Pincus T, Fries JF. Usefulness of the HAQ in the clinic. Ann Rheum Dis 2001; 60: 811.

13. Noonan VK, Cook KF, Bamer AM, Choi SW, Kim J, Amtmann D. Measuring fatigue in persons with multiple sclerosis: creating a crosswalk between the Modified Fatigue Impact Scale and the PROMIS Fatigue Short Form. Qual Life Res 2012;21:1123-33

14. Cella D, Yount S, Rothrock N et al. The Patient-Reported Outcomes Measurement Information System (PROMIS): progress of an NIH Roadmap cooperative group during its first two years. Med Care 2007; 45: S3-S11.

15. Roorda L, Jones C, Waltz M et al. Satisfactory cross cultural equivalence of the Dutch WOMAC in patients with hip osteoarthritis waiting for arthroplasty. Annals of the rheumatic diseases 2004; 63: 36. 
16. Oude Voshaar MA, Glas CA, Ten Klooster PM et al. Crosscultural Measurement Equivalence of the Health Assessment Questionnaire II. Arthritis Care Res (Hoboken) 2013; 65: 1000-1004. 
94 I Chapter 4 


\section{Chapter 5}

Dutch translation and cross-cultural adaptation of the PROMIS(R) physical function item bank and cognitive pre-test in Dutch arthritis

patients

Oude Voshaar MA, Ten Klooster PM, Taal E, Krishnan E, van de Laar MA. Dutch translation and cross-cultural adaptation of the PROMIS(R) physical function item bank and cognitive pre-test in Dutch arthritis patients. Arthritis Res Ther. 2012 Mar 5;14(2):R47. 


\section{Abstract}

Introduction: Patient-reported physical function is an established outcome domain in clinical studies in rheumatology. To overcome the limitations of the current generation of questionnaires, the Patient-Reported Outcomes Measurement Information System (PROMIS ${ }^{\circledR}$ ) project in the USA has developed calibrated item banks for measuring several domains of health status in people with a wide range of chronic diseases. The aim of this study was to translate and cross-culturally adapt the PROMIS physical function item bank to the Dutch language and to pretest it in a sample of patients with arthritis.

Methods: The items of the PROMIS physical function item bank were translated using rigorous forward-backward protocols and the translated version was subsequently cognitively pretested in a sample of Dutch patients with rheumatoid arthritis.

Results: Few issues were encountered in the forward-backward translation. Only 5 of the 124 items to be translated had to be rewritten because of culturally inappropriate content. Subsequent pretesting showed that overall, questions of the Dutch version were understood as they were intended, while only one item required rewriting.

Conclusions: Results suggest that the translated version of the PROMIS physical function item bank is semantically and conceptually equivalent to the original. Future work will be directed at creating a Dutch-Flemish final version of the item bank to be used in research with Dutch speaking populations. 


\section{Introduction}

Physical function is impaired by musculoskeletal disease in patients with arthritis. So physical function has a long tradition as a core outcome domain in this field (1,2). Since its introduction in the 1980's, the Health Assessment Questionnaire-Disability Index (HAQ-DI) has become a standard outcome measure of physical function in clinical trials and observational studies (3). However, over time some considerable limitations of the scale have become apparent. The most frequently cited of these are its burdensomeness to patients and administrators due to a high number of questions and complex scoring and its relatively short measurement range, which leads to ceiling effects and reduced sensitivity to measure change, especially for relatively highfunctioning patients (4-9).

Recent studies indicate that these shortcomings can be overcome by the development of a calibrated item bank, using Item Response Theory (IRT) as a statistical method. From such an item bank, short forms or computerized adaptive testing protocols (CAT) of physical function can be developed $(10,11)$. Both methods of assessment help ensure that patients only respond to questions that are relevant to their specific level of disability and that only minimal questions need to be answered by patients, while retaining or surpassing the measurement precision of classical instruments.(12) A number of efforts have already demonstrated that IRT based measurement has the potential to provide more robust and responsive assessment of PF in arthritis than classical counterparts (13-16).

Perhaps the most ambitious effort to bring in modern testing approaches to measurement of health status is the Patient Reported Outcomes Measurement Information System (PROMIS ${ }^{\circledR}$ ). This NIH initiative aims to revolutionize the way patient-reported outcome tools are selected and employed in clinical research and practice evaluation by developing item banks and CAT's for important health-related quality of life outcome domains (17). A recent study with patients with RA showed that a 10 items simulated PROMIS ${ }^{\circledR}$ physical function CAT outperformed the legacy HAQ-DI in terms of measurement precision and width (10). These findings underscore the role computer based assessment of physical function with the PROMIS physical function item bank could play in bypassing the trade-off between measurement precision and burdensomeness to patients that necessarily exists when using fixed length tests.

Now that the PROMIS physical function item bank is ready for use and studies have demonstrated its benefits over legacy instruments such as the HAQ-DI, an important next step is to disseminate it to other countries and cultures. It is generally recognized that if measures are to be used across cultures, the items must not only be translated well linguistically, but also must be adapted culturally to maintain the content validity of the instrument at a conceptual level across 
different cultures $(18,19)$. To date no cross-cultural adaptations of the PROMIS item bank are available for use in the Netherlands. Moreover, although the psychometric properties of most Dutch translations of frequently used PF instruments are well known (e.g., the HAQ (16) and AIMS2 (20)) this is one of the first studies to offer a detailed description of the methodology of the cross-cultural translation of PF items to the Dutch language. In fact, the International Quality of Life Assessment (IQOLA) project is the only such effort in the peer-reviewed literature. The IQOLA project documents the translation of the MOS physical functioning scale using rigorous methodology and showed that PF items are particularly difficult to translate because they frequently refer to activities not common outside the USA $(21,22)$.

The aim of this study was to cross-culturally translate the PROMIS ${ }^{\circledR}$ physical function item bank items to Dutch, according to strict and rigorous guidelines for the translation of health-related quality of life instruments and to pretest the translated version in a sample of Dutch patients with arthritis.

\section{Methods}

PROMIS ${ }^{\circledR}$ physical function item bank

The PROMIS physical function item bank measures self-reported, current capability of physical activities. The item bank contains 124 questions assessing the functioning of the upper extremities (dexterity), lower extremities (walking or mobility), and central regions (neck, back), as well as instrumental activities of daily living, such as running errands (23)Questions were derived from 1865 extant physical function items that were identified in a systematic review of the literature on existing physical function instruments. Eligible items underwent extensive qualitative evaluation with patient surveys and focus groups (24). Subsequently, items were standardized in terms of item stems and response options. The resulting item bank was empirically tested in more than 21,000 persons from the general population, which included clinical samples of 1473 adults with selfreported arthritis $(10,14,25)$.

\section{Adaptation process}

Various guidelines for the process of cross-cultural translation of health-related quality of life instruments have been proposed $(12,18,19,26)$. There is consensus in the literature that the main elements in the procedure should include: (I) forward translation into the target language; (II) backtranslation into the source language by native speakers; (III) consensus meetings of people involved; and (IV) testing of the translation to the target language. What the scope of this final stage should be differs between guidelines, however. Although there is consensus that the main objective of this phase is to verify that all questions are comprehended as intended by respondents, 
Beaton et al. propose to investigate the distribution of responses as well, to check for high proportions of missing items and single responses (19). However, for the pretesting of item banks with large numbers of items, respondents are usually debriefed about subsets of items. This makes it a cumbersome process to enroll enough respondents to obtain meaningful information about these issues. Therefore these issues might better be investigated when data is being collected for calibrating the translated item bank.

Step 1: Forward translation

Two translators, both bilingual health professionals working in the field of rheumatology with Dutch as their mother tongue and proficient in English independently produced a forward translation of the 124 items. Both translators were provided with a spread sheet containing item definitions and potential item-specific translatability problems as identified by PROMIS ${ }^{\circledR}$.

Step 2: Synthesis of the translations

Inconsistencies between the forward translations were reconciled in a consensus meeting that was attended by both translators and a third health professional working in the field of rheumatology who recorded the process of reaching consensus and participated in the process of reconciling versions to create a synthesis version of the translation.

Step 3: Back translation into English

The items were translated back into American English by two professional translators, who were both native speakers of English, proficient in Dutch and living in the Netherlands. One of the translators was a British English native speaker and the other translator was an American English native speaker. Both translators were not informed about the concepts underlying the items' content and were not medically schooled or trained. Back translators were instructed to translate the Dutch items into American English and were told that measurement units of the metric system which feature in the Dutch items should, by approximation, be converted back to the corresponding imperial measurement units that that are used in the US. Following back translation, back translators were given access to the original English items to comment on the initial forward translation.

Step 4: Expert committee

Following correspondence with both back translators about the adequacy of the original forward translations, an expert meeting was organised to consolidate all the versions. During the expert meeting, all discrepancies between the translations were reviewed and potential cross-cultural issues were discussed. During the meeting final decisions were made to generate a pre-final version of the PROMIS PF item bank ready for testing by patients. Besides the input from the back translators, 
the committee consisted of one practicing rheumatologist, one social psychologist working in the field of rheumatology, one methodologist and both forward translators.

Step 5 test of the pre-final version

The aim of this final stage was to check the understanding and interpretation of the translated items in a population of Dutch patients with arthritis and thereby validate the conceptual equivalence between the US and Dutch versions. To be eligible for inclusion patients had to have a clinical diagnosis of Rheumatoid Arthritis, Osteoarthritis or Psoriatic Arthritis, be at least 18 years old and be free of any concurrent medical or psychiatric condition that might preclude participation in the study. As it would be overly burdensome for participants to be interviewed about all 124 items, a sampling scheme was applied that allowed for each participant to be interviewed on between 25 and 33 items. This allowed each item to be evaluated by 5 patients, as stipulated in the PROMIS qualitative item review protocol (27). Informed consent was provided according to the Declaration of Helsinki and obtained from all participating patients. According to the Dutch law for medical research with humans, approval by an ethical committee was not indicated for this study. Three Step Test Interview (TSTI) method, which is a cognitive interviewing method based on think aloud methodology (28). The TSTI is a qualitative research instrument specifically designed for testing self-assessment questionnaires that has proven to be effective in identifying reporting errors in health-related quality of life questionnaires (29). The TSTI consists of the following three steps: Respondent driven observation of response behavior; Interviewer driven follow-up probing aimed at identifying gaps in observational data and interviewer driven debriefing aimed at eliciting experiences and opinions of respondents.

Content analysis and descriptive summary statistics were used to evaluate the information gathered during the cognitive debriefing interviews and to characterize the participant sample. The analysis was based on notes taken by the interviewer and done on an item-by-item basis. This information was used either as a final seal of approval of an item or as input for item revision.

\section{Results}

Steps 1 to 3: Translation process

Only minor inconsistencies were observed between both forward translations, mostly related to different word choices. The term 'full pint container' used in item 31 does not have a direct Dutch translation that would be relatable for patients as a concept; therefore it was replaced by the term 'glass containing half a liter of water'. The only inconsistency between translations that required more elaborate discussion concerned the stem of the first set of items (are you able to). From a semantic point of view it can be translated as 'kunt u' (can you) and 'bent u in staat om' (are you 
able to). Although the former translation is less literal, it conveys the same meaning as the latter translation and it has the added benefit of resulting in less structurally complex sentences, which is why it was eventually adopted.

\section{Step 4: Expert committee}

During the expert committee meeting it was decided that inconsistencies between the back translations and the original items were too minor to warrant changing the initial forward translations. A number of cross-cultural issues were identified, however, that needed to be addressed: First, in the Netherlands street patterns are irregularly shaped, unlike in the US where city blocks are a central element in urban planning, so to walk a block will have a different meaning to different persons. Therefore item 17 was changed to: can you walk 150 meters (approximately 150 yards). Second, doors with door knobs are quite uncommon in the Netherlands. Most doors here have latches. To ensure that item 20 will be understandable for all patients we replaced the word 'doorknob' with 'door latch' Third, the Dutch word for 'liquid' is used mostly to refer to a specific state of matter, rather than referring to something that can be drunk in everyday live. Therefore we replaced the word 'liquid' by 'water' in item 44. Fourth, both items 56 and 59 refer to reaching into low and high cupboards, respectively. However to reach into is not directly translatable to Dutch, the closest approximation being 'to reach for'. Therefore the wording of these items was changed to: 'to get something from low/high cupboards'. Finally all imperial measurement units were converted to corresponding units in the metric system and rounded to the nearest 0 or 5 . An overview of all adjustments relative to the source items is presented in table 1 .

Table 1: adjustments of expressions and items made during the process of translating the item bank

\begin{tabular}{llll}
\hline Source Item & Dutch version; & Final Dutch version & Reason for adaptation \\
& English equivalent & &
\end{tabular}

\begin{tabular}{|c|c|c|c|}
\hline $\begin{array}{l}\text { Are you able to walk } \\
\text { a block on flat } \\
\text { ground? }\end{array}$ & $\begin{array}{l}\text { Are you able to walk } \\
150 \text { meter on flat } \\
\text { ground? }\end{array}$ & $\begin{array}{l}\text { Kunt u } 150 \text { meter lopen op } \\
\text { vlakke ondergrond? }\end{array}$ & $\begin{array}{l}\text { 'Block' is a poorly understood } \\
\text { concept in Dutch }\end{array}$ \\
\hline $\begin{array}{l}\text { Are you able to push } \\
\text { open a door after } \\
\text { turning the knob? }\end{array}$ & $\begin{array}{l}\text { Are you able to push } \\
\text { open a door after } \\
\text { pushing down the } \\
\text { latch? }\end{array}$ & $\begin{array}{ll}\text { Kunt u een deur open } \\
\text { duwen na nadat u de } & \text { klink } \\
\text { naar beneden } & \text { heeft } \\
\text { geduwd? } & \end{array}$ & $\begin{array}{l}\text { Doors in the Netherlands do not } \\
\text { have knob-type door operating } \\
\text { mechanisms }\end{array}$ \\
\hline $\begin{array}{l}\text { Are you able to pour } \\
\text { liquid from a bottle } \\
\text { into a glass? }\end{array}$ & $\begin{array}{l}\text { Are you able to pour } \\
\text { water from a bottle } \\
\text { into a glass? }\end{array}$ & $\begin{array}{l}\text { Kunt u water vanuit een fles } \\
\text { in een glas schenken? }\end{array}$ & $\begin{array}{l}\text { The word 'liquid' is mostly used to } \\
\text { refer to a specific state of matter, } \\
\text { rather than something that can be } \\
\text { drunk. }\end{array}$ \\
\hline $\begin{array}{l}\text { Are you able to reach } \\
\text { into a high } \\
\text { cupboard? }\end{array}$ & $\begin{array}{l}\text { Are you able to } \\
\text { retrieve something } \\
\text { from a high cupboard? }\end{array}$ & $\begin{array}{l}\text { Kunt u iets uit een hoog } \\
\text { keukenkastje pakken? }\end{array}$ & $\begin{array}{l}\text { To reach into is not directly } \\
\text { translatable to Dutch. }\end{array}$ \\
\hline $\begin{array}{l}\text { Are you able to reach } \\
\text { into a low cupboard? }\end{array}$ & $\begin{array}{l}\text { Are you able to } \\
\text { retrieve something } \\
\text { from a low cupboard? }\end{array}$ & $\begin{array}{l}\text { Kunt u iets uit een laag } \\
\text { keukenkastje pakken? }\end{array}$ & $\begin{array}{l}\text { To reach into is not directly } \\
\text { translatable to Dutch. }\end{array}$ \\
\hline
\end{tabular}




\section{Step 5: Pretest}

The resulting item pool was pretested in 20 patients with rheumatic diseases. Some clinical and demographic information about the participating patients is listed in table 2 .

Table 2 Patient characteristics $(n=20)$

\begin{tabular}{cll}
\hline Characteristic & N or Mean (SD) & Range \\
\hline Diagnosis $(\%)$ & & \\
Rheumatoid arthritis & 15 \\
Osteoarthritis & 3 \\
Psoriatic arthritis & 2
\end{tabular}

\begin{tabular}{llc} 
Gender $(\%$ female $)$ & $70 \%$ & \\
Age & $53.7(7.5)$ & $39-63$ \\
$\begin{array}{l}\text { Disease duration in years } \\
\text { Mean }\end{array}$ & $10.6(7.9)$ & $3-31$ \\
\hline
\end{tabular}

Interview data indicated that questions were well understood by patients. Generally, the questions were filled in quickly in a consistent speed. Patients rarely hesitated or corrected a previously reported answer. When thinking aloud, patients tended to reflect on the activities as they carry them out in their daily lives and mentally went over problems that are associated with carrying out the activities. This provided a good indication that patients understood the items as they were intended. The only exception to this concerned item 31 (Are you able to lift one pound (a full pint container) to shoulder level without bending your elbow?). All five patients took considerably more time in answering this question and four out of five patients asked for additional clarification regarding the meaning of the question.. These observations indicate that this item was not well understood by patients and the formulation was changed. In addition, two questions with doublebarreled content were identified that prohibited respondents to give a consistent answer. The first was item 52 (are you able to use your hands, such as for turning faucets, using kitchen gadgets, or sewing?). Four out of five patients indicated that it was not possible for them to give a consistent answer to this question. Patients indicated that sowing is an activity much more related to dexterity of the fingers than the other activities, which seem to be more related to gross motor skills and movements of the wrist. The second problem concerned item 122 (Are you currently restricted by your health from taking part in physically active sports such as swimming, tennis or basketball). Three out of five patients indicated that they experience significantly less difficulty with swimming than with performing either of the ball sports, because swimming is far less strenuous to the joints. Although the activities in these questions serve an illustrative purpose, patients interpreted the question as if they are being asked if they can perform those exact activities. Consequently, it becomes impossible to give a consistent answer in case they experience the activities to be 
unequally difficult. Because this problem does not appear to stem from the translation of the items or from cross-cultural issues, these items were not changed.

Aside from theses item specific problems, two issues related to the questions in general were identified. The first is that patients often indicated that they missed a reference to time in the questions. The second, related, problem that was encountered with items referring to strenuous activities such as walking or running more than a mile or working in the garden is that patients indicate they can, in principle, perform the tasks referred to in the items but are nevertheless reluctant to do so because they know that they will suffer increased fatigue, stiffness and pain in the days after. As with the double barreled questions, however, these issues do not seem to stem from the translation process and consequently no remedial action was undertaken.

\section{Discussion}

This study describes the process of cross-culturally adapting the PROMIS ${ }^{\circledR}$ physical function item bank items according to rigorous methodological standards for use in the Dutch culture. The main aim of the study was to verify the conceptual equivalence and linguistic validity of the PROMIS PF items for use in Dutch arthritic patient by using cognitive interviewing methodology.

We noted few inconsistencies between both forward translations and between the back translations and the original items, indicating that the translated version is reflecting the same item content as the original version. In fact, the back translation from the American native back translator was almost perfectly equivalent to the original items that did not require cross-cultural adaptation. An explanation for this might be that all questions in the PROMIS physical function item bank refer to very concrete, every day activities. Moreover, the items in the original American item bank already underwent rigorous qualitative assessment by experts and respondents to ensure that the reading level would be suitable for all respondents (24). Most changes that were made in the adaptation process concerned cross-cultural issues. In all cases these changes concerned substituting uncommon or non-used concepts and objects for objects and concepts that are better suited to the Dutch culture. For most questions it was possible to make small conceptual changes while retaining the difficulty level of questions. For instance, imperial measurement units were converted to grossly corresponding units of the metric system. However, some concepts such as walking a block do not have a straightforward equivalent translation in Dutch, as was noted in the IQOLA project as well (22). Sometimes more radical changes were required. For example, opening a door with a door knob may be harder to do than opening a door with a door latch, especially for patients with arthritis. This may undermine the cross-cultural measurement equivalence of this specific item. However the impact this might have on the item's function needs to be investigated 
empirically. The HAQ (30) and SF-36 (22) physical functioning items have previously been translated to the Dutch language and also feature in adapted form (i.e. more response options and sometimes changed wording) in the PROMIS PF item bank. Our Dutch translation of the 15 HAQ items that were left unchanged by PROMIS were equivalent to the items in the Dutch Consensus HAQ, except for item 10: 'are you able to wash and dry your body?'. We chose a literal translation whereas in the Dutch HAQ the literal English translation would read: 'Are you able to wash and dry your body yourself?'. Also the sequence of words of item 16 : 'Are you able to open previously opened jars?' is slightly different in our translation than in the Dutch HAQ. In the Dutch translation of the SF-36 items, we deviated from the Wagner et al. translation for two out of ten items; We translated mile in the item: 'Does your health now limit you in walking more than a mile?' as 1.5 kilometres instead of 1 , in order to assure the measurement equivalence of the item, cross-culturally. Also Wagner et al translated 'bowling' and 'playing golf as 'swimming' and 'cycling', respectively in the item: 'Does your health now limit you in doing moderate activities, such as moving a table, pushing a vacuum cleaner, bowling, or playing golf?', whereas we chose to preserve the original content for this item.

There is general consensus in the literature that the process of translating a questionnaire or item bank should be followed by a pretest to assess the success of the translation by verifying that the item wording is clear, unambiguous and permits respondents to successfully answer the questions $(18,19,26)$. Cognitive interviewing techniques are well suited for this because the verbalized reflections of patients provide an excellent source of information to verify that questions are understood and answered to as intended. Two major types of cognitive interviewing methods are generally distinguished in the literature: think-aloud interviewing and verbal probing techniques (31). The item review of the original PROMIS ${ }^{\circledR}$ item banks employed verbal probing techniques. In this approach respondents undergo a structured interview where the goal is to use targeted probing to guide the interchange in a way that is controlled mainly by the interviewer. The main advantage of this approach is that the interviewer can focus on particular areas that appear to be relevant as potential sources of response error. Item review of the Dutch translation of the PROMIS PF item bank however, employed think-aloud methodology. The main advantage of think-aloud methods is that there is minimal interviewer-imposed bias, and consequently, unanticipated problems in the response behavior of participants are more likely to be detected. These two methods therefore complement each other: Verbal probing techniques provide a good way to verify that questions are comprehended as intended on a semantic and conceptual level in a structured setting where the interviewer controls the course of the exchange. However response errors can occur even though questions are correctly understood by patients if questions have 
different meaning to patients than initially expected by the developers of the questions. For instance, in this study it was revealed that patients consistently had problems with item 121 (Are you currently restricted by your health from taking part in physically active sports such as swimming, tennis or basketball), because they perceive these activities to be unequally difficult. This type of important issue that precludes patients to give a consistent answer is more likely to be detected if patients are allowed to freely verbalize their thoughts when formulating an answer to the question.

\section{Future work}

Given the objective of PROMIS to develop one version for multiple countries instead of countryspecific versions of the same language, the translation effort described in this study is currently incorporated in the official Dutch-Flemish PROMIS item bank translation process, together with 3 independent translations produced by FACIT. Following the PROMIS methodology, the most appropriate translation considering both the Dutch and Flemish cultures will be chosen for each item. The consensus translation will then be tested through cognitive debriefing in a small sample of members from the general population in both the Netherlands and Belgium to produce a definite official translation. After that phase, data will be collected to calibrate the Dutch translation of the PROMIS physical function item bank and to assess its psychometric performance in several chronic diseases, including patients with arthritis.

\section{Conclusions}

This study describes the process of cross-culturally adapting the PROMIS ${ }^{\circledR}$ physical function item bank for use with Dutch patients with arthritis. This is, to our best knowledge, the first study describing the cross-cultural adaptation of any of the PROMIS ${ }^{\circledR}$ item banks. The rigorous translation methodology employed ensures that the Dutch version is semantically and conceptually equivalent to the original. Furthermore item review verified that all Dutch items are comprehended by patients as they were intended although some minor general problems in the response process persist that are most likely to be prevalent in the original version of the item bank as well.

\section{References}

1. Felson DT, Anderson JJ, Boers M, Bombardier C, Chernoff M, Fried B, Furst D, Goldsmith C, Kieszak S, Lightfoot R, Paulus H, Tugwell P, Weinblatt M, Widmark R, Williams H, Wolfe F: The American College of Rheumatology preliminary core set of disease activity measures for rheumatoid arthritis clinical trials. The Committee on Outcome Measures in Rheumatoid Arthritis Clinical Trials. Arthritis Rheum 1993, 36:729740. 

Symmons D, Silman A, van Riel P, Tugwell P, Boers M: Preliminary core set of domains and reporting requirements for longitudinal observational studies in rheumatology. J Rheumatol 1999, 26:484-489.

3. Kalyoncu U, Dougados M, Daures JP, Gossec L: Reporting of patient-reported outcomes in recent trials in rheumatoid arthritis: a systematic literature review. Ann Rheum Dis 2009, 68:183-190.

4. Pincus T, Summey JA, Soraci SA, Jr., Wallston KA, Hummon NP: Assessment of patient satisfaction in activities of daily living using a modified Stanford Health Assessment Questionnaire. Arthritis Rheum 1983, 26:1346-1353.

5. Stucki G, Stucki S, Bruhlmann P, Michel BA: Ceiling effects of the Health Assessment Questionnaire and its modified version in some ambulatory rheumatoid arthritis patients. Ann Rheum Dis 1995, 54:461-465.

6. Pincus T, Swearingen C, Wolfe F: Toward a multidimensional Health Assessment Questionnaire (MDHAQ): assessment of advanced activities of daily living and psychological status in the patient-friendly health assessment questionnaire format. Arthritis Rheum 1999, 42:2220-2230.

7. Wolfe F, Michaud K, Pincus T: Development and validation of the health assessment questionnaire II: a revised version of the health assessment questionnaire. Arthritis Rheum 2004, 50:3296-3305.

8. Pincus T, Sokka T, Kautiainen H: Further development of a physical function scale on a MDHAQ (corrected) for standard care of patients with rheumatic diseases. J Rheumatol 2005, 32:1432-1439.

9. Oude Voshaar MA, Ten Klooster PM, Taal E, van de Laar MA: Measurement properties of physical function scales validated for use in patients with rheumatoid arthritis: A systematic review of the literature. Health Qual Life Outcomes 2011, 9:99.

10. Fries JF, Cella D, Rose M, Krishnan E, Bruce B: Progress in assessing physical function in arthritis: PROMIS short forms and computerized adaptive testing. J Rheumatol 2009, 36:2061-2066.

11. Rose M, Bjorner JB, Becker J, Fries JF, Ware JE: Evaluation of a preliminary physical function item bank supported the expected advantages of the Patient-Reported Outcomes Measurement Information System (PROMIS). J Clin Epidemiol 2008, 61:17-33.

12. Bonomi AE, Cella DF, Hahn EA, Bjordal K, Sperner-Unterweger B, Gangeri L, Bergman B, Willems-Groot J, Hanquet P, Zittoun R: Multilingual translation of the Functional Assessment of Cancer Therapy (FACT) quality of life measurement system. Qual Life Res 1996, 5:309-320.

13. Martin M, Kosinski M, Bjorner JB, Ware JE, Jr., Maclean R, Li T: Item response theory methods can improve the measurement of physical function by combining the modified health assessment questionnaire and the SF-36 physical function scale. Qual Life Res 2007, 16:647-660.

14. Fries JF, Krishnan E, Rose M, Lingala B, Bruce B: Improved responsiveness and reduced sample size requirements of PROMIS physical function scales with item response theory. Arthritis Res Ther 2011, 13:R147.

15. van Groen MM, ten Klooster PM, Taal E, van de Laar MA, Glas CA: Application of the health assessment questionnaire disability index to various rheumatic diseases. Qual Life Res 2010, 19:1255-1263.

16. ten Klooster PM, Taal E, van de Laar MA: Rasch analysis of the Dutch Health Assessment Questionnaire disability index and the Health Assessment Questionnaire II in patients with rheumatoid arthritis. Arthritis Rheum 2008, 59:1721-1728. 
17. Cella D, Yount S, Rothrock N, Gershon R, Cook K, Reeve B, Ader D, Fries JF, Bruce B, Rose M: The Patient-Reported Outcomes Measurement Information System (PROMIS): progress of an NIH Roadmap cooperative group during its first two years. Med Care 2007, 45:S3-S11.

18. Guillemin F, Bombardier C, Beaton D: Cross-cultural adaptation of health-related quality of life measures: literature review and proposed guidelines. J Clin Epidemiol 1993, 46:1417-1432.

19. Beaton DE, Bombardier C, Guillemin F, Ferraz MB: Guidelines for the process of cross-cultural adaptation of self-report measures. Spine (Phila Pa 1976) 2000, 25:3186-3191.

20. Riemsma RP, Taal E, Rasker JJ, Houtman PM, Van Paassen HC, Wiegman O: Evaluation of a Dutch version of the AIMS2 for patients with rheumatoid arthritis. Br J Rheumatol 1996, 35:755-760.

21. Aaronson NK, Muller M, Cohen PD, Essink-Bot ML, Fekkes M, Sanderman R, Sprangers MA, te Velde A, Verrips E: Translation, validation, and norming of the Dutch language version of the SF-36 Health Survey in community and chronic disease populations. J Clin Epidemiol 1998, 51:1055-1068.

22. Wagner AK, Gandek B, Aaronson NK, Acquadro C, Alonso J, Apolone G, Bullinger M, Bjorner J, Fukuhara S, Kaasa S Leplege A, Sullivan M, Wood-Dauphinee S, Ware JE: Cross-cultural comparisons of the content of SF-36 translations across 10 countries: results from the IQOLA Project. International Quality of Life Assessment. J Clin Epidemiol 1998, 51:925-932.

23. Patient-reported outcomes measurement information system (http://nihpromis.org/)

24. Bruce B, Fries JF, Ambrosini D, Lingala B, Gandek B, Rose M, Ware JE, Jr.: Better assessment of physical function: item improvement is neglected but essential. Arthritis Res Ther 2009, 11:R191.

25. Hung M, Clegg DO, Greene T, Saltzman CL: Evaluation of the PROMIS physical function item bank in orthopaedic patients. J Orthop Res 2011, 29:947-953.

26. Process of translation and adaptation of instruments (http://www.who.int/substance_abuse/research_tools/translation/en/.)

27. DeWalt DA, Rothrock N, Yount S, Stone AA: Evaluation of item candidates: the PROMIS qualitative item review. Med Care 2007, 45:S12-21.

28. Hak T, Van der Veer K, Jansen H: The Three-Step Test-Interview (TSTI): An observational instrument for pretesting self-completion questionnaires. Addiction Research 2004, 4.

29. Hak T, Van Der Veer K, Ommundsen R: An application of the Three-Step Test-Interview (TSTI): A validation study of the Dutch and Norwegian versions of the 'Illegal Aliens scale'. International Journal of Social Research Methodology 2006, 9:215-227.

30. Boers M, Jacobs JW, van Vliet Vlieland TP, van Riel PL: Consensus Dutch health assessment questionnaire. Ann Rheum Dis 2007, 66:132-133.

31. Willis GB: Cognitive interviewing: A "How To" Guide. In: Meeting of the American Statistical Association. 1999. 
108 I Chapter 5 


\section{Chapter 6}

Calibration and evaluation of cross-cultural measurement equivalence of the PROMIS physical function item bank in Dutch patients with rheumatoid arthritis

Oude Voshaar, M. A. H., Ten Klooster, P. M., Glas, C. A. W., Vonkeman, H. E., Taal, E., Krishnan, E., Moens, H.J., Boers, M., Terwee, C.B., van Riel, P.L.C.M. van de Laar, M. A. F. J. (2014). Calibration of the PROMIS Physical Function Item Bank in Dutch Patients with Rheumatoid Arthritis. PloS One, 9(3), e92367. doi:10.1371/journal.pone.0092367 


\begin{abstract}
Objective: To calibrate the Dutch-Flemish version of the PROMIS physical function (PF) item bank in patients with rheumatoid arthritis (RA) and to evaluate cross-cultural measurement equivalence with US general population and RA data.

Methods: Data were collected from RA patients enrolled in the Dutch DREAM registry. An incomplete longitudinal anchored design was used where patients completed all 121 items of the item bank over the course of three waves of data collection. Item responses were fit to a generalized partial credit model adapted for longitudinal data and the item parameters were examined for differential item functioning (DIF) across country, age, and sex

Results: In total, 690 patients participated in the study at time point 1 (T2, N=489; T3, N=311). The item bank could be successfully fitted to a generalized partial credit model, with the number of misfitting items falling within acceptable limits. Seven items demonstrated DIF for sex, while 5 items showed DIF for age in the Dutch RA sample. Twenty-five (20\%) items were flagged for cross-cultural DIF compared to the US general population. However, the impact of observed DIF on total physical function estimates was negligible.

Discussion: The results of this study showed that the PROMIS PF item bank adequately fit a unidimensional IRT model which provides support for applications that require invariant estimates of physical function, such as computer adaptive testing and targeted short forms. More studies are needed to further investigate the cross-cultural applicability of the US-based PROMIS calibration and standardized metric.
\end{abstract}




\section{Introduction}

Rheumatoid arthritis (RA) is one of the most prevalent rheumatic diseases, characterized by pain and swelling of the joints which may lead to significant disability. Patient-reported physical function is a core outcome domain in RA research $(1,2)$. Physical function is typically assessed using standard, fixed-length questionnaires. Although often extensively validated, key limitations of these traditional questionnaires remain their static nature and limited measurement range and measurement precision, frequently leading to ceiling and floor effects and limited sensitivity to change (3-8). Recent studies have suggested that these shortcomings may be overcome by item response theory (IRT) based item banking $(9,10)$. IRT calibrated item banks can serve as a platform for tailored assessment of patient-reported outcomes, through developing targeted short forms or computerized adaptive tests (CATs). Both methods of assessment ensure that patients respond to questions that are more relevant to their specific level of disability and that only minimal questions need to be answered, while retaining or surpassing the measurement precision of fixed-length instruments.

The Patient-Reported Outcomes Measurement Information System (PROMIS ${ }^{\circledR}$ ) initiative has developed and calibrated item banks for assessing several important domains of health status, including physical function, across a wide variety of chronic diseases and conditions and the general population in the US (11). Using data from the general population and several clinical samples in the US, all items in the item banks are calibrated on a common, standardized metric. Potentially, the PROMIS physical function (PF) item bank could also lead to improved assessment of physical function in clinical or comparative studies in RA. Indeed, recent studies have already shown a 20item PROMIS PF short form to be more precise and more responsive to change than traditional questionnaires in RA (12). Recently, the PROMIS PF item bank has been translated and culturally adapted for use among Dutch and Flemish populations. Pretesting of the translated items revealed that the items were understood by patients as intended and culturally appropriate for use in Dutch populations with arthritis $(13,14)$. Before an item bank can be used in a new population, however, it should be demonstrated that data collected from that population can be fit to an appropriate IRT model. If this is the case, a latent metric specific for this population can be created that allows invariant estimates of the item parameters and physical function levels to be obtained (e.g., item parameters that are independent of the physical function level of the respondents used to calibrate the item bank) (15). As a result, physical function estimates on a common scale may be obtained from any number and combination of items in the item bank and applications such as CATs and targeted short forms become possible. A second question that needs to be addressed is whether the relationship between observed physical function scores and the physical function trait measured 
by the item bank is equivalent to this relationship for the original population. If this is the case, this would provide evidence that the model parameters can be expressed on a common scale (16). In case of the PROMIS PF item bank, this would mean that data from the specific population can be scored using the US-based PROMIS calibration and standardized metric, making scores directly comparable between populations.

The aims of the current study were to calibrate the Dutch-Flemish PROMIS PF item bank in a prospective cohort of Dutch patients with RA and to evaluate its measurement equivalence with data from the total PROMIS wave 1 calibration sample in the US and a smaller subset of US RA patients.

\section{Methods}

\section{Patients}

Data for this study were collected within the Dutch Rheumatoid Arthritis Monitoring (DREAM) registry. The DREAM registry is an observational multicenter cohort study that monitors the course of unselected RA patients in the Netherlands. Both patient-reported and clinical outcomes are collected and monitored using a web-based data acquisition and storage system. Patientreported outcomes, including the Health Assessment Questionnaire disability index (HAQ-DI) and the SF-36 health survey, are completed preceding every visit to the outpatient clinic. Between September 2012 and September 2013, all participating patients from three DREAM hospitals were informed about the study and invited to participate upon logging on to their patient portals preceding their visit to the clinic.

\section{Data collection designs}

\section{Dutch DREAM data}

To optimize data quality and minimize patient burden, an incomplete longitudinal design was used for calibrating the Dutch-Flemish item bank in the Dutch RA patients, in which different subsets of items (booklets) were administered to different patients. The booklets were linked using common items, making it possible to place all items on a single scale (17). Since previous research has found that the number of common items within booklets improves the stability of IRT models estimated from incomplete calibration designs, (18) the item responses on the HAQ-DI and the SF-36 physical functioning scale (PF-10), the two most widely used measures of physical function in RA, were added to the calibration design. A graphical overview of the calibration design is presented in Figure 1.

Upon consenting to participate, patients were allocated randomly to one of six booklets. Besides the HAQ-DI and PF-10, each booklet contained two sets of approximately 20 of the 121 
PROMIS PF items and each of the six sets featured in two booklets in such a way that half of the items in each booklet overlapped with the previous booklet and half with the next. On successive participations, patients were allocated to booklet $\mathrm{N}+2$ (for $\mathrm{N}=1,2,3,4$ ) or $\mathrm{N}-4$ (for $\mathrm{N}=5,6$ ), where $\mathrm{N}$ is the booklet that was administered at the preceding participation, so that patients completed the full item bank after three participations. The sample sizes of the six groups were approximately equal so that all items received an approximately equal number of responses.

From historical log data of physical function items in the DREAM registry, it was estimated that the majority of patients would need no more than 10 minutes to complete each booklet of approximately 40 items. An effort was made to balance the relative difficulty of the items in each booklet by ordering the items according to their peak statistical information on the latent IRT metric according to the US PROMIS wave 1 calibration results. As $20 \%$ of the PROMIS PF items has a different stem (i.e., 'does your health now limit you...' rather 'than are you able to...') and associated set of response options, each booklet contained a proportional number of these items. US PROMIS wave 1 data

PROMIS wave 1 data for 14 candidate item pools, including three pools of physical function items, were collected between July 2006 to March 2007 from over 21,000 participants selected from both the US general population and specific clinical populations (19). The data collection design of the wave 1 data consisted of both so-called 'full bank administrations', where participants were administered two sets of 56 items from only one or two item pools, and 'block administrations' where participants completed 14 blocks of seven items from all item pools. To avoid complicating the calibration design and analyses, we chose to model only the available full bank data from the general population sample and the block data available from the clinical sample of RA patients.

The full bank arm of the data collection design for physical function in the general population consisted of two booklets that were completed by two independent samples of 942 and 995 respondents, respectively. The booklets were complementary in that each PF item featured in only one booklet and together the booklets contained all 121 final items of the PROMIS PF item bank. Besides the PROMIS PF items, respondents completed the HAQ-DI or PF-10 or both. The HAQ-DI and PF-10 data were included in the calibrations in order to obtain a linked structure so that the US item parameters could be placed on a common latent scale, despite the lack of overlapping PROMIS PF items between the two booklets. Additionally, two clinical samples of 273 and 280 RA patients completed a booklet with a selection of seven items from each of the three PF item pools. Twenty-four of these 42 administered items were calibrated in the final US PROMIS PF item bank (13 and 11 Items from each booklet, respectively). 
Figure 1: Longitudinal patient sampling and booklet allocation design

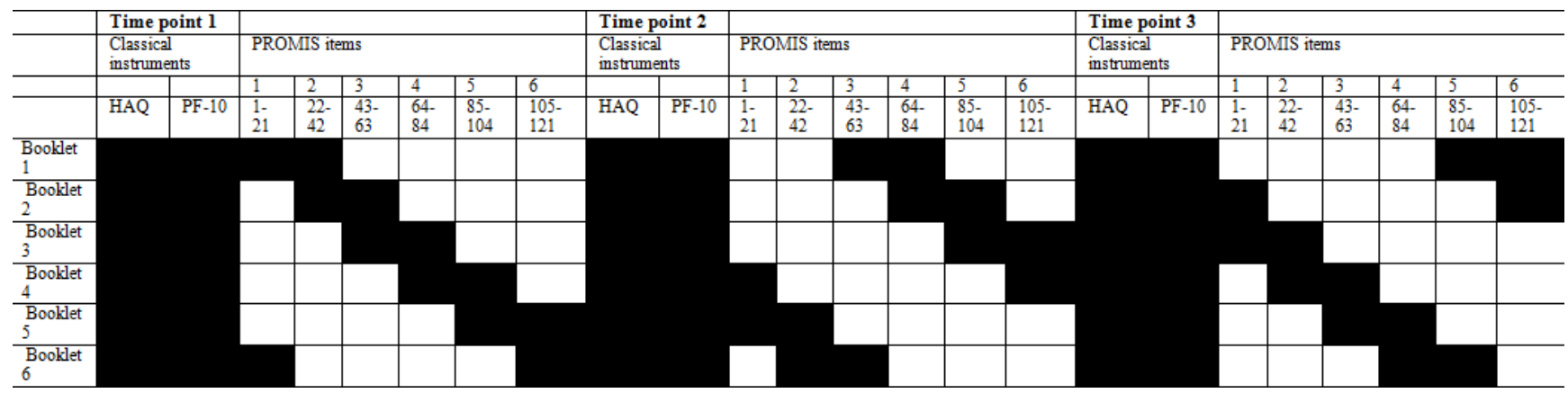

HAQ $=$ Health Assessment Questionnaire disability index; PF-10 = SF36 physical functioning scale; PROMIS = patient reported outcome information system

\section{Measures}

PROMIS physical function (PF) item bank

The PROMIS PF item bank measures self-reported, current capability to carry out activities that require physical actions, ranging from self-care (activities of daily living) to more complex activities that require a combination of skills, often within a social context. The final calibrated item bank contains 121 questions assessing the functioning of the upper extremities (dexterity), lower extremities (walking or mobility), and central regions (neck, back), as well as instrumental activities of daily living, such as running errands (19). Each item is scored on a 5 point rating scale, with higher scores indicating better functioning. The Dutch-Flemish translation of the item bank was developed according to the universal PROMIS translation approach (http://www.nihpromis.org/measures/translations), which included extensive forward-back translation procedures, expert reviews, and cognitive debriefing interviews among Dutch and Flemish participants (20).

Health Assessment Questionnaire disability index (HAQ-DI)

The HAQ-DI contains 20 items measuring physical disabilities over the past week in eight categories of daily living: dressing and grooming, rising, eating, walking, hygiene, reach, grip, and activities (21). Each item is scored on a 4-point rating scale from 0 (without any difficulty) to 3 (unable to do). Disability scores were calculated according to the alternative scoring rule, which does not account for the use of aids and help from others (22). Category scores are averaged to produce a total score between 0 and 3, with higher values indicating more disability. The Dutch consensus version of the HAQ-DI was used in the DREAM data collection.

SF-36 Health Survey physical functioning scale (PF-10)

The PF-10 is one of the eight scales of the SF-36 Health Survey and consists of 10 items measuring perceived current limitations in a variety of physical activities on a 3-point response scale from 1 (yes, limited a lot) to 3 (no, not limited at all). Scores of the PF-10 items are summed and linearly 
transformed to range between 0 and 100, with higher scores indicating better physical functioning (23). The Dutch version of the SF-36v2 was used in the DREAM study (24).

Additional patient-reported and clinical measures

The Dutch DREAM registry additionally collected patient-reported general health, disease activity, fatigue, and pain in the past week on 0-100 visual analog scales (VASs), with higher scores indicating worse status. Clinical data were collected during visits to the outpatient clinic, including a 28-tender joint count, 28-swollen joint count, and erythrocyte sedimentation rate. Together with the VAS general health, these measures were combined into a single index of clinical disease activity (DAS28) (25).

\section{Statistical analysis}

All IRT analyses were performed with the MIRT software package (26). The marginal maximum likelihood estimation procedure was utilized to estimate the model parameters and the latent physical function levels of patients were estimated using the expected a posteriori (EAP) method throughout all analyses. Latent physical function scores are expressed on a scale with a mean of 0 and SD of 1. A multidimensional generalization of the two-parameter generalized partial credit model (GPCM), suitable for the analysis of longitudinal, polytomous data (27), was used to model the Dutch data. In this model, the item parameters pertain to time point specific latent dimensions and the dependency between item responses at different time points is modeled by the correlation between the dimensions. The model allows patients' levels of physical function to change over time but item parameters are constrained to be equal across time points. To evaluate whether the item parameters were stable over time, the presence of longitudinal differential item functioning (DIF) was evaluated using regression analysis as proposed by Te Marvelde \& Glas (28). To this end, unidimensional GPCM estimates of the Dutch PROMIS data were obtained for each time point separately. The resulting threshold parameters were regressed on the threshold parameters emanating from one of the other two models in a series of univariate regression models. Individual items were considered to display statistically significant longitudinal DIF in case an item's 99\% confidence interval did not intersect the regression line (28).

Fit of the longitudinal IRT model was assessed using Lagrange multiplier (LM) statistics, which evaluate whether observed item scores correspond to those expected by the item characteristic function (29). To evaluate the magnitude of model violation of significant LM tests, effect size statistics (ES) were also obtained. These effect sizes are differences between average observed and expected scores across 3 total-score level groups. To compute these effect sizes, the patients were divided in 3 groups of approximately equal size obtaining low, intermediate, and high scores. The observed and expected scores were divided by the maximum attainable item score, 
such that a difference of, say, 0.10 indicated that the observed average score was $10 \%$ different from its expectation under the model. Items were considered to lack fit in case $P$ 's $<0.05$ and ES statistics were $>0.10$ (30). We first evaluated fit within time points by estimating the unidimensional GPCM 3 times, once for each time point. Subsequently, fit of the total multidimensional model, with item parameters constrained to be equal across time points and which includes the covariance matrix between time points, was evaluated. The Dutch data was evaluated for DIF across age (median split at 58 years) and sex. To this end the baseline model was extended by partitioning the booklets further according to age or sex and DIF was evaluated across two marginal distributions of physical function of males vs. females and younger vs. older patients, respectively. DIF across the marginal distributions was evaluated with an LM test for DIF (31).

Cross-cultural equivalence with the original US data was investigated first using the wave 1 general population data. The analysis was subsequently repeated on the independent subset of 25 items administered to the US RA patients (19). US item parameters were obtained from a unidimensional GPCM and analysis of cross-cultural DIF was again performed with the regression analysis method outlined above (28). To examine the impact of any observed DIF, US and Dutch baseline data were jointly modeled in a unidimensional GPCM with country-specific item parameters for those items flagged for cross-cultural DIF. The resulting EAP estimates were compared to those emanating from a model without country-specific item parameters. In both models, the mean was set to zero for US respondents $(\mathrm{SD}=1)$. The agreement between the resulting latent EAP estimates was evaluated by calculating intraclass correlation coefficients (ICCs, model A,1) and the limits of agreement according to the Bland-Altman method (32). Two independent data sets were available of US RA patients. The first sample (Stanford sample) contained 14 items administered to 273 patients and the second sample (Polimetrix sample) contained 10 items administered to 280 patients. To evaluate RA-related DIF, the baseline model of Dutch RApatients was extended to incorporate these data. DIF was subsequently evaluated across three marginal distributions (Dutch, Stanford, and Polimetrix) using the LM test approach outlined above.

\section{Results}

\section{Participant characteristics}

Baseline data of 690 Dutch RA patients was available for analysis (Table 1). Of these, 489 and 311 patients completed booklets at T2 and T3, respectively. Average time between participations was 6.0 months $(\mathrm{SD}=2.5)$ for $\mathrm{T} 1$ to $\mathrm{T} 2$ and 4.1 months $(\mathrm{SD}=1.8)$ for $\mathrm{T} 2$ and $\mathrm{T} 3$. On average, Dutch patients had relatively low disease activity and high levels of physical function at baseline. Whereas 
the US general population and the combined RA samples had a balanced sex distribution, 64\% of the Dutch RA patients were female, reflecting the greater prevalence of RA among women. The average level of physical function of US general population respondents was higher than that of Dutch RA patients according to the HAQ-DI and the average age of US general population respondents was lower.

Table 2. Sample characteristics

\begin{tabular}{lccc}
\hline & $\begin{array}{c}\text { Dutch RA patients } \\
(\mathrm{N}=690)\end{array}$ & $\begin{array}{c}\text { US RA patients } \\
(\mathrm{N}=557)\end{array}$ & $\begin{array}{c}\text { US general population } \\
(\mathrm{N}=1937)\end{array}$ \\
\hline Female, N (\%) & $371(63.6 \%)$ & $293(52.6 \%)$ & $1004(51.8)$ \\
Age, M (SD) & $56.8(11.8)$ & $56.66(10.9)$ & $50.5(18.3)$ \\
DAS28, M (SD) & $2.1(1.1)$ & - & - \\
VAS General health, M (SD) & $25.1(23.6)$ & - & - \\
VAS Disease activity, M (SD) & $28.2(23.4)$ & - & - \\
VAS Fatigue, M (SD) & $33.1(29.8)$ & - & - \\
VAS Pain, M (SD) & $27.6(22.7)$ & - & $0.2(0.4)$ \\
HAQ-ADI, M (SD) & $0.5(0.6)$ & - &
\end{tabular}

\section{Evaluation of the longitudinal IRT model in the Dutch data}

Table 2 presents an overview of the LM tests and the average observed and average expected item scores across three total score level groups for the PROMIS PF items administered in the odd booklets at T1 (see Figure 1). Results were similar for the even booklets and the other time points. The items are organized according to the point on the latent scale where they provide their optimum information, as an indication of the relative difficulty of the activities they refer to. As expected, more 'easy' items referred to simple activities of daily living, such as eating or getting up from a chair, while items involving increasingly higher levels of cardiopulmonary function were clustered around the higher end of the latent metric. For most items, average observed scores were quite high considering the 1-5 rating scale of the PROMIS items, reflecting the relatively high level of physical function of the sample. Item scores expected by the IRT model tended to be close to the observed item scores across total score groups, leading to an acceptable average ES of 0.01 for time point 1.

The number of items exhibiting lack of fit was very low for all three time points. For T1, T2 and T3 respectively, only $14(3 \%), 12(3 \%)$ and $5(1 \%)$ items demonstrated misfit according to the LM test. Moreover, ESs exceeded 0.10 only for two items, both at T3 (PFA9, ES=0.10 and PFA15, ES=0.11) The item parameters were stable over time, with all correlations between threshold parameters at different time points exceeding 0.90 and all of the $99 \%$ confidence intervals intersecting the regression line in the three univariate regression analyses.

In the subsequent evaluation of the longitudinal (multidimensional) model, $6.3 \%$ of item level fit statistics showed lack of fit to the model, which corresponds approximately to the level of 
significant item tests expected based on chance. None of the items showed lack of fit in both or, in case of the HAQ-DI and PF-10 items, all booklets that it was included in, nor did any item show misfit across time points. The multidimensional IRT model provides estimates of the correlation of PF over the three different time points. The correlation between latent PF levels across the three time points ranged from 0.73 between $\mathrm{T} 1$ and $\mathrm{T} 3$ to 0.87 between $\mathrm{T} 1$ and $\mathrm{T} 2$, indicating that physical function levels were quite stable over time. The overall conclusion was that model fit was acceptable.

Table 3. Evaluation of item fit for PROMIS items in the odd booklets at time 1

Score group

Item

code

Item stem

$\begin{array}{lllll}\text { LM } & \mathrm{P} & \mathrm{ES} & 1 & 2\end{array}$

3

PFA20 Are you able to cut your food using eating 1.21 utensils?

PFB48 Does your health now limit you in taking a 0.35 shower?

PFA15 Are you able to stand up from an armless 1.13 straight chair?

PFC6 Are you able to walk a block (about $100 \mathrm{~m}$ ) on flat ground? *

PFB26 Are you able to shampoo your hair?

PFA45 Are you able to get out of bed into a chair?

PFA51 Are you able to sit on the edge of a bed?

PFA30 Are you able to step up and down curbs?

PFC47 Are you able to be out of bed most of the day?

PFB18 Are you able to shave your face or apply makeup?

PFC46 Are you able to transfer from a bed to a chair and back?

PFA40 Are you able to turn a key in a lock?

PFB16 Are you able to press with your index finger (for 2.4 example ringing a doorbell)?

PFC39 Are you able to stand without losing your 7.7 balance for several minutes? PFC51 Are you able to wipe yourself after using the
toilet?

PFA54 Are you able to button your shirt?

PFB31 Are you able to open car doors?

PFB29 Are you able to lift a full cup or glass to your mouth?

PFA50 Are you able to brush your teeth? 1.79

PFC45 Are you able to sit on and get up from the 2.88 toilet? +

PFB27 Are you able to tie a knot or a bow? 7.91

PFB20 Are you able to cut a piece of paper with 3.24 scissors?

PFA44 Are you able to put on a shirt or blouse? 5.81

PFA35 Are you able to open and close a zipper? 3.76

PFB22 Are you able to hold a plate full of food? 1.34

PFA16 Are you able to dress yourself, including tying 1.88 shoelaces and buttoning your clothes?

PFA38 Are you able to stand for short periods of time?

PFA48 Are you able to peel fruit?

PFB15 Are you able to change the bulb in a table lamp?

PFC49 Are you able to water a house plant? + 


\begin{tabular}{|c|c|c|c|c|c|c|c|c|c|c|}
\hline PFB33 & $\begin{array}{l}\text { Are you able to remove something from your } \\
\text { back pocket? }\end{array}$ & 2.95 & 0.23 & 0.03 & 3.83 & 4.05 & 4.83 & 4.78 & 4.97 & 4.98 \\
\hline PFB21 & Are you able to pick up coins from a table top? & 0.68 & 0.71 & 0.02 & 3.97 & 3.89 & 4.63 & 4.57 & 4.89 & 4.92 \\
\hline PFB10 & Are you able to climb up five steps? & 0.12 & 0.94 & 0.01 & 3.76 & 3.81 & 4.66 & 4.64 & 5.00 & 4.97 \\
\hline PFB19 & $\begin{array}{l}\text { Are you able to squeeze a new tube of } \\
\text { toothpaste? }\end{array}$ & 0.49 & 0.78 & 0.01 & 4.18 & 4.10 & 4.84 & 4.85 & 5.00 & 4.98 \\
\hline PFB36 & Are you able to put on a pullover sweater? & 0.73 & 0.70 & 0.01 & 4.17 & 4.09 & 4.76 & 4.80 & 4.95 & 4.96 \\
\hline PFC29 & Are you able to walk up and down two steps? & 0.97 & 0.61 & 0.02 & 3.89 & 3.77 & 4.59 & 4.71 & 4.92 & 4.91 \\
\hline PFA56 & Are you able to get in and out of a car? & 0.24 & 0.89 & 0.01 & 3.89 & 3.89 & 4.55 & 4.51 & 4.95 & 4.95 \\
\hline PFA36 & $\begin{array}{l}\text { Are you able to put on and take off a coat or } \\
\text { jacket? } \dagger\end{array}$ & 1.51 & 0.47 & 0.02 & 3.74 & 3.83 & 4.58 & 4.50 & 4.98 & 4.95 \\
\hline PFA32 & $\begin{array}{l}\text { Are you able to stand with your knees } \\
\text { straight? }\end{array}$ & 2.44 & 0.30 & 0.02 & 4.20 & 4.10 & 4.90 & 4.84 & 5.00 & 4.99 \\
\hline PFA43 & Are you able to write with a pen or pencil? & 0.32 & 0.85 & 0.01 & 3.89 & 3.85 & 4.71 & 4.67 & 4.97 & 4.97 \\
\hline PFB49 & $\begin{array}{l}\text { Does your health now limit you in going for a } \\
\text { short walk (less than } 15 \text { minutes)? }\end{array}$ & 0.03 & 0.98 & 0.01 & 3.34 & 3.32 & 4.24 & 4.26 & 4.86 & 4.88 \\
\hline PFA22 & Are you able to open previously opened jars? & 1.09 & 0.58 & 0.01 & 3.78 & 3.68 & 4.49 & 4.50 & 4.88 & 4.88 \\
\hline PFB25 & $\begin{array}{l}\text { Are you able to push open a door after turning } \\
\text { the knob? }\end{array}$ & 1.65 & 0.44 & 0.02 & 4.42 & 4.32 & 4.82 & 4.87 & 5.00 & 4.98 \\
\hline PFB41 & Are you able to trim your fingernails? & 3.30 & 0.19 & 0.03 & 4.03 & 3.81 & 4.67 & 4.72 & 4.92 & 4.96 \\
\hline PFB23 & $\begin{array}{l}\text { Are you able to pour liquid from a bottle into a } \\
\text { glass? }\end{array}$ & 1.40 & 0.50 & 0.01 & 4.43 & 4.40 & 4.84 & 4.91 & 5.00 & 4.99 \\
\hline PFA52 & Are you able to tie your shoelaces? & 4.11 & 0.13 & 0.02 & 3.48 & 3.58 & 4.64 & 4.49 & 4.98 & 4.95 \\
\hline PFA49 & Are you able to bend or twist your back? * & 0.29 & 0.86 & 0.01 & 3.77 & 3.84 & 4.52 & 4.55 & 4.91 & 4.93 \\
\hline PFB3 & $\begin{array}{l}\text { Does your health now limit you in putting a } \\
\text { trash bag outside? } \dagger\end{array}$ & 2.27 & 0.32 & 0.03 & 3.19 & 3.08 & 3.82 & 3.97 & 4.82 & 4.88 \\
\hline PFA9 & $\begin{array}{l}\text { Are you able to bend down and pick up clothing } \\
\text { from the floor? }\end{array}$ & 1.13 & 0.57 & 0.02 & 3.85 & 3.72 & 4.55 & 4.54 & 4.90 & 4.94 \\
\hline PFA37 & Are you able to stand for short periods of time? & 2.04 & 0.36 & 0.02 & 4.00 & 3.88 & 4.74 & 4.66 & 5.00 & 4.95 \\
\hline PFA17 & Are you able to reach into a high cupboard? & 1.98 & 0.37 & 0.02 & 3.31 & 3.24 & 4.34 & 4.22 & 4.89 & 4.88 \\
\hline PFB43 & $\begin{array}{l}\text { Does your health now limit you in taking care } \\
\text { of your personal needs (dress, comb hair, toilet, } \\
\text { eat, bathe)? }\end{array}$ & 0.09 & 0.95 & 0.01 & 3.63 & 3.59 & 4.42 & 4.42 & 4.92 & 4.95 \\
\hline PFC31 & Are you able to reach into a low cupboard? & 0.64 & .73 & 0.01 & 3.43 & 3.44 & 4.50 & 4.39 & 4.92 & 4.91 \\
\hline PFB11 & $\begin{array}{l}\text { Are you able to wash dishes, pots, and utensils } \\
\text { by hand while standing at a sink? }\end{array}$ & 0.13 & 0.94 & 0.01 & 3.88 & 3.88 & 4.71 & 4.67 & 4.97 & 4.97 \\
\hline PFA18 & Are you able to use a hammer to pound a nail? & 0.10 & .95 & 0.01 & .45 & 3.43 & 4.58 & 4.60 & 4.92 & 4.94 \\
\hline PFB37 & Are you able to turn faucets on and off? & 0.67 & 0.72 & 0.01 & 80 & 3.78 & 4.78 & 4.73 & 4.92 & 4.96 \\
\hline PFB56 & $\begin{array}{l}\text { Are you able to lift one pound }(0.5 \mathrm{~kg}) \text { to } \\
\text { shoulder level without bending your elbow? }\end{array}$ & 0.47 & 0.79 & 0.01 & 3.47 & 3.47 & 4.68 & 4.62 & 4.92 & 4.93 \\
\hline PFC43 & $\begin{array}{l}\text { Are you able to use your hands, such as for } \\
\text { turning faucets, using kitchen gadgets, or } \\
\text { sewing? } \dagger\end{array}$ & 0.80 & 0.67 & 0.02 & 3.44 & 3.54 & 4.21 & 4.26 & 4.83 & 4.88 \\
\hline PFC52 & Are you able to turn from side to side in bed? & 2.25 & 0.32 & 0.02 & 3.45 & 3.59 & 4.63 & 4.55 & 4.90 & 4.95 \\
\hline PFB32 & $\begin{array}{l}\text { Are you able to stand unsupported for } 10 \\
\text { minutes? }\end{array}$ & 1.17 & 0.56 & 0.03 & 3.34 & 3.50 & 4.50 & 4.38 & 4.95 & 4.87 \\
\hline PFA53 & Are you able to run errands and shop? & 0.96 & 0.62 & 0.02 & .39 & 3.28 & 4.37 & 4.32 & 4.92 & 4.95 \\
\hline PFB17 & Are you able to put on and take off your socks? & 0.96 & 0.62 & 0.01 & 3.87 & 3.76 & 4.71 & 4.70 & 4.97 & 4.96 \\
\hline PFA28 & $\begin{array}{l}\text { Are you able to open a can with a hand can } \\
\text { opener? }\end{array}$ & 2.45 & 0.29 & 0.02 & 3.19 & 3.09 & 4.15 & 4.30 & 4.85 & 4.84 \\
\hline PFA21 & $\begin{array}{l}\text { Are you able to go up and down stairs at a } \\
\text { normal pace? } *\end{array}$ & 0.55 & 0.76 & 0.02 & 3.17 & 3.22 & 4.21 & 4.14 & 4.83 & 4.88 \\
\hline PFB13 & $\begin{array}{l}\text { Are you able to carry a shopping bag or } \\
\text { briefcase? } \dagger\end{array}$ & 0.06 & 0.97 & $<0.01$ & 3.30 & 3.31 & 4.12 & 4.14 & 4.91 & 4.90 \\
\hline PFA34 & Are you able to wash your back? & 2.38 & 0 & 2 & .15 & 3.13 & 4.37 & 4.22 & 4.80 & 4.85 \\
\hline PFC41 & $\begin{array}{l}\text { Are you able to sit down in and stand up from } \\
\text { a low, soft couch? }\end{array}$ & 3.48 & 0.18 & 0.03 & 2.89 & 3.11 & 4.06 & 3.93 & 4.73 & 4.70 \\
\hline PFC38 & Are you able to walk at a normal speed? & 0.09 & 95 & 0.01 & 3.23 & 3.17 & 4.31 & 4.31 & 4.91 & 4.91 \\
\hline PFB40 & Are you able to stand up on tiptoes? & 0.14 & 0.93 & 0.01 & 3.24 & 3.20 & 4.50 & 4.47 & 4.89 & 4.85 \\
\hline PFA25 & $\begin{array}{l}\text { Are you able to do yard work like raking } \\
\text { leaves, weeding, or pushing a lawn mower? } \\
*\end{array}$ & 0.68 & 0.71 & 0.02 & 2.79 & 2.69 & 3.58 & 3.55 & 4.68 & 4.65 \\
\hline PFA29 & $\begin{array}{l}\text { Are you able to pull heavy objects }(10 \\
\text { pounds } / 5 \mathrm{~kg}) \text { towards yourself? } \dagger\end{array}$ & 0.46 & 0.79 & 0.01 & 2.74 & 2.74 & 3.74 & 3.68 & 4.77 & 4.70 \\
\hline PFA47 & Are you able to pull on trousers? $†$ & 0.96 & 0.62 & 0.01 & 3.95 & 3.88 & 4.78 & 4.81 & 5.00 & 5.00 \\
\hline PFC56 & $\begin{array}{l}\text { Does your health now limit you in walking } \\
\text { about the house? }\end{array}$ & 2.21 & 0.33 & 0.02 & 3.54 & 3.78 & 4.56 & 4.54 & 4.95 & 4.96 \\
\hline PFA12 & Are you able to push open a heavy door? $\dagger$ & 0.59 & 0.75 & 0.01 & 2.97 & 2.89 & 4.03 & 4.06 & 4.79 & 4.79 \\
\hline
\end{tabular}




\begin{tabular}{|c|c|c|c|c|c|c|c|c|c|c|}
\hline PFA8 & $\begin{array}{l}\text { Are you able to move a chair from one room to } \\
\text { another? }\end{array}$ & 1.83 & 0.40 & 0.02 & 2.84 & 3.03 & 4.37 & 4.35 & 4.95 & 4.90 \\
\hline PFB54 & $\begin{array}{l}\text { Does your health now limit you in going } \\
\text { OUTSIDE the home, for example to shop or } \\
\text { visit a doctor's office? }\end{array}$ & 0.16 & 0.92 & 0.01 & 3.73 & 3.76 & 4.79 & 4.77 & 5.00 & 4.97 \\
\hline PFC32 & $\begin{array}{l}\text { Are you able to climb up } 5 \text { flights of stairs? } \\
*\end{array}$ & 0.39 & 0.82 & 0.02 & 3.08 & 3.15 & 4.20 & 4.27 & 4.80 & 4.84 \\
\hline PFA42 & $\begin{array}{l}\text { Are you able to carry a laundry basket up a } \\
\text { flight of stairs? * }\end{array}$ & 4.66 & 0.10 & 0.04 & 2.74 & 2.71 & 3.70 & 3.99 & 4.91 & 4.81 \\
\hline PFB39 & $\begin{array}{l}\text { Are you able to reach and get down a } 5 \text { pound } \\
(2 \mathrm{~kg}) \text { object from above your head? }\end{array}$ & 2.72 & 0.26 & 0.04 & 2.34 & 2.59 & 3.57 & 3.62 & 4.51 & 4.65 \\
\hline PFA23 & $\begin{array}{l}\text { Are you able to go for a walk of at least } 15 \\
\text { minutes? }\end{array}$ & 0.52 & 0.77 & 0.02 & 3.41 & 3.28 & 4.37 & 4.36 & 4.92 & 4.90 \\
\hline PFA11 & $\begin{array}{l}\text { Are you able to do chores such as vacuuming or } \\
\text { yard work? }\end{array}$ & 0.57 & 0.75 & 0.02 & 2.94 & 2.88 & 3.71 & 3.79 & 4.83 & 4.70 \\
\hline PFB34 & Are you able to change a light bulb overhead? & 0.29 & 0.86 & 0.01 & 2.89 & 2.88 & 4.18 & 4.25 & 4.85 & 4.84 \\
\hline PFA6 & $\begin{array}{l}\text { Does your health now limit you in bathing or } \\
\text { dressing yourself? }\end{array}$ & 0.32 & 0.85 & 0.01 & 3.43 & 3.48 & 4.34 & 4.33 & 4.93 & 4.95 \\
\hline PFA55 & Are you able to wash and dry your body? $\dagger$ & 2.31 & 0.31 & 0.01 & 3.62 & 3.62 & 4.56 & 4.70 & 5.00 & 4.99 \\
\hline PFB14 & Are you able to take a tub bath? & 2.53 & 0.28 & 0.04 & 3.25 & 2.96 & 4.38 & 4.48 & 4.97 & 4.87 \\
\hline PFB12 & $\begin{array}{l}\text { Are you able to make a bed, including spreading } \\
\text { and tucking in bed sheets? }\end{array}$ & 2.42 & 0.30 & 0.03 & 2.69 & 2.84 & 4.03 & 4.17 & 4.92 & 4.82 \\
\hline PFA14 & $\begin{array}{l}\text { Are you able to carry a heavy object (over } 10 \\
\text { pounds } / 5 \mathrm{~kg} \text { )? }\end{array}$ & 0.27 & 0.88 & 0.01 & 2.72 & 2.65 & 3.63 & 3.62 & 4.64 & 4.59 \\
\hline PFA31 & $\begin{array}{l}\text { Are you able to get up from the floor from lying } \\
\text { on your back without help? }\end{array}$ & 1.52 & 0.47 & 0.03 & 2.88 & 2.70 & 3.61 & 3.66 & 4.78 & 4.70 \\
\hline PFC40 & Are you able to kneel on the floor? & 1.60 & 0.45 & 0.03 & 2.54 & 2.50 & 3.37 & 3.62 & 4.60 & 4.56 \\
\hline PFB42 & $\begin{array}{l}\text { Are you able to stand unsupported for } 30 \\
\text { minutes? }\end{array}$ & 0.65 & 0.72 & 0.02 & 2.69 & 2.59 & 3.91 & 3.79 & 4.71 & 4.70 \\
\hline PFC37 & $\begin{array}{l}\text { Does your health now limit you in climbing } \\
\text { one flight of stairs? } *\end{array}$ & 0.49 & 0.78 & 0.01 & 3.18 & 3.25 & 4.35 & 4.40 & 4.90 & 4.93 \\
\hline PFB28 & $\begin{array}{l}\text { Are you able to lift } 10 \text { pounds }(5 \mathrm{~kg}) \text { above } \\
\text { your shoulder? }\end{array}$ & 6.43 & 0.04 & 0.05 & 2.68 & 2.26 & 3.59 & 3.69 & 4.69 & 4.65 \\
\hline PFC54 & $\begin{array}{l}\text { Does your health now limit you in getting in and } \\
\text { out of the bathtub? }\end{array}$ & 7.25 & 0.03 & 0.05 & 3.05 & 2.66 & 3.65 & 3.70 & 4.91 & 4.81 \\
\hline PFB8 & $\begin{array}{l}\text { Are you able to carry two bags filled with } \\
\text { groceries } 100 \text { yards }(100 \mathrm{~m}) \text { ? }\end{array}$ & 3.58 & 0.17 & 0.04 & 2.15 & 2.05 & 3.43 & 3.08 & 4.44 & 4.41 \\
\hline PFA41 & Are you able to squat and get up? & 0.93 & 0.63 & 0.02 & 2.79 & 2.66 & 3.65 & 3.61 & 4.67 & 4.62 \\
\hline PFA10 & and for one hour? & 2.83 & 0.24 & 0.04 & 2.43 & 2.36 & 3.74 & 3.49 & 4.69 & 4.49 \\
\hline PFB9 & Are you able to jump up and down? & 0.58 & 0.75 & 0.02 & 2.62 & 2.51 & 4.16 & 4.10 & 4.85 & 4.80 \\
\hline PFA5 & $\begin{array}{l}\text { Does your health now limit you in lifting or } \\
\text { carrying groceries? }\end{array}$ & 1.22 & 0.54 & 0.02 & 2.45 & 2.55 & 3.43 & 3.32 & 4.51 & 4.53 \\
\hline PFA13 & Are you able to exercise for an hour? & 4.52 & 0.10 & 0.04 & 2.33 & 2.40 & 3.58 & 3.25 & 4.44 & 4.35 \\
\hline PFB24 & $\begin{array}{l}\text { Are you able to run a short distance, such as to } \\
\text { catch a bus? }\end{array}$ & 0.83 & 0.66 & 0.02 & 2.39 & 2.34 & 3.63 & 3.76 & 4.67 & 4.65 \\
\hline PFC10 & $\begin{array}{l}\text { Does your health now limit you in climbing } \\
\text { several flights of stairs? * }\end{array}$ & 3.02 & 0.22 & 0.04 & 3.22 & 2.96 & 4.14 & 4.19 & 4.95 & 4.84 \\
\hline PFC36 & $\begin{array}{l}\text { Does your health now limit you in walking more } \\
\text { than a mile }(1.6 \mathrm{~km}) \text { ? }\end{array}$ & 0.76 & 0.68 & 0.02 & 2.77 & 2.77 & 4.27 & 4.14 & 4.73 & 4.81 \\
\hline PFB1 & $\begin{array}{l}\text { Does your health now limit you in doing } \\
\text { moderate work around the house like } \\
\text { vacuuming, sweeping floors or carrying in } \\
\text { groceries? }\end{array}$ & 2.15 & 0.34 & 0.03 & 2.35 & 2.42 & 3.43 & 3.25 & 4.50 & 4.57 \\
\hline PFB50 & $\begin{array}{l}\text { How much difficulty do you have doing your } \\
\text { daily physical activities, because of your health? }\end{array}$ & 0.51 & 0.78 & 0.01 & 2.74 & 2.76 & 3.59 & 3.52 & 4.56 & 4.59 \\
\hline PFB44 & $\begin{array}{l}\text { Does your health now limit you in doing } \\
\text { moderate activities, such as moving a table, } \\
\text { pushing a vacuum cleaner, bowling, or playing } \\
\text { golf? }\end{array}$ & 0.75 & 0.69 & 0.02 & 2.32 & 2.34 & 3.20 & 3.08 & 4.47 & 4.43 \\
\hline FA33 & Are you able to exercise hard for half an hour? & 2.8 & .24 & ${ }^{2}$ & 2.06 & 2.24 & 3.36 & 3.56 & 4.51 & 4.54 \\
\hline PFA3 & $\begin{array}{l}\text { Does your health now limit you in bending, } \\
\text { kneeling, or stooping? }\end{array}$ & 0.03 & 0.99 & 0.01 & 2.54 & 2.52 & 3.53 & 3.52 & 4.51 & 4.53 \\
\hline PFC13 & 100 vards $(100 \mathrm{~m})^{2}$ & 4.6 & 0.10 & 0. & 1.89 & 1.89 & 3.08 & 3.52 & 4.50 & 4.55 \\
\hline PFB5 & $\begin{array}{l}\text { Does your health now limit you in hiking a } \\
\text { couple of miles }(3 \mathrm{~km}) \text { on uneven surfaces, } \\
\text { including hills? } *\end{array}$ & 0.73 & 0.69 & 0.02 & 1.89 & 1.99 & 3.32 & 3.37 & 4.59 & 4.62 \\
\hline PFC12 & $\begin{array}{l}\text { Does your health now limit you in doing two } \\
\text { hours of physical labor? }\end{array}$ & 3.49 & 0.18 & 0.04 & 2.68 & 2.61 & 3.02 & 3.22 & 4.23 & 4.43 \\
\hline
\end{tabular}




\begin{tabular}{|c|c|c|c|c|c|c|c|c|c|c|}
\hline PFC35 & $\begin{array}{l}\text { Does your health now limit you in doing eight } \\
\text { hours of physical labor? }\end{array}$ & 4.17 & 0.12 & 0.04 & 1.33 & 1.52 & 2.50 & 2.62 & 4.03 & 4.15 \\
\hline PFA4 & $\begin{array}{l}\text { Does your health now limit you in doing } \\
\text { heavy work around the house like scrubbing } \\
\text { floors, or lifting or moving heavy furniture? } \\
*\end{array}$ & 0.11 & 0.95 & 0.01 & 1.59 & 1.58 & 2.47 & 2.51 & 4.23 & 4.13 \\
\hline PFB51 & $\begin{array}{l}\text { Does your health now limit you in participating } \\
\text { in active sports such as swimming, tennis, or } \\
\text { basketball? }\end{array}$ & 3.41 & 0.18 & 0.05 & 2.23 & 2.01 & 2.45 & 2.64 & 4.02 & 3.85 \\
\hline PFA1 & $\begin{array}{l}\text { Does your health now limit you in doing } \\
\text { vigorous activities, such as running, lifting } \\
\text { heavy objects, participating in strenuous } \\
\text { sports? * }\end{array}$ & 1.48 & 0.48 & 0.04 & 1.56 & 1.44 & 1.95 & 2.05 & 3.69 & 3.47 \\
\hline PFB7 & $\begin{array}{l}\text { Does your health now limit you in doing } \\
\text { strenuous activities such as backpacking, skiing, } \\
\text { playing tennis, bicycling or jogging? }\end{array}$ & 2.27 & 0.32 & 0.05 & 1.46 & 1.60 & 2.00 & 1.96 & 3.65 & 3.30 \\
\hline PFA19 & Are you able to run or jog for two miles $(3 \mathrm{~km})$ ? & 2.12 & 0.35 & 0.02 & 1.29 & 1.26 & 1.25 & 1.40 & 2.59 & 2.57 \\
\hline PFA39 & $\begin{array}{l}\text { Are you able to run at a fast pace for two miles } \\
(3 \mathrm{~km}) \text { ? }\end{array}$ & 3.27 & 0.19 & 0.03 & 1.25 & 1.35 & 1.45 & 1.60 & 2.51 & 2.60 \\
\hline FC7 & Are you able to run five miles $(8 \mathrm{~km})$ & 2.16 & 0.34 & 0.03 & 1.1 & 1.14 & 1.23 & 1.38 & 2.67 & 2.49 \\
\hline CC33 & miles $(16 \mathrm{~km})$ ? & 99.00 & 1.00 & 0.02 & 1.09 & 1.07 & 1.00 & 1.06 & 1.59 & 1.46 \\
\hline PFB30 & Are you able to open a new milk carton? $\dagger$ & 1.07 & 0.58 & 0.02 & 2.85 & 3.01 & 3.97 & 3.93 & 4.71 & 4.75 \\
\hline
\end{tabular}

$\mathrm{LM}=$ Lagrange multiplier statistic; ES= Effect size statistic; Obs = Average observed item score; Exp = Average expected item score; Items flagged for cross-cultural DIF are presented in bold. *Activity is relatively more difficult to perform for the US general population sample; †Activity is relatively more easy to perform for US general population sample.

\section{DIF across age and gender}

Seven items demonstrated DIF for sex, while five items showed DIF for age in the Dutch RA sample at baseline (Table 3). For all items flagged for sex DIF, men reported slightly higher scores than expected by the IRT model, whereas women reported lower scores than expected, indicating that the activities were easier for male RA patients. Likewise, all items flagged for age DIF, except item PFA53 ('Are you able to run errands and shop?') were more easily endorsed by younger rather than older patients.

Table 4. Differential item functioning (DIF) across age and sex in the Dutch RA sample

\begin{tabular}{|c|c|c|c|c|c|c|c|c|}
\hline $\begin{array}{l}\text { Item } \\
\text { code }\end{array}$ & Item stem & LM & P & ES & Obs & Exp & Obs & Exp \\
\hline Sex & & & & & \multicolumn{2}{|c|}{ Female } & \multicolumn{2}{|c|}{ Male } \\
\hline PFB28 & Are you able to lift 10 pounds $(5 \mathrm{~kg}$ ) above your shoulder? & 13.60 & $<0.01$ & 0.31 & 3.10 & 3.39 & 4.09 & 3.74 \\
\hline PFA12 & Are you able to push open a heavy door? & 8.38 & $<0.01$ & 0.19 & 3.60 & 3.76 & 4.29 & 4.06 \\
\hline PFA14 & $\begin{array}{l}\text { Are you able to carry a heavy object (over } 10 \text { pounds } / 5 \mathrm{~kg} \text { )? } \\
\text { Are you able to reach and get down a } 5 \text { pound }(2 \mathrm{~kg}) \text { object }\end{array}$ & 9.56 & $<0.01$ & 0.28 & 3.37 & 3.56 & 4.17 & 3.81 \\
\hline PFB39 & from above your head? & 5.51 & 0.02 & 0.20 & 3.45 & 3.64 & 4.07 & 3.84 \\
\hline PFB14 & Are you able to take a tub bath? & 4.53 & 0.03 & 0.16 & 3.89 & 4.08 & 4.35 & 4.22 \\
\hline PFC45 & $\begin{array}{l}\text { Are you able to sit on and get up from the toilet? } \\
\text { Are you able to pull heavy objects ( } 10 \text { pounds } / 5 \mathrm{~kg}) \text { towards }\end{array}$ & 5.00 & 0.03 & 0.10 & 4.64 & 4.56 & 4.61 & 4.72 \\
\hline $\begin{array}{l}\text { PFA29 } \\
\text { Age }\end{array}$ & yourself? & 4.32 & 0.04 & 0.18 & $\begin{array}{r}3.54 \\
\mathrm{O}\end{array}$ & $\begin{array}{l}3.66 \\
\text { ler }\end{array}$ & $\begin{array}{l}4.16 \\
\text { You }\end{array}$ & $\begin{array}{l}3.92 \\
\text { ger }\end{array}$ \\
\hline PFC13 & Are you able to run 100 yards $(100 \mathrm{~m})$ ? & 10.42 & $<0.01$ & 0.25 & 2.93 & 3.27 & 3.64 & 3.45 \\
\hline PFC35 & $\begin{array}{l}\text { Does your health now limit you in doing eight hours of physical } \\
\text { labor? }\end{array}$ & 6.32 & 0.01 & 0.22 & 2.37 & 2.60 & 3.01 & 2.79 \\
\hline PFC12 & $\begin{array}{l}\text { Does your health now limit you in doing two hours of physical } \\
\text { labor? }\end{array}$ & 5.07 & 0.02 & 0.14 & 3.25 & 3.42 & 3.62 & 3.50 \\
\hline PFA53 & Are you able to run errands and shop? & 5.84 & 0.02 & 0.11 & 4.30 & 4.16 & 4.21 & 4.29 \\
\hline PFA4 & $\begin{array}{l}\text { Does your health now limit you in doing heavy work around } \\
\text { the house like scrubbing floors, or lifting or moving heavy } \\
\text { furniture? }\end{array}$ & 4.45 & 0.03 & 0.14 & 2.46 & 2.60 & 3.01 & 2.87 \\
\hline
\end{tabular}

$\overline{\mathrm{LM}}=$ Lagrange multiplier statistic; ES= Effect size statistic; Obs = Average observed item score; Exp = Average expected item score 


\section{Equivalence with PROMIS wave 1 data.}

To evaluate measurement equivalence, US item parameters were obtained and compared with the Dutch item parameters using the regression analysis approach. Twenty-five items showed at least some level of uniform DIF in the regression analysis. For 11 of these items, Dutch patients were more likely to endorse lower response options according to the item response curves, indicating that these activities were relatively more difficult for them compared to the US general population. All these items involved the use of the hand or arms (see Table 2). Twelve items were more difficult for US respondents, of which five involved climbing stairs. Consequently, all items referring to climbing stairs were more precise at lower levels of overall physical function in the Dutch RA patients, whereas items involving dexterity tended to have better measurement precision at higher levels of function, as illustrated by two typical item information curves in Figure 2.

In the analysis of cross-cultural DIF in Dutch and US RA patients, the mean was set to zero for the Polimetrix sample and the latent means of the Dutch and Stanford sample were respectively -0.07 and 0.09 , indicating that physical function levels were comparable between the samples. Seven out of 24 items showed significant DIF in the analysis (table 4).

Table 4: Differential item functioning (DIF) across Dutch and US RA patients.

\begin{tabular}{|c|c|c|c|c|c|c|c|c|}
\hline & & LM & $\mathrm{P}$ & ES & $\begin{array}{l}\text { OBS } \\
\text { Dutch }\end{array}$ & EXP & $\begin{array}{l}\text { OBS } \\
\text { US }\end{array}$ & EXP \\
\hline PFB27 & Are you able to tie a knot or a bow? & 7.49 & 0.01 & 0.11 & 4.37 & 4.49 & 4.72 & 4.62 \\
\hline PFB20 & Are you able to cut a piece of paper with scissors? & 2.55 & 0.11 & 0.05 & 4.58 & 4.63 & 4.83 & 4.78 \\
\hline PFA17 & Are you able to reach into a high cupboard? & 1.07 & 0.30 & 0.04 & 4.13 & 4.17 & 4.49 & 4.46 \\
\hline PFB16 & $\begin{array}{l}\text { Are you able to press with your index finger (for example } \\
\text { ringing a doorbell)? }\end{array}$ & 0.30 & 0.58 & 0.02 & 4.75 & 4.76 & 4.89 & 4.87 \\
\hline PFA19 & Are you able to run or jog for two miles $(3 \mathrm{~km})$ ? & 3.67 & 0.06 & 0.07 & 1.74 & 1.85 & 2.03 & 2.01 \\
\hline PFB21 & Are you able to pick up coins from a table top? & 0.41 & 0.52 & 0.03 & 4.49 & 4.52 & 4.73 & 4.71 \\
\hline PFA23 & Are you able to go for a walk of at least 15 minutes? & 12.71 & $<0.01$ & 0.19 & 4.21 & 3.98 & 4.05 & 4.20 \\
\hline PFA22 & Are you able to open previously opened jars? & 5.39 & 0.02 & 0.09 & 4.35 & 4.44 & 4.56 & 4.48 \\
\hline PFB25 & Are you able to push open a door after turning the knob? & $<0.01$ & 0.95 & $<0.01$ & 4.71 & 4.71 & 4.75 & 4.74 \\
\hline PFB17 & Are you able to put on and take off your socks? & 0.36 & 0.55 & 0.02 & 4.45 & 4.47 & 4.62 & 4.60 \\
\hline PFB19 & Are you able to squeeze a new tube of toothpaste? & 4.41 & 0.04 & 0.07 & 4.63 & 4.70 & 4.86 & 4.80 \\
\hline PFB22 & Are you able to hold a plate full of food? & 1.32 & 0.25 & 0.04 & 4.57 & 4.61 & 4.69 & 4.65 \\
\hline PFA28 & Are you able to open a can with a hand can opener? & 7.23 & 0.01 & 0.13 & 4.05 & 4.19 & 4.35 & 4.24 \\
\hline PFB24 & $\begin{array}{l}\text { Are you able to run a short distance, such as to catch a } \\
\text { bus? }\end{array}$ & 4.97 & 0.03 & 0.13 & 3.53 & 3.40 & 3.30 & 3.42 \\
\hline PFA18 & Are you able to use a hammer to pound a nail? & 2.04 & 0.15 & 0.06 & 4.28 & 4.35 & 4.58 & 4.53 \\
\hline PFA16 & $\begin{array}{l}\text { Are you able to dress yourself, including tying shoelaces } \\
\text { and buttoning your clothes? }\end{array}$ & 1.49 & 0.22 & 0.03 & 4.41 & 4.45 & 4.59 & 4.56 \\
\hline PFA20 & Are you able to cut your food using eating utensils? & 8.65 & $<0.01$ & 0.10 & 4.51 & 4.62 & 4.81 & 4.73 \\
\hline PFB23 & Are you able to pour liquid from a bottle into a glass? & 0.06 & 0.80 & 0.01 & 4.74 & 4.74 & 4.75 & 4.76 \\
\hline PFA21 & Are you able to go up and down stairs at a normal pace? & 30.32 & $<0.01$ & 0.24 & 4.12 & 3.87 & 3.89 & 4.12 \\
\hline PFA25 & $\begin{array}{l}\text { Are you able to do yard work like raking leaves, weeding, } \\
\text { or pushing a lawn mower? }\end{array}$ & 7.77 & 0.01 & 0.12 & 3.67 & 3.55 & 3.53 & 3.64 \\
\hline PFB26 & Are you able to shampoo your hair? & 1.89 & 0.17 & 0.04 & 4.64 & 4.68 & 4.78 & 4.75 \\
\hline PFA15 & Are you able to stand up from an armless straight chair? & 35.86 & $<0.01$ & 0.19 & 4.51 & 4.31 & 4.32 & 4.50 \\
\hline PFB15 & Are you able to change the bulb in a table lamp? & 1.44 & 0.23 & 0.04 & 4.62 & 4.66 & 4.83 & 4.79 \\
\hline PFB18 & Are you able to shave your face or apply makeup? & 0.95 & 0.33 & 0.03 & 4.72 & 4.75 & 4.88 & 4.85 \\
\hline
\end{tabular}

$\mathrm{LM}=$ Lagrange multiplier statistic; ES= Effect size statistic; Obs = Average observed item score; Exp = Average expected item score 


\section{Impact of cross-cultural DIF}

In the joint calibration of the Dutch RA data and the US general population data, with countryspecific item parameters for the 25 DIF items, the mean of the latent physical function scores was set to $0(\mathrm{SD}=1)$ for the US sample and the mean for Dutch RA patients was -1.18 (SD=1.21), illustrating the considerably lower level of physical function of the Dutch RA patients. This estimate was very close to that observed in the original model without country-specific item parameters $(M=-1.01, S D=1.08)$, suggesting that the observed item DIF had little impact influence on the average total estimate obtained from all administered items. Moreover, agreement between total estimates was high $(\mathrm{ICC}=0.99)$ and the limits of agreement were narrow, ranging from -0.23 to 0.25 in the Dutch data and from -0.20 to 0.18 in the US data.

Figure 2: Country specific local measurement precision of two culturally biased items.

PFC32: Are you able to climb up 5 flights of stairs?

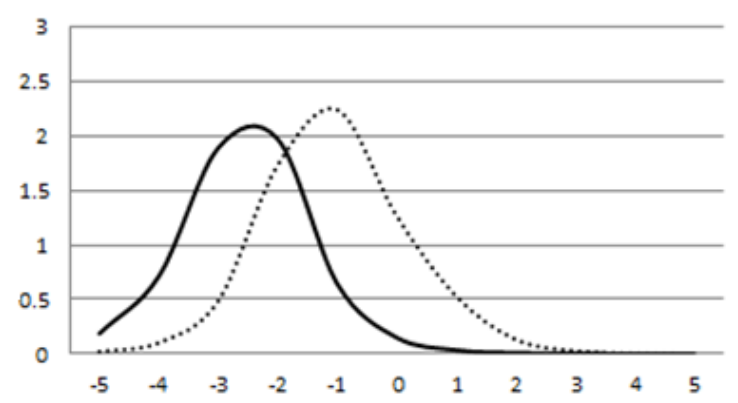

PFA28: Are you able to open a can with a hand can opener?

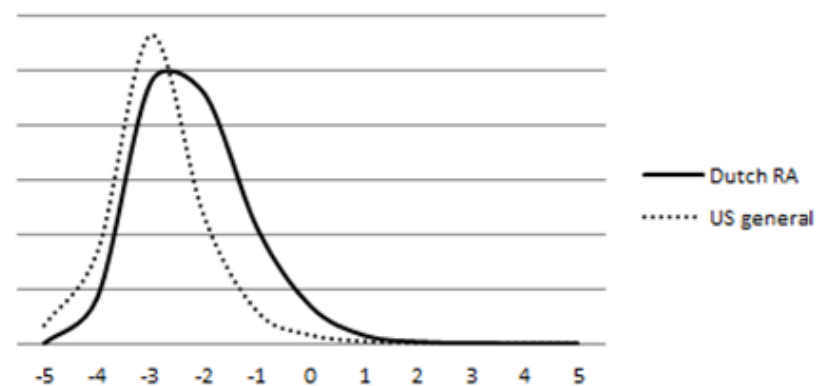

\section{Discussion}

This study presents the preliminary calibration and cross-cultural evaluation of the Dutch-Flemish translation of the PROMIS physical function (PF) item bank for Dutch patients with RA. The findings of the study indicate that the PROMIS PF item bank is a promising tool for applications such as CAT and tailored short forms in RA patients. However, some concerns remain regarding its cross-cultural measurement equivalence. Using the US-based standardized PROMIS calibration and metric requires further study.

The first principal finding of the current study was that the item bank could be successfully calibrated in a sample of Dutch patients with RA using an appropriate IRT model. To our knowledge, this is the first study to actually demonstrate that the full PROMIS PF item bank can be fitted to an appropriate IRT model in an RA sample. Therefore the current study provides support for the validity of applications of the item bank that require invariant estimates of the item and person parameters, such as CAT or short forms using a metric specific to Dutch patients with RA. 
As a general rule, the stability of item parameters increases with more data. In that sense, the item parameters obtained in the current study should be considered preliminary and data that will be collected in future studies with the item bank in Dutch RA patients can be used to update the calibrations. Several ongoing studies in the Netherlands are evaluating the item bank in other patient groups. Future studies should evaluate the equivalence of the resulting item parameters across conditions to evaluate whether a common Dutch metric can be created.

The second principal finding of the study was that 25 of the PROMIS items (20\%) showed substantial cross-cultural uniform DIF. The relatively high number of DIF items was not unexpected given that many items assess similar content (e.g. climbing stairs). Moreover, similar percentages of items with cross-cultural DIF are generally identified in scales with fewer items $(30,33)$. Interestingly, all the PROMIS physical function item bank items that involve climbing stairs were more difficult for the US general population sample, compared to Dutch RA patients. This replicates findings in an earlier study we performed on the cross-cultural equivalence of HAQII in US and Dutch RA patients (30). One speculative explanation for this repeated finding could be that Europeans are more accustomed to climbing stairs, since stairs are more prevalent in Europe, both in domestic and communal settings. However the US and Dutch sample might have also differed on key variables that might explain the observed DIF. For example body mass index has been linked to stair climbing in previous studies (34). It would be interesting for future studies to evaluate the presence of body mass index related DIF in the PROMIS physical function items. By contrast, most items that were found to be more difficult for Dutch RA patients refer to activities involving the hands or the arms. This was not a surprising result, considering that disability of particularly the hands is a well-known clinical feature in RA. In fact, we had anticipated to find more DIF items between RA and the general population sample for items measuring dexterity. However, it should be noted that DREAM registry includes patients upon diagnosis with very early RA and these patients are treated aggressively. This is reflected in the average level of disease activity being below the commonly used DAS28 remission criterion of 2.6 and the low levels of disability observed, compared with international benchmarks in RA $(35,36)$. Therefore, typical manifestations of RA-related disability may have been absent for many patients in the current study. Moreover, all items with collapsed response options involved measuring disability of the hands and these items showed severe distributional problems, even in the Dutch RA data with very few patients endorsing the lower response options. These two factors limit the sensitivity of the analyses with respect to RA-related DIF, and therefore studies in RA populations with more pronounced disease are desirable. 
The results of the DIF analyses suggest that the Dutch RA data is not strictly equivalent to US general population data at the level of individual items, which was also observed in a previous study evaluating a Spanish language version of the item bank (37). A limitation of the study design is that it cannot be definitively concluded whether observed differences in response probabilities conditional on overall level of function occurred because of disease characteristics or cross-cultural differences, since not all items were administered to US RA patients and no general population Dutch data is yet available. However, previous studies have generally shown European versions of physical function instruments to be equivalent to US versions in arthritis populations $(30,33)$, while substantial DIF has been observed across rheumatic conditions in one previous study (38). It also seems unlikely that observed DIF occurred as a result of translation errors, given the rigorous approach in translating and that all items refer to everyday activities that are very common in both US and The Netherlands. For these reasons, more studies are needed before firm conclusions regarding the measurement equivalence can be made. If such studies consistently identify certain items to exhibit DIF, their item parameters can still be expressed on a common metric by assigning group-specific item parameters to biased items. This allows cross-cultural comparison even in the presence of significantly biased items and physical function levels to be expressed on the PROMIS standardized metric if this is desired. In the mean time we recommend that those interested in expressing physical function levels of Dutch RA patients on the PROMIS standardized metric to select only items that were not flagged for DIF in the current study.

In the analysis of impact of DIF on total EAP estimates of physical function, we observed that biased items appeared to have a negligible influence on total physical function estimates from all items that were administered to patients at baseline. It should be stressed though that patients were administered between 48 and 72 items which is likely to be greater than the number of items that will be administered in practical applications of the item bank. In a recent validation study of a PROMIS PF CAT only four items were administered on average to obtain physical function estimates (39). The impact of DIF on physical function estimates is likely to be greater in such situations, provided that the item characteristics of biased items make them likely to be selected in such an application. Future studies should further evaluate the impact on physical function estimates in situations were fewer items are administered.

In the current study we used different methods to identify DIF. Whenever possible, DIF was evaluated using LM statistics. An advantage of this method is that violations of model assumptions can be investigated within a framework that directly pertains to the observed scores. As a result, the magnitude and direction of DIF can also be directly inferred from a weighted difference between average observed and average expected scores. In the regression analysis the 
direction of DIF had to be inferred indirectly by inspecting the response curves and item information functions visually. A limitation of the DIF analysis is therefore that no qualifications regarding the magnitude of DIF could be given in the current study of equivalence with the PROMIS wave 1 general population data. The reason we resorted to the regression analysis in the analysis of cross-cultural equivalence was that the US general population data suffered from severe ceiling effects, with the majority of respondents endorsing the higher response options. Consequently, insufficient variability was present within total score level groups for the LM test to produce interpretable results. For this reason also, no indication of model fit could be given for the US data. The longitudinal DIF analysis could not be performed with the LM test since the test compares scores on individual items between two groups, but in the longitudinal design, each item was presented to each patient only once.

In summary, the results of this study show that the PROMIS physical function item bank could be fitted to an IRT model that assumes physical function to be a unidimensional trait. However, a substantial number of its items showed statistically significant DIF compared to the US general population wave 1 data. Although the impact of observed DIF on physical function estimates was minimal in this study, more studies are needed to evaluate the validity of the PROMIS standardized metric in RA patients in the Netherlands.

\section{References}

1. Felson DT, Anderson JJ, Boers M, Bombardier C, Chernoff M, et al. (1993) The American College of Rheumatology preliminary core set of disease activity measures for rheumatoid arthritis clinical trials. The Committee on Outcome Measures in Rheumatoid Arthritis Clinical Trials. Arthritis Rheum 36: 729-740.

2. Wolfe F, Lassere M, van der Heijde D, Stucki G, Suarez-Almazor M, et al. (1999) Preliminary core set of domains and reporting requirements for longitudinal observational studies in rheumatology. J Rheumatol 26: 484-489.

3. Pincus T, Summey JA, Soraci SA, Jr., Wallston KA, Hummon NP (1983) Assessment of patient satisfaction in activities of daily living using a modified Stanford Health Assessment Questionnaire. Arthritis Rheum 26: 1346-1353.

4. Stucki G, Stucki S, Bruhlmann P, Michel BA (1995) Ceiling effects of the Health Assessment Questionnaire and its modified version in some ambulatory rheumatoid arthritis patients. Ann Rheum Dis 54: 461-465.

5. Pincus T, Swearingen C, Wolfe F (1999) Toward a multidimensional Health Assessment Questionnaire (MDHAQ): assessment of advanced activities of daily living and psychological status in the patient-friendly health assessment questionnaire format. Arthritis Rheum 42: 2220-2230.

6. Wolfe F, Michaud K, Pincus T (2004) Development and validation of the health assessment questionnaire II: a revised version of the health assessment questionnaire. Arthritis Rheum 50: 3296-3305.

7. Pincus T, Sokka T, Kautiainen H (2005) Further development of a physical function scale on a MDHAQ (corrected) for standard care of patients with rheumatic diseases. J Rheumatol 32: 1432-1439. 
8. $\quad$ Oude Voshaar MA, Ten Klooster PM, Taal E, van de Laar MA (2011) Measurement properties of physical function scales validated for use in patients with rheumatoid arthritis: A systematic review of the literature. Health Qual Life Outcomes 9: 99.

9. Fries JF, Cella D, Rose M, Krishnan E, Bruce B (2009) Progress in assessing physical function in arthritis: PROMIS short forms and computerized adaptive testing. J Rheumatol 36: 2061-2066.

10. Rose M, Bjorner JB, Becker J, Fries JF, Ware JE (2008) Evaluation of a preliminary physical function item bank supported the expected advantages of the Patient-Reported Outcomes Measurement Information System (PROMIS). J Clin Epidemiol 61: 17-33.

11. Cella D, Yount S, Rothrock N, Gershon R, Cook K, et al. (2007) The Patient-Reported Outcomes Measurement Information System (PROMIS): progress of an NIH Roadmap cooperative group during its first two years. Med Care 45: S3-S11.

12. Hays RD, Spritzer KL, Fries JF, Krishnan E (2013) Responsiveness and minimally important difference for the Patient-Reported Outcomes Measurement Information System (PROMIS) 20-item physical functioning short form in a prospective observational study of rheumatoid arthritis. Ann Rheum Dis.

13. Terwee CB, Roorda LD, de Vet HC, Dekker J, Westhovens R, et al. (2014) Dutch-Flemish translation of 17 item banks from the Patient-Reported Outcomes Measurement Information System (PROMIS). Qual Life Res.

14. Oude Voshaar MA, Ten Klooster PM, Taal E, Krishnan E, van de Laar MA (2012) Dutch translation and cross-cultural adaptation of the PROMIS(R) physical function item bank and cognitive pre-test in Dutch arthritis patients. Arthritis Res Ther 14: R47.

15. Hambleton RK, Swaminathan H, Rogers HJ (1991) Fundamentals of item response theory: Sage.

16. Ellis BB (1989) Differential item functioning: Implications for test translations. Journal of Applied Psychology 74: 912.

17. Holman R, Lindeboom R, Glas CA, Vermeulen M, de Haan RJ (2003) Constructing an item bank using item response theory: the AMC Linear Disability Score project. Health Services and Outcomes Research Methodology 4: 19-33.

18. Kim S-H, Cohen AS (2002) A comparison of linking and concurrent calibration under the graded response model. Applied Psychological Measurement 26: 25-41.

19. Cella D, Riley W, Stone A, Rothrock N, Reeve B, et al. (2010) The Patient-Reported Outcomes Measurement Information System (PROMIS) developed and tested its first wave of adult self-reported health outcome item banks: 2005-2008. J Clin Epidemiol 63: 1179-1194.

20. Terwee CB, Roorda LD, De Vet HC, Dekker J, Westhovens R, et al. (submitted for publication) DutchFlemish translation of 17 item banks from the Patient Reported Outcomes Measurement Information System (PROMIS).

21. Fries JF, Spitz P, Kraines RG, Holman HR (1980) Measurement of patient outcome in arthritis. Arthritis Rheum 23: 137-145.

22. Fries JF (2009) The Health Assessment Questionnaire (HAQ) and the Improved HAQ. Stanford: Stanford University School of Medicine, Division of Immunology \& Rheumatology.

23. Ware JE, Jr., Sherbourne CD (1992) The MOS 36-item short-form health survey (SF-36). I. Conceptual framework and item selection. Med Care 30: 473-483. 
24. ten Klooster PM, Vonkeman HE, Taal E, Siemons L, Hendriks L, et al. (2013) Performance of the Dutch SF-36 version 2 as a measure of health-related quality of life in patients with rheumatoid arthritis. Health Qual Life Outcomes 11: 77.

25. Prevoo ML, van 't Hof MA, Kuper HH, van Leeuwen MA, van de Putte LB, et al. (1995) Modified disease activity scores that include twenty-eight-joint counts. Development and validation in a prospective longitudinal study of patients with rheumatoid arthritis. Arthritis Rheum 38: 44-48.

26. Glas CA (2010) Preliminary manual of the software program Multidimensional Item Response Theory (MIRT). University of Twente, Enschede, The Netherlands

27. Muraki E (1992) A generalized partial credit model: Application of an EM algorithm. Appl Psychol Meas 16: $159-176$.

28. te Marvelde JM, Glas CA, Van Landeghem G, Van Damme J (2006) Application of multidimensional item response theory models to longitudinal data. Educational and Psychological Measurement 66: 5-34.

29. Glas CAW (1999) Modification indices for the 2-PL and the nominal response model. Psychometrika 64: 273-294.

30. Oude Voshaar MA, Glas CA, Ten Klooster PM, Taal E, Wolfe F, et al. (2013) Crosscultural Measurement Equivalence of the Health Assessment Questionnaire II. Arthritis Care Res (Hoboken) 65: 1000-1004.

31. Glas CAW (1998) Detection of differential item functioning using Lagrange multiplier tests. Statistica Sinica 8: 647-668.

32. Bland JM, Altman DG (1986) Statistical methods for assessing agreement between two methods of clinical measurement. Lancet 1: 307-310.

33. Roorda L, Jones C, Waltz M, Lankhorst G, Bouter L, et al. (2004) Satisfactory cross cultural equivalence of the Dutch WOMAC in patients with hip osteoarthritis waiting for arthroplasty. Annals of the rheumatic diseases 63: 36 .

34. Vincent HK, Vincent KR, Lamb KM (2010) Obesity and mobility disability in the older adult. Obes Rev 11: 568-579.

35. Krishnan E, Tugwell P, Fries JF (2004) Percentile benchmarks in patients with rheumatoid arthritis: Health Assessment Questionnaire as a quality indicator (QI). Arthritis Res Ther 6: R505-513.

36. van Riel PL, van Gestel AM (2000) Clinical outcome measures in rheumatoid arthritis. Ann Rheum Dis 59 Suppl 1: i28-31.

37. Paz SH, Spritzer KL, Morales LS, Hays RD (2013) Evaluation of the Patient-Reported Outcomes Information System (PROMIS((R))) Spanish-language physical functioning items. Qual Life Res 22: 18191830.

38. van Groen MM, ten Klooster PM, Taal E, van de Laar MA, Glas CA (2010) Application of the health assessment questionnaire disability index to various rheumatic diseases. Qual Life Res 19: 1255-1263.

39. Hung M, Baumhauer JF, Latt LD, Saltzman CL, Soohoo NF, et al. (2013) Validation of PROMIS Physical Function Computerized Adaptive Tests for Orthopaedic Foot and Ankle Outcome Research. Clin Orthop Relat Res 471: 3466-3474. 
130 | Chapter 6 


\section{Chapter 7}

Measurement properties of the PROMIS physical function item bank in rheumatoid arthritis; Comparison with HAQ-DI and SF-36 physical functioning scale

Oude Voshaar MAH, Klooster PM ten, Glas CAW, Vonkeman HE, Taal E, Krishnan E, et al. Measurement properties of the PROMIS physical function item bank in rheumatoid arthritis; Comparison with HAQ-DI and SF-36 physical functioning scale. (Under Review). 


\section{Abstract}

Objective: To evaluate content validity and measurement properties of the patient reported outcome measurement information system (PROMIS) physical function item bank in patients with rheumatoid arthritis (RA) in comparison with the Health Assessment Questionnaire disability index (HAQ-DI) and SF-36 physical functioning scale (PF-10).

Methods: content validity of the three instruments was evaluated by linking their items to the international classification for functioning, disability and health (ICF) core set for RA. The measures were administered to 690 RA patients enrolled in the Dutch DREAM registry. Measurement precision was evaluated using item response theory methods and construct validity was evaluated by correlating physical function scores to other clinical and patient-reported outcome measures.

Results: All 207 health concepts that were identified in the physical function items referred to activities that feature in the ICF core set for RA. 23 of 26 ICF RA core set domains feature in the PROMIS physical function item bank compared to 13 and 8 for HAQ-DI and PF-10 respectively. PROMIS physical function item bank showed high internal consistency $(\mathrm{r}=0.96)$. As hypothesized, all three physical function instruments were highly inter-correlated (range $=r=0.74$ to $r=0.84$ ), correlated moderately with disease activity measures (range $=\mathrm{t}=0.44$ to $\mathrm{r}=0.63$ ) and weakly with age (range $=r=0.07$ to $r=0.14$ ). Item response theory based analysis revealed that PROMIS physical function items cover a wider range of physical function levels than either HAQ-DI or PF10.

Conclusion: The PROMIS physical function item bank demonstrated excellent content coverage, measurement precision, and construct validity in RA. 
Physical function is a core outcome domain in rheumatoid arthritis (RA) (1). Physical function is usually assessed with fixed-length questionnaires such as the Health Assessment Questionnaire disability index (HAQ-DI) and the SF-36 health survey physical functioning scale (PF-10) (2). Although these measures possess generally favorable measurement properties, key shortcomings associated with their use in RA are floor and ceiling effects and patient and administrator burden (2 3). Accurate assessment with fewer items is therefore of major interest.

Item response theory (IRT) based item banking enables computerized adaptive tests (CAT) which facilitates tailoring the level of questions posed to the specific population or individual patient. The Patient Reported Outcome Measurement Information System (PROMIS) project has developed item banks for a great number of patient reported outcome domains, including physical function (4 5). In a previous study, the Dutch-Flemish PROMIS physical function item bank was calibrated in a sample of Dutch patients with patients with RA (6). In the current study we examined content validity, measurement precision and construct validity of the PROMIS physical function item bank in comparison with the HAQ-DI and PF-10.

\section{Methods}

\section{Patients and sampling design}

The current study is an analysis of baseline data from a larger, longitudinal study aimed at calibrating the Dutch-Flemish PROMIS physical function item bank in Dutch RA patients (6). Data were collected in the Dutch Rheumatoid Arthritis Monitoring (DREAM) registry. The DREAM registry is an observational multicenter cohort study that monitors the course of RA patients undergoing different treatment regimens in 12 hospitals in the Netherlands. Clinical and patient-reported outcomes of patients with RA are monitored over time using a web-based data collection and storage system. Patient-reported outcomes are administered preceding every visit to the clinic. For this study, RA patients of three participating DREAM hospitals were informed about and invited to participate after logging in to their personal DREAM web portal. Informed consent was provided according to the Declaration of Helsinki and digitally obtained from all participating patients. According to the Dutch law for medical research in humans, approval by an ethical committee was not required for this study.

The calibration study followed a longitudinal design where data was collected preceding three scheduled clinic visits. Patients completed randomly allocated questionnaires containing approximately 40, partially overlapping, items from the 121-item PROMIS physical function item bank at each time point (7) along with the HAQ-DI and PF-10. Questionnaires and allocation of patients to questionnaires was organized in such a way that patients answered all items exactly once 
after three clinic visits. More elaborate information about the data collection design, item calibration and model fit analyses are described elsewhere (6). All analyses of the PROMIS physical function scores were performed on the latent expected a posteriori (EAP) estimates obtained from the first time point of assessment for each patient (i.e., $\sim 40$ items per patient).

\section{Measures}

Patients completed the HAQ-DI, the SF-36v2 health survey, and single item measures of general health, disease activity, pain, stiffness and fatigue alongside the PROMIS physical function items. For a subgroup of patients visiting the outpatient clinic around the time of completing the questionnaire, clinical measures were available to calculate the 28 -joint disease activity score for (DAS28).

PROMIS physical function item bank

The PROMIS physical function item bank measures self-reported, current capability of physical activities. The item bank contains 121 questions assessing the functioning of the upper extremities (dexterity), lower extremities (walking or mobility), and central regions (neck, back), as well as instrumental activities of daily living, such as running errands Each item is scored on a 5 point rating scale, with higher scores indicating better functioning.

Health Assessment Questionnaire disability index (HAQ-DI)

The HAQ-DI contains 20 items measuring physical disabilities over the past week in eight categories of daily living: dressing and grooming, rising, eating, walking, hygiene, reach, grip, and activities (8). Each item is scored on a 4-point rating scale from 0 (without any difficulty) to 3 (unable to do). Disability scores were calculated according to the alternative scoring rule, which does not takes the use of aids and help from others into account (9). The highest scores from each category scores are averaged to produce a total score between 0 and 3 , with higher values indicating more disability.

SF-36 health survey physical functioning scale (PF-10)

The PF-10 is one of the eight scales of the SF-36 health survey and consists of 10 items measuring perceived current limitations in a variety of physical activities on a 3-point response scale from 1 (yes, limited a lot) to 3 (no, not limited at all). Scores of the PF-10 items are summed and linearly transformed to range between 0 and 100, with higher scores indicating better physical functioning (10).

Diseases activity score for 28 joints (DAS28)

The 28-joint disease activity score (DAS28) is a pooled clinical index that includes a tender and swollen joint count of 28 joints, the erythrocyte sedimentation rate, and the patient's global assessment of general health (11). 
Numerical rating scales

Patient-reported general health, disease activity, pain, stiffness and fatigue were each assessed using 10-point numerical ratings scales, with higher values reflecting worse health status.

Analysis

Content validity

A patient reported outcome measure has content validity in case its items all refer to aspects of the construct to be measured that are relevant to the construct and to the intended study population. Together, the items must comprehensively reflect the construct to be measured and be suitable for the intended purpose of an instrument (12). The content validity of the PROMIS physical function item bank as well as the HAQ-DI and PF-10 for measuring physical function in patients with RA was evaluated by linking their items to the International Classification of Functioning and Health (ICF) codes using proposed linking rules $(13$ 14). The ICF is an exhaustive taxonomy of functioning that categorizes health concepts into dimensions, chapters, and codes of functioning, with each successive step representing increasingly specific health concepts. For example, 'walking more than a mile' is a health concept that belongs to the ICF dimension 'activities and participation', the chapter 'mobility' and the second level code 'walking and moving'. Health concepts embodied in the items of the various instruments were considered to be relevant indicators of function in patients with RA in case they belonged to the ICF activities domain and were included in the ICF core set for RA or specifically mentioned by patients as important omissions from the core set in a subsequent qualitative study (15 16). Because of their relevance to physical function in RA and inclusion in the core set, ICF chapters writing (d170) and sports (d920) were considered relevant as well. Comprehensiveness of the instruments was evaluated by evaluating the representation of ICF second level codes in the instruments and by evaluating the proportional distribution of health concepts across the mobility, activities of daily living and domestic life domains.

Measurement precision

Test information functions for the HAQ-DI, PF-10 and PROMIS physical function item bank were calculated and compared to provide insight into the measurement precision of the various instruments across different levels of physical function. Test information functions are the reciprocal of the standard error of measurement associated with a specific level of physical function and provide information about the precision of instrument scores at individual levels of the underlying physical function trait. Global reliability of the various instruments was evaluated with an IRT based index of reliability analogous to Cronbach's alpha. Values $\geq 0.70$ and $\geq 0.90$ were 
considered to indicate adequate reliability for group level and individual level applications, respectively.

Construct validity

Construct validity was evaluated by calculating Pearson correlation coefficients between the physical function instruments and other patient-reported outcome measures and by comparing scores between known groups. Since all evaluated physical function instruments assess similar constructs, the pattern of correlations with clinical and patient-reported outcomes were hypothesized to be similar for the HAQ-DI, PF-10 and PROMIS physical function item bank. Moreover, the physical function measures were hypothesized to be highly inter-correlated (i.e. $>0.60$ ). We further hypothesized that strongest correlations would be observed among the three physical function instruments, followed by the correlation between physical function scores and other patient-reported outcomes (wellbeing, fatigue, stiffness, patient-reported disease activity and pain). Weak correlations (i.e. $r \geq 0.10, \leq 0.30$ ) were expected with age. The relative validity of the three physical function instruments to discriminate between patients in clinical remission and those with active disease according to the DAS28 was analyzed by comparing ratios of F-statistics from univariate one-way analysis of variance (ANOVA) tests $(17$ 18). DAS28 scores $<2.6$ were considered to reflect clinical remission.

\section{Results}

Patient characteristics are summarized in table 1. A total of 690 unique patients completed at least one questionnaire from the item bank and the other patient-reported outcomes. There were no missing data. On average, patients had low levels of disease activity and high levels of physical function. Substantial ceiling effects were observed on the HAQ-DI (53\%), but not on any of the other physical function measures.

Table 1: Baseline characteristics

\begin{tabular}{lc}
\multicolumn{2}{c}{ Table 1: Baseline characteristics } \\
\hline & Mean $(\mathrm{SD}) / \mathrm{N}(\%)$ \\
\hline Female & $439(63.6)$ \\
Age & $56.8(11.9)$ \\
DAS28 & $2.1(1.2)$ \\
General health & $25.1(23.7)$ \\
Disease activity & $28.2(23.5)$ \\
Fatigue & $33.2(29.8)$ \\
stiffness & $18.8(41.4)$ \\
pain & $27.7(22.8)$ \\
PROMIS PF & \\
HAQ-DI & $0.6(0.5)$ \\
PF-10 & $66.7(25.0)$ \\
\hline
\end{tabular}

DAS28 = Disease Activity Score based on 28 joint count; PROMIS PF = Patient Reported Outcome Information System Physical Function item bank; HAQ-DI = Health Assessment Questionnaire, Disability Index; PF-10 = SF-36 physical function scale 


\section{Content validity}

In total, 207 health concepts were identified in the 151 items of the three physical function instruments (table 2). Only 15 (7\%) of these could not be linked to the ICF. In all cases these health concepts were too broad to be linked (e.g. 'usual physical activities' or 'vigorous activities'). All health concepts that were linked to the ICF either featured in the ICF core set for RA or were identified as important by patients with RA. Therefore all the evaluated items of the HAQ-DI, PF10 and PROMIS physical function item bank refer to health concepts that are relevant indicators of physical function in RA. The generic nature of the PF-10 is reflected in its items being linked to predominantly ICF codes within the mobility domain and sports chapter, whereas the HAQ-DI has more items reflecting basic activities of daily living such as eating and washing and mobility items related to use of the hands and arms (table 2). The PROMIS physical function item bank most comprehensively reflects all areas of physical function that are relevant to RA patients, according to the ICF core set. Except for 'assisting others' (d660), 'driving' (d475) and 'moving around using equipment' (d465), all the relevant ICF activities domain that feature in the ICF core set for RA are represented in the PROMIS physical function item bank.

Table 2. Content validity of HAQ-DI, PF-10 and PROMIS physical function item bank according to ICF RA core set.

\begin{tabular}{|c|c|c|c|}
\hline ICF core set for RA second level codes & PROMIS PF & HAQ-DI & PF-10 \\
\hline Writing & $1(0.6 \%)$ & - & - \\
\hline Changing basic body position & $13(8.1 \%)$ & $5(17.9 \%)$ & $3(15.7 \%)$ \\
\hline Maintaining a body position & $10(6.3 \%)$ & - & - \\
\hline Transferring oneself & $2(1.3 \%)$ & - & - \\
\hline Lifting and carrying objects & $16(10.0 \%)$ & $2(7.7 \%)$ & $3(15.7 \%)$ \\
\hline Fine hand use & $17(10.6 \%)$ & $4(15.4 \%)$ & \\
\hline Hand and arm use & $14(8.8 \%)$ & $1(3.8 \%)$ & $2(10.5 \%)$ \\
\hline Walking & $10(6.3 \%)$ & $1(3.8 \%)$ & $3(15.7 \%)$ \\
\hline Moving around & $19(11.9 \%)$ & $1(3.8 \%)$ & $3(15.7 \%)$ \\
\hline Moving around in different locations & $2(1.3 \%)$ & - & - \\
\hline Moving around using equipment & - & - & - \\
\hline Using transportation & $1(0.6 \%)$ & - & - \\
\hline Driving & - & - & - \\
\hline Mobility total & $105(65 \%)$ & $14(53 \%)$ & $14(74 \%)$ \\
\hline Washing oneself & $8(5.0 \%)$ & $3(11.5 \%)$ & $1(5.2 \%)$ \\
\hline Caring for body parts & $4(2.5 \%)$ & - & - \\
\hline Toileting & $1(0.6 \%)$ & - & - \\
\hline Dressing & $13(8.1 \%)$ & $3(11.5 \%)$ & $1(5.2 \%)$ \\
\hline Eating & $4(2.5 \%)$ & $2(7.7 \%)$ & - \\
\hline Drinking & $1(0.6 \%)$ & $1(3.8)$ & - \\
\hline Looking after one's health & $1(0.6 \%)$ & - & - \\
\hline Self-care total & $32(19 \%)$ & $7(26 \%)$ & $2(10.0 \%)$ \\
\hline Acquisition of goods and services & $3(1.9 \%)$ & $2(7.7 \%)$ & - \\
\hline Preparing meals & $1(0.6 \%)$ & - & - \\
\hline Doing housework & $8(5.0 \%)$ & $1(3.8 \%)$ & - \\
\hline Caring for household objects & $42.5 \%)$ & $1(3.8 \%)$ & - \\
\hline Assisting others & - & - & - \\
\hline Domestic life total & $16(7.5 \%)$ & $3(11.5 \%)$ & $0(0.0 \%$ \\
\hline Sports & $7(4.4 \%)$ & - & $3(15.7 \%)$ \\
\hline Total & 160 & 28 & 19 \\
\hline
\end{tabular}




\section{Measurement precision}

The global reliability of the instruments was high for all three instruments, with reliability coefficients of 0.96 and 0.90 for PROMIS and PF-10 respectively and only HAQ-DI $(r=0.89)$ falling below the cut-off point for individual level comparisons. The information functions belonging to the individual physical function instruments are plotted in figure 1, against the distribution of latent physical function scores observed at baseline. The precision of the PROMIS physical function item bank surpasses that of the HAQ-DI and PF-10 for all levels of physical function by virtue of having more items than either of the other instruments. However, precision of the PROMIS physical function item bank was high across all physical function levels, while physical function scores $>0$, which were observed in $47 \%$ of patients cannot be precisely measured with HAQ-DI or PF-10

Figure 1. Test information functions of the instruments (upper panel) in relation to the percentage of patients at each of the EAP physical function score levels (lower panel).
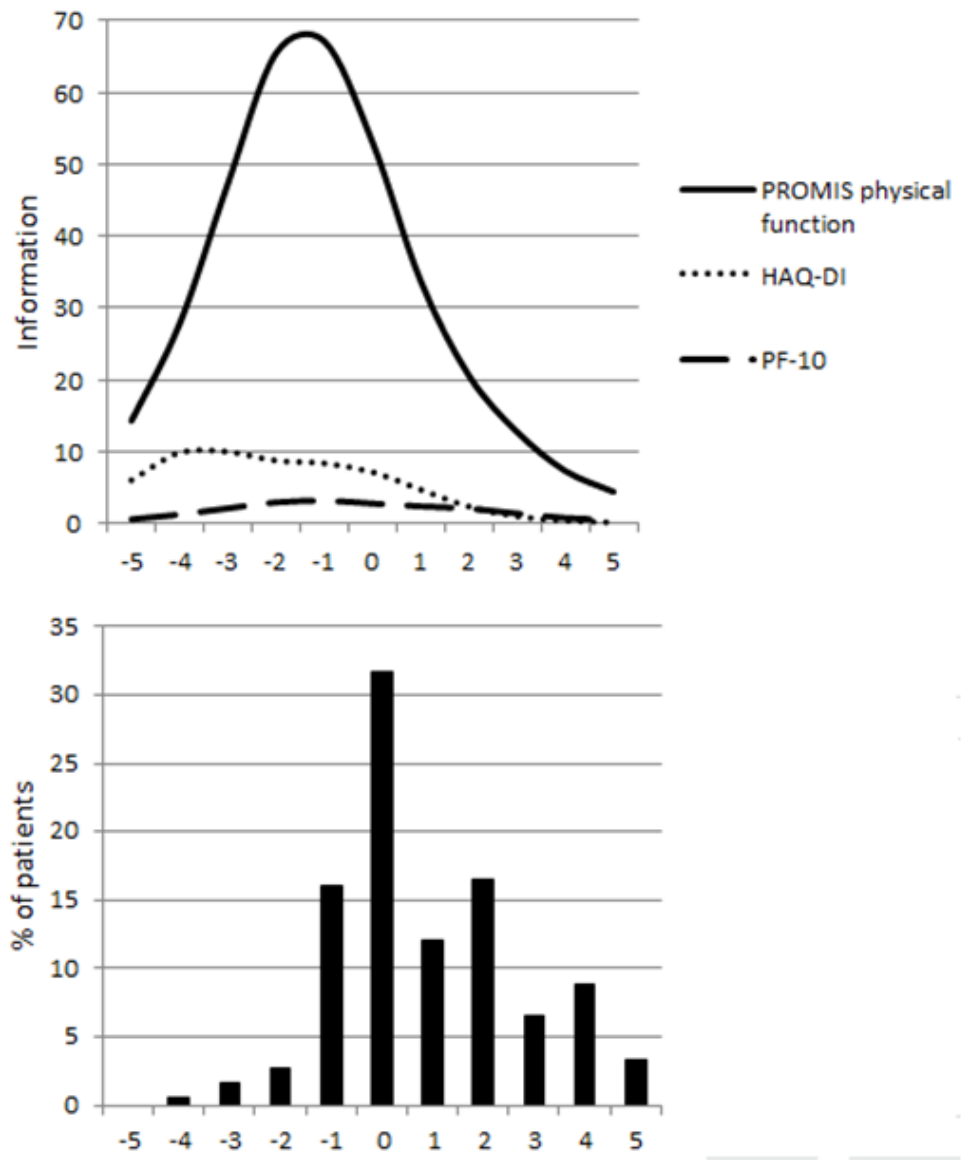

EAP scores on the $\mathrm{x}$-axes are scaled around $0(\mathrm{SD}=1)$ and represent physical function levels with higher values indicating better functioning. Information in the upper panel represents measurement precision, higher values represents more reliable measurement. 


\section{Construct validity}

Table 3 summarizes correlations between the PROMIS physical function item bank, the HAQ-DI and the PF-10 and other patient-related variables. The three physical function instruments were highly inter-correlated and the pattern of correlations with other clinical and patient-reported measures was also highly similar. In addition, the association between the three physical function instruments and the other measures was of the expected magnitude for all comparisons, except for the correlation between age and HAQ-DI. Taken together, these results were in accordance with the pre-specified hypotheses, indicating adequate convergent and construct validity for PROMIS physical function item bank. In table 3, the relative validity of the three instruments to discriminate between active disease and remission is presented. HAQ-DI and PROMIS were about equally efficient, while the PF-10 was less efficient in distinguishing between levels of disease activity.

Table 3. Pearson correlations between the psychical function measures and other variables

\begin{tabular}{lccccccccc}
\hline Instrument & $\begin{array}{c}\text { HAQ- } \\
\text { DI } \\
(\mathrm{n}=677)\end{array}$ & $\begin{array}{c}\text { PF-10 } \\
(\mathrm{n}=669)\end{array}$ & $\begin{array}{c}\text { Pain } \\
(\mathrm{n}=383)\end{array}$ & $\begin{array}{c}\text { General } \\
\text { health } \\
(\mathrm{n}=223)\end{array}$ & $\begin{array}{c}\text { Disease } \\
\text { activity } \\
(\mathrm{n}=147)\end{array}$ & $\begin{array}{c}\text { Fatigue } \\
(\mathrm{n}=74)\end{array}$ & $\begin{array}{c}\text { Stiffness } \\
(\mathrm{n}=74)\end{array}$ & $\begin{array}{c}\text { Age } \\
(\mathrm{n}=\end{array}$ \\
\hline $\begin{array}{l}\text { PROMIS } \\
\text { function }\end{array}$ & physical & 0.76 & 0.84 & -0.52 & -0.53 & -0.46 & -0.47 & -0.63 & 0.14 \\
HAQ-DI & & & & & & & & & \\
PF-10 & 1 & -0.74 & 0.52 & 0.48 & 0.50 & 0.46 & 0.62 & $-0.07^{*}$ \\
$\begin{array}{l}\text { Hypothesized } \\
\text { correlation }\end{array}$ & -0.74 & 1 & -0.52 & -0.44 & -0.46 & -0.52 & -0.46 & 0.11 \\
$*$ Not significant at $\mathrm{P}<0.05$ & $>0.60$ & $>0.60$ & $0.30-.60$ & $0.30-0.60$ & $0.30-0.60$ & $0.30-$ & $0.30-$ & $0.10-$ \\
\end{tabular}

Not significant at $\mathrm{P}<0.05$

Table 4. Relative validity of the instruments to differentiate between patients in remission and those with active disease according to the DAS28

\begin{tabular}{lcccc}
\hline Instrument & $\begin{array}{c}\text { Remission } \\
(\mathrm{n}=37)\end{array}$ & $\begin{array}{c}\text { Active disease } \\
(\mathrm{n}=79)\end{array}$ & $F$ & $\mathrm{RV}$ \\
\hline PROMIS physical function & $2.06(1.89)$ & $-0.06(1.86)$ & 31.87 & 1.00 \\
HAQ-DI & $0.35(0.51)$ & $0.87(0.51)$ & 31.57 & 0.99 \\
PF-10 & $75.90(20.48)$ & $54.86(23.73)$ & 20.99 & 0.65 \\
\hline
\end{tabular}

$F=$ F-statistic from one-way ANOVA; RV = Relative validity (ratio of F-statistics compared with observed PROMIS physical function)

\section{Discussion}

The data of this study demonstrated that the PROMIS physical function item bank assesses a similar construct as the HAQ-DI and PF-10. Additionally, the PROMIS physical function item bank assesses a wider range of physical functioning than do both traditional instruments and its item content more comprehensively reflects the physical function domain relevant for RA.

The global reliability of all three instruments was high, which corresponds to previous research with the HAQ-DI and PF-10 where reliability coefficients sufficient for individual comparisons were observed as well (19 20). The current study extends previous research on HAQDI and PF-10 by evaluating their local reliability, relative to each other and in comparison to the PROMIS physical function item bank. The instrument-specific information functions showed that the HAQ-DI was best at discriminating between patients with the poorest levels of function. This corresponds with the results from the analysis of content validity that showed that many of its 
items refer to basic activities of daily living such as eating or dressing unassisted and mobility issues related to the use of the hands. The analysis of local measurement precision showed that the items of HAQ-DI and PF-10 do not reliably measure higher levels of function, which were commonly experienced by patients with RA in our sample. In fact $53 \%$ of patients scored the best possible HAQ-DI score, which is well over the commonly accepted criterion for ceiling effects of $15 \%(21)$. Although ceiling effects of the HAQ-DI are a well-known and often reported shortcoming in various settings, the proportion of patients scoring the best possible score was even higher than reported in previous studies in RA (2 3). This likely reflects improved general status of current patients as a result of aggressive and early treatment. The precision of the PROMIS physical function item bank as a whole surpassed that of both classical instruments and better captured the various levels of function that were observed in the current study. These findings underscore the need for personalized assessment of physical function and suggest that practical applications of the PROMIS physical function item bank might allow more precise measurement of patients of various levels of function and reduce floor and ceiling effects. Precision of such applications will depend on the number of administered items and the success of tailoring these applications to the samples' or individual patients' level of functioning. Previous research has shown that a preliminary CAT version of the PROMIS physical function item bank approached the reliability of the full bank and outperforms an equal number of HAQ-DI or PF-10 items (22). Based on the current results, especially gains in the precision of measuring higher levels of functioning are to be expected in such applications.

All 121 items of the PROMIS physical function item bank refer to ICF codes that are relevant for measuring function in RA according to the ICF core set for RA. Moreover, the item bank covers almost all ICF chapters that feature in the core set. These results strongly support the content validity of the item bank. The lack of items reflecting 'assisting others', 'driving' and 'moving around using equipment' may be considered omissions. However, items reflecting moving around using equipment, such as for example ski's or ice skates, or assisting others in their daily activities are not likely to be relevant for many patients. Considering the need for the items to be appropriate to patients with various cultural and demographic backgrounds it is debatable whether the addition of such items would substantially benefit the content validity of the item bank. On the other hand, activities involving walking around with equipment might provide an opportunity to increase the precision of measuring patients with relatively good levels of physical function. The sensitivity of individual items to occurred changes in functional status is also an important aspect of content validity that could not be tested using the data of this study. Future studies should evaluate responsiveness of individual PROMIS physical function items. Moreover, many items in 
the item bank measure relatively simple activities of daily living, which is reflected in very high measurement precision at lower levels of function. Therefore the item bank might benefit from more items reflecting more 'difficult' physical activities, which is a research topic that is currently being addressed (23).

The pattern of observed correlations with other measures was highly similar for all three evaluated physical function instruments, which supports the construct validity of the PROMIS physical function item bank in RA. Previous studies of the HAQ-DI and PF-10 (2 24) also found moderate correlations with other patient-reported outcomes and disease severity measures and low, but significant, correlations with age. However, the correlation between the PROMIS physical function item bank and the HAQ-DI and PF-10, respectively, was slightly higher than the intercorrelation between the latter two instruments. This might reflect differing foci of the instruments, with the items of the HAQ-DI measuring predominantly activities related to the use of the hands and arms and the PF-10 focusing more on the lower extremities, while the PROMIS physical function item bank incorporates both types of content to about an equal degree. Although the differences appear subtle, impairments in hand and finger function are typical manifestations of disability in patients with RA, and the HAQ-DI was clearly superior to the PF-10 in differentiating between active disease and remission according to the DAS-28. Previous research suggested that upper and lower extremity function might reflect two separate, but highly correlated dimensions in RA (25 26). Recently, distinct upper and lower extremities domains with a moderate intercorrelation $(\mathrm{r}=0.59)$ were identified in the PROMIS physical function item bank(25). Future studies should evaluate the sensitivity of the upper and lower extremities items in more detail so that optimally sensitive applications of the PROMIS physical function item bank can be developed for use in RA.

Taken together, the results of the current study suggest that the PROMIS physical function item bank is an instrument that will result in improved measurement precision and less patient burden in the assessment of self-reported physical function in patients with RA.

\section{References}

1. Felson DT, Anderson JJ, Boers M, et al. The American college of rheumatology preliminary core set of disease activity measures for rheumatoid arthritis clinical trials. Arthritis \& Rheumatism 1993;36(6):729-40 doi: 10.1002/art.1780360601(published Online First: Epub Date)|.

2. Oude Voshaar MA, Ten Klooster PM, Taal E, van de Laar MA. Measurement properties of physical function scales validated for use in patients with rheumatoid arthritis: A systematic review of the literature. Health Qual Life Outcomes 2011;9:99 doi: 10.1186/1477-7525-9-99(published Online First: Epub Date)|.

3. Stucki G, Stucki S, Bruhlmann P, Michel BA. Ceiling effects of the Health Assessment Questionnaire and its modified version in some ambulatory rheumatoid arthritis patients. Ann Rheum Dis 1995;54:461-5 
4. Cella D, Riley W, Stone A, et al. The Patient-Reported Outcomes Measurement Information System (PROMIS) developed and tested its first wave of adult self-reported health outcome item banks: 2005-2008. Journal of clinical epidemiology 2010;63(11):1179-94 doi: S0895-4356(10)00173-3 (pii) 10.1016/j.jclinepi.2010.04.011 (doi)(published Online First: Epub Date)|.

5. Cella D, Yount S, Rothrock N, et al. The Patient-Reported Outcomes Measurement Information System (PROMIS): progress of an NIH Roadmap cooperative group during its first two years. Med Care 2007;45:S3S11 doi: 10.1097/01.mlr.0000258615.42478.55(published Online First: Epub Date)|.

6. Oude Voshaar AH, Ten Klooster PM, Glas CAW, et al. Calibration of the PROMIS physical function item bank in Dutch patients with rheumatoid arthritis. submitted for publication

7. Oude Voshaar MA, Ten Klooster PM, Taal E, Krishnan E, van de Laar MA. Dutch translation and crosscultural adaptation of the PROMIS(R) physical function item bank and cognitive pre-test in Dutch arthritis patients. Arthritis Res Ther 2012;14(2):R47 doi: 10.1186/ar3760(published Online First: Epub Date)|.

8. Fries JF, Spitz P, Kraines RG, Holman HR. Measurement of patient outcome in arthritis. Arthritis and Rheumatism 1980;23(2):137-45

9. Fries JF. The Health Assessment Questionnaire (HAQ) and the Improved HAQ. Stanford: Stanford University School of Medicine, Division of Immunology \& Rheumatology, 2009.

10. Ware JE, Jr., Sherbourne CD. The MOS 36-item short-form health survey (SF-36). I. Conceptual framework and item selection. Med Care 1992;30(6):473-83

11. Prevoo ML, van 't Hof MA, Kuper HH, van Leeuwen MA, van de Putte LB, van Riel PL. Modified Disease Activity Scores that include twenty-eight-joint counts: development and validation in a prospective longitudinal study of patients with rheumatoid arthritis. Arthritis Rheum 1995;38(1):44-8

12. Mokkink LB, Terwee CB, Patrick DL, et al. The COSMIN study reached international consensus on taxonomy, terminology, and definitions of measurement properties for health-related patient-reported outcomes. J Clin Epidemiol 2010;63(7):737-45 doi: 10.1016/j.jclinepi.2010.02.006(published Online First: Epub Date)|.

13. Cieza A, Geyh S, Chatterji S, Kostanjsek N, Ustun B, Stucki G. ICF linking rules: an update based on lessons learned. J Rehabil Med 2005;37(4):212-8 doi: 10.1080/16501970510040263(published Online First: Epub Date) $\mid$.

14. Cieza A, Brockow T, Ewert T, et al. Linking health-status measurements to the international classification of functioning, disability and health. J Rehabil Med 2002;34(5):205-10

15. Stucki G, Cieza A, Geyh S, et al. ICF Core Sets for rheumatoid arthritis. J Rehabil Med 2004(44 Suppl):8793 doi: 10.1080/16501960410015470(published Online First: Epub Date)|.

16. Coenen M, Cieza A, Stamm TA, Amann E, Kollerits B, Stucki G. Validation of the International Classification of Functioning, Disability and Health (ICF) Core Set for rheumatoid arthritis from the patient perspective using focus groups. Arthritis Res Ther 2006;8(4):R84 doi: 10.1186/ar1956(published Online First: Epub Date)|.

17. McHorney CA, Ware JE, Jr., Raczek AE. The MOS 36-Item Short-Form Health Survey (SF-36): II. Psychometric and clinical tests of validity in measuring physical and mental health constructs. Medical care 1993;31(3):247-63

18. Liang MH, Larson MG, Cullen KE, Schwartz JA. Comparative measurement efficiency and sensitivity of five health status instruments for arthritis research. Arthritis Rheum 1985;28(5):542-7 
19. ten Klooster PM, Taal E, van de Laar MA. Rasch analysis of the Dutch Health Assessment Questionnaire disability index and the Health Assessment Questionnaire II in patients with rheumatoid arthritis. Arthritis Rheum 2008;59:1721-8 doi: 10.1002/art.24065(published Online First: Epub Date)|.

20. Kosinski M, Zhao SZ, Dedhiya S, Osterhaus JT, Ware JE, Jr. Determining minimally important changes in generic and disease-specific health-related quality of life questionnaires in clinical trials of rheumatoid arthritis. Arthritis Rheum 2000;43(7):1478-87 doi: 10.1002/1529-0131(200007)43:7<1478::aid-anr10>3.0.co;2$\mathrm{m}$ (published Online First: Epub Date) $\mid$.

21. Terwee CB, Bot SD, de Boer MR, et al. Quality criteria were proposed for measurement properties of health status questionnaires. Journal of clinical epidemiology 2007;60(1):34-42 doi: S0895-4356(06)00174-0 (pii)10.1016/j.jclinepi.2006.03.012 (doi)(published Online First: Epub Date)|.

22. Rose M, Bjorner JB, Becker J, Fries JF, Ware JE. Evaluation of a preliminary physical function item bank supported the expected advantages of the Patient-Reported Outcomes Measurement Information System (PROMIS). J Clin Epidemiol 2008;61(1):17-33 doi: 10.1016/j.jclinepi.2006.06.025(published Online First: Epub Date)|.

23. Fries JF, Bharathi L, Siemons L, Glas CAW, Bruce B, Krishnan E. Extending the floor and the ceiling for assessment of physical function (disability). submitted 2013

24. Wolfe F, Michaud K, Pincus T. Development and validation of the health assessment questionnaire II: a revised version of the health assessment questionnaire. Arthritis Rheum 2004;50:3296-305 doi: 10.1002/art.20549(published Online First: Epub Date)|.

25. Hays RD, Spritzer KL, Amtmann D, et al. Upper-Extremity and Mobility Subdomains From the PatientReported Outcomes Measurement Information System (PROMIS) Adult Physical Functioning Item Bank. Arch Phys Med Rehabil 2013 doi: 10.1016/j.apmr.2013.05.014(published Online First: Epub Date)|.

26. ten Klooster PM, Veehof MM, Taal E, van Riel PL, van de Laar MA. Confirmatory factor analysis of the Arthritis Impact Measurement Scales 2 short form in patients with rheumatoid arthritis. Arthritis Rheum 2008;59(5):692-8 doi: 10.1002/art.23569(published Online First: Epub Date)|. 
144 | Chapter 7 


\section{Chapter 8}

Relative performance of commonly used physical function questionnaires in rheumatoid arthritis and a PROMIS computerized adaptive test: A simulation study.

Oude Voshaar MAH, Klooster PM ten, Glas CAW, Vonkeman HE, Krishnan E, Laar MAFJ van de. Relative performance of commonly used physical function questionnaires in rheumatoid arthritis and a PROMIS computerized adaptive test: A simulation study. (under Review) 


\begin{abstract}
Objective: Recently a Dutch-Flemish version of the patient-reported outcome measurement information system (PROMIS) physical function (PF) item bank was concurrently calibrated with the Health Assessment Questionnaire disability index (HAQ-DI) and SF-36 physical functioning scale (PF-10), for use in RA. The resulting item parameters were used in this study to evaluate and compare the measurement precision and sensitivity to change of the HAQ-DI, the PF-10 and simulated PROMIS PF computer adaptive tests (CATs), with respectively 5, 10 and15 items using item response theory based simulation studies.

Methods: Measurement precision of the various physical function instruments was evaluated by calculating the root of the mean squared errors (RMSE) between true physical function levels $(\theta)$ and estimated physical function levels $(\hat{\theta})$. Measurement precision was evaluated at nine levels of physical function with $n=5000$ simulated response patterns per level. Sensitivity to change was evaluated by the ability of a simple statistical test to detect simulated change scores of small to strong magnitude (standardized effect size $=0.20,0.35$ and 0.50 ).

Results: RMSE's were smaller for the PROMIS PF CAT-15 and CAT-10 than teh HAQ-DI and PF-10 across all levels of $\theta$. Only marginal improvement in performance was observed for the CAT-15 compared with the and the CAT-5 performed quite similarly to the HAQ-DI and PF-10 across most levels of $\theta$. Substantially improved sensitivity to chance was observed for the CAT-10 compared with HAQ-DI and PF-10, particularly in detecting moderate to strong effect sizes.

Conclusion: A simulated Dutch-Flemish PROMIS PF CAT with 10 items showed clearly higher measurement precision than the HAQ-DI and PF-10. The observed higher reliability translates to lower sample size requirements for detecting changes in clinical status.
\end{abstract}


Rheumatoid arthritis (RA) is a chronic, systemic inflammatory disease characterized by progressive inflammation of the connective tissue of the body. Inflammation of synovial membranes damages the joint capsule and articular cartilage. This characteristic joint damage evolves slowly over the course of the disease, with an incremental effect on the ability of the patient to perform routine daily activities. Therefore, preservation of physical function is a key therapeutic goal in the longterm management of rheumatoid arthritis (RA) and physical function has been an endorsed study endpoint since the first proposed core set of outcome measures in this field $(1,2)$.

Most contemporary clinical and observational studies in RA employ self-report questionnaires to assess physical function (3). However, the concurrent assessment of patientreported physical function and the increasing number of other relevant patient-reported outcome domains places a considerable and increasing burden, both on the patient and the administrator. Moreover, it has proven difficult to develop feasible fixed-length questionnaires that adequately measure the variety of physical function levels that occur in various stages of RA. Consequently, floor and ceiling effects are common on standard outcome measures such as the Health Assessment Questionnaire disability index (HAQ-DI), particularly in relatively well-functioning populations $(4,5)$. This has led to increased interest in the flexibility of item response theory (IRT) based computerized adaptive assessment of physical function (6-8).

In the IRT framework, item and person parameters are calibrated on a common latent metric, commonly referred to as $\theta$. Individual items are described by item characteristic functions which give the probability of a given response as a function of $\theta(9)$. After a set of items has been calibrated under an IRT model, maximum likelihood or Bayesian procedures can be used to estimate $\theta$ for future respondents within the same population from any subset of items. Calibrated item banks can therefore be used to create more efficient measures by administering only the most relevant questions for specific research needs, either by manually selecting items or by computerized adaptive testing (CAT) algorithms, where physical function estimates of individual patients are sequentially statistically optimized (10). This is achieved by capitalizing on the local definition of reliability in IRT, where so-called information functions describe the measurement precision of individual items at each of the different levels of physical function that are measured by the ensemble of the calibrated items. Given the practical constraint that only a limited number of items can be administered, the most reliable physical function estimates are obtained if those questions are administered which have the highest measurement precision at the (estimated) level of physical function of the responding patient. Theoretically this means that more precise and optimally efficient estimates of physical function may be obtained with CAT compared to classical 
instruments where the same number of untailored items is administered to each patient, provided that the CAT algorithm can select items from a sufficiently suitable item bank.

However, no studies as of yet have directly evaluated whether these theoretical advantages translate into meaningful practical gains in measurement precision and efficiency for assessing physical function in RA. We recently concurrently calibrated a Dutch-Flemish version of the Patient Reported Outcome Information System (PROMIS) physical function item bank and both the HAQ-DI and SF-36 physical functioning scale (PF-10) for use in RA (11). The objective of the current study was to evaluate and compare the measurement precision of a PROMIS physical function CAT with respectively 5, 10 and 15 items with the measurement precision of the HAQDI and the PF-10, which are currently the most frequently used tools for assessing physical function in this field. Furthermore, we evaluated whether observed differences in measurement precision would also yield more power to detect changes in functional status. Both objectives were evaluated by means of simulation studies.

\section{Materials and methods}

\section{Measures}

SF-36 physical functioning scale (PF-10)

The PF-10 is one of the eight scales of the SF-36 Health Survey and consists of 10 items measuring perceived current limitations in a variety of physical activities on a 3-point response scale from 1 (yes, limited a lot) to 3 (no, not limited at all). Scores on the PF-10 items are summed and linearly transformed to range between 0 and 100, with higher scores indicating more favorable levels of physical functioning (12).

Health Assessment Questionnaire disability index (HAQ-DI)

The HAQ-DI contains 20 items measuring physical disabilities over the past week in eight categories of daily living: dressing and grooming, rising, eating, walking, hygiene, reach, grip, and activities. Each item is scored on a 4-point rating scale from 0 (without any difficulty) to 3 (unable to do). 8 category scores are obtained by ranking the worst item score in each of the respective categories and a total HAQ-DI score is obtained by averaging the 8 category scores (13).

PROMIS physical function (PF) item bank

The PROMIS PF item bank measures self-reported, current capability to carry out activities that require physical actions, ranging from self-care (activities of daily living) to more complex activities that require a combination of skills, often within a social context. The final calibrated item bank contains 121 questions assessing the functioning of the upper extremities (dexterity), lower extremities (walking or mobility), and central regions (neck, back), as well as instrumental activities 
of daily living, such as running errands. Each item is scored on a 5-point rating scale, with higher scores indicating better functioning. The Dutch-Flemish translation of the item bank was developed according to the universal PROMIS translation approach which included extensive forward-back translation procedures, expert reviews, and cognitive debriefing interviews among Dutch and Flemish participants $(7,14)$.

\section{Item bank calibration}

The data that was used to calibrate the item bank were collected from 690 patients with RA participating in the Dutch Rheumatology Monitoring (DREAM) registry. Consecutive patients were invited to participate in the study upon logging on to their patient portals. The generalized partial credit model (GPCM) was used to concurrently calibrate the HAQ-DI, PF-10 and PROMIS PF item bank in a single IRT model. The GPCM is an IRT model suitable for polytomous data that allows the number of response options to differ between items (15). This feature allowed the items of the different instruments to be concurrently calibrated despite their differing number of response options. The resulting IRT metric allows physical function levels $(\theta)$ for individual instruments to be estimated on a common scale so that their relative accuracy in recovering simulated physical function levels could be straightforwardly compared. The latent scale has a mean of 0 , which is centered around the average level of physical function observed in the sample of RA patients that was used to calibrate the scale, and a standard deviation (SD) of 1. More details regarding the calibration sample and model fit are described elsewhere (11).

\section{CAT specifications}

The CAT algorithm adaptively selects items from the PROMIS PF item bank and the specifications used in the current study correspond to the first generation PROMIS CAT engine (16). In this study, Bayesian procedures were used, that is, the expected a posteriori method (EAP) was used to obtain (interim) physical function estimates and the maximum posterior weighted information item selection criterion was employed (17). The CAT algorithm was specified to assume a physical function level of $\theta=0$ before the administration of items was started. Therefore all simulated runs started with the item 'Are you able to reach into a low cupboard?' (PFC31), which is the item with the highest precision at this level of physical function.

\section{Data simulation and statistical analysis}

The first set of simulations pertained to the relative measurement precision of the HAQ-DI and PF-10 compared with a PROMIS PF CAT algorithm with 5, 10 or 15 items. The ability of the different instruments to recover simulated 'true' physical function scores, was evaluated at nine different levels of physical function ranging from $\theta=-4$ (i.e. 4 SD below the mean level of physical function in the calibration sample) to $\theta=4$. For each of these score levels, $5000 \theta$ 's were sampled 
from a normal distribution with a SD of 1 . WinGen (18) was used to generate response patterns consistent with the item parameters obtained in Oude Voshaar et al (11) and the specified levels of $\theta$. Instrument specific simulations were subsequently run in Firestar (19) and the difference between the actual specified level of $\theta$ and the estimates obtained from these runs was quantified by calculating the square root of the mean squared error (RMSE), for each instrument, at each of the nine levels of $\theta$.

A second set of simulations was performed to evaluate the statistical power of the HAQDI, PF-10 and PROMIS PF CAT-10 to detect treatment effects on physical function that are typically observed in clinical trials. To be able to assess the performance of the various instruments at those levels that are likely to be seen in clinical trial settings we consulted a recent meta-analysis of treatment effects of biologic agents on physical function in rheumatoid arthritis (20). The mean HAQ-DI baseline score across the 28 studies included in the meta analysis was close to 1.50, which corresponds to $\theta=-1.27$ (see table 1 ). Therefore, the means were set equal to $\theta=-1.27$ for the analysis at baseline (T1) and to an effect size (ES) of respectively $0.20,0.35$ and 0.50 for the second assessment (T2). The means of the distribution of $\theta$ at the two time points were estimated using marginal maximum likelihood for a repeated measures design (29). For this procedure, the autocorrelation across time points was set to equal 0.70. Further, the second series of simulations was run with analogous settings as outlined above. All estimates and their SDs were obtained in the MIRT software package (21). The ability of the instruments to detect the occurred changes in true $\theta$ was quantified by calculating the proportion of times the difference between the means at 'T1 and $\mathrm{T} 2$ was significant at alpha $=5 \%$ (one-sided) for sample sizes of 25, 50, 75 and 100 patients. The statistical test used was the estimated difference between the means divided by the SD of this difference. This statistic was considered to follow a normal distribution.

\section{Results}

Table 1 presents a mapping of physical function scores for the HAQ-DI and PF-10, obtained by applying the standard scoring algorithms, on the latent IRT-based metric. Despite the different ways the scores are obtained and expressed, IRT and summed score based approaches generally yield highly correlated scores. The correlation between IRT-based and standard scores was 0.97 and 0.95 for the HAQ-DI and PF-10, respectively. Throughout the remainder of the paper results will be reported for the IRT metric only, but table 1 can be used as a frame of reference for those more familiar with the standard scoring algorithms for these questionnaires. 
Table 1: Mapping of HAQ-DI and PF-10 total scores on the latent IRT metric

\begin{tabular}{|c|c|c|c|}
\hline PF-10 score & $\theta$ & HAQ-DI Score & $\theta$ \\
\hline 0 & -2.18 & 0.000 & 3.90 \\
\hline 5 & -1.45 & 0.125 & 2.59 \\
\hline 10 & -1.80 & 0.250 & 2.13 \\
\hline 15 & -1.68 & 0.375 & 1.71 \\
\hline 20 & -1.26 & 0.500 & 0.75 \\
\hline 25 & -1.08 & 0.625 & 0.69 \\
\hline 30 & -0.88 & 0.750 & 0.65 \\
\hline 35 & -1.34 & 0.875 & -0.31 \\
\hline 40 & -0.92 & 1.000 & -0.37 \\
\hline 45 & -0.39 & 1.125 & -0.36 \\
\hline 50 & -0.02 & 1.250 & -1.18 \\
\hline 55 & 0.28 & 1.375 & -1.21 \\
\hline 60 & 0.04 & 1.500 & -1.27 \\
\hline 65 & 0.59 & 1.625 & -1.68 \\
\hline 70 & 0.84 & 1.750 & -2.43 \\
\hline 75 & 1.13 & 1.875 & -2.82 \\
\hline 80 & 1.72 & 2.000 & -3.20 \\
\hline 85 & 2.33 & 2.125 & -3.58 \\
\hline 90 & 2.75 & 2.250 & -3.97 \\
\hline 95 & 3.81 & 2.375 & -4.35 \\
\hline \multirow[t]{5}{*}{100} & 4.59 & 2.500 & -4.73 \\
\hline & & 2.625 & -5.12 \\
\hline & & 2.750 & -5.50 \\
\hline & & 2.875 & -5.88 \\
\hline & & 3.000 & -6.27 \\
\hline
\end{tabular}

*HAQ-DI score $>1.875$ were imputed by linear regression, due to data paucity; PF-10 = SF-36 physical functioning scale; HAQDI $=$ Health Assessment Questionnaire Disability Index; $\theta=$ Latent physical function score.

Measurement precision

Figure 1 presents the conditional precision of the instruments across nine levels of physical function. The most precise estimates of physical function were achieved at physical function levels at or $1 \mathrm{SD}$ below the average of the scale. In general, the precision of all instruments was better for lower levels of function and measurement performance decreased sharply for physical function levels $\geq 2$ SD above average, with, for example, RMSE $=0.44$ for the CAT- 15 . Performance of the HAQ-DI was optimal for lower levels of physical function and its precision remained relatively constant for below average physical function levels. By contrast, the PF-10 performed comparatively poorly at the lowest levels of physical function but outperformed the HAQ-DI at above average levels of physical function. Interestingly, a CAT with as few as 5 items outperformed both the HAQ-DI and PF-10 across most levels of function. The CAT algorithms with 10 and 15 
items produced the most accurate and very similar results across all levels of physical function, with the CAT-15 having marginally higher precision for very low levels of physical function only.

Figure 1: Conditional precision of physical function measures across various levels of $\theta$

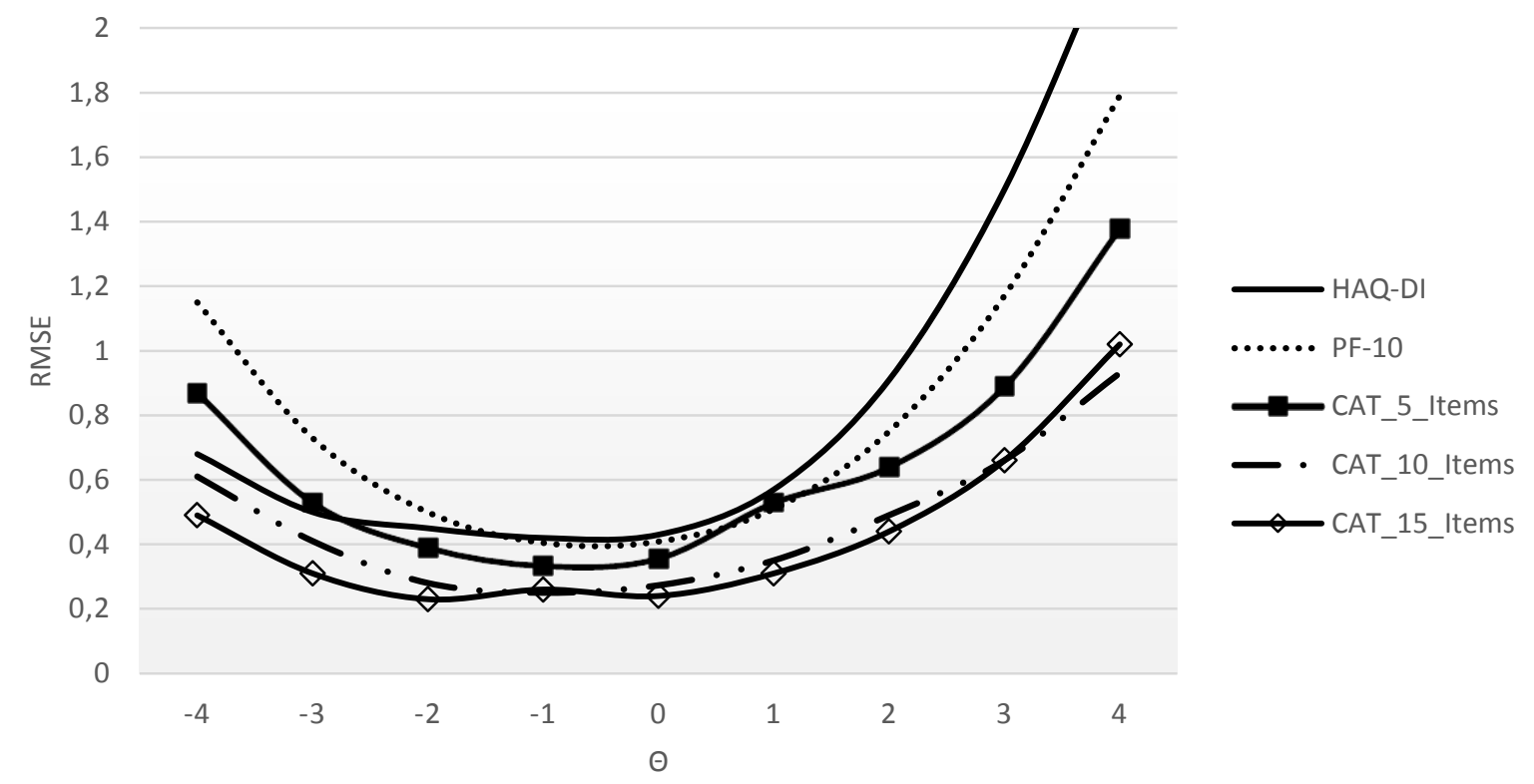

RMSE $=$ Root mean squared error; $\theta=$ Latent physical function scale; HAQ-DI $=$ Health Assessment Questionnaire Disability Index; PF-10 = SF-36 physical functioning scale; CAT $=$ Computer Adaptive Testing algorithm

\section{Detection of treatment effects}

In the analysis of power for ES $=0.50,45$ out of 121 PROMIS PF items were elected by the CAT10. Item exposure rates are presented in Table 2, ranked from least to most difficult items to perform. Generally, more difficult items had higher exposure rates at T2, consistent with the improved level of simulated physical function at that time point. The test information function of the 10 items with the highest exposure at T1 are plotted in figure 2 together with the test information functions of the PF-10 and HAQ-DI. Test information functions describe the local reliability of the measures across the latent continuum of physical function. The HAQ-DI had higher overall reliability than PF-10 for lower

Table 2: Exposure rates of PROMIS physical function bank items in the analysis of power 


\begin{tabular}{|c|c|c|c|}
\hline item & & Exposure at & Exposure at \\
\hline code & Item & T1 & $\mathrm{T} 2$ \\
\hline PFC31 & Does your health now limit you in taking a shower? & 518 & 255 \\
\hline PFA8 & Are you able to stand up from an armless straight chair? & 192 & 267 \\
\hline PFA55 & Are you able to walk a block (about $100 \mathrm{~m}$ ) on flat ground? & 671 & 330 \\
\hline PFA21 & Are you able to step up and down curbs? & 2072 & 1346 \\
\hline PFA42 & re you able to carry a laundry basket up a flight of stairs? & 2 & 0 \\
\hline PFB9 & $\begin{array}{l}\text { Are you able to stand without losing your balance for several minutes? } \\
\text { Are you able to dress yourself, including tying shoelaces and buttoning }\end{array}$ & 34 & 14 \\
\hline PFA53 & your clothes? & 71 & 33 \\
\hline PFB10 & Are you able to climb up five steps? & 2406 & 1971 \\
\hline PFA6 & Are you able to put on and take off a coat or jacket? & 0 & 2905 \\
\hline PFB14 & Are you able to remove something from your back pocket? & 869 & 605 \\
\hline PFC13 & Are you able to get in and out of a car? & 0 & \\
\hline PFA30 & Are you able to pour liquid from a bottle into a glass? & 1080 & 566 \\
\hline PFB54 & $\begin{array}{l}\text { Does your health now limit you in going for a short walk (less than } 15 \\
\text { minutes)? }\end{array}$ & 49 & 26 \\
\hline PFB1 & Are you able to reach into a low cupboard? & 5000 & 5000 \\
\hline PFA36 & Are you able to use a hammer to pound a nail? & 1012 & 526 \\
\hline PFB24 & $\begin{array}{l}\text { Are you able to lift one pound }(0.5 \mathrm{~kg}) \text { to shoulder level without bending } \\
\text { your elbow? }\end{array}$ & 827 & 422 \\
\hline PFB23 & Are you able to stand for short periods of time? & 392 & 199 \\
\hline PFA18 & Are you able to go up and down stairs at a normal pace? & 3818 & 4662 \\
\hline PFB33 & Are you able to run errands and shop? & 2233 & 2951 \\
\hline PFB5 & Are you able to carry a shopping bag or briefcase? & 0 & 19 \\
\hline PFC10 & Are you able to stand up on tiptoes? & 460 & 269 \\
\hline & Are you able to do yard work like raking leaves, weeding, or pushing a & & \\
\hline PFB56 & lawn mower? & 0 & 534 \\
\hline PFC6 & Are you able to walk at a normal speed? & 46 & 25 \\
\hline PFA5 & Are you able to move a chair from one room to another? & 4541 & 4664 \\
\hline PFB44 & Are you able to carry a laundry basket up a flight of stairs? & 4221 & 1990 \\
\hline PFB48 & $\begin{array}{l}\text { Does your health now limit you in going OUTSIDE the home, for } \\
\text { example to shop or visit a doctor's office? }\end{array}$ & 1871 & 1453 \\
\hline PFB40 & Are you able to wash and dry your body? & 4525 & 4365 \\
\hline PFA37 & Does your health now limit you in bathing or dressing yourself? & 678 & 3328 \\
\hline PFA25 & Are you able to do chores such as vacuuming or yard work? & 98 & 401 \\
\hline PFA11 & Are you able to take a tub bath? & 2134 & 1682 \\
\hline PFA15 & Are you able to jump up and down? & 2784 & 2813 \\
\hline PFA4 & Does your health now limit you in lifting or carrying groceries? & 240 & 722 \\
\hline PFA56 & Are you able to run a short distance, such as to catch a bus? & 863 & 1309 \\
\hline PFA16 & Does your health now limit you in climbing several flights of stairs? & 391 & 887 \\
\hline PFB49 & $\begin{array}{l}\text { Does your health now limit you in doing moderate work around the } \\
\text { house like vacuuming, sweeping floors or carrying in groceries? }\end{array}$ & 1028 & 1945 \\
\hline PFB50 & $\begin{array}{l}\text { Does your health now limit you in doing moderate activities, such as } \\
\text { moving a table, pushing a vacuum cleaner, bowling, or playing golf? }\end{array}$ & 169 & 607 \\
\hline PFC12 & Does your health now limit you in bending, kneeling, or stooping? & 6 & 29 \\
\hline PFC39 & Are you able to run 100 yards $(100 \mathrm{~m})$ ? & 1368 & 2062 \\
\hline PFB13 & Does your health now limit you in doing two hours of physical labor? & 0 & 66 \\
\hline PFA10 & Does your health now limit you in doing heavy work around the house & 78 & 327 \\
\hline & Does your health now limit you in doing vigorous activities, such as & & \\
\hline PFA39 & running, lifting heavy objects, participating in strenuous sports? & 0 & 1 \\
\hline PFC46 & Are you able to run or jog for two miles $(3 \mathrm{~km})$ ? & 0 & 12 \\
\hline PFA1 & Are you able to run at a fast pace for two miles $(3 \mathrm{~km})$ ? & 0 & 4 \\
\hline PFC7 & Are you able to run five miles $(8 \mathrm{~km})$ & 0 & 1 \\
\hline PFC31 & Does your health now limit you in taking a shower? & 518 & 255 \\
\hline
\end{tabular}


levels of physical function which corresponds to the results of the previous analyses. Furthermore, the CAT-10 was successful at optimizing measurement precision at $\theta=-1.27$. Measurement precision of the 10 most frequently elected items was in fact higher than that of both classical instruments across most levels of physical function. This likely reflects the extra information provided by the greater number of response options of the PROMIS PF items compared with the HAQ-DI or PF-10 items.

Figure 2: Local reliabiltiy of 10 most frequently administered PROMIS physical function items at $\theta=-1.27$ compared with the HAQ-DI and PF-10

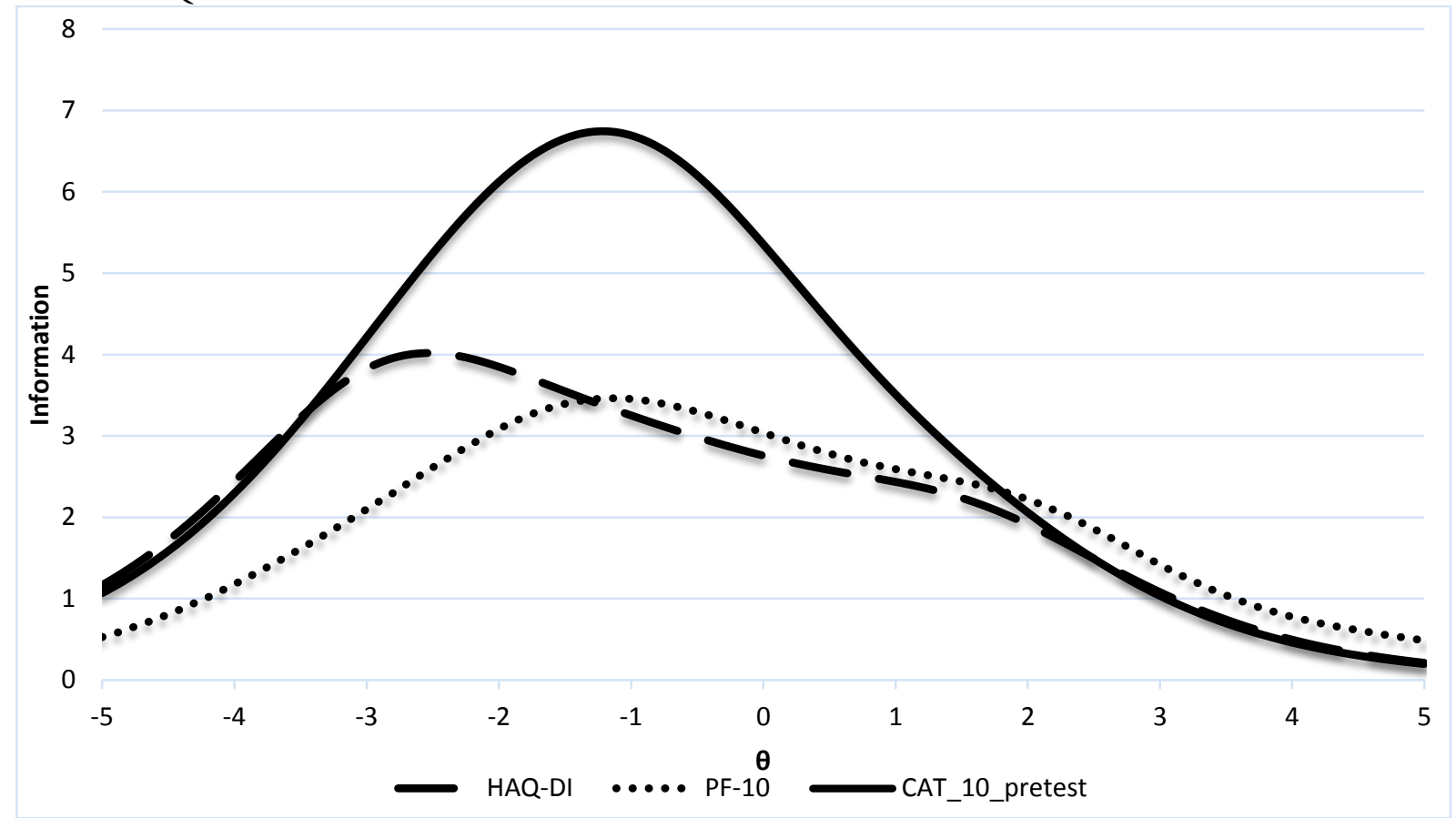

Information $=$ measure of local reliability; $\theta=$ Latent physical function scale; HAQ-DI $=$ Health Assessment Questionnaire Disability Index; PF-10 = SF-36 physical functioning scale; CAT_10_pretest $=10$ most frequently selected PROMIS physical function items by CAT algorithm at $\theta=-1.27$

Table 3 presents the results of the power analysis of the various instruments to detect treatment effects of various magnitudes and sample sizes. Performance of the three measures to detect small treatment effects was very similar, except for an higher detection rate for the HAQ$\mathrm{DI}$ at $\mathrm{n}=25$. For $\mathrm{ES}=0.35$ and $\mathrm{ES}=0.50$, the PROMIS PF CAT -10 began to clearly outperform both classical measures. This likely reflects that the higher $\theta$ 's at T2 enable the CAT algorithm to select items from the range where the item bank is richest in information (i.e. the range of $\theta$ 's between -1 and 0$)$. 
Table 3: The percentage of 1000 simulated clinical trials in which the statistical test of the hypothesis of equal means across time points was rejected at $\mathrm{Z}=1.645$

\begin{tabular}{|c|c|c|c|c|c|c|c|c|c|}
\hline & \multicolumn{3}{|c|}{$\mathrm{ES}=0.20$} & \multicolumn{3}{|c|}{$\mathrm{ES}=0.35$} & \multicolumn{3}{|c|}{$\mathrm{ES}=0.50$} \\
\hline & PF-10 & HAQ- & PROMIS & HAQ- & PF-10 & PROMIS & PF-10 & HAQ- & PROMIS \\
\hline & & DI & CAT-10 & DI & & CAT-10 & & DI & CAT-10 \\
\hline 25 & $5.8 \%$ & $8.4 \%$ & $4.3 \%$ & $17.5 \%$ & $15.5 \%$ & $19.5 \%$ & $51.4 \%$ & $39.5 \%$ & $61.8 \%$ \\
\hline 50 & $12.9 \%$ & $11.9 \%$ & $11.2 \%$ & $40.2 \%$ & $36.1 \%$ & $49.8 \%$ & $85.1 \%$ & $75.6 \%$ & $93.9 \%$ \\
\hline 75 & $19.9 \%$ & $18.1 \%$ & $18.3 \%$ & $58.9 \%$ & $55.1 \%$ & $72.5 \%$ & $95.7 \%$ & $94.2 \%$ & $99.8 \%$ \\
\hline 100 & $28.3 \%$ & $27.8 \%$ & $26.1 \%$ & $73.9 \%$ & $68.1 \%$ & $86.5 \%$ & $99.5 \%$ & $98.8 \%$ & $100 \%$ \\
\hline
\end{tabular}

HAQ-DI = Health Assessment Questionnaire Disability Index; PF-10 = SF-36 physical functioning scale; CAT = Computer Adaptive Testing algorithm

\section{Discussion}

Applications of IRT-based item banking such as CAT are potentially useful tools that facilitate the assessment of the broad range of physical function levels observed in RA, without the need to resort to extensively long fixed-length questionnaires. The current study explored the measurement precision and efficiency of the commonly used fixed-length HAQ-DI and PF10, compared with a CAT algorithm based on the PROMIS PF item bank, using simulation studies. Overall, the findings suggest that a 10-item PROMIS PF CAT performs better than the HAQ-DI and PF-10 in terms of measurements precision and sensitivity to change.

The results of the current study illustrate that the items of the HAQ-DI are slightly better suited for relatively poor functioning patients and the PF-10 items slightly better for wellfunctioning populations. These results correspond to previous work in RA, where substantial ceiling and floor effects, respectively, were observed for these measures $(4,5)$. In fact it has also been demonstrated using IRT-based methodology that more favorable scaling properties with respect to ceiling and floor effects could be achieved in RA if items of a modified HAQ and PF10 were concurrently calibrated (22). Administering multiple fixed-length measures of physical function to extend the range of physical function levels, however, is not a practically feasible solution to scaling problems of physical function assessment in RA, considering the added burden this would entail for patients and administrators.

However, before the use of CATs in clinical settings can be recommended it is necessary to evaluate the performance of CAT applications in comparison with the existing measures that are routinely employed in current clinical studies and that have proven their worth over time (23). The current study is the first to evaluate the comparative performance of CAT assessment based on the PROMIS PF item bank with the established HAQ-DI and PF-10 in RA, using simulation studies. The CAT algorithm yielded superior precision compared to both fixed-length questionnaires in recovering simulated physical function scores across all but the very lowest levels 
of physical function with only 5 items and across all evaluated levels of physical function with 10 and 15 items. Similar results were obtained with a preliminary version of the PROMIS PF item bank based on a calibration of historical physical function data (24).

These findings suggest that impressive gains in efficiency of physical function assessment can be achieved in practice by CAT assessments based on the PROMIS PF item bank, without sacrificing measurement precision. At below average levels of physical function, the HAQ-DI performed reasonably well, reflecting its items measuring mostly simply activities of daily living, while the largest differences in measurement precision between the PROMIS PF CAT and both classical instruments were observed at above average levels of physical function. Relatively wellfunctioning RA patients are an increasingly relevant population in light of the overall improved status of current patients with RA (25). for example, recently an increase in studies evaluating the possibility of down titrating anti-TNF treatment or disease modifying anti rheumatic drugs in patients with stable remission $(26,27)$.

It has often been suggested that the PROMIS measures are highly reliable and hence smaller sample sizes would be needed for clinical studies utilizing these measures (28). The current study demonstrates that large differences indeed existed in the power of the instruments to identify occurred changes. Clinical studies in RA typically show improvements in physical function of moderate to large magnitude (i.e. $\mathrm{ES} \geq 0.50$ ), (20). In the present study almost $95 \%$ of the simulated moderate effects were correctly identified by statistical tests based on the estimates obtained with the PROMIS PF CAT-10 at $\mathrm{n}=50$ patients. To achieve similar power with the HAQ-DI or PF-10, 75 patients would have to be included in the active condition. These results have important practical implications because the inclusion of fewer patients in clinical trials saves costs. An important point to note here is that the number of patients needed to achieve a certain power was higher than would be suggested by power tables that are routinely used for determining sample size in clinical studies. The main reason for this phenomenon is that when using a t-test or similar statistical technique it is assumed that the endpoint is measured without error. However the estimation error associated with the IRT estimates has to be taken into account. Therefore, the reliability of the instrument is an extra variable that should be taken into consideration when determining the sample size for a study. This is accomplished by using the marginal maximum likelihood method to estimate the means of the latent variable distribution at the two time points (29).

Although the results of the current study are highly encouraging, limited availability of technology and familiarity with CAT are potential bottlenecks in the adoption of CAT in current research practice (30). Researchers interested in using the PROMIS PF item bank in RA in settings 
where computerized assessment is not feasible may choose to administer a subset of the items that were most frequently chosen in the evaluation of power (see table 3). These items are specifically tailored to the average level of physical function experienced by patients with RA upon study entry in clinical trials and the 10 most frequently chosen items were shown to represent a more reliable assessment of physical function than the 20 items of the HAQ-DI or the PF-10, not only with respect to the relevant levels of physical function, but across all but the very highest levels of physic function. The obtained item response data can then be scored using the item parameters available at the PROMIS assessment center (www.assessmentcenter.net), so that results can be expressed on the standardized PROMIS metric. This allows the impact of RA on physical function to be compared with other conditions (31) A general limitation of the use of short-forms instead of CATs is that they are not optimally tailored to individual patients, resulting in lower than optimal reliability for patients with unusual levels of function and possible floor and ceiling effects. On the other hand, manually selecting fixed items to be administered is one way to ensure the content validity of the assessment. In the CAT algorithms in the current study, items were selected purely based on their measurement precision without considering the content of the individual items. By contrast, the HAQ-DI has eight categories of physical function that are all of particular relevance to RA, which strengthens its content validity for RA. Content constraints may also be imposed on the CAT selection algorithm which will ensure a balanced assessment of various aspects of physical function that are deemed relevant a priori (32).

An inevitable limitation of the simulation methodology employed in the current study is that it is assumed that the model holds perfectly. The validity of a post-hoc simulation study can in principle be confirmed by performing empirical simulation studies that use real data to simulate the CAT responses. Due to the research design that was utilized to obtain the item parameters for the PROMIS PF items in both the US and Dutch calibration study, only a limited number of items were filled out per patient, precluding a realistic empirical simulation. However, previous studies with polytomous data have generally found small differences between empirical and post-hoc simulations (33).

In summary, the current study demonstrates the considerable gains in efficiency and measurement precision that may be achieved in the assessment of physical function in RA using CATs based on the PROMIS PF item bank. Overall a 10-item CAT demonstrated better measurement precision than classical fixed-length questionnaires which may translate to increased power to detect treatment effects in clinical studies in RA. 


\section{References}

1. Wolfe F, Lassere M, Heijde D van der, Stucki G, Suarez-Almazor M, Pincus T, et al. Preliminary core set of domains and reporting requirements for longitudinal observational studies in rheumatology. J Rheumatol 1999;26:484-9.

2. Heijde D van Der. Impact of rheumatoid arthritis on physical function during the first five years. No longer a question mark? Rheumatology (Oxford) 2000;39:579-80.

3. Kalyoncu U, Dougados M, Daurès J-P, Gossec L. Reporting of patient-reported outcomes in recent trials in rheumatoid arthritis: a systematic literature review. Ann Rheum Dis 2009;68:183-90.

4. Oude Voshaar M a H, Klooster PM ten, Taal E, Laar M a FJ van de. Measurement properties of physical function scales validated for use in patients with rheumatoid arthritis: a systematic review of the literature. Health Qual Life Outcomes 2011;9:99.

5. Stucki G, Stucki S, Brühlmann P, Michel B a. Ceiling effects of the Health Assessment Questionnaire and its modified version in some ambulatory rheumatoid arthritis patients. Ann Rheum Dis 1995;54:461-5

6. Ni P, McDonough CM, Jette AM, Bogusz K, Marfeo EE, Rasch EK, et al. Development of a computeradaptive physical function instrument for Social Security Administration disability determination. Arch Phys Med Rehabil 2013;94:1661-9.

7. Cella D, Riley W, Stone A, Rothrock N, Reeve B, Yount S, et al. The Patient-Reported Outcomes Measurement Information System (PROMIS) developed and tested its first wave of adult self-reported health outcome item banks: 2005-2008. J Clin Epidemiol 2010;63:1179-94.

8. Haley SM, Ni P, Hambleton RK, Slavin MD, Jette AM. Computer adaptive testing improved accuracy and precision of scores over random item selection in a physical functioning item bank. J Clin Epidemiol 2006;59:1174-82.

9. Hambleton R, Swaminathan H, Rogers H. Fundamentals of item response theory. 1991.

10. Linden W van der, Glas C. Computerized adaptive testing: Theory and practice. 2000.

11. Oude Voshaar MAH, Klooster PM ten, Glas CAW, Vonkeman HE, Taal E, Moens HJB, et al. Calibration of the PROMIS physical function item bank in Dutch patients with rheumatoid arthritis. PLoS One 2014;9:e92367.

12. Ware JE, Sherbourne C. The MOS 36-Item Short-Form Health Survey (SF-36). Med Care 1992;30:473-483.

13. Fries JF, Spitz PRN, Kraines R, Halsted RH. Measurement of patient outcome in arthritis. Arthritis Rheum 1980:137-148.

14. Terwee CB, Roorda LD, Vet HCW de, Dekker J, Westhovens R, Leeuwen J van, et al. Dutch-Flemish translation of 17 item banks from the Patient-Reported Outcomes Measurement Information System (PROMIS). Qual Life Res 2014.

15. Muraki E. A generalized partial credit model: Application of an EM algorithm. Appl Psychol Meas 1992.

16. Choi SW, Reise SP, Pilkonis P a, Hays RD, Cella D. Efficiency of static and computer adaptive short forms compared to full-length measures of depressive symptoms. Qual Life Res 2010;19:125-36.

17. Linden W Van der. Bayesian item selection criteria for adaptive testing. Psychometrika 1998;63:201-

18. Han KT. WinGen: Windows Software That Generates Item Response Theory Parameters and Item Responses. Appl Psychol Meas 2007;31:457-459. 
19. Choi SW. Firestar: Computerized Adaptive Testing Simulation Program for Polytomous Item Response Theory Models. Appl Psychol Meas 2009;33:644-645.

20. Barra L, Ha A, Sun L, Fonseca C, Pope J. Efficacy of biologic agents in improving the Health Assessment Questionnaire (HAQ) score in established and early rheumatoid arthritis: a meta-analysis with indirect comparisons. Clin Exp Rheumatol 2014.

21. Glas CAW, Analysis D. Preliminary Manual of the software program Multidimensional Item Response Theory (MIRT). 2010.

22. Martin M, Kosinski M, Bjorner JB, Ware JE, Maclean R, Li T. Item response theory methods can improve the measurement of physical function by combining the modified health assessment questionnaire and the SF-36 physical function scale. Qual Life Res 2007;16:647-60.

23. Bruce B, Fries JF. The Stanford Health Assessment Questionnaire: a review of its history, issues, progress, and documentation. J Rheumatol 2003;30:167-78.

24. Rose M, Bjorner JB, Becker J, Fries JF, Ware JE. Evaluation of a preliminary physical function item bank supported the expected advantages of the Patient-Reported Outcomes Measurement Information System (PROMIS). J Clin Epidemiol 2008;61:17-33.

25. Welsing PMJ, Fransen J, Riel PLCM van. Is the disease course of rheumatoid arthritis becoming milder? Time trends since 1985 in an inception cohort of early rheumatoid arthritis. Arthritis Rheum 2005;52:2616-24.

26. Herwaarden $\mathrm{N}$ van. Down titration and discontinuation strategies of tumor necrosis factor blocking agents for rheumatoid arthritis in patients with low disease activity. Cochrane ... 2013.

27. O'Mahony R, Richards A, Deighton C, Scott D. Withdrawal of disease-modifying antirheumatic drugs in patients with rheumatoid arthritis: a systematic review and meta-analysis. Ann Rheum Dis 2010;69:1823-6.

28. Fries JF, Krishnan E, Rose M, Lingala B, Bruce B. Improved responsiveness and reduced sample size requirements of PROMIS physical function scales with item response theory. Arthritis Res Ther 2011;13:R147.

29. Glas $\mathrm{C}$ a W, Geerlings H, Laar M a FJ van de, Taal E. Analysis of longitudinal randomized clinical trials using item response models. Contemp Clin Trials 2009;30:158-70.

30. Revicki DA, Sloan J. Practical and philosophical issues surrounding a national item bank: if we build it will they come? Qual Life Res 2007;16 Suppl 1:167-74.

31. Rothrock NE, Hays RD, Spritzer K, Yount SE, Riley W, Cella D. Relative to the general US population, chronic diseases are associated with poorer health-related quality of life as measured by the Patient-Reported Outcomes Measurement Information System (PROMIS). J Clin Epidemiol 2010;63:1195-204.

32. Veldkamp B, Linden W Van der. Multidimensional adaptive testing with constraints on test content. 2002;67:575-588.

33. Makransky G, Mortensen EL, Glas C a W. Improving personality facet scores with multidimensional computer adaptive testing: an illustration with the NEO PI-R. Assessment 2013;20:3-13. 
160 | Chapter 8 


\section{Chapter 9}

Summary and general discussion of findings 
Physical function is an established outcome in the field of RA $(1,2)$. Since it has first been proposed as a key outcome in this field, the assessment of physical function has evolved from simple, standardized performance tests to patient reported outcome measures that aim to comprehensively assess patients' overall level of physical function. The results of two systematic reviews in chapter 2 have revealed that no less than 26 different questionnaires are currently available for measuring physical function in RA, of which 10 were also evaluated in Dutch patients $(3,4)$. The interpretability of patient reported physical function outcomes is ampered by the availability of so many specific questionnaires that all have unique items and scoring procedures so that studies that utilize different measures are difficult to compare. Moreover, although many questionnaires were found to have satisfactory content and construct validity, floor and ceiling effects were common, even for the most frequently used questionnaires and particularly in more recent studies. This was an anticipated finding given the known heterogeneity of physical disability in RA and the predominantly short, fixed-length nature of the included physical function questionnaires. These findings together underscore the need for further standardization and personalized assessment that could potentially be realized with IRT based measurement.

Another salient finding of chapter 2 was that the cross-cultural equivalence of the translated Dutch questionnaires had never been studied and the process of translating questionnaires was also poorly documented or not documented at all. This is troubling in light of the increasing international field that RA research has become over the last decade and the resulting increased relevance of translated versions of patient questionnaires. Although cross-cultural validity is generally acknowledged as a key measurement property $(5,6)$, no guidelines are currently available on how to evaluate crosscultural equivalence or how to proceed when important cultural bias is present in a translated version of a physical function questionnaire. This might explain the observed paucity of studies of this measurement property. The first study of chapter 3 presents a case study in which the crosscultural equivalence of a Dutch version of the commonly used HAQ-II is evaluated using IRT analysis (7). The study illustrates that IRT provides a natural framework for evaluating the presence of biased items and for evaluating their impact on the comparability of total scores. The results of the study indicated that total scores were comparable across cultures, despite the presence of items with significant cultural bias. However if important total score level bias is considered to be present in a questionnaire, IRT scoring procedures can be developed by implementing group specific item parameters for biased items, as was demonstrated in chapter 3. This general methodology can also be applied to create valid scoring procedures for different versions of a questionnaire or with respect to bias caused by other qualitative background variables such as gender. This is illustrated in the second study of Chapter 3 where two different versions of the Dutch HAQ-DI were found 
to be free of total score level bias (8). We recommend that researchers interested in introducing altered or translated versions of patient reported outcome measures in a new setting, explore its measurement equivalence with the original version as part of the routine evaluation of validity and introduce IRT based scoring procedures for use in the new setting or for the altered instrument, in case substantial bias is found to be present.

An associated problem of the proliferation of physical function questionnaires in the field of RA observed in chapter 2 is that study results are difficult to compare since each measure usually has unique items and scoring procedures. Consequently, the level of physical function actually experienced by patients in specific settings is difficult to characterize. In IRT, physical function estimates on the same scale may be obtained, independent of the questionnaire that was administered, provided that their item parameters have been calibrated under a common IRT model. In chapter 4 it is illustrated how this feature can be utilized to develop conversion tables that link total scores of two or more questionnaires. It was demonstrated that a crosswalk between the two most commonly used physical function questionnaires in RA could be developed and used to obtain quite accurate score conversions at the group level in an independent sample of Dutch patients with RA (9). The second study of chapter 4 demonstrated that accurate conversions could also be achieved in a sample of US patients with RA, fibromyalgia or systemic lupus erythematosus. In developing the crosswalk, we decided to convert latent physical function estimates back to the metric of the concurrently calibrated questionnaires, since we expected it to be a more familiar frame of reference for most clinicians and researchers in the field of RA who are working with these questionnaires. However, doing so introduces an extra source of measurement error related to the fact that observed total score levels rarely perfectly intersect on the latent metric. Consequently, the use of converted scores in for example meta-analyses with small sample sizes is not to be recommended, since it may slightly attenuate the studied effects. Moreover it is likely not possible to develop crosswalks between all of the many physical function measures that are used in the field of RA.

A more direct and precise approach to linking physical function outcomes in the field of RA is to develop a comprehensive physical function item bank and to map all existing physical function questionnaires on this metric. Subsequently the metric can be utilized to provide a common currency for physical function outcomes in RA research. The remaining chapters of the thesis describe the process of calibrating an item bank that could be used in the future for these purposes in RA. Chapter 5 described the rigorous methodology employed and the issues encountered in the process of translating the PROMIS physical function item bank to the Dutch language and culturally adapting it for use in Dutch arthritis populations (10). This step is very important to both 
identify potentially problematic items and to use the collective expertise of a team of content experts as well as the perspective of patients to create a translated version that is both conceptually and semantically optimally equivalent to the original version $(11,12)$. Only five items were identified with potentially culturally inappropriate content, which had to be rewritten to better suit the Dutch setting (10). The results of this study provided valuable information regarding the face validity of the translated version for use in Dutch patients with arthritis. However a drawback of the methodology is that it relies on the consensus between experts and the analysis of the patient reported feedback to resolve problems and there is no way to directly infer from the results whether cross-cultural equivalence of any changed items has been preserved or whether any problematic items were missed. Therefore, In chapter 6 a study is presented where the translated item bank was calibrated in a sample of Dutch patients with RA and its measurement equivalence with the original US version was evaluated. The results demonstrated that the physical function item bank could be fitted to an appropriate IRT model. This finding provides support for the validity of applications of the item bank in patients with RA that require invariant estimates of the item parameters such as CAT or tailored short-forms. Unfortunately however, a definitive evaluation of measurement equivalence with the original US general population data was not yet possible due to distributional problems with the available US general population data as detailed in chapter 6. Moreover the calibration presented in chapter 6 must be considered preliminary due to the relatively small sample size and it is possible that some of the observed bias was due to sampling error. Future studies and more data of US general population and Dutch RA patients are needed before definitive conclusions can be reached and, if needed, valid scoring procedures can be developed that would allow Dutch results to be expressed on the US scale, despite the presence of culturally biased items.

In Chapter 7 the measurement properties of the PROMIS physical function item bank were explored and compared with two traditional measures of physical function. Not surprisingly, the item bank more comprehensively reflected the content areas relevant to physical function in RA and had higher measurement precision than the HAQ-DI and PF-10. Interestingly however, measurement precision of the item bank spanned a much wider range of physical function levels than either of the classical instruments, with particularly superior measurement precision for higher levels of function. Since relatively high levels of function were frequently observed in our sample, the study also illustrates the shortcomings of the classical instruments HAQ-DI and PF10. Practical applications of the item bank will likely prove useful to overcome the ceiling effects that frequently occur on traditional measures in current use. These results were corroborated by the simulation study in chapter 8. In line with previous results (13-15), it was observed that the HAQ-DI functioned optimally, and quite similarly to the various CAT algorithms for below average levels 
of physical function, whereas the SF-36 PF-10 functioned optimally at above average levels of function. Overall the results demonstrated that CAT assessment with only 5 items was equally or more accurate than either of the classical instruments across all levels of physical function. This was an impressive finding, considering that traditional physical function questionnaires typically consist of ten to twenty items. The optimum number of items in terms of measurement precision was achieved with 10 items and it was shown that the physical function CAT with 10 items had more power to detect simulated change scores of moderate magnitude than classical questionnaires. In summary, the findings in chapter 2 revealed that many physical function questionnaires are available for measuring physical function in RA. All 26 included instruments were fixed length questionnaires with a scoring rule based on summing of the individual items, according to the principles of classical test theory. The main shortcomings of the evaluated questionnaires were found to correspond to the theoretical limitations of classical test theory based assessment, resulting from arbitrary scoring procedures that can only be understood with detailed knowledge of the items and rating scale structure of individual instruments and the restrictions imposed on an instrument to assess all occurring levels of physical function with a limited number of items. In the remaining chapters of the thesis, it was demonstrated how IRT based concurrent calibration of physical function instruments and item banking, respectively could be utilized to facilitate the interpretability of physical function instruments and to extend the measurement range of physical function outcomes. In addition it was illustrated how analysis of and statistical correction for measurement bias can be performed using IRT analysis.

\section{Future directions}

Patient reported outcomes are increasingly recognized as core endpoints in clinical research settings where they are used to characterize the patient's perception of the impact of disease and treatment on health and functioning $(5,6)$. This has naturally led to an increasing number of patient reported outcome domains to be considered relevant in the evaluation of patient outcome. For example in RA physical function, pain and fatigue are considered core outcomes to be evaluated in every clinical trial and observational study, while other patient reported outcomes such as social participation and work disability are also considered increasingly important in a variety of settings in this field $(1,2,17,8)$. Patient reported outcome measures are usually administered concurrently, which imposes considerable burden, both on the patient and the administrator (19). This has resulted in increased interest in the flexibility of computerized and IRT based assessment and the development of various item banks for measuring different patient reported outcome domains (20, 21), such as physical function (22-26). These or other calibrated item banks might be used in the 
near future to create more efficient measures by tailoring the level of posed items to specific research needs, either by manually creating short-forms or computerized adaptive testing. However, although recent efforts have evaluated the performance of computerized adaptive testing of health outcomes, e.g., $(26,27)$, most major clinical and observational studies continue to rely on classical instruments that have proven their worth over time.

One concern of many stakeholders is the ability of CAT assessment to reflect changes in clinical status (28-29). The few available head-to-head comparisons have generally shown that (simulated) CAT assessment was slightly less responsive than their comparators (26, 30-32). However, in the majority of these studies CAT assessment was compared to full item bank administration. Future studies are needed that compare the sensitivity of CAT assessment to occurred changes in clinical status to established classical measures of physical function such as HAQ-DI or SF-36 PF10. Moreover, future studies should address how to optimize the sensitivity of CAT assessment to detect change in clinical status.

In the meantime, the urgent need for standardization of the many available measures for a given measurement goal, sometimes referred to as 'the tower of babel' has driven various efforts to establish a common IRT based metric between existing outcome measures that are used for the same purpose in a setting $(3,33-35)$. Once established, such metrics facilitate the comparability and interpretability of outcomes by the development of IRT based scoring procedures that allow study results to be expressed on one standardized metric irrespective of the questionnaire that was used in a specific study. They also pave the way for flexible assessment using manual or computerized tailoring of items to specific research needs. The results of chapter 4 and 6 demonstrated that it was possible to concurrently calibrate the 121 items of the PROMIS physical function item bank and the two most commonly used physical function questionnaires in the field of RA. This work might be considered a first step toward creating a common metric for physical function outcomes in the field of RA. Considering the increasingly apparent limitations of the HAQ-DI for monitoring patients with low disease activity, one of the benefits of a common metric of physical function instruments would be that comparability with historical clinical studies is maintained in studies that resort to measures that are better suited to measuring patients with higher levels of function. Future efforts could expand this common metric by including other commonly used questionnaires such as for example HAQ-II (14) or AIM2-SF (37) or by adding items to the item bank that specifically target poorly represented section of the physical function dimension. Another interesting avenue for future research would be to define patient level statistics such as the 'patient acceptable symptom state' or 'low disease activity' $(38,39)$ using IRT based latent estimates. Categorical endpoints such as these are frequently used as treatment targets in clinical studies and allow study 
outcomes to be evaluated at the level of individual patients. To define such cut-off points for the latent metric of an item bank has the advantage that these apply to any application of the item bank, which means that the same level of physical function is used as a cut-off score, regardless of the items that were administered in the study. This is an important advantage since previous studies have shown that categorical endpoints with a similar semantic meaning, e.g. remission, may turn out to correspond to quite different severity levels on the latent IRT metric when multiple instruments are concurrently calibrated (35). Another potential advantage of IRT based estimation of physical function is that the estimation error of IRT estimates can be utilized in CAT algorithms where the administration of new items is stopped once a pre-specified level of certainty (e.g. 95\%) is achieved regarding the patient's level of physical function in relation to the cut-off point. This is referred to as adaptive mastery testing in educational settings $(41,42)$.

Finally, studies such as those in chapters 7 and 8 of the current thesis demonstrate the gains in efficiency that may be achieved by utilizing IRT based scoring procedures based on a calibrated item bank. Even further gains in efficiency of assessment of patient reported outcomes may be achievable by multidimensional IRT modeling and multidimensional CAT (43). Patient reported outcomes such as physical function and fatigue are highly correlated constructs $(44,45)$. Between item MIRT models can be used to simultaneously calibrate instruments measuring several related domains. The correlation between the domains is a parameter in such models and the information regarding patient's standing on one domain is taken into account in estimating other domains, resulting in more precise estimates within the individual domains (43). Previous studies have shown that multidimensional CAT of several aspects of physical function (46) and in the field of personality testing (47). Future efforts could be directed at concurrently calibrating the core patient reported outcome measures in RA, pain, physical function and fatigue and study the gains in efficiency that would result from multidimensional CAT. Furthermore, the between item MIRT model adapted for longitudinal data analysis might also have an important place in the calibration phase of item banks in RA in the future. The results of chapter 6 have demonstrated that a longitudinal sampling design was useful to obtain a more stable calibration of the item bank, despite the availability of a relatively modest sample size, compared to recommendations for IRT calibrations (48). Typically, in clinical settings patients are monitored over time and longitudinal models could be utilized to incorporate data across time points in estimating the item parameters. This not only increases the virtual sample size but, provided that clinical status change over time, may also improve the distribution of the data over the response options. 


\section{References}

1. Felson DT, Anderson JJ, Boers M et al. The American college of rheumatology preliminary core set of disease activity measures for rheumatoid arthritis clinical trials. Arthritis \& Rheumatism 1993; 36: 729740 .

2. Wolfe F, Hawley DJ. The longterm outcomes of rheumatoid arthritis: Work disability: a prospective 18 year study of 823 patients. J Rheumatol 1998; 25: 2108-2117.

3. Oude Voshaar MA, Ten Klooster PM, Taal E, van de Laar MA. Measurement properties of physical function scales validated for use in patients with rheumatoid arthritis: A systematic review of the literature. Health Qual Life Outcomes 2011; 9: 99.

4. Oude Voshaar AH, Ten Klooster PM, Taal E, Van de Laar MAFJ. Meeteigenschappen van vragenlijsten voor fysiek functioneren bij patiënten met reumatoïde artritis. Nederlands tijdschrift voor reumatologie 2012; 3: 6 - 11.

5. Patrick DL, Burke LB, Powers JH et al. Patient-reported outcomes to support medical product labeling claims: FDA perspective. Value Health 2007; 10 Suppl 2: S125-137.

6. Mokkink LB, Terwee CB, Patrick DL et al. The COSMIN checklist for assessing the methodological quality of studies on measurement properties of health status measurement instruments: an international Delphi study. Qual Life Res 2010; 19: 539-549.

7. Terwee CB, Bot SD, de Boer MR et al. Quality criteria were proposed for measurement properties of health status questionnaires. J Clin Epidemiol 2007; 60: 34-42.

8. Oude Voshaar MA, Glas CA, Ten Klooster PM et al. Crosscultural Measurement Equivalence of the Health Assessment Questionnaire II. Arthritis Care Res (Hoboken) 2013; 65: 1000-1004.

9. Oude Voshaar MA, Ten Klooster PM, Vonkeman HE et al. Measurement bias in different versions of the Dutch Health Assessment Questionnaire Disability Index. Ann Rheum Dis 2013.

10. Ten Klooster PM, Oude Voshaar MA, Gandek B et al. Development and evaluation of a crosswalk between the SF-36 physical functioning scale and Health Assessment Questionnaire disability index in rheumatoid arthritis. Health Qual Life Outcomes 2013; 11: 199.

11. Oude Voshaar MA, Ten Klooster PM, Taal E et al. Dutch translation and cross-cultural adaptation of the PROMIS(R) physical function item bank and cognitive pre-test in Dutch arthritis patients. Arthritis Res Ther 2012; 14: R47.

12. Beaton DE, Bombardier C, Guillemin F, Ferraz MB. Guidelines for the process of cross-cultural adaptation of self-report measures. Spine (Phila Pa 1976) 2000; 25: 3186-3191.

13. Guillemin F, Bombardier C, Beaton D. Cross-cultural adaptation of health-related quality of life measures: literature review and proposed guidelines. J Clin Epidemiol 1993; 46: 1417-1432.

14. Pincus T, Sokka T, Kautiainen H. Further development of a physical function scale on a MDHAQ [corrected] for standard care of patients with rheumatic diseases. J Rheumatol 2005; 32: 1432-1439.

15. Wolfe F, Michaud K, Pincus T. Development and validation of the health assessment questionnaire II: a revised version of the health assessment questionnaire. Arthritis Rheum 2004; 50: 3296-3305.

16. Stucki G, Stucki S, Bruhlmann P, Michel BA. Ceiling effects of the Health Assessment Questionnaire and its modified version in some ambulatory rheumatoid arthritis patients. Ann Rheum Dis 1995; 54: 461-465. 
17. Oude Voshaar AH, Ten Klooster PM, Glas CA et al. Measurement properties of the PROMIS physical function item bank in rheumatoid arthritis; Comparison with HAQ-DI and SF-36 physical functioning scale. (under review).

18. Kirwan JR, Minnock P, Adebajo A et al. Patient perspective: fatigue as a recommended patient centered outcome measure in rheumatoid arthritis. J Rheumatol 2007; 34: 1174-1177.

19. Cardol M, de Jong BA, van den Bos GA et al. Beyond disability: perceived participation in people with a chronic disabling condition. Clin Rehabil 2002; 16: 27-35.

20. Guidance for industry: patient-reported outcome measures: use in medical product development to support labeling claims: draft guidance. Health Qual Life Outcomes 2006; 4: 79.

21. Cella D, Yount S, Rothrock N et al. The Patient-Reported Outcomes Measurement Information System (PROMIS): progress of an NIH Roadmap cooperative group during its first two years. Med Care 2007; 45: S3-S11.

22. Nikolaus S, Bode C, Taal E et al. Items and dimensions for the construction of a multidimensional computerized adaptive test to measure fatigue in patients with rheumatoid arthritis. J Clin Epidemiol 2013; 66: 1175-1183.

23. Rose M, Bjorner JB, Becker J et al. Evaluation of a preliminary physical function item bank supported the expected advantages of the Patient-Reported Outcomes Measurement Information System (PROMIS). J Clin Epidemiol 2008; 61: 17-33.

24. Hsueh IP, Chen JH, Wang $\mathrm{CH}$ et al. Development of a computerized adaptive test for assessing activities of daily living in outpatients with stroke. Phys Ther 2013; 93: 681-693.

25. Bode RK, Cella D, Lai JS, Heinemann AW. Developing an initial physical function item bank from existing sources. J Appl Meas 2003; 4: 124-136.

26. Hung M, Stuart AR, Higgins TF et al. Computerized Adaptive Testing using the PROMIS Physical Function Item Bank Reduces Test Burden with Less Ceiling Effects Compared to the Short Musculoskeletal Function Assessment in Orthopaedic Trauma Patients. J Orthop Trauma 2013.

27. Hart DL, Mioduski JE, Stratford PW. Simulated computerized adaptive tests for measuring functional status were efficient with good discriminant validity in patients with hip, knee, or foot/ankle impairments. J Clin Epidemiol 2005; 58: 629-638.

28. Rose M, Bjorner JB, Fischer F et al. Computerized adaptive testing--ready for ambulatory monitoring? Psychosom Med 2012; 74: 338-348.

29. Revicki DA, Sloan J. Practical and philosophical issues surrounding a national item bank: if we build it will they come? Qual Life Res 2007; 16 Suppl 1: 167-174.

30. Flynn KE, Dombeck CB, DeWitt EM et al. Using item banks to construct measures of patient reported outcomes in clinical trials: investigator perceptions. Clin Trials 2008; 5: 575-586.

31. Haley SM, Gandek B, Siebens $\mathrm{H}$ et al. Computerized adaptive testing for follow-up after discharge from inpatient rehabilitation: II. Participation outcomes. Arch Phys Med Rehabil 2008; 89: 275-283.

32. Haley SM, Siebens H, Coster WJ et al. Computerized adaptive testing for follow-up after discharge from inpatient rehabilitation: I. Activity outcomes. Arch Phys Med Rehabil 2006; 87: 1033-1042.

33. Ware JE, Jr., Kosinski M, Bjorner JB et al. Applications of computerized adaptive testing (CAT) to the assessment of headache impact. Qual Life Res 2003; 12: 935-952. 
34. Schalet BD, Cook KF, Choi SW, Cella D. Establishing a Common Metric for Self-Reported Anxiety: Linking the MASQ, PANAS, and GAD-7 to PROMIS Anxiety. Journal of Anxiety Disorders 2013.

35. Wahl I, Löwe B, Bjorner JB et al. Standardization of depression measurement: a common metric was developed for 11 self-report depression measures. Journal of clinical epidemiology 2014; 67: 73-86.

36. Martin M, Kosinski M, Bjorner JB et al. Item response theory methods can improve the measurement of physical function by combining the modified health assessment questionnaire and the SF-36 physical function scale. Qual Life Res 2007; 16: 647-660.

37. Guillemin F, Coste J, Pouchot J et al. The AIMS2-SF: a short form of the Arthritis Impact Measurement Scales 2. French Quality of Life in Rheumatology Group. Arthritis Rheum 1997; 40: 1267-1274.

38. Boers M, Anderson JJ, Felson DT. Deriving an operational definition of low disease activity state in rheumatoid arthritis. J Rheumatol 2003; 30: 1112-1114.

39. Tubach F, Ravaud P, Baron G et al. Evaluation of clinically relevant states in patient reported outcomes in knee and hip osteoarthritis: the patient acceptable symptom state. Ann Rheum Dis 2005; 64: 34-37.

40. Glas CA, Geerlings H, van de Laar MA, Taal E. Analysis of longitudinal randomized clinical trials using item response models. Contemp Clin Trials 2009; 30: 158-170.

41. Kingsbury GG, Weiss DJ. A comparison of IRT-based adaptive mastery testing and a sequential mastery testing procedure. New horizons in testing: Latent trait test theory and computerized adaptive testing 1983; 44.

42. Ferguson RL. Computer-Assisted Criterion-Referenced Measurement. 1969.

43. van der Linden WJ, Hambleton RK. Handbook of modern item response theory. Springer 1997.

44. van Hoogmoed D, Fransen J, Bleijenberg G, van Riel P. Physical and psychosocial correlates of severe fatigue in rheumatoid arthritis. Rheumatology (Oxford) 2010; 49: 1294-1302.

45. Pollard LC, Choy EH, Gonzalez J et al. Fatigue in rheumatoid arthritis reflects pain, not disease activity. Rheumatology (Oxford) 2006; 45: 885-889.

46. Allen DD, Ni P, Haley SM. Efficiency and sensitivity of multidimensional computerized adaptive testing of pediatric physical functioning. Disabil Rehabil 2008; 30: 479-484.

47. Makransky G, Mortensen EL, Glas CA. Improving Personality Facet Scores With Multidimensional Computer Adaptive Testing An Illustration With the Neo Pi-R. Assessment 2013; 20: 3-13.

48. Reise SP, Yu J. Parameter recovery in the graded response model using MULTILOG. Journal of Educational Measurement 1990; 27: 133-144. 
172 Chapter 9 


\section{Appendix}

Introduction to IRT models 


\section{Appendix: Introduction to IRT models}

A variety of IRT models exist, that are suitable for different data formats. The IRT models that were used in the studies in this thesis will be briefly introduced here. These models can be viewed as a series of generalizations of the first, and most basic IRT model proposed, the Rasch model for dichotomous responses $(1,2)$. This model gives the probability of endorsing a dichotomous item (e.g., favoring the answer yes over no in response to the question: 'Are you able to walk up three flights of stairs?') as a logistic function of the difference between the patient's level of physical function $(\theta)$ and the difficulty of the activity $(\beta)$. This model is given by:

$P_{1 n i}=\frac{\exp \left(\theta_{n}-\beta_{i}\right)}{1+\exp \left(\theta_{n}-\beta_{i}\right)}$

where $P_{1 n i}$ is person $n$ 's probability of endorsing item $i$,

$\theta_{n}$ is a parameter reflecting the level of physical function of patient $n$

$\beta_{i}$ is a parameter reflecting the difficulty of the activity in item $i$, defined as the position on the latent scale where $P_{1 n i}=P_{0 n i}$.

In this model, the probability of endorsing the question increases as the functional capacity of the responding patient increases. However, all physical function questionnaires that were evaluated in the current thesis have an ordered polytomous response format. For example, the Health Assessment Questionnaire Disability Index (HAQ-DI) asks respondents to rate the level of difficulty they experience in performing daily activities on a 4-point rating scale ranging from [0] 'without any difficulty' to [3] 'unable to do'(3). For an item with such a response format, a score of 1 is obviously not expected to be increasingly likely with increasing levels of disability. Rather, beyond some level of functional disability, a score of 1 should become less likely and a score of 2 more likely, etc. The partial credit model is a generalization of the Rasch model for dichotomous responses suitable for the analysis of polytomous data that takes the implications of the intended ordering of categories of polytomous items into account $(5,6)$. The partial credit model utilizes the dichotomous Rasch model as an elemental unit to trace, for each pair of bordering response categories $x$ and $x-1$, the conditional probability of a response in category $\mathrm{x}$, given that the response was in either category $x$ or $x-1(2,5)$ : 


$$
P_{x n i \mid x-1, x}=\frac{\exp \left(\theta_{n}-\beta_{i x}\right)}{1+\exp \left(\theta_{n}-\beta_{i x}\right)}
$$

where $P_{i x \mid x-1, x}$ refers to the conditional probability of person $n$ responding in category $x$, rather than item 1 , given that the response was in either category $x-1$ or $x$, with $x=0,1,2 \ldots, m$.

$\beta_{i x}$ is a category bounds parameter reflecting the location on the latent metric where both response options are equally likely.

The only difference between the trace line for a dichotomous item under the Rasch model and the trace line for $P_{1 n i \mid 0,1}$ is that here $P_{1 n i \mid 0,1}<1$, since only the conditional probability of responding in $x$ rather than $x-1$ is considered. Furthermore it is assumed that respondents must score in one of the $m+1$ categories so that the sum of these conditional probabilities is 1 and the unconditional probabilities of a patient $n$ with physical function level $\theta_{n}$ responding in categories $0,1,2$ and 3 of item $i$ are given by (5):

$$
\begin{aligned}
& P_{n i 0}=1 / \Psi \\
& P_{n i 1}=\exp \left(\theta_{n}-\beta_{i 1}\right) / \Psi \\
& P_{n i 2}=\exp \left(2 \theta_{n}-\beta_{i 1}-\beta_{i 2}\right) / \Psi \\
& P_{n i 3}=\exp \left(3 \theta_{n}-\beta_{i 1}-\beta_{i 2}-\beta_{i 3}\right) / \Psi,
\end{aligned}
$$

where $\Psi$ is the sum of the four numerators.

This set of equations is usually written as one general expression:

$$
P_{\text {nix }}=\frac{\exp \sum_{j=0}^{x}(Z)}{\sum_{k=0}^{m} \exp \sum_{j=0}^{k}(Z)}, \text { with } \quad x=0,1, \ldots m
$$

which gives the probability of person $n$ with ability $\theta_{n}$ responding in category $x(x=0,1 . ., m)$ of item $i$. Here $Z=\left(\theta_{n}-\right.$ $\left.\beta_{i j}\right)$, The expected score $E(x \mid \theta)$ is monotonically increasing throughout $\theta$, that is the expected score increases as $\theta$ increases. This also applies to the other polytomous models that will subsequently be introduced.

One of the features of the model is that it is assumed that all items discriminate equally well between different levels of physical function. A practical drawback of this feature is that it imposes a pattern on the predicted scores that may be insufficiently reflected in the observed data (6) The generalized partial credit model (GPCM) relaxes the assumption of equal discrimination by incorporating a second item parameter that allows variations in the discriminating power of items to be modelled (7) As a result it will provide a more realistic description of the modelled data in many practical situations. 
In the GPCM, (Z) of equation (4) has the following form:

$$
\mathrm{Z}=a_{i}\left(\theta_{n}-\beta_{i j}\right)
$$

where $a_{i}=$ a discrimination parameter for item i.

This model can be further elaborated to incorporate multiple dimensions (i.e. MIRT models). MIRT models extend to cases where patients are characterized by their standing on multiple traits (8) . For example for a so called within-item multidimensional extension (9) of the GPCM, Z of equation (4) has the following form:

$$
\mathrm{Z}=\left(\sum_{q}^{Q}\left(a_{i q} \Theta_{q}\right)-\beta_{i j}\right.
$$

where $a_{i q}=$ a discrimination parameters for item $i$ on dimension $q$,

$\Theta_{q}=$ the latent trait value of dimension $q$.

$\beta_{i j}=$ is the point on the latent metric where responding in category $j-1$ is equally likely as responding in category $j$ for item $i$.

Here, each item is still described by one set of $m$ threshold parameters, but has dimension-specific discrimination and latent trait parameters. The special case of this model where each item only has 1 non-zero discrimination parameter and where the relationship between the dimensions is modelled by their correlation is known as a between item MIRT model. Between item MIRT models can also be employed to analyze longitudinal data, by specifying data on different time points as separate dimensions and imposing linear restrictions on the item parameters. The dependency between item scores across time points is then modelled by the correlation between the dimensions (10)

\section{References}

1. Rasch G. Studies in mathematical psychology: I. Probabilistic models for some intelligence and attainment tests. 1960.

2. Thissen D, Steinberg L. A taxonomy of item response models. Psychometrika 1986; 51: 567-577.

3. Fries JF, Spitz P, Kraines RG, Holman HR. Measurement of patient outcome in arthritis. Arthritis Rheum 1980; 23: 137-145.

4. Masters GN. A Rasch model for partial credit scoring. Psychometrika 1982; 47: 149-174.

5. Masters GN. The analysis of partial credit scoring. Applied Measurement in Education 1988; 1: 279-297.

6. Glas CA. Preliminary manual of the software program Multidimensional Item Response Theory (MIRT). Enschede, The Netherlands: University of Twente 2010. 
7. Muraki E. A generalized partial credit model: Application of an EM algorithm. Applied psychological measurement 1992; 16: 159-176.

8. $\quad$ Reckase M. Multidimensional item response theory. Springer 2009.

9. Adams RJ, Wilson M, Wang W-c. The multidimensional random coefficients multinomial logit model. Applied Psychological Measurement 1997; 21: 1-23.

10. te Marvelde JM, Glas CA, Van Landeghem G, Van Damme J. Application of multidimensional item response theory models to longitudinal data. Educational and Psychological Measurement 2006; 66: 5-34. 


\section{Journal publications}

1. Ten Klooster PM, Oude Voshaar MA, Taal E, van de Laar MA. Comparison of measures of functional disability in patients with gout. Rheumatology (Oxford). 2010 Dec 2.

2. Oude Voshaar MA, Ten Klooster PM, Taal E, va[1]n de Laar MA. Measurement properties of physical function scales validated for use in patients with rheumatoid arthritis: A systematic review of the literature. Health Qual Life Outcomes. 2011;9:99.

3. Fledderus M, Oude Voshaar MA, Ten Klooster PM, Bohlmeijer ET. Further evaluation of the psychometric properties of the Acceptance and Action Questionnaire-II. Psychol Assess. 2012 Dec;24(4):925-36.

4. Oude Voshaar AH, Ten Klooster PM, Taal E, Van de Laar MAFJ. Meeteigenschappen van vragenlijsten voor fysiek functioneren bij patiënten met reumatoïde artritis. Nederlands tijdschrift voor reumatologie 2012; 3: 6 - 11.

5. Oude Voshaar MA, Ten Klooster PM, Taal E, Krishnan E, van de Laar MA. Dutch translation and crosscultural adaptation of the PROMIS(R) physical function item bank and cognitive pre-test in Dutch arthritis patients. Arthritis Res Ther. 2012 Mar 5;14(2):R47.

6. Islam N, Baron Basak T, Oude voshaar MA, Ferdous N, Rasker JJ, Atiqul Haq S. Cross-cultural adaptation and validation of a Bengali Health Assessment Questionnaire for use in rheumatoid arthritis patients. Int J Rheum Dis. 2013 Aug;16(4):413-7.

7. Oude Voshaar MA, Ten Klooster PM, Vonkeman HE, Kievit W, van Riel PL, van de Laar MA. Measurement bias in different versions of the Dutch Health Assessment Questionnaire Disability Index. Ann Rheum Dis. 2013 Jul 12.

8. Oude Voshaar MA, Glas CA, ten Klooster PM, Taal E, Wolfe F, van de Laar MA. Crosscultural measurement equivalence of the Health Assessment Questionnaire II. Arthritis Care Res (Hoboken). 2013 Jun;65(6):1000-4.

9. Klooster PM ten, Oude Voshaar MAH, Gandek B, Rose M, Bjorner JB, Taal E, et al. Development and evaluation of a crosswalk between the SF-36 physical functioning scale and Health Assessment Questionnaire disability index in rheumatoid arthritis. Health Qual Life Outcomes 2013;11:199.

10. Klooster PM Ten, Vonkeman HE, Oude Voshaar MAH, Bode C, Laar MAFJ van de. Experiences of goutrelated disability from the patients' perspective: a mixed methods study.Clin Rheumatol 2013.

11. Oude Voshaar AH, Ten Klooster PM, Glas CA, Taal E, Krishnan E, Boers M, et al. Calibration and evaluation of cross-cultural measurement equivalence of the PROMIS physical function item bank in Dutch patients with rheumatoid arthritis. PLOS one. 2014, Mar 17

12. Oude Voshaar MAH, Klooster PM ten, Taal E, Wolfe F, Vonkeman HE, Glas CAW, et al. Linking physical function outcomes in rheumatology: Performance of a crosswalk for converting HAQ scores to SF36 PF10 scores. acceptd for publication at Arhritis care \& research 


\section{Nederlandse samenvatting}

Fysiek functioneren is een gevestigd uitkomstdomein in het veld van reumatoïde artritis onderzoek. Sinds fysiek functioneren voor het eerst is voorgesteld als kern uitkomstdomein in dit veld, heeft het meten van fysieke beperkingen zich ontwikkeld van simpele, gestandaardiseerde prestatietests tot patiënt gerapporteerde uitkomst instrumenten die beogen een omvattende evaluatie te verschaffen van de verschillende aspecten van het functioneren van de patiënt. De resultaten van twee systematische literatuurstudies in hoofdstuk 2 laten zien dat er maar liefst 26 verschillende vragenlijsten beschikbaar zijn voor het meten van fysiek functioneren bij patiënten met reumatoïde artritis, waarvan 10 er ook zijn geëvalueerd bij Nederlands sprekende patiënten. De interpreteerbaarheid van fysiek functioneren uitkomsten wordt belemmerd door de beschikbaarheid van zo veel verschillende instrumenten met elk zijn eigen unieke items en scoringsprocedures, zodat studies die verschillende vragenlijsten gebruiken vaak moeilijk te vergelijken zijn. Verder is het zo dat hoewel veel van de geëvalueerde vragenlijsten over voldoende inhoudsvaliditeit en constructvaliditeit bleken te beschikken, vloer en plafond effecten ook vaak aanwezig bleken te zijn, zelfs bij de meest gebruikte vragenlijsten en met name in recentere studies. Dit was een verwachte bevinding met het oog op de bekende heterogeniteit van fysieke belemmeringen bij patiënten met reumatoïde artritis en doordat de geïncludeerde vragenlijsten een beperkt aantal vragen bevatten. Deze bevindingen onderschrijven het belang van verdere standaardisatie en gepersonaliseerde evaluatie van fysiek functioneren die gerealiseerd kan worden binnen het IRT raamwerk.

De eerste sectie van hoofdstuk 3 presenteert een studie waarin de cross-culturele equivalentie van een Nederlandse vertaling van de veelgebruikte HAQ-II wordt geëvalueerd. De studie illustreert dat IRT een natuurlijk raamwerk biedt voor het evalueren van de aanwezigheid van items met culturele bias en voor het evalueren van hun impact op de vergelijkbaarheid van totaalscores tussen landen. De resultaten lieten zien dat HAQ-II totaalscores vergelijkt kunnen worden tussen culturen, ondanks de aanwezigheid van een aantal individuele items met culturele bias. Echter, in gevallen waarin de vergelijkbaarheid van scores ondermijnd wordt door de aanwezigheid van culturele onzuiverheid, kunnen scores vergelijkbaar gemaakt worden door IRT scoringsprocedures te ontwikkelen waarbij land-specifieke item parameters worden toegewezen aan items met bias. Deze methodologie kan in algemene zin worden toegepast om valide scoringsprocedures te ontwikkelen voor verschillende versies van een vragenlijst of voor vragenlijsten met bias veroorzaakt door achtergrondvariabelen zoals geslacht. Dit werd geillustreerd in de tweede studie van hoofdstuk 3, waar twee verschillende versies van de 
Nederlandse HAQ-DI onderling uitwisselbaar bleken te zijn. Wij raden onderzoekers die geïnteresseerd zijn in het introduceren van aangepaste of vertaalde versies van een vragenlijst aan om de meetequivalentie ten opzichte van het origineel te onderzoeken als onderdeel van de routinematige evaluatie van validiteit en betrouwbaarheid en, indien nodig, IRT scoringsprocedures te ontwikkelen in het geval van aanzienlijke bias.

Een probleem dat gerelateerd is aan de wildgroei aan fysiek functioneren vragenlijsten die vastgesteld werd in hoofdstuk 2 , is dat studies die verschillende fysiek functioneren vragenlijsten gebruikt hebben moeilijk te vergelijken zijn, omdat vragenlijsten vaak hun eigen items en scoringsprocedures hebben. Als gevolg daarvan is het functieniveau van patiënten moeilijk te karakteriseren met patiënten vragenlijsten. In het IRT raamwerk kunnen fysiek functioneren scores uitgedrukt worden op een gemeenschappelijke schaal, onafhankelijk van welk instrument is afgenomen in een studie, onder de voorwaarde dat de item parameters zijn gekalibreerd onder een gezamenlijk IRT model. In hoofdstuk 4 werd geillustreerd hoe deze eigenschap benut kan worden om conversietabellen te ontwikkelen die totaalscores van twee of meer vragenlijsten verbinden. De resultaten lieten zien dat een zogenaamde crosswalk-tabel tussen de twee meest gebruikte vragenlijsten in reumatoïde artritis onderzoek, de HAQ-DI en SF-36 PF10, betrouwbare score conversies mogelijk maakt op groepsniveau. De conversietabellen werden ontwikkeld in een Nederlandse steekproef van patiënten met reumatoïde artritis. De tweede studie in hoofdstuk 4 liet zien dat de tabellen ook gebruikt kunnen worden om scores om te zetten bij Amerikaanse patiënten met reumatoïde artritis, fybromyalgie en lupus. Bij het ontwikkelen van de crosswalk tabellen hebben we er voor gekozen om IRT scores terug te converteren naar de metriek van de gebruikte vragenlijsten omdat we verwachtten dat dit beter begrepen zou worden door de onderzoekers en clinici die met deze vragenlijsten werken. Dit introduceert echter een extra bron van meetfouten, gerelateerd aan het feit dat geobserveerde totaalscores bijna nooit perfect overlappen op de latente schaal. Dit heeft als gevolg dat voorzichtigheid geboden is bij het gebruik van de conversietabellen met kleine steekproeven, met name in meta-analyses omdat effecten hierdoor waarschijnlijk enigszins onderschat kunnen worden. Verder is het waarschijnlijk niet mogelijk om conversietabellen te ontwikkelen voor elk van de vele fysiek functioneren vragenlijsten die gebruikt worden in dit veld.

Een meer directe en precieze aanpak om fysiek functioneren uitkomsten te linken in het reumatoïde artritis veld is om een omvattende fysiek functioneren item bank te kalibreren die alle bestaande fysiek functioneren items bevat. De resulterende metriek kan dan gebruikt worden als een gestandaardiseerde eenheid voor fysiek functioneren uitkomsten in reumatoïde artritis onderzoek. De resterende hoofdstukken van deze these beschrijven het proces van het kalibreren 
van een item bank die in de toekomst gebuikt kan worden voor deze doeleinden in dit veld. Hoofdstuk 5 beschrijft de rigoureuze methodologie die gevolgd is bij het vertalen van de in Amerika ontwikkelde PROMIS fysiek functioneren item bank naar de Nederlandse taal en het cross-cultureel aanpassen daarvan voor gebruik in Nederlandse patiënten met reumatoïde artritis. Deze stap was belangrijk, zowel om potentieel problematische items op het spoor te komen als om de collectieve expertise van een team van inhoudsdeskundigen en patiënten te benutten om een vertaalde versie te creëren die zowel conceptueel als semantisch optimaal equivalent is aan het origineel. In het geval van de PROMIS fysiek functioneren item bank in hoofdstuk 5 werden slechts 5 items geïdentificeerd met mogelijk culturele ontoepasselijke inhoud. Deze items werden herschreven om beter te passen in de Nederlandse setting. De resultaten van deze exercitie leverden waardevolle informatie over de indrukvaliditeit van de vertaalde versie voor Nederlandse patiënten met reumatoïde artritis. Echter een nadeel van de methodologie is dat het niet mogelijk is om direct uit de resultaten af te leiden of aanpassing van problematische items leidt tot cross-cultureel equivalente versies vanuit een meetperspectief en of er mogelijk andere problematische items gemist zijn. In hoofdstuk 6 werd een studie gepresenteerd waarin de vertaalde item bank werd gekalibreerd in een steekproef van Nederlandse patiënten met reumatoïde artritis waarin onder meer de meetequivalentie met het origineel werd onderzocht. De resultaten lieten zie dat de item bank gekalibreerd kon worden onder een toepasselijk IRT model. Deze bevinding levert empirisch bewijs voor de validiteit van toepassingen van de item bank die invariante schattingen vereist van de item parameters zoals computer adaptief toetsen of gepersonaliseerde korte vragenlijsten. Helaas was het nog niet mogelijk om een definitieve analyse uit te voeren naar de meetequivalentie ten opzichte van het origineel door een problematische verdeling van de Amerikaanse algemene populatie data. Verder moet de kalibratie die gepresenteerd is in hoofdstuk 6 als voorlopig beschouwd worden doordat de steekproef betrekkelijk bescheiden was en het is daardoor mogelijk dat sommige items bias vertoonden door steekproef willekeurigheden. Toekomstige studies zijn nodig om definitieve conclusies mogelijk te maken met betrekking tot de equivalentie van de Nederlandse versie van de item bank ten opzichte van het origineel en als het nodig is valide scoringsprocedures te kunnen ontwikkelende het mogelijk maken om Nederlandse onderzoeksresultaten tot uitdrukking te brengen op de Amerikaanse schaal, ook als er items met bias zijn. Dit zal er dan voor zorgen dat Amerikaanse en Nederlandse studieresultaten vergeleken kunnen worden.

In hoofdstuk 7 werden de meeteigenschappen van de PROMIS fysiek functioneren item bank onderzocht en vergeleken met de meeteigenschappen van twee veel gebruikte fysiek functioneren vragenlijsten, de HAQ-DI en SF-36 Pf-10. Het was niet verrassend dat de item bank 
een meer omvattende dekking van het gehele fysiek functioneren construct had en een hogere ideale meetprecisie. Een interessante bevinding was echter dat de item bank daarnaast ook een veel breder meetbereik had, waardoor vooral de betrouwbaarheid van fysiek functioneren scores van patiënten met relatief hoog fysiek functioneren sterk verbeterd. Relatief hoge niveaus van functioneren komen steeds vaker voor door vroege en agressieve behandeling. De resultaten van deze studie illustreren in dat opzicht de tekortkomingen van klassieke instrumenten die meer gericht zijn op patiënten met fysieke beperkingen. Praktische toepassingen van de item bank zullen dan ook in de partkijk ingezet kunnen worden om zogenaamde plafond effecten van klassieke instrumenten te overkomen. Deze resultaten werden bevestigd in de simulatiestudie in hoofdstuk 8. In overeenstemming met eerder onderzoek werd ook door ons gevonden dat de HAQ-DI optimaal en bijna even goed als de verschillende geëvalueerde computer adaptieve test algoritmes functioneert voor lage niveaus van fysiek functioneren, terwijl de SF-36 fysiek functioneren schaal optimaal functioneerde voor bovengemiddelde niveaus van functioneren. Verder lieten de resultaten zien dat een computer adaptieve test met 5 items even hoge of hogere meetprecisie heeft dan de beide klassieke instrumenten, voor alle niveaus van functioneren. Dit was een indrukwekkende bevinding omdat de beide klassieke instrumenten respectievelijk 20 en 10 vragen bevatten. We vonden verder dat een computer adaptieve test met 10 items optimaal was en dat de meetprecisie niet veel meer verbeterde met meer items. De hogere meetprecisie van de computer adaptieve test met 10 items resulteerde ook in meer onderscheidingsvermogen om veranderde niveaus van functioneren vast te stellen dan de beide klassieke vragenlijsten.

Samenvattend laten resultaten van hoofdstuk 2 zien dat er veel verschillende vragenlijsten beschikbaar zijn voor het meten van fysiek functioneren bij patiënten met reumatoïde artritis. Alle 26 gevonden instrumenten waren vragenlijsten met een vast aantal items en een scoringsregel gebaseerd op het optellen van de individuele item scores, in overeenstemming met de principes van de klassieke test theorie. De belangrijkste tekortkomingen van de geëvalueerde vragenlijsten bleken dan ook verklaarbaar te zijn vanuit de theoretische tekortkomingen klassieke testtheorie die in de inleiding van dit proefschrift besproken zijn. Deze tekortkomingen zijn het resultaat van arbitraire scoringsprocedures die alleen interpreteerbaar zijn met gedetailleerde kennis van de items en de antwoordalternatieven. Daarnaast bleek dat de vragenlijsten die elk een beperkt, vast aantal items bevatten, vaak niet in staat waren om alle voorkomende niveaus van fysiek functioneren te weerspiegelen. In de resterende hoofdstukken van deze these werd beschreven hoe de kalibratie van bestaande vragenlijsten of item banken met bet behulp van IRT gebruikt kan worden om de interpreteerbaarheid van fysiek functioneren uitkomsten te bevorderen en om het meetbereik van fysiek functioneren instrumenten te vergtoten. Verder werd aangetoond hoe analyse van en 
statistische correctie voor bias veroorzaakt door vertaling of achtergrondvariabelen bij fysiek functioneren instrumenten uitgevoerd kan worden binnen het IRT raamwerk. 


\section{Dankwoord}

$\mathrm{Na}$ vier jaren te hebben gewerkt aan dit proefschrift kijk ik nu terug op een buitengewoon leerzame en plezierige tijd als promovendus bij de afdeling Psychologie, Gezondheid \& Technologie aan de Universiteit Twente. Ik wil bij deze graag iedereen bedanken die direct of indirect heeft bijgedragen aan het tot stand komen van dit proefschrift. Een aantal personen wil ik daarbij in het bijzonder noemen.

Zonder de hulp van mijn beide promotoren en dagelijks begeleider was dit proefschrift ondenkbaar geweest. Mart, bedankt voor je toegewijde begeleiding van mijn project, in het bijzonder bij het maken van soms lastige keuzes op kritieke punten en voor het bieden van uitstekende onderzoeksfaciliteiten voor mijn onderzoek. Ik heb over de afgelopen vier jaren in toenemende mate bewondering gekregen voor je positieve kijk op zaken en aanstekelijke gedrevenheid. Cees, bedankt voor je waardevolle adviezen en begeleiding. Ondanks het toegepaste karakter van dit project heb ik veel geleerd van je grote kennis van de item response theorie. Peter, ongetwijfeld zou dit proefschrift niet geworden zijn wat het is zonder jouw betrokken begeleiding. Ik waardeer het enorm dat ik altijd bij je binnen kon lopen voor vragen of overleg over het project.

Aangezien het onmogelijk is empirisch onderzoek te doen zonder data, gaat mijn dank verder uit naar iedereen die heeft bijgedragen aan het verzamelen van data voor mijn onderzoek. In de eerste plaats zijn dat het Radboud Universitair Medisch Centrum, Ziekenhuisgroep Twente, het Medisch Spectrum Twente en natuurlijk de bijna 700 patiënten die hebben deelgenomen aan de PROMIS studie waarvan de resultaten werden beschreven in de hoofdstukken $6 \mathrm{t} / \mathrm{m} 8$. In het bijzonder wil ik verder ook de patiënten van het patiëntenforum Reuma Research Partners in Twente bedanken die ik heb mogen interviewen voor de kwalitatieve studie in hoofdstuk 5 . Harald en Nancy, jullie hebben mij enorm geholpen bij het realiseren van allerlei praktische aspecten van mijn project. Nancy, hartelijk dank voor je inspanningen bij het werven van centra voor de PROMIS studie. Harald, bedankt voor je kritische blik op verschillende manuscripten in dit proefschrift en voor al je inspanningen die bijgedragen hebben aan het tot stand komen van de computer adaptieve test en het verzamelen van de daarvoor benodigde data. Het Reumafonds en de Stichting Reuma Onderzoek Twente dank ik hartelijk voor de financiële steun die dit project mogelijk heeft gemaakt.

Mijn dank gaat ook uit naar alle onderzoekers van de afdeling PGT die mij tijdens dit project terloops hebben bijgestaan met raad en advies. In het bijzonder wil ik graag Christina en Erik daarbij noemen. Bedankt voor de interessante gedachtewisselingen die we over de loop van de afgelopen vier jaren vaak hebben kunnen voeren tijdens de verschillende congressen. Ik heb ook 
met veel plezier met jullie samengewerkt aan verschillende onderzoeksprojecten naast mijn promotieonderzoek. Daaruit zijn met de paper over de meeteigenschappen van verschillende vragenlijsten voor vermoeidheid en natuurlijk het op de EULAR bekroonde 'best abstract' een aantal mooie publicaties voortgekomen. Henk en Stans, ik wil jullie graag bedanken voor jullie bevlogen begeleiding en voor de interessante onderzoeksprojecten waar ik me mee heb kunnen bezighouden tijdens respectievelijk mijn bachelor- en masteropdracht. Sebie, Hans en Bernard, als student-assistent bij de vakgroep Onderzoeksmethodologie, Meetmethoden en Data-Analyse heb ik veel van jullie geleerd over onderzoekmethodologie, statistiek en wetenschapsfilosofie. De werkzaamheden die ik heb uitgevoerd tijdens de verschillende afstudeerprojecten en als studentassistent hebben een belangrijke bijdrage geleverd aan mijn enthousiasme voor en kennis van de wetenschap.

Veel dank ben ik ook verschuldigd aan mijn medepromovendi. In het bijzonder mijn generatie- en kamergenootjes in de toren: (vanaf de deur, met de klok mee) Roos A, Liseth, Anne Marie, Maarten, Jobke en Hester. Later zijn daar Ingrid, Laura, Nadine en Nienke bijgekomen en 'in het midden' hebben ook verschillende kamergenoten gezeten met andere functies binnen de afdeling. Afgezien van alle gezelligheid ben ik jullie allemaal dankbaar dat jullie mij telkens op de hoogte hebben gehouden van uiteenlopende zaken als het tijdig aanvragen van VISA en promovendi overleg, maar ook minder prozaïsche zaken zoals verschillende etentjes en de WKpoule. Dit geldt natuurlijk in het bijzonder voor Liseth. Liseth, doordat wij vergelijkbare projecten en daaruit voortvloeiende werkzaamheden hadden heb ik erg kunnen profiteren van je organiserend vermogen en ook de dagelijkse gesprekken die ik met je heb kunnen voeren over onze projecten heb ik zeer gewaardeerd. Het toppunt van je organisatorische bekwaamheid heb ik mogen ervaren in Chicago waar we in een beperkt aantal dagen het bezoeken van alle schitterende toeristische bezienswaardigheden hebben kunnen combineren met het drukke schema van het bezoeken van het ACR congres. Ik wil ook Stephie graag bedanken voor een fijne tijd gedurende ons verblijf in Chicago, wat toch wel een van de meest memorabele ervaringen van het project was. Verder wil ik Roos V, Roos A, Laurien, Marloes en Ingrid bedanken voor de gezelligheid en morele steun tijdens de verschillende congressen en alle andere collega's van de afdeling PGT voor de positieve sfeer op de afdeling die sterk heeft bijgedragen aan het werkplezier dat ik dagelijks heb ervaren tijdens mijn vier jaren als promovendus. Marieke, Ria, Marion en Marja bedank ik daarnaast graag hartelijk voor alle secretariële ondersteuning.

Ik wil ook graag iedereen die een bijdrage heeft geleverd aan de verdediging van mijn proefschrift hartelijk danken voor de tijd en moeite. Prof. Sjef van der Linden, Prof. Piet van Riel, Prof. Robbert Sanderman, Prof. Eswar Krishnan, Dr. Harald Vonkeman en Dr. Erik Taal bedankt 
dat jullie jullie in mijn promotiecommissie zitting hebben willen nemen. Robin en Joyce, fijn dat jullie mij als paranimf willen bijstaan tijdens de openbare verdediging van mijn proefschrift.

$\mathrm{Pa}$, bedankt dat je mij in mijn jeugd betrokken hebt bij je vele belangstellingen in onder meer de fotografie, natuur, muziek en de politiek en dat je me meenam fossielen zoeken, naar je vele tentoonstellingen, verschillende musea en natuurgebieden. Deze ervaringen hebben in mij de nieuwsgierigheid en brede belangstelling gewekt die ik nu kenmerkend voor mezelf vind. Ook in moeilijke tijden is deze nieuwsgierigheid en de daaraan gerelateerde gedrevenheid om te blijven leren en mijzelf verder te ontwikkelen voor mij een oriëntatiepunt geweest en van doorslaggevend belang bij het maken van de keuzes die er uiteindelijk voor gezorgd hebben dat ik nu hier sta. Ma, bedankt voor je voortdurende bezorgdheid en dat je altijd trots op me bent. De foto van de prijsuitreiking op de EULAR heeft volgens mij wel drie keer op je facebook wall gestaan.

Als laatste een woord van dank aan de mensen die het dichtst bij me staan: Mary Ann, schatje, onze reünie op Schiphol, toen je terug kwam uit Noorwegen en het moment dat plotseling alle spanning en angst, als sneeuw voor de zon, plaatsmaakten voor een bijzonder gevoel van vreugde toen we Jaidan voor het eerst hoorden schreeuwen toen hij ter wereld kwam, zijn mijn meest gekoesterde herinneringen. Deze zullen altijd bij mij blijven, wat er ook gebeurt. Jaidan, jouw nieuwsgierigheid naar het leven, vreugde en onschuld en het onvoorwaardelijke vertrouwen dat je hebt in ons geven mij nieuwe hoop en kracht om positief te blijven en om door te gaan. 